SANDRO PEREIRA DA SILVA

Contribuição para a modelagem da operação de retificação cilíndrica externa de mergulho. 


\section{Contribuição para a modelagem da operação de retificação cilíndrica externa de mergulho.}

Tese apresentada à Escola de Engenharia de São Carlos da Universidade de São Paulo, como parte dos requisitos para a obtenção do título de Doutor em Ciências.

Área de Concentração: Manufatura.

Orientador: Prof. Dr. Eraldo Jannone da Silva

ESTE EXEMPLAR TRATA-SE DA VERSÃO CORRIGIDA.

A VERSÃO ORIGINAL ENCONTRASE DISPONIVEL JUNTO AO DEPARTAMENTO DE ENGENHARIA MECANICA DA EESC-USP. 


\section{AUTORIZO A REPRODUÇÃO TOTAL OU PARCIAL DESTE TRABALHO, POR QUALQUER MEIO CONVENCIONAL OU ELETRỐNICO, PARA FINS DE ESTUDO E PESQUISA, DESDE QUE CITADA A FONTE.}
Silva, Sandro Pereira da
s586c Contribuiçäo para a modelagem da operação de retificaçäo cilíndrica externa de mergulho/ sandro Pereira da Silva; orientador Eraldo Jannone da Silva. Săo Carlos, 2015 .

Tese (Doutorado) - Programa de Pós-Graduaçäo em Engenharia Mecânica e Area de Concentração em Manufatura -- Escola de Engenharia de sẫo Carlos da Universidade de sâo Eaulo, 2015.

1. Retificação. 2. Centelhamento. 3. Rigidez de processo. 4. Ciclo de retificaçäo. 5. Deformaçäo de máquina. I. Título. 
FOLHA DE JULGAMENTO

Candidato: Engenheiro SANDRO PEREIRA DA SILVA.

Título da "ese: "Contribuição para a modelagem da operação de retificação cilíndrica externa de mergulho ".

Data da defesa: 06/07/2015

Comissäo Julgadora:

Resultado:

Prof. Dr. Eraldo Janonne da Silva

ATROVAOTO

(Orientador)

(Escola de Engenharia de São Carlos/EESC)

Prof. Titular Reginaldo Teixeira Coelho

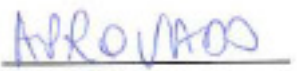

(Escola de Engenharia de São Carlos/EESC)

Prof. Dr. Eduardo Carlos Bianchi

(Universidade Estadual Paulista" Júlio de Mesquita Filho" - UNESP - Bauru)

Prof. Dr. Alexandre Mendes Abrão

(Universidade Federal de Minas Gerais/UFMG)

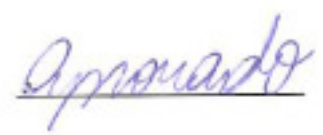

Prof. Dr. Jalon de Morais Vieira

(Instituto Federal do Sudeste de Minas Gerais/IFSEMG)

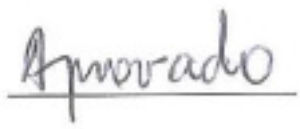

Coordenador do Programa de Pós-Graduação em Engenheira Mecânica: Prof. Associado Gherhardt Ribatski

Presidente da Comissão de Pós-Graduação:

Prof. Associado Paulo César Lima Segantine 
Dedico este trabalho a DEUS e Nossa Senhora Aparecida, que em todos os momentos da vida tem amparado a mim e minha família com luz e sabedoria! 


\section{AGRADECIMENTOS}

Todas as vezes que pensar no caminho percorrido para finalizar este trabalho, sempre lembrarei com muito respeito, gratidão e orgulho de ter conhecido:

Ao Prof. Dr. Reginaldo Teixeira Coelho, sempre encorajador, muito mais que um amigo! Mesmo sabendo de minhas limitações nunca deixou de acreditar e orientar a conclusão deste trabalho. Nos momentos mais difíceis esteve sempre presente. Muitos foram os dias de empenho com valiosos aprendizados. Tenho a certeza de ter conhecido um ser humano extraordinário, que sempre será referência em minha vida.

Ao Prof. Dr. Lincoln Cardoso Brandão, expresso profundo respeito e admiração pelo grande professor que é, sou grato pela amizade, motivação e parceria ao longo destes anos.

Ao Prof. Dr. Eraldo Jannone da Silva, pelos ensinamentos em suas aulas de retificação e pelas contribuições dirigidas no exame de qualificação, que foram encorajadoras para produção deste trabalho. Hoje entendo perfeitamente o quanto foi importante redirecionar o trabalho.

Ao Prof. Dr. Eduardo Carlos Bianchi, pelas orientações e motivação para seguir em frente com a pesquisa.

Ao Dr. Fábio Wagner Pinto pela amizade e sempre prontidão em orientar, pelas noites e noites de discussão sobre os resultados.

Aos meus pais, Oscar Pereira da Silva e Marilene Pereira da Silva, que sempre estiveram presentes em minha vida dando forças para seguir em frente.

Aos meus queridos avós, Da. Iracema Moretto Medeiros e Vicente Antônio Medeiros, que são referência para mim em amor e simplicidade.

A minha família, Erika Fabiane Vernier Pereira da Silva e nossa filha Bianca Vernier Pereira da Silva, que em muitos momentos compreenderam minha ausência para dedicar-me a conclusão deste trabalho, retribuindo com amor e carinho. 
"Se a princípio a ideia não parecer impossível [...]

[...] não existe a menor possibilidade de dar certo!"

Albert Einstein 


\section{RESUMO}

SILVA, S. P. Contribuição para a modelagem da operação de retificação cilíndrica externa tangencial de mergulho, 2015. 193 f. Tese (Doutorado) - Faculdade de Engenharia Mecânica, Universidade de São Paulo, São Carlos, 2015.

A retificação é um dos processos mais utilizados em operações de acabamento, geralmente caracterizada pelo resultado dimensional atingido e baixas rugosidades. Apesar de seu uso intenso na indústria, há aspectos ainda desconhecidos do processo e de sua estabilidade, sendo considerados tempos excessivos de centelhamento para atingir boas condições dimensionais. Este trabalho propõe um novo modelo para determinar o menor tempo de centelhamento necessário para que as deformações do sistema máquina-rebolo-peça sejam absorvidas e a dimensão objetivo da peça alcançada. Esse modelo partiu do equacionamento descrito por S. Malkin para obtenção da rigidez da máquina e avançou na obtenção da constante característica do tempo $\tau$ de forma experimental. A comprovação do modelo proposto deu-se em dois experimentos, sendo o primeiro experimento aplicado para determinar o valor de $\tau$ em função da velocidade de avanço, segundo o modelo de Malkin. Comprovou-se que o $\tau$ varia, principalmente em baixas velocidades de avanço. O segundo experimento teve como objetivo determinar qual o menor tempo de centelhamento necessário para que as deformações do sistema máquina-rebolo-peça sejam plenamente absorvidas e compará-las com o modelo proposto. Os resultados teórico e experimental comprovaram que, para as velocidades de mergulho 3,0 e 2,5 mm/min, com $\tau=0,219$ e 0,204 s, respectivamente, o tempo mínimo de centelhamento de 1,0 s foi sucifiente para absorver as deformações elásticas inseridas no sistema. De forma comparativa, o modelo proposto foi mais eficaz que o de Malkin para o cálculo do tempo de centelhamento e do erro diametral da peça para relações $t_{1} / \tau$ menores ou iguais a 20 , sendo $t_{1}$ o tempo em segundos da fase de retificação em desbaste. Conclui-se que o modelo proposto neste trabalho mostrou-se eficiente para predizer o tempo mínimo necessário para centelhamento e a redução diametral da peça, considerando o valor experimental de $\tau$.

Palavras Chave: Retificação, Centelhamento, Rigidez de processo, Ciclo de retificação, Deformação de máquina. 


\begin{abstract}
SILVA, S. P. Contribution to the modeling of external cylindrical plunge grinding, 2015. 193 f. Thesis - Faculdade de Engenharia Mecânica, Universidade de São Paulo, São Carlos, 2015.
\end{abstract}

Grinding is one of the processes most commonly used in finishing operations, usually characterized by good dimensional results and low roughness values. Despite the extensive use in industry, there are still unknown aspects of the grinding process and its stability, with excessive spark-out times being used to achieve good dimensional requirements. This research work proposed a new model to determine the shortest spark-out time required to absorb the machine-wheel-workpiece system deformations and to achieve the desired workpiece diameter. This model derived from the equation described by S. Malkin to obtain the machine stiffness and consisted in experimentally obtaining the time characteristic constant $\tau$. The verification of the proposed model was done in two experiments. The first one was performed to determine the value of $\tau$ according to the radial infeed velocity $\left(\mathrm{v}_{\mathrm{f}}\right)$, as proposed by $\mathrm{S}$. Malkin. It was shown that the $\tau$ varies, especially at low feed rates. The second objective was to determine the shortest spark-out time needed, in which all machine-wheel-workpiece system deformations were fully eliminated and to compare it to the one calculated by the proposed model. The theoretical and experimental results showed that for radial infeed velocities of 3.0 and 2.5 $\mathrm{mm} / \mathrm{min}$, with $\tau=0.219$ and $0.204 \mathrm{~s}$, respectively, the spark-out time of $1 \mathrm{~s}$ was long enough to ensure that the elastic deformations introduced into the system were fully absorbed. Comparatively, the proposed model was more effective than the Malkin's one to predict the spark-out time and the diametric error for the ratio $t_{1} / \tau$ lower that 20 , being $t_{1}$ the time in seconds for the rough grinding stage. As a conclusion, the proposed model proved to be effective in predicting the minimum spark-out time and the workpiece diameter reduction, when considering the experimental value of $\tau$.

Keywords: Grinding, Spark-out, Process Stiffness, Grinding Cycle, Machine Deformation. 


\section{LISTA DE FIGURAS}

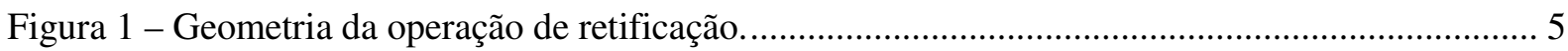

Figura 2 - Geometria do arco de contato na retificação cilíndrica externa de mergulho......................... 6

Figura 3 - Espessura máxima do cavaco não deformado na retificação cilíndrica externa...................... 7

Figura 4 - Representação esquemática da espessura de corte equivalente............................................ 8

Figura 5 - Variáveis influentes no grau de recobrimento. ................................................................ 10

Figura 6 - Comprimento de contato do rebolo abrasivo antes e após deformação ................................. 12

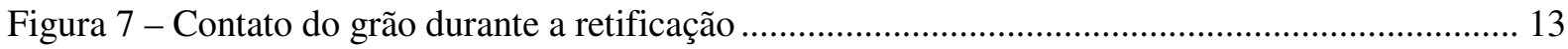

Figura 8 - Esquema contato do grão, fase (1) fricção, fase (2) deformação plástica e fase (3) formação

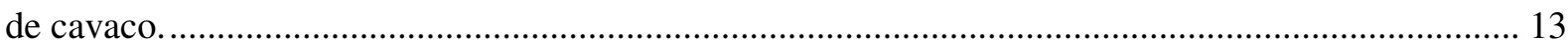

Figura 9 - Modelo teórico do estado de interface entre grão e a peça no processo de retificação......... 15

Figura 10 - Deflexão do grão aplicando a força normal durante o processo de retificação. ................. 16

Figura 11 - Deflexão do grão aplicando a força tangencial durante o processo de retificação. ............ 16

Figura 12 - Esquema teórico das fases de retificação cilíndrica externa tangencial de mergulho......... 18

Figura 13 - Dispositivo de teste para determinar rigidez estática do sistema MRP ............................. 19

Figura 14 - Medição rigidez estática com sensor LVDT.................................................................... 20

Figura 15 - Esquema para determinação da rigidez estática.................................................................. 21

Figura 16 - Contato entre o rebolo e a peça durante a retificação ....................................................... 23

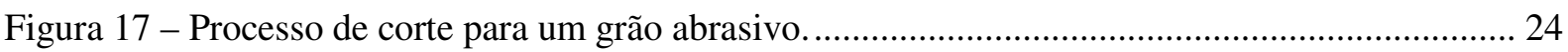

Figura 18 - Flexão de ponta no grão aplicando a força tangencial durante o processo de retificação.. 25

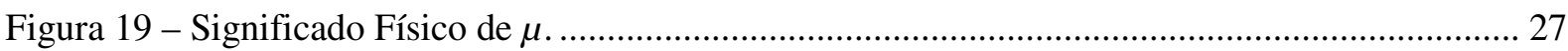

Figura 20 - Penetração do rebolo numa operação de mergulho ......................................................... 27

Figura 21 Corpo de prova utilizado no experimento........................................................................ 28

Figura 22 - Modelo idealizado de retificação cilíndrica...................................................................... 31

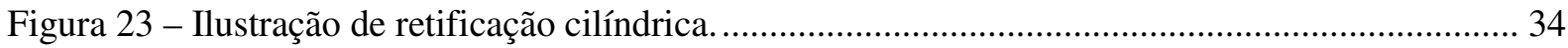

Figura 24 - Simplificação esquemática do ciclo de retificação com desbaste e centelhamento............ 36

Figura 25 - Ciclo de retificação com desbaste, acabamento e centelhamento...................................... 38

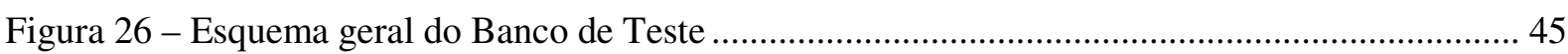

Figura 27 - Set up utilizado para o processo de retificação por mergulho na retificadora BONELI.... 46

Figura 28 - Dressador utilizado no experimento de retificação............................................................. 48

Figura 29 - Peça utilizada no experimento de retificação...................................................................... 49

Figura 30 - Esquema de fixação da peça no sistema de arraste e contra pontas..................................... 49

Figura 31 - Tipologia utilizada na instrumentação para aquisição dos dados ...................................... 53

Figura 32- Esquema geral do sistema de aquisição utilizado no experimento ................................... 172 
Figura 33 - Programa em LabView do sistema de monitoramento, estruturas gerais. 173

Figura 34 - Programa em LabView do sistema de monitoramento, estruturas em $2^{\circ}$ nível. 173

Figura 35 - Tela customizada com os parâmetros de processo para retificação. 174

Figura 36 - Sistema filtragem utilizado no experimento de retificação..... 175

Figura 37 - Equipamento "Spectro" para caracterização de materia-prima da peça .. 176 


\section{LISTA DE GRÁFICOS}

Gráfico 1 - Deformação sistema MRP 29

Gráfico 2 - Aquisição dados durante o processo retificação 55

Gráfico 3 - Curva de deformação no processo de retificação. 56

Gráfico 4 - Curvas características de estimativa de $\tau-M_{\text {atLab }}{ }^{\circledR}$ 58

Gráfico 5 - Curvas características de estimativa de $\tau-$ MatLab $^{\circledR}$ 59

Gráfico 6 - Curvas Experimentais Excel ${ }^{\circledR}$ - Vel. de mergulho $=3,0 \mathrm{~mm} / \mathrm{min}$. Tempo de Centelhamento $=0 \mathrm{~s}$.

Gráfico 7 - Curvas Experimentais MatLab ${ }^{\circledR}-$ Vel. de mergulho $=3,0 \mathrm{~mm} / \mathrm{min}$. Centelhamento $=0 \mathrm{~s} 61$

Gráfico 8 - Curvas Experimentais Excel ${ }^{\circledR}-$ Vel. de mergulho $=2,5 \mathrm{~mm} / \mathrm{min}$. centelhamento $=0 \mathrm{~s} \ldots 62$

Gráfico 9 - Curvas Experimentais MatLab ${ }^{\circledR}-$ Vel. de mergulho $=2,5 \mathrm{~mm} / \mathrm{min}$.

Gráfico 10 - Curvas Experimentais Excel ${ }^{\circledR}$ - Vel. de mergulho $=1,6 \mathrm{~mm} / \mathrm{min}$.

Gráfico 11 - Curvas Experimentais MatLab ${ }^{\circledR}$ - Vel. de mergulho = 1,6mm/min. 65

Gráfico 12 - Curvas Experimentais Excel ${ }^{\circledR}-$ Vel. de mergulho $=0,8 \mathrm{~mm} / \mathrm{min}$. 66

Gráfico 13 - Curvas Experimentais MatLab ${ }^{\circledR}$ - Vel. de mergulho $=0,8 \mathrm{~mm} / \mathrm{min}$.

Gráfico 14 - Curvas Experimentais Excel ${ }^{\circledR}-$ Vel. de mergulho $=0,08 \mathrm{~mm} / \mathrm{min}$.

Gráfico 15 - Curvas Experimentais MatLab ${ }^{\circledR}$ - Vel. de mergulho = 0,08mm $/ \mathrm{min}$.

Gráfico 16 - Curvas teóricas de deformação do sistema MRP. .

Gráfico 17 - Curva teórica - Tempo mínimo de centelhamento. 72

Gráfico 18 - Ciclo convencional processo usinagem - Veloc. de mergulho = 3, 2,5, 1,6, 0,8 e 0,08 $\mathrm{mm} / \mathrm{min}$.

Gráfico 19 - Valores de $\tau$ para Veloc. de mergulho $=3,2,5,1,6,0,8$ e $0,08 \mathrm{~mm} / \mathrm{min}$. 75

Gráfico 20 - Ciclo convencional processo usinagem - velocidade de mergulho $=3,0 \mathrm{~mm} / \mathrm{min}$. 77

Gráfico 21 - Curvas experimental e teórica do ciclo convencional processo usinagem - velocidade de mergulho $=3,0 \mathrm{~mm} / \mathrm{min}$. 78

Gráfico 22 - Resultado teórico Equação (38), (51) e Experimento - velocidade de mergulho = 3,0 $\mathrm{mm} / \mathrm{min}$.

Gráfico 23 - Comparação dos erros entre os modelos Equação (38) e Equação (51) velocidade de mergulho $=3,0 \mathrm{~mm} / \mathrm{min}$.

Gráfico 24 - Resultado teórico Equação (38), (51) e Experimento - velocidade de mergulho = 2,5 $\mathrm{mm} / \mathrm{min}$.

Gráfico 25 - Comparação dos erros entre os modelos Equação (38) e Equação (51) velocidade de mergulho $=2,5 \mathrm{~mm} / \mathrm{min}$.

Gráfico 26 - Resultado teórico Equação (38), (51) e Experimento - velocidade de mergulho = 1,6 $\mathrm{mm} / \mathrm{min}$. 
Gráfico 27 - Comparação dos erros entre os modelos Equação (38) e Equação (51) velocidade de mergulho $=1,6 \mathrm{~mm} / \mathrm{min}$. 84

Gráfico 28 - Resultado teórico Equação (38), (51) e Experimento - velocidade de mergulho = 0,8 $\mathrm{mm} / \mathrm{min}$. 85

Gráfico 29 - Comparação dos erros entre os modelos Equação (38) e Equação (51) velocidade de mergulho $=0,8 \mathrm{~mm} / \mathrm{min}$. 86

Gráfico 30 - Relação $t_{1} / \tau$ para velocidades de mergulho = 3,0, 2,5, 1,6 e 0,8 mm/min. 87

Gráfico 31 - Aquisição dados processo retificação - Vel. 3,0mm/min. 0seg. Centelhamento. 100

Gráfico 32 - Aquisição dados processo retificação - Vel. 3,0mm/min. 0,3seg. Centelhamento......... 101

Gráfico 33 - Aquisição dados processo retificação - Vel. 3,0mm/min. 0,6seg. Centelhamento......... 102

Gráfico 34 - Aquisição dados processo retificação - Vel. 3,0mm/min. 1seg. Centelhamento............ 103

Gráfico 35 - Aquisição dados processo retificação - Vel. 3,0mm/min. 2 seg. Centelhamento........... 104

Gráfico 36 - Aquisição dados processo retificação - Vel. 3,0mm $/ \mathrm{min} .3$ seg. Centelhamento........... 105

Gráfico 37 - Aquisição dados processo retificação - Vel. 2,5mm/min. 0seg. Centelhamento............ 106

Gráfico 38 - Aquisição dados processo retificação - Vel. 2,5mm/min. 0,3seg. Centelhamento........ 107

Gráfico 39 - Aquisição dados processo retificação - Vel. 2,5mm/min. 0,6seg. Centelhamento........ 108

Gráfico 40 - Aquisição dados processo retificação - Vel. 2,5mm/min. 1seg. Centelhamento............ 109

Gráfico 41 - Aquisição dados processo retificação - Vel. 2,5mm/min. 2seg. Centelhamento............ 110

Gráfico 42 - Aquisição dados processo retificação - Vel. 2,5mm/min. 3seg. Centelhamento............ 111

Gráfico 43 - Aquisição dados processo retificação - Vel. 1,6mm/min. 0seg. Centelhamento............ 112

Gráfico 44 - Aquisição dados processo retificação - Vel. 1,6mm/min. 0,3 seg. Centelhamento....... 113

Gráfico 45 - Aquisição dados processo retificação - Vel. 1,6mm/min. 0,6 seg. Centelhamento........ 114

Gráfico 46 - Aquisição dados processo retificação - Vel. 1,6mm/min. 1 seg. Centelhamento........... 115

Gráfico 47 - Aquisição dados processo retificação - Vel. 1,6mm/min. 2 seg. Centelhamento........... 116

Gráfico 48 - Aquisição dados processo retificação - Vel. 1,6mm/min. 3 seg. Centelhamento........... 117

Gráfico 49 - Aquisição dados processo retificação - Vel. 0,8mm/min. 0 seg. Centelhamento........... 118

Gráfico 50 - Aquisição dados processo retificação - Vel. 0,8mm/min. 0,3 seg. Centelhamento....... 119

Gráfico 51 - Aquisição dados processo retificação - Vel. 0,8mm/min. 0,6 seg. Centelhamento........ 120

Gráfico 52 - Aquisição dados processo retificação - Vel. 0,8mm/min. 1 seg. Centelhamento........... 121

Gráfico 53 - Aquisição dados processo retificação - Vel. 0,8mm/min. 2 seg. Centelhamento........... 122

Gráfico 54 - Aquisição dados processo retificação - Vel. 0,8mm/min. 3 seg. Centelhamento........... 123

Gráfico 55 - Aquisição dados processo retificação - Vel. 0,08mm $/ \mathrm{min}$. 0 seg. Centelhamento........ 124

Gráfico 56 - Aquisição dados processo retificação - Vel. 0,08mm/min. 0,3 seg. Centelhamento..... 125

Gráfico 57 - Aquisição dados processo retificação - Vel. 0,08mm $/ \mathrm{min}$. 0,6 seg. Centelhamento..... 126

Gráfico 58 - Aquisição dados processo retificação - Vel. 0,08mm/min. 1 seg. Centelhamento........ 127

Gráfico 59 - Aquisição dados processo retificação - Vel. 0,08mm/min. 2 seg. Centelhamento........ 128

Gráfico 60 - Aquisição dados processo retificação - Vel. 0,08mm/min. 3 seg. Centelhamento........ 129 
Gráfico 61 - Curvas Experimentais Excel ${ }^{\circledR}$ - Vel. 3,0mm/min. - 0 seg. Centelhamento. 130

Gráfico 62 - Curvas Experimentais MatLab ${ }^{\circledR}$ - Vel. 3,0mm/min. - Tempo 0 Seg. Centelhamento. . 131

Gráfico 63 - Curvas Experimentais Excel ${ }^{\circledR}$ - Vel. 3,0mm/min. - 0,6 seg. Centelhamento..... 132

Gráfico 64 - Curvas Experimentais MatLab ${ }^{\circledR}$ - Vel. 3,0mm/min. - Tempo 0,6 Seg. Centelhamento.

Gráfico 65 - Curvas Experimentais Excel ${ }^{\circledR}$ - Vel. 3,0mm/min. - 1 seg. Centelhamento. 134

Gráfico 66 - Curvas Experimentais MatLab ${ }^{\circledR}$ - Vel. 3,0mm/min. - Tempo 1 Seg. Centelhamento. . 135

Gráfico 67 - Curvas Experimentais Excel ${ }^{\circledR}$ - Vel. 3,0mm/min. - 2 seg. Centelhamento. 136

Gráfico 68 - Curvas Experimentais MatLab ${ }^{\circledR}$ - Vel. 3,0mm/min. - Tempo 2 Seg. Centelhamento. . 137

Gráfico 69 - Curvas Experimentais Excel ${ }^{\circledR}$ - Vel. 3,0mm/min. - 3 seg. Centelhamento. 138

Gráfico 70 - Curvas Experimentais MatLab ${ }^{\circledR}$ - Vel. 3,0mm/min. - Tempo 3 Seg. Centelhamento. . 139

Gráfico 71 - Curvas Experimentais Excel ${ }^{\circledR}$ - Vel. 2,5mm/min. - 0 seg. Centelhamento. 140

Gráfico 72 - Curvas Experimentais MatLab ${ }^{\circledR}$ - Vel. 2,5mm/min. - Tempo 0 Seg. Centelhamento. . 141

Gráfico 73 - Curvas Experimentais Excel ${ }^{\circledR}$ - Vel. 2,5mm/min. - 0,6 seg. Centelhamento. 142

Gráfico 74 - Curvas Experimentais MatLab ${ }^{\circledR}$ - Vel. 2,5mm/min. - Tempo 0,6 Seg. Centelhamento.

Gráfico 75 - Curvas Experimentais Excel ${ }^{\circledR}$ - Vel. 2,5mm/min. - 1 seg. Centelhamento. 144

Gráfico 76 - Curvas Experimentais MatLab ${ }^{\circledR}$ - Vel. 2,5mm/min. - Tempo 1 Seg. Centelhamento. . 145

Gráfico 77 - Curvas Experimentais Excel ${ }^{\circledR}$ - Vel. 2,5mm/min. - 2 seg. Centelhamento. 146

Gráfico 78 - Curvas Experimentais MatLab ${ }^{\circledR}$ - Vel. 2,5mm/min. - Tempo 2 Seg. Centelhamento. . 147

Gráfico 79 - Curvas Experimentais Excel ${ }^{\circledR}$ - Vel. 2,5mm/min. - 3 seg. Centelhamento................... 148

Gráfico 80 - Curvas Experimentais MatLab ${ }^{\circledR}$ - Vel. 2,5mm/min. - Tempo 3 Seg. Centelhamento. . 149

Gráfico 81 - Curvas Experimentais Excel ${ }^{\circledR}$ - Vel. 1,6mm/min. - 0 seg. Centelhamento................... 150

Gráfico 82 - Curvas Experimentais MatLab ${ }^{\circledR}$ - Vel. 1,6mm/min. - Tempo 0 Seg. Centelhamento. 151

Gráfico 83 - Curvas Experimentais Excel ${ }^{\circledR}$ - Vel. 1,6mm/min. - 0,6 seg. Centelhamento................ 152

Gráfico 84 - Curvas Experimentais MatLab ${ }^{\circledR}$ - Vel. 1,6mm/min. - Tempo 0,6 Seg. Centelhamento.

Gráfico 85 - Curvas Experimentais Excel ${ }^{\circledR}$ - Vel. 1,6mm/min. - 1 seg. Centelhamento. 154

Gráfico 86 - Curvas Experimentais MatLab ${ }^{\circledR}$ - Vel. 1,6mm/min. - Tempo 1 Seg. Centelhamento. . 155

Gráfico 87 - Curvas Experimentais Excel ${ }^{\circledR}$ - Vel. 1,6mm/min. - 2 seg. Centelhamento................... 156

Gráfico 88 - Curvas Experimentais MatLab ${ }^{\circledR}$ - Vel. 1,6mm/min. - Tempo 2 Seg. Centelhamento. . 157

Gráfico 89 - Curvas Experimentais Excel ${ }^{\circledR}$ - Vel. 1,6mm/min. - 3 seg. Centelhamento................... 158

Gráfico 90 - Curvas Experimentais MatLab ${ }^{\circledR}$ - Vel. 1,6mm/min. - Tempo 3 Seg. Centelhamento. . 159

Gráfico 91 - Curvas Experimentais Excel ${ }^{\circledR}$ - Vel. 0,8mm/min. - 0 seg. Centelhamento................... 160

Gráfico 92 - Curvas Experimentais MatLab ${ }^{\circledR}$ - Vel. 0,8mm/min. - Tempo 0 Seg. Centelhamento. . 161

Gráfico 93 - Curvas Experimentais Excel ${ }^{\circledR}$ - Vel. 0,8mm/min. - 0,6 seg. Centelhamento. 162 
Gráfico 94 - Curvas Experimentais MatLab ${ }^{\circledR}$ - Vel. 0,8mm/min. - Tempo 0,6 Seg. Centelhamento. 163

Gráfico 95 - Curvas Experimentais Excel ${ }^{\circledR}$ - Vel. 0,8mm/min. - 1 seg. Centelhamento. 164

Gráfico 96 - Curvas Experimentais MatLab ${ }^{\circledR}$ - Vel. 0,8mm/min. - Tempo 1 Seg. Centelhamento. . 165

Gráfico 97 - Curvas Experimentais Excel ${ }^{\circledR}$ - Vel. 0,8mm/min. - 2 seg. Centelhamento................... 166

Gráfico 98 - Curvas Experimentais MatLab ${ }^{\circledR}$ - Vel. 0,8mm/min. - Tempo 2 Seg. Centelhamento. . 167

Gráfico 99 - Curvas Experimentais Excel ${ }^{\circledR}$ - Vel. 0,8mm/min. - 3 seg. Centelhamento.. 168

Gráfico 100 - Curvas Experimentais MatLab ${ }^{\circledR}$ - Vel. 0,8mm/min. - Tempo 3 Seg. Centelhamento. 169 


\section{LISTA DE SÍMBOLOS}

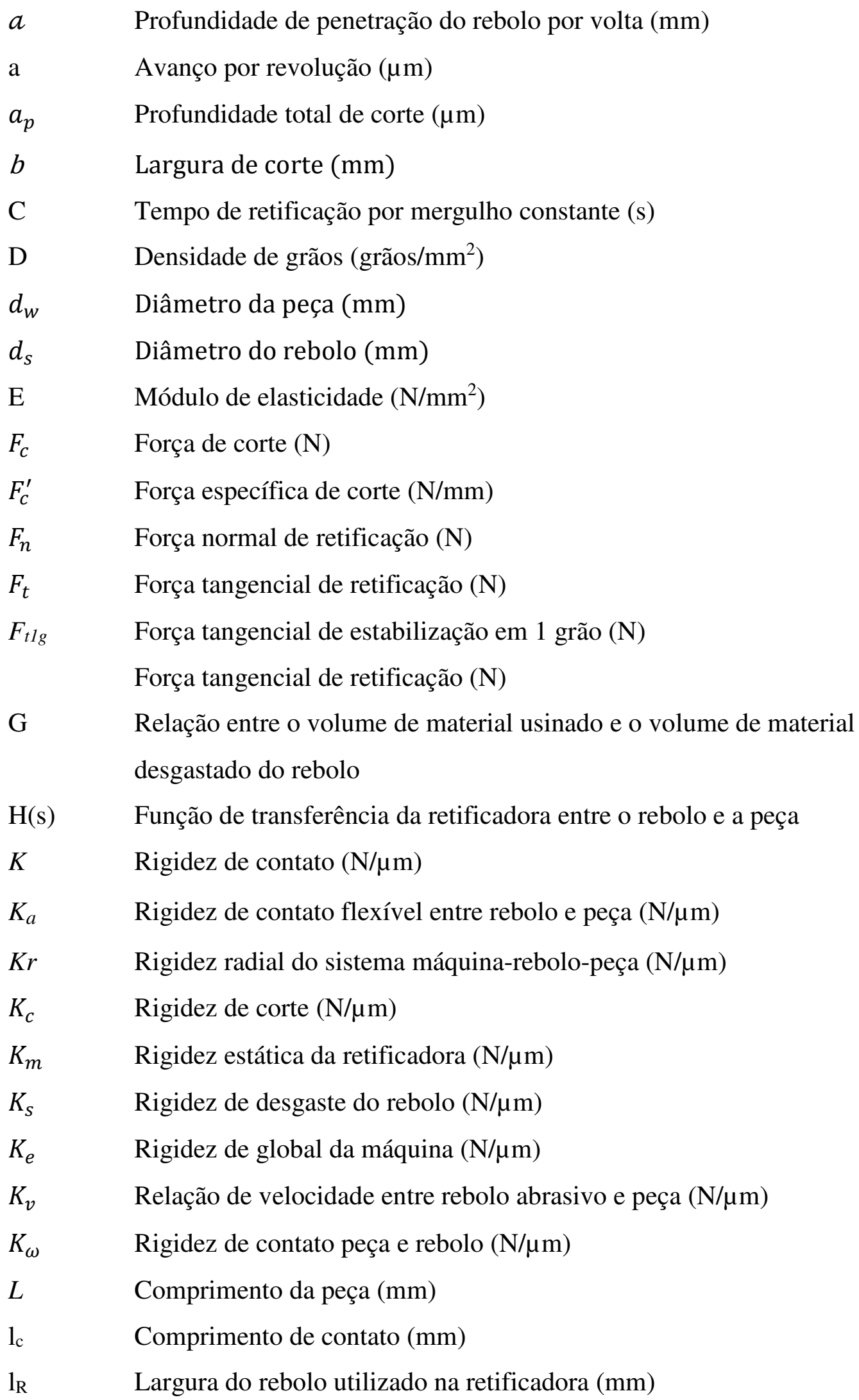




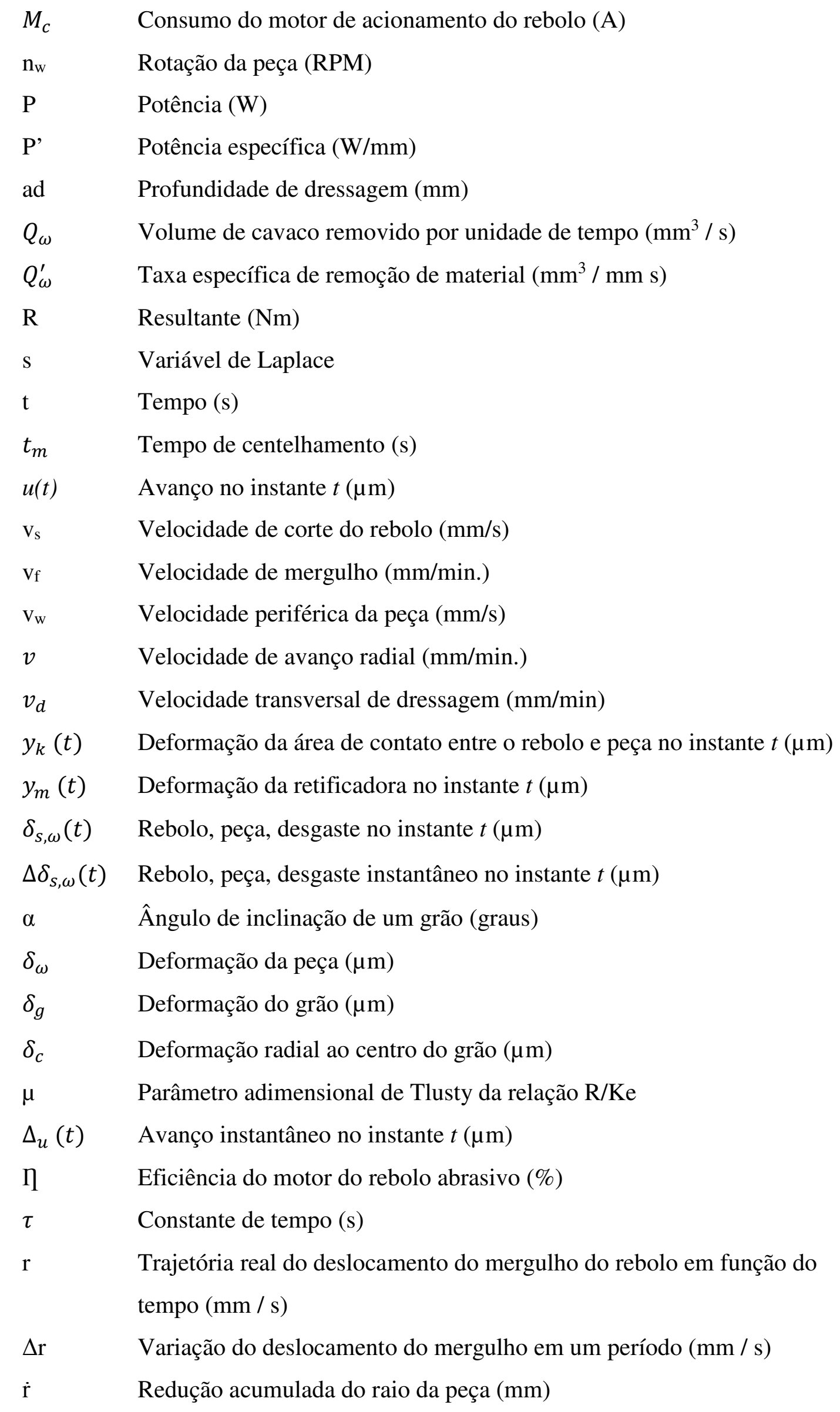


$\mathrm{W}_{\mathrm{t}} \quad$ Desgaste radial do rebolo $(\mathrm{mm})$

$\tau_{\omega} \quad$ Período de contato com a peça (s)

$\varepsilon \quad$ Deformação $(\mathrm{N} / \mu \mathrm{m})$

$\varphi_{s} \quad$ Ângulo de contato (graus) 
LISTA DE ABREVIATURAS E SIGLAS

\author{
CNC Comando numérico computadorizado (abreviatura) \\ MRP Máquina rebolo peça (abreviatura)
}




\section{LISTA DE TABELAS}

Tabela 1 - Resultados obtidos da composição química do material SAE 1045.

Tabela 2 - Taxa de Remoção específica adotado nos experimentos

Tabela 3 - Parâmetros de processo adotados nos bancos de testes

Tabela 4 - Parâmetros de processo de dressagem 52

Tabela 5 - Dados coletados do processo de retificação - Vel. de mergulho = 3,0 $\mathrm{mm} / \mathrm{min}$. 57

Tabela 6 - Dados do processo de retificação aplicando Equação (34) Malkin e Guo (2008)

Tabela 7 - Dados calculados deformação sistema MRP

Tabela 8 - Relação $t_{1} / \tau$ para as velocidades radiais $3,0,2,5,1,6,0,8$ e $0,08 \mathrm{~mm} / \mathrm{min}$ em função do $\tau$

Tabela 9 - Dados obtidos de deformação com velocidade de 3,0mm / min.

Tabela 10 - Dados obtidos de deformação com velocidade de $2,5 \mathrm{~mm} / \mathrm{min}$..

Tabela 11 - Dados obtidos de deformação com velocidade de 1,6mm / min..

Tabela 12 - Dados obtidos de deformação com velocidade de $0,8 \mathrm{~mm} / \mathrm{min}$..

Tabela 13 - Dados obtidos de deformação com velocidade de $0,08 \mathrm{~mm} / \mathrm{min}$. 
1 INTRODUÇÃO 1

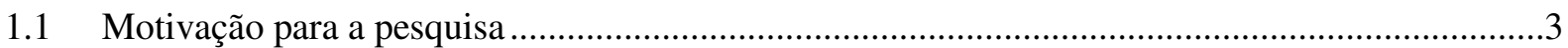

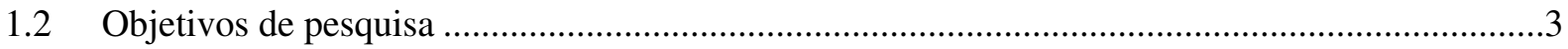

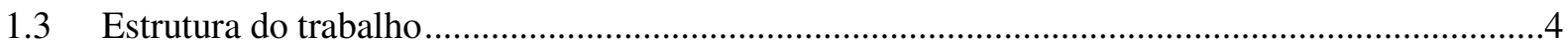

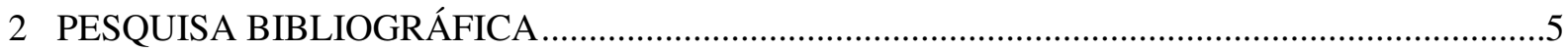

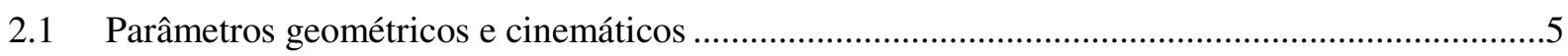

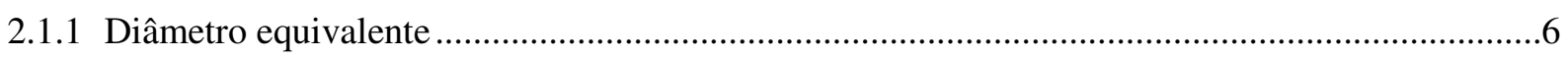

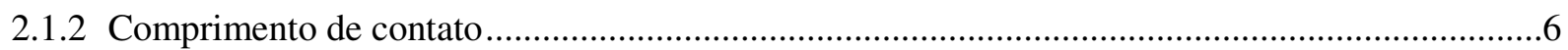

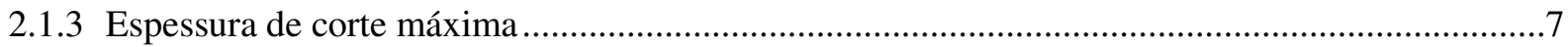

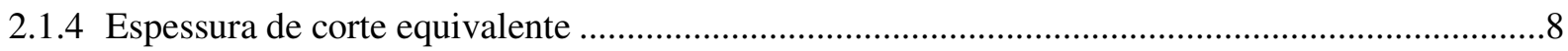

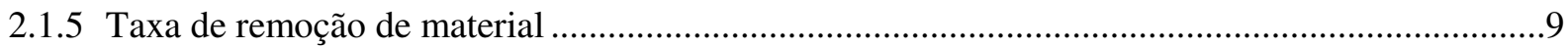

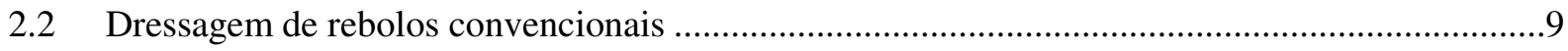

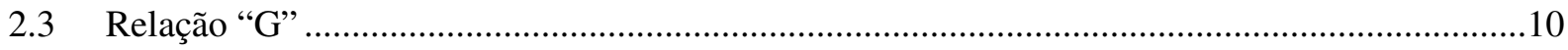

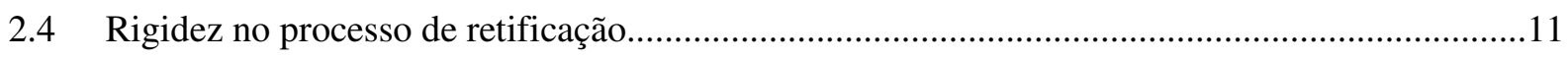

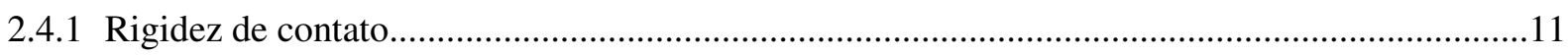

2.4.1.1 Fatores que influenciam a rigidez de contato ..................................................................14

2.4.1.2 Fatores de deflexão no grão que influenciam a rigidez de contato ..........................................16

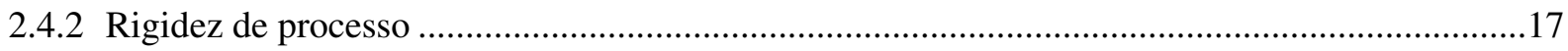

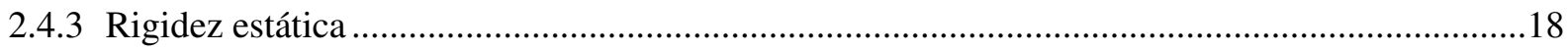

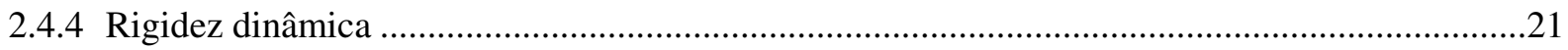

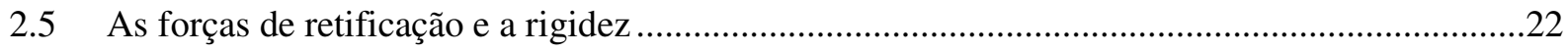

2.6 Método prático para determinar a rigidez do processo descrito por Rossi (2009)......................28

2.7 Modelos matemáticos para determinação da rigidez do sistema MRP ........................................30

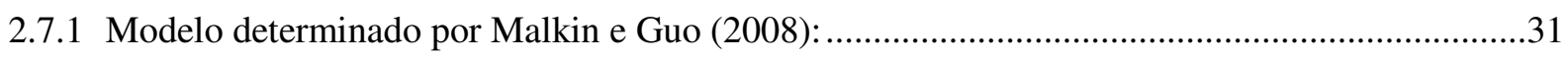

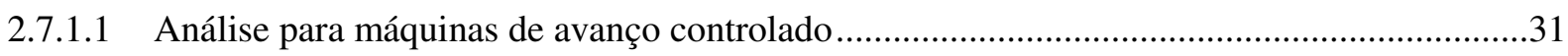

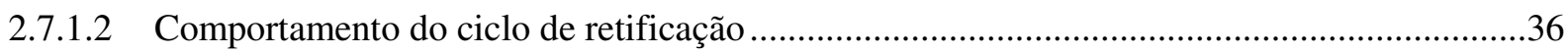

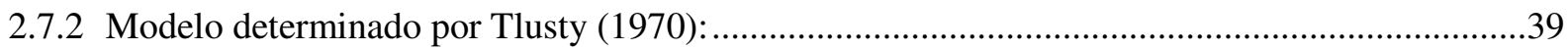

2.8 Sistemas de aquisição de dados em processo de retificação .........................................................40

3 PROPOSTA DE APRIMORAMENTO DO MODELAMENTO PARA A DETERMINAÇÃO DA RIGIDEZ DE UM SISTEMA MRP PARA RETIFICAÇÃO EXTERNA DE MERGULHO ...............42

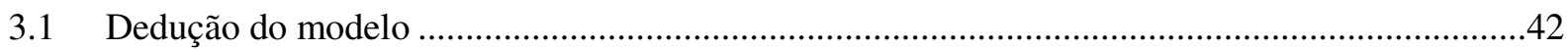




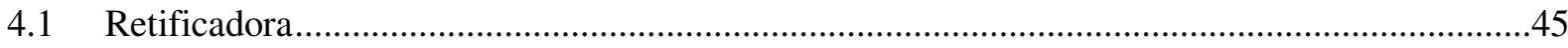

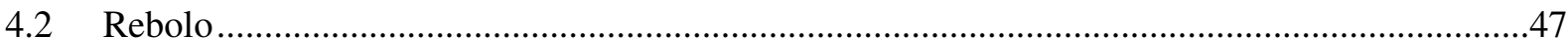

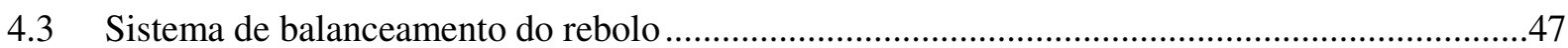

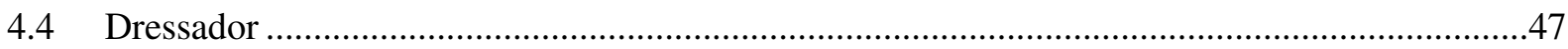

4.5 Sistema de refrigeração e filtragem do fluido de corte ……......................................................48

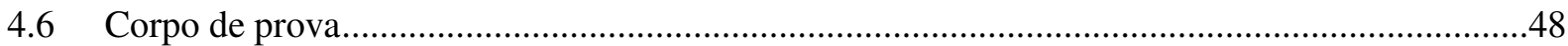

4.7 Sistema de aquisição para coleta de dados de diâmetro instantâneo da peça e coordenada X do rebolo50

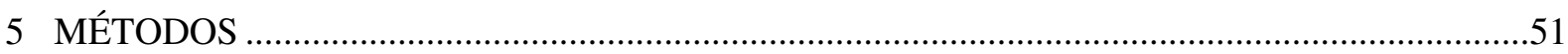

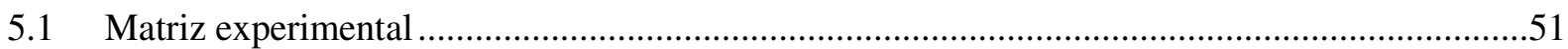

5.2 Método para coleta de dados de diâmetro instantâneo da peça e coordenada X do rebolo ..........53

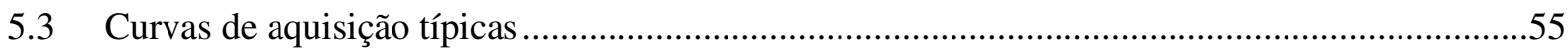

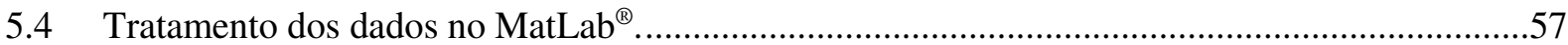

5.5 Experimento 1: Determinação da constante de tempo $\tau$ em função de $v f$...................................57

5.6 Experimento2: Avaliação do tempo de centelhamento...............................................................70

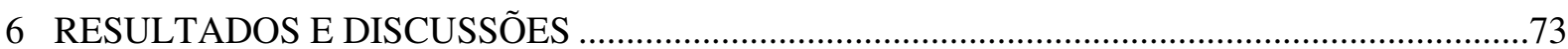

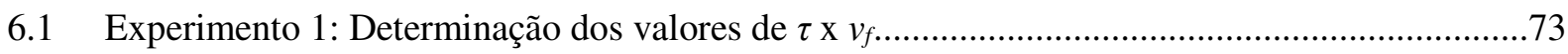

6.2 Experimento2: Avaliação do centelhamento ................................................................................

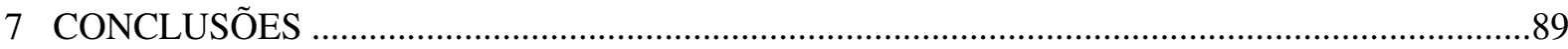

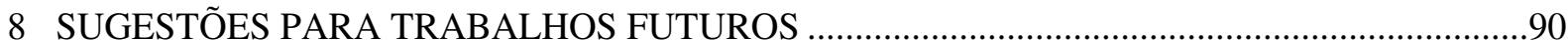

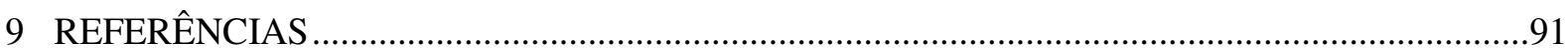

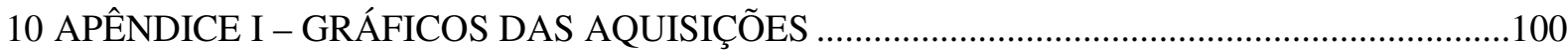

11 APÊNDICE II - CURVAS EXPERIMENTAIS EXCEL ${ }^{\circledR}$ E MATLAB $^{\circledR}$ T X “CENT.” ...............130

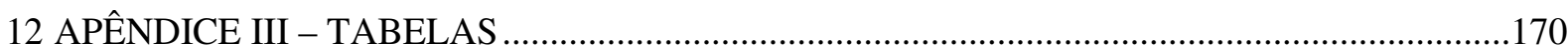

13 APÊNDICE IV - SOFTWARES E ESTRUTURA DO PROGRAMA ...........................................172

14 APÊNDICE V - ESQUEMA DO SISTEMA DE FILTRAGEM ...................................................175

15 APÊNDICE VI - EQUIPAMENTO DE CARACTERIZAÇÃO DO MATERIAL ........................176 


\section{INTRODUÇÃO}

A retificação é um dos processos mais utilizados em operações de acabamento, para a produção de componentes de alta exatidão dimensional e de forma. Certas aplicações também se destinam a altas taxas de remoção e operações de desbaste, embora ainda não representem as principais aplicações para esse processo de usinagem.

Com o uso de comando numérico computadorizado (CNC) e componentes mecânicos cada vez mais precisos, as retificadoras adquiriram grande capacidade dimensional, com precisão de posicionamento na ordem de nanômetros (OLIVEIRA; FRANÇA; WANG, 2008). Ao mesmo tempo, os fabricantes de rebolos evoluíram muito na tecnologia de produzir ferramentas com alta capacidade de remoção e durabilidade entre afiações consecutivas do rebolo (WEGENER et. al., 2011). Todavia, o processo de remoção de material por retificação gera esforços que causam deformações elásticas no sistema máquina-rebolo-peça (MRP). Dependendo da magnitude desses esforços e da rigidez do sistema MRP, as deformações introduzidas ao longo do ciclo de retificação superam, em muito, a profundidade de corte do rebolo. Estas levam a erros de forma na peça, podendo ainda causar vibrações, com prejuízo significativo na qualidade superficial da peça (MALKIN; GUO, 2008) e (OLIVEIRA, 1988). Grande parte dessa deformação elástica pode ser recuperada através de um tempo de centelhamento (spark-out) ao final do ciclo de retificação, no qual o rebolo é mantido na sua posição de final de ciclo, por um determinado tempo em segundos, antes do seu desengajamento da peça. Neste estágio a circularidade e a rugosidade são melhoradas, beneficiando uma operação de acabamento, por exemplo.

Sendo assim, o projeto de um ciclo de retificação deve levar em consideração a necessidade da minimização ou eliminação das deformações elásticas geradas ao longo do ciclo de retificação. Na busca pela produtividade, deseja-se remover o sobremetal de retificação no menor tempo possível, adotando-se assim, altas taxas de remoção de material. Considerandose a proporcionalidade entre a velocidade de avanço e as força normal de retificação (MALKIN; GUO, 2008) e (ROSSI, 2009), para um sistema MRP de baixa rigidez, a deformação elástica introduzida pode ser tornar proibitiva para avanços elevados, requerendo tempos de centelhamento superiores ao tempo de corte propriamente dito. Dessa forma, não serão obtidos os requisitos dimensionais e de qualidade desejados. Mesmo em máquinas que utilizam medidores do diâmetro da peça em processo, pode-se necessitar de tempos proibitivos para 
atingir-se o valor especificado, inviabilizando o ciclo proposto e os supostos ganhos de produtividade.

Em face ao problema exposto, o aumento do interesse em conhecer e aprimorar os aspectos de rigidez do sistema MRP resultam em algumas hipóteses e modelos, que até o momento, buscam elucidar o mecanismo envolvido (MALKIN; GUO, 2008).

Em uma operação de retificação, existem vários tipos de flexões que podem ocorrer de forma simultânea. É muito difícil separar a deformação de contato rebolo-peça das outras deformações, que podem ser do próprio mecanismo de fixação da peça, do eixo-árvore, da estrutura da máquina, deformação térmica do rebolo, etc. A rigidez de contato na retificação é definida como a relação entre a força normal de compressão pela deformação elástica do rebolo na zona de contato (INASAKI; KARPUSCHEWSKI; LEE, 2001). Esta deve ser considerada no processo, pois seu valor não é pequeno o suficiente para ser ignorado principalmente em operações de acabamento. O comportamento elástico é considerado fator importante no mecanismo de remoção de material, na precisão de peças a serem fabricadas, na eficiência e na produtividade do processo de retificação (OLIVEIRA, 1988). As flexões no contato entre grão abrasivo e a peça são compostas por diversas partes, sendo cada uma delas influenciadas por fatores diferentes, por exemplo: velocidade de mergulho, velocidade de corte, rotação da peça, profundidade de corte, forma e geometria da ponta dos grãos, área projetada dos grãos que entram em contato com o material da peça, quantidade de grãos em contato simultaneamente com a peça, tipo de grão e forma de contato com os grãos que estão abaixo deste, as forças tangencial e normal durante o processo de retificação (WAGER; SAINI, 1986).

Apesar das extensas pesquisas desenvolvidas nesta área, ainda se usa o aumento do tempo de centelhamento e redução de parâmetros de processo para alcançar melhoria na peça retificada, no acabamento superficial e tolerâncias geométricas (SAINI, 1990 e MALKIN; GUO, 2008). Estas alternativas geralmente acarretam aumento no tempo de retificação e, por consequência, redução na produtividade do equipamento, particularmente quando a tendência industrial é no sentido oposto. Por esta razão, é importante não só compreender a natureza da rigidez do conjunto, mas conseguir determinar em que condições se podem aumentar a produtividade, tendo em vista o melhor desempenho de qualidade e produtividade em que o processo é capaz de fornecer.

Portanto, acredita-se que seja possível avançar no conhecimento da rigidez do processo de retificação para que este seja cada vez mais eficiente como operação de acabamento, ampliando suas aplicações na indústria metal mecânica. 


\subsection{Motivação para a pesquisa}

Dentro do contexto atual da necessidade de uma maior produtividade com minimização de resíduos e retrabalhos, ter um processo de retificação robusto e capaz de produzir peças de acordo com os padrões pré-estabelecidos de qualidade e produtividade é uma necessidade da indústria. Um dos caminhos para a construção de uma maior previsibilidade do processo de retificação é a adoção, no meio fabril, de ferramentas que permitam, através de testes práticos, alimentar modelos teóricos do processo de retificação. Como resultados, busca-se alcançar equilíbrio entre o menor tempo de retificação e as qualidades dimensional e geométrica da peça. Desta forma, a motivação para esta pesquisa está em avançar no conhecimento da rigidez do processo de retificação. Busca-se prover um modelamento capaz de determinar o menor tempo de centelhamento, para que as deformações elásticas provenientes do processo de retificação sejam plenamente absorvidas e o diâmetro especificado para a peça alcançado, para um determinado sistema máquina-rebolo-peça (MRP).

\subsection{Objetivos de pesquisa}

Este trabalho teve como objetivo principal desenvolver um modelo matemático que permita determinar o tempo de centelhamento mínimo para que as deformações de um dado sistema máquina-rebolo-peça (MRP) sejam absorvidas e o diâmetro especificado possa ser obtido e testá-lo de forma experimental.

Tem-se os seguintes objetivos secundários:

- Determinar os modelos existentes e suas limitações.

- Investigar a influência de velocidade de mergulho na rigidez do processo.

- Verificar os requisitos para a implementação do modelo no ambiente fabril. 


\subsection{Estrutura do trabalho}

A estrutura do trabalho contém no capítulo 1 a Introdução da pesquisa, abordando o objetivo, o problema, a declaração dos objetivos, a relevância e os procedimentos da pesquisa.

No capítulo 2 será apresentada a pesquisa bibliográfica com renomados autores que versam pelos parâmetros geométricos e cinemáticos na retificação, mecanismos de desgaste, rigidez do processo de retificação, método prático para otimização do processo de retificação descrito por ROSSI (2009), os modelos de MALKIN; GUO (2008) e TLUSTY (1970) e os sistemas de aquisição de dados para retificação.

No capítulo 3 é descrito um novo modelo para estimar o tempo de centelhamento em uma operação de retificação externa de mergulho.

No capítulo 4 é apresentado os materiais e métodos aplicados neste trabalho, como o tipo de rebolo, dressador, corpo de prova, sistema de aquisição de dados desenvolvido em LabView ${ }^{\circledR}$ e as curvas de aquisição típicas deste sistema.

No capítulo 5 é apresentado o método de experimento para obtenção da constante de tempo $\tau$ e o método para avaliação do centelhamento.

No capítulo 6 é apresentado os resultados e discussões sobre a medição do $\tau$ em função da velocidade de avanço e a avaliação do centelhamento.

As conclusões são apresentadas no capítulo 7.

Sugestões para trabalhos futuros, Referências Bibliográficas, Apêndices I, II, III, IV, V e VI são apresentados nos capítulos 8 a 15 respectivamente. 


\section{PESQUISA BIBLIOGRÁFICA}

\subsection{Parâmetros geométricos e cinemáticos}

As operações de retificação são realizadas por um número grande de arestas cortantes com geometria indefinida e distribuídas de forma irregular sobre a superfície de trabalho do rebolo. A Figura 1 ilustra a geometria do processo de retificação cilíndrica externa, definindose os seguintes parâmetros:

- Diâmetro do rebolo $\left(\mathrm{d}_{\mathrm{s}}\right)$

- Diâmetro da peça $\left(\mathrm{d}_{\mathrm{w}}\right)$

- Velocidade de corte $\left(\mathrm{v}_{\mathrm{s}}\right)$

- Velocidade da peça $\left(\mathrm{v}_{\mathrm{w}}\right)$

- Velocidade de mergulho $\left(\mathrm{v}_{\mathrm{f}}\right)$

- Profundidade de corte (a)

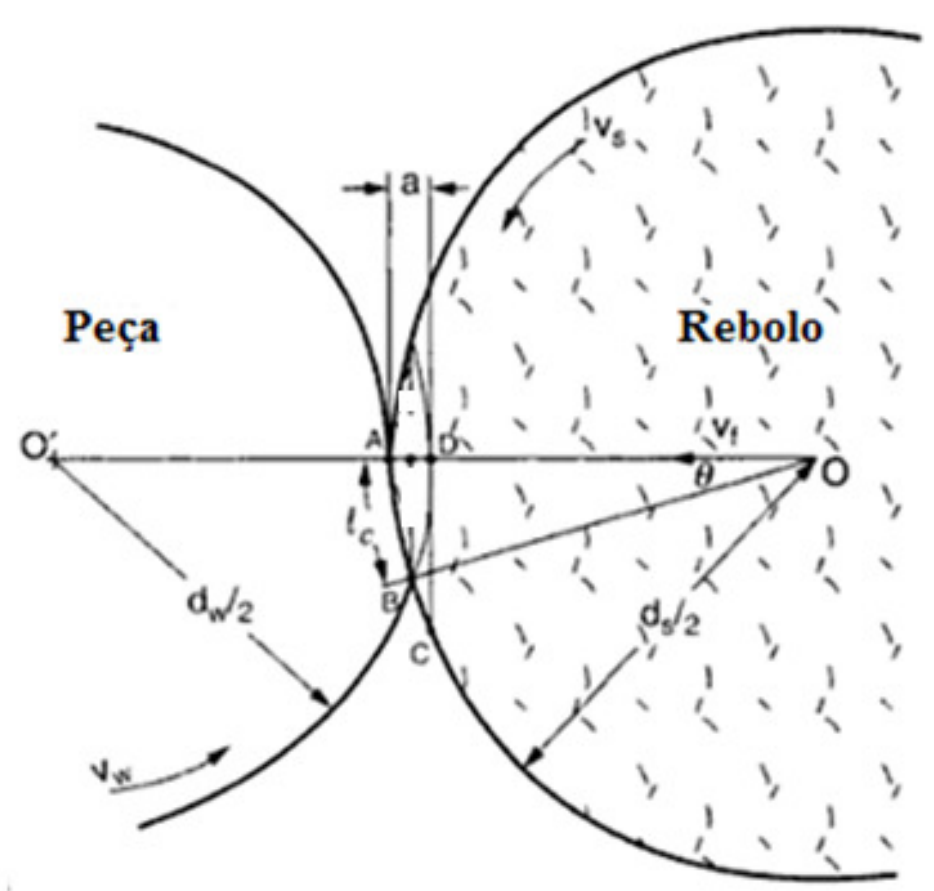

Figura 1 - Geometria da operação de retificação.

Fonte: Adaptado de Guo e Malkin, 2008. 


\subsubsection{Diâmetro equivalente}

Segundo Oliveira (1988), o diâmetro equivalente "de", foi um parâmetro criado por Robert S. Hahn em 1955 para representar o nível em que a superfície do rebolo e a peça se conformam. O diâmetro equivalente é um parâmetro que relaciona as várias formas de retificação, por exemplo: a retificação tangencial plana com a cilíndrica tangencial externa ou interna, para qualquer variação de diâmetro de rebolo e peça. A Equação (1) representa o cálculo do "de".

$$
d_{e}=\frac{d_{s}}{1 \pm\left(\frac{d_{s}}{d_{w}}\right)}
$$

Onde:

$\pm=$ O sinal de “+” indica operações de retificação cilíndrica externa e o sinal de "-” indica retificação cilíndrica interna.

\subsubsection{Comprimento de contato}

O comprimento do arco de contato na retificação cilíndrica externa de mergulho é representado por " $l_{\mathrm{c}}$ " conforme representado na Figura 2, expresso pela Equação (2), desprezando as deformações do sistema máquina-rebolo-peça (MRP) (MALKIN; GUO, 2008).
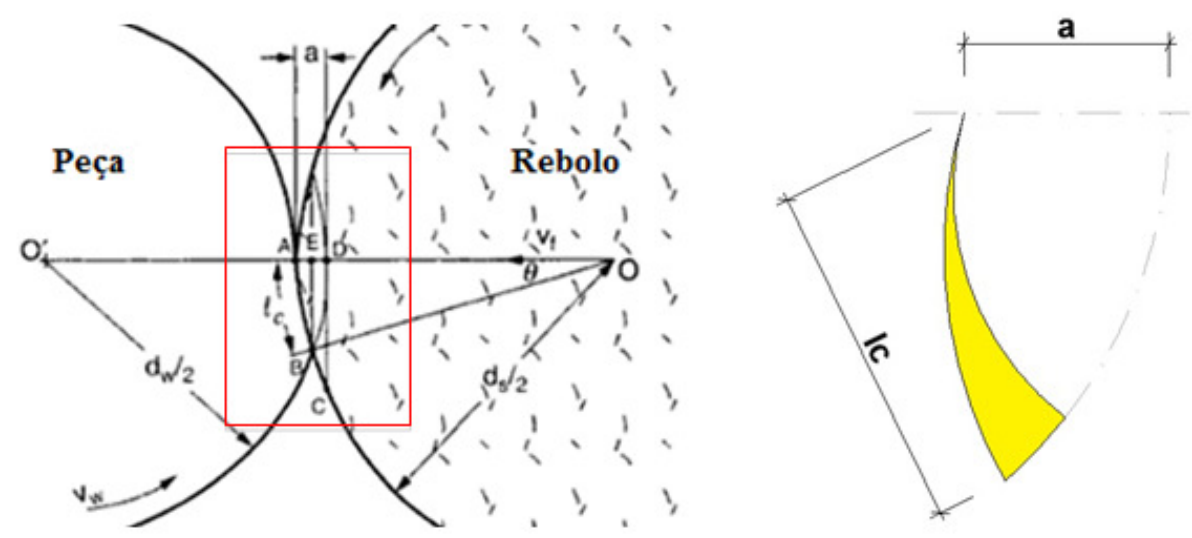

Figura 2 - Geometria do arco de contato na retificação cilíndrica externa de mergulho. 
O comprimento de contato é expresso por:

$$
l_{c}=\left(a * d_{s}\right)^{\frac{1}{2}}
$$

\subsubsection{Espessura de corte máxima}

Considerando o comprimento total da trajetória de corte " $l_{k}$ " como um arco circular, a espessura de corte máxima do cavaco não deformado para retificação cilíndrica externa " $\mathrm{h}_{\mathrm{m}}$ " é representado na Figura 3 (MALKIN; GUO, 2008), sendo calculado pela Equação (3). Teoricamente $l_{\mathrm{k}}=1_{\mathrm{c}}$ :

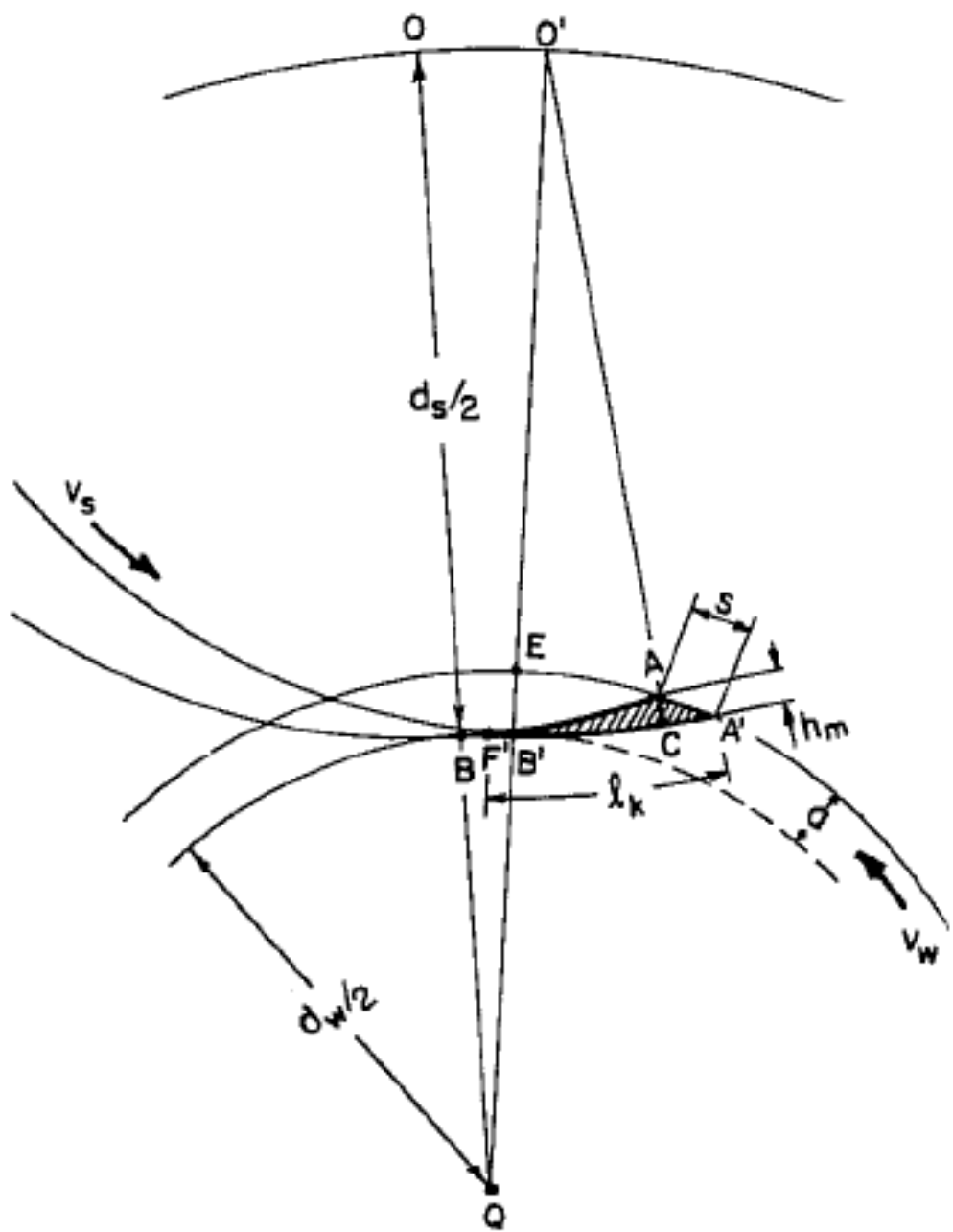

Figura 3 - Espessura máxima do cavaco não deformado na retificação cilíndrica externa. Fonte: Adaptado de MALKIN; GUO, 2008. 
$h_{m}=\left[\frac{6}{C_{r}} *\left(\frac{v_{w}}{v_{s}}\right) *\left(\frac{a}{d_{e}}\right)^{\frac{1}{2}}\right]^{\frac{1}{2}}$

Onde:

$\mathrm{C}=$ Número de arestas de corte por unidade de área.

$\mathrm{r}=$ Razão entre largura e espessura do cavaco em qualquer ponto da linha de corte.

\subsubsection{Espessura de corte equivalente}

A espessura de corte equivalente " $h_{\text {eq" }}$ " representa a espessura da camada de material removida pelo rebolo com a velocidade de corte deste e cujo volume específico equivale ao material retirado na peça em um intervalo de tempo, ou seja, corresponde a espessura que teria uma fita de cavaco caso fosse possível retirá-la continuamente, conforme representado na Figura 4 e expresso na Equação (4). (OLIVEIRA, 1989).

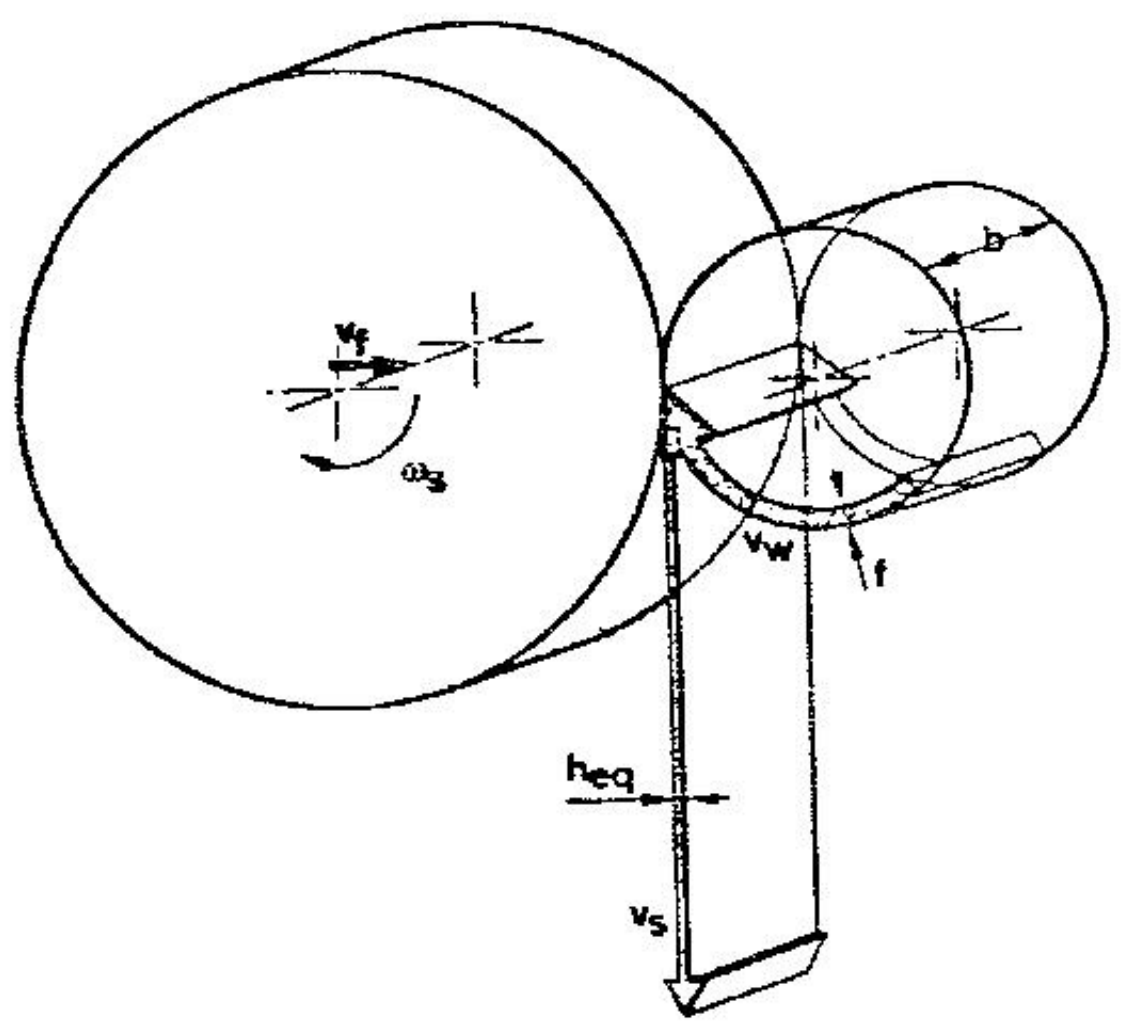

Figura 4 - Representação esquemática da espessura de corte equivalente. 


$$
h_{e q}=\frac{\left(\pi * d_{w} * v_{f}\right)}{v_{s}}
$$

\subsubsection{Taxa de remoção de material}

A taxa de remoção de material " $\mathrm{Q}_{\mathrm{w}}$ " é o volume de material removido por unidade de tempo expresso na Equação (5) (MALKIN; GUO, 2008).

$$
Q_{w}=\pi * d_{w} * v_{f} * b
$$

Onde:

$\mathrm{b}=$ largura de retificação $[\mathrm{mm}]$

A taxa de remoção de material específica “Q' w" está relacionada a $1 \mathrm{~mm}$ de largura de contato de retificação expresso na Equação (6). Este equacionamento pode ser utilizado para comparar diferentes operações de retificação (MALKIN; GUO, 2008).

$$
Q_{w}^{\prime}=\pi * d_{w} * v_{f}
$$

\subsection{Dressagem de rebolos convencionais}

Durante o processo de retificação, cargas mecânicas, térmicas e químicas são aplicadas ao rebolo tendo como efeito o desgaste. Este pode ser de forma macro, descrevendo a modificação da topografia do rebolo e de forma micro, descrevendo a deterioração da geometria do grão (WEGENER et. al., 2011).

Para que o rebolo recupere sua capacidade de corte, a dressagem deve ser executada. Esta pode ser feita, geralmente por dressadores de ponta única, o qual transfere seu perfil de atuação para a superfície do rebolo. O macro efeito de dressagem consiste na transferência da geometria do dressador e as condições de dressagem estabelecidas ao rebolo, onde a transposição desta geometria dá-se pela profundidade de dressagem, "ad", associada à velocidade de deslocamento do dressador na largura de corte do rebolo, "vd". O micro efeito de dressagem é o resultado da 
fratura e ou arrancamento dos grãos em função do contato entre o dressador com a superfície do rebolo (OLIVEIRA, 1988 e COELHO, 1991).

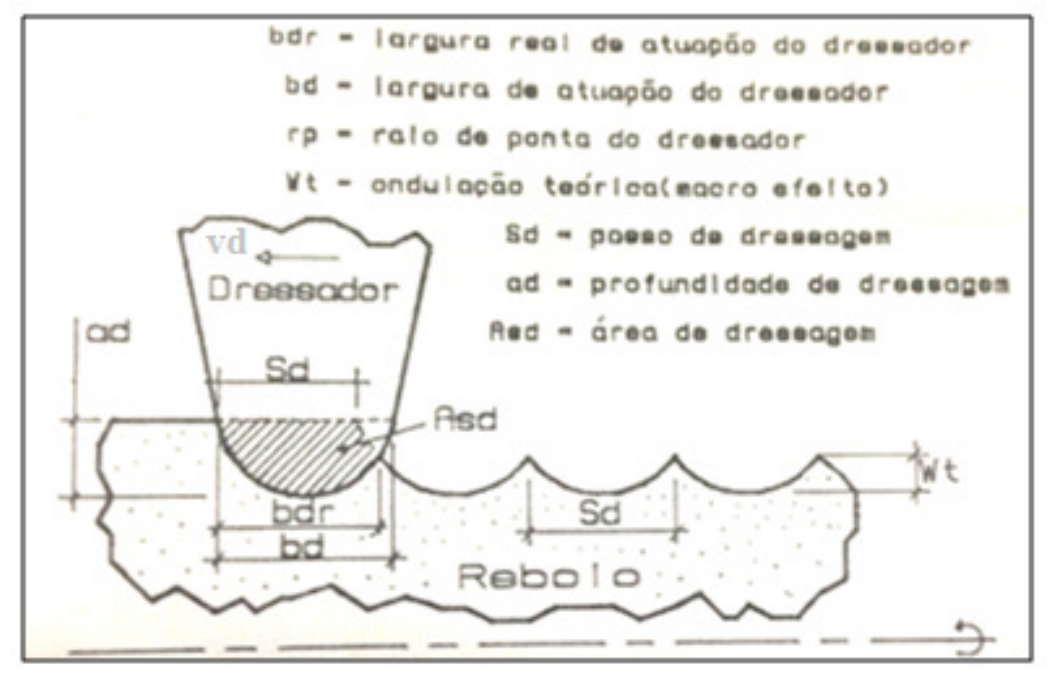

Figura 5 - Variáveis influentes no grau de recobrimento. Fonte: Adaptado de Oliveira (1988).

\subsection{Relação "G"}

Segundo Malkin e Guo (2008) e Oliveira (1988), o índice de desempenho do processo retificação é expresso pela relação "G”, que tem como definição o volume de material removido em relação ao desgaste volumétrico do rebolo. Quanto menor for a relação "G”, menor é a resistência do rebolo ao desgaste. A Equação (7) demonstra a relação "G".

$G=\frac{V_{w}}{V_{s}}$

Onde:

$\mathrm{V}_{\mathrm{w}}=$ volume de material removido da peça durante a retificação;

$\mathrm{V}_{\mathrm{s}}=$ volume desgastado do rebolo; 


\subsection{Rigidez no processo de retificação}

Segundo Malkin e Guo (2008), a rigidez, de modo mais abrangente, está ligada à relação entre a força e a deformação. A rigidez em um processo de retificação pode ser dividida em:

- Rigidez de contato;

- Rigidez de processo;

- Rigidez estática;

- Rigidez dinâmica;

\subsubsection{Rigidez de contato}

As deformações elásticas no contato entre rebolo e peça são consideradas como efeitos de ordem microscópica, relativamente àquelas provocadas pelas forças atuantes durante o ciclo de retificação no conjunto máquina-rebolo-peça (MRP) (ZHANG, et. al.,1993). A aresta de corte do grão abrasivo entra em contato com o material da peça, em uma fase inicial, na qual há somente riscamento da peça. A força normal é aumentada até que a fase de riscamento se comute para a fase de corte (NAKAYAMA; SHARPNEES, 1980). Tal rigidez de contato entre o rebolo e a peça é um aspecto de suma importância ao atendimento das características dimensionais, resultando na qualidade final da peça. (ZHOU; LUTTERWELT, 1992) e (FURUTANI et al., 2003). Mesmo considerando que a estrutura da retificadora seja concebida de forma muito rígida, ocorrem deformações de contato durante o processo de retificação, na razão de poucos milésimos de milímetro, os quais podem ter impacto direto na qualidade da peça (BRINKSMEIER, et. al., 2006 e SAINI, 1989). Essas deformações podem ser classificadas como: flexões de contato, provocadas pelo comportamento elástico do rebolo e da peça, tornando-se uma importante área de pesquisa em retificação. As deformações de contato não só afetam o mecanismo de remoção de material, a precisão dimensional e o acabamento da superfície da peça, mas também influenciam, de forma direta, a eficiência e produtividade do processo de retificação, (SAINI; WAGER, 1985). 
A determinação da diferença entre o valor teórico e real do comprimento de contato entre o rebolo e a peça tem sido adotada como forma de análise da rigidez de contato (ZHANG et al., 1999). Neste caso, o comprimento de contato apresenta diferença da curvatura teórica em relação ao real valor atingido no exato momento de contato. Com a deformação, mais grãos entram em contato com a peça, conforme demonstrado na Figura 6.

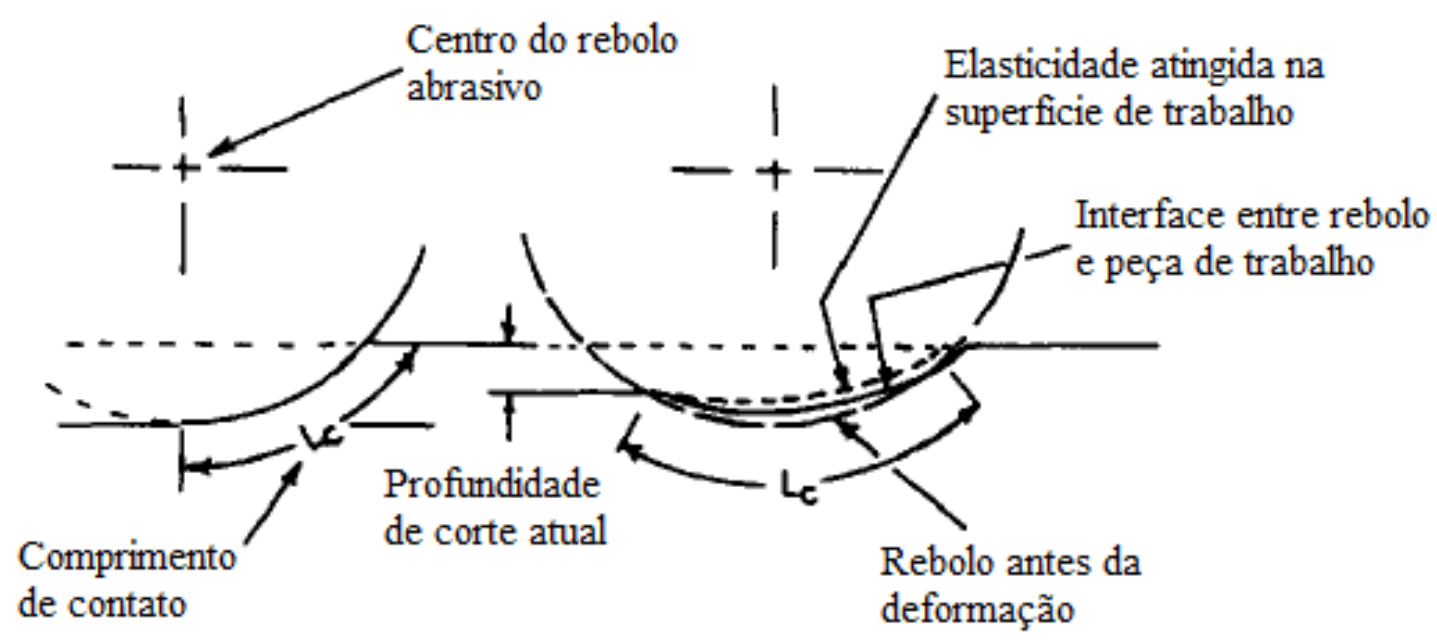

Figura 6 - Comprimento de contato do rebolo abrasivo antes e após deformação

Fonte: Adaptado de Saini e Brown (1980).

Segundo Rowe (2009), o comprimento de contato real entre a peça e o rebolo, com base na teoria da mecânica de contato, possui relação com a rigidez de contato.

Pesquisas publicadas por MALKIN (1977), MALKIN; GUO (2008) e SAINI; BROWN (1980) relatam a influência e magnitude da rigidez de contato em função dos parâmetros de processo, explorando efeitos como: o tipo de rebolo, tamanho e tipo do grão e a correlação do comprimento de contato.

Segundo Saini e Brown (1980), em 1955, o pesquisador Robert S. Hahn foi o primeiro a considerar a existência das flexões, rotações, achatamentos e fissuras nos grãos abrasivos, devido à deformação elástica dos mesmos na zona de contato. Este efeito elástico proporciona aumento da largura de contato entre o rebolo e a peça, exposição de outros grãos em função da deformação decorrente das forças atuantes no corte e, por consequência, mais grãos abrasivos em contato por unidade de área da superfície do rebolo, conforme demonstrado na Figura 7. 


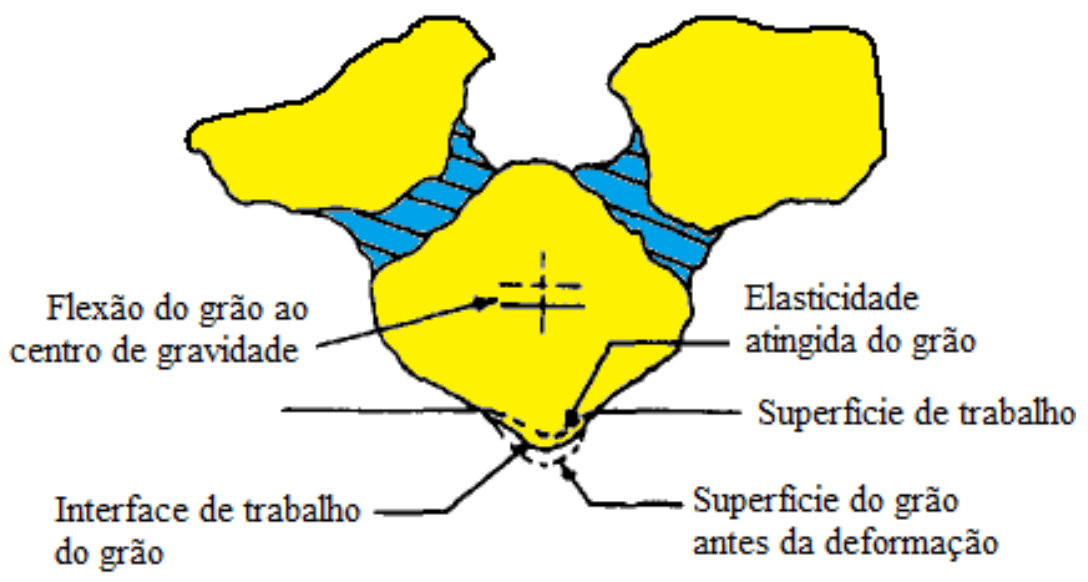

Figura 7 - Contato do grão durante a retificação Fonte: Adaptado de Saini (1980).

Doman, Warkentin e Bauer (2009) apontam em seu estudo as três fases distintas que retratam o fenômeno de remoção de material no processo de retificação, de forma teórica, conforme demonstrado na Figura 8.

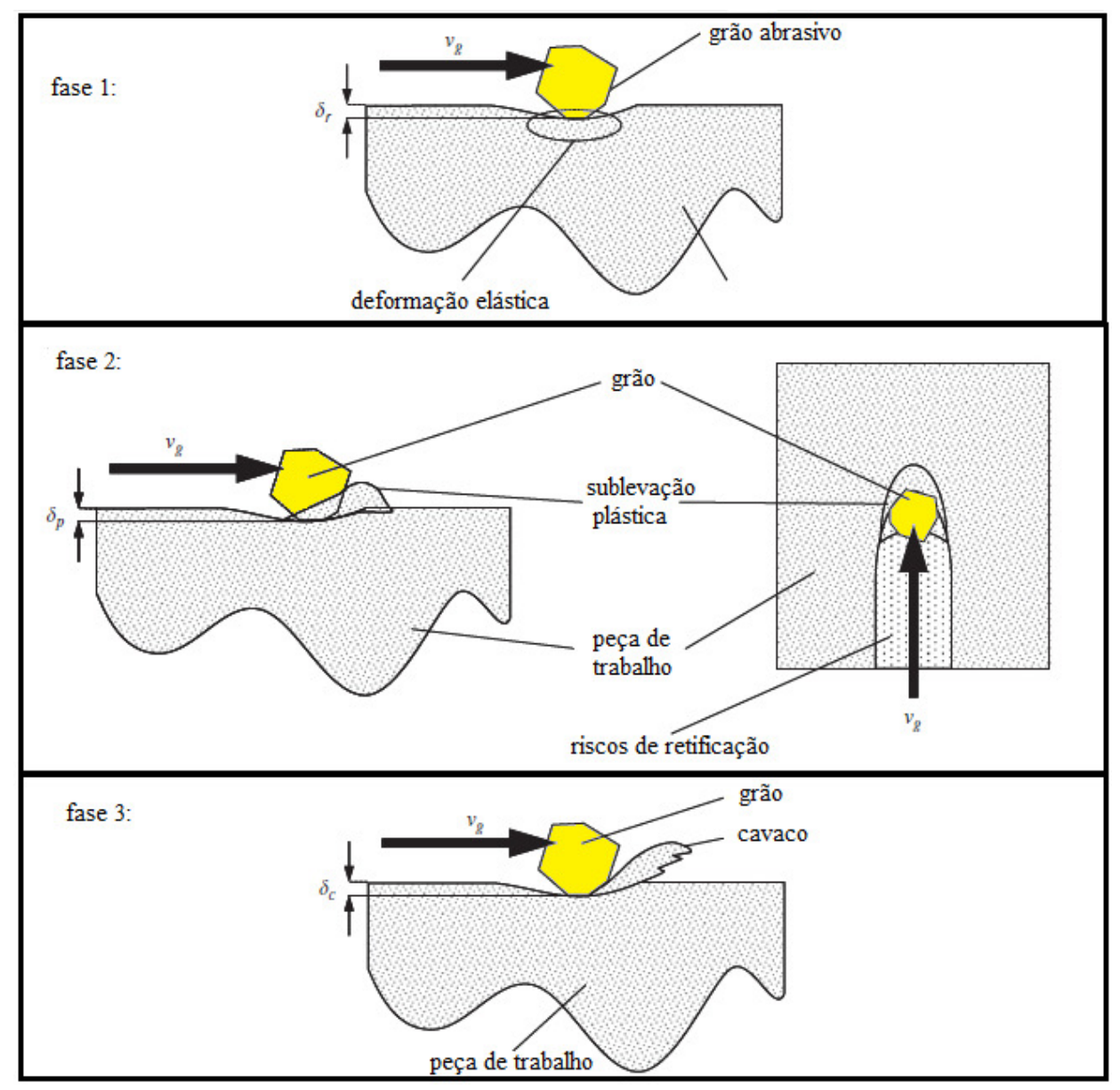

Figura 8 - Esquema contato do grão, fase (1) fricção, fase (2) deformação plástica e fase (3) formação de cavaco. Fonte: Adaptado de Doman, Warkentin e Bauer (2009). 
A fase 1 escorregamento (sliding) é onde ocorre a deformação elástica no grão abrasivo e na peça, causada apenas pelo atrito. A fase 2 - riscamento (plowing) apresenta a deformação plástica, com deslocamento de material, lateralmente ao grão, durante sua trajetória de corte, sem que haja a remoção de material. Na fase 3 - corte (chip formation) efetivamente ocorre o corte e a formação de cavaco.

\subsubsection{Fatores que influenciam a rigidez de contato}

Pesquisadores como Saini e Wager (1985), Choi et al.(2007), Malkin e Guo (2008), Oliveira (1988) e Zhou e Lutterwelt (1992), demonstram através de estudos que as flexões totais de contato entre os grãos e a peça durante o processo de corte, são influenciados por diversos fatores, como:

- Área projetada e geometria da ponta do grão: de acordo com Malkin (1989) e Malkin e Guo (2008), os grãos em contato direto com a peça sofrem maiores esforços de corte do que os que pertencem ao interior do rebolo.

- Especificação do rebolo: a combinação entre tipo de grão, dureza do ligante e sua estrutura resultam em diferentes valores de rigidez de contato. Rebolos duros com menor porosidade e grãos mais resistentes apresentarão maior rigidez de contato se comparados a rebolos moles, de estrutura aberta e grãos de menor resistência mecânica.

Malkin e Guo (2008) afirmam que as deformações de contato, quando conhecidas e consideradas no projeto do processo de retificação, podem auxiliar a caracterização dos parâmetros de processo, minimizando as variações dimensionais na peça.

Segundo Shaw (1996), cerca de 5 a $25 \%$ das flexões que ocorrem no grão, durante o processo de retificação, dependem basicamente do tipo de material e da dureza da peça, associado ao avanço por volta programado.

Zhang et. al. (1993), afirma que é razoável assumir que as flexões de contato estão relacionadas de forma direta ao tamanho do grão, tipo do grão e tipo do elemento ligante. 
Vários estudos produzidos por Malkin (1989), Chiu e Malkin (1993), Oliveira, França e Wang (2008) e Hassui e Diniz (2003), tem sido desenvolvidos com o propósito de propor modelos analíticos e numéricos para o processo de retificação, a fim de determinar os efeitos estruturais na rigidez de contato.

Zhang et. al. (1993) sugeriram um modelo teórico descritivo para a interface entre o grão e a peça na zona de contato, conforme demonstrado na Figura 9. É exemplificado um processo de retificação plana, com velocidade constante de passagem do rebolo em relação à peça, " $v_{w}$ ", e profundidade de corte, " $h$ ", onde o limite de contato entre o grão e a peça desloca-se em função de " $v_{w}$ ".

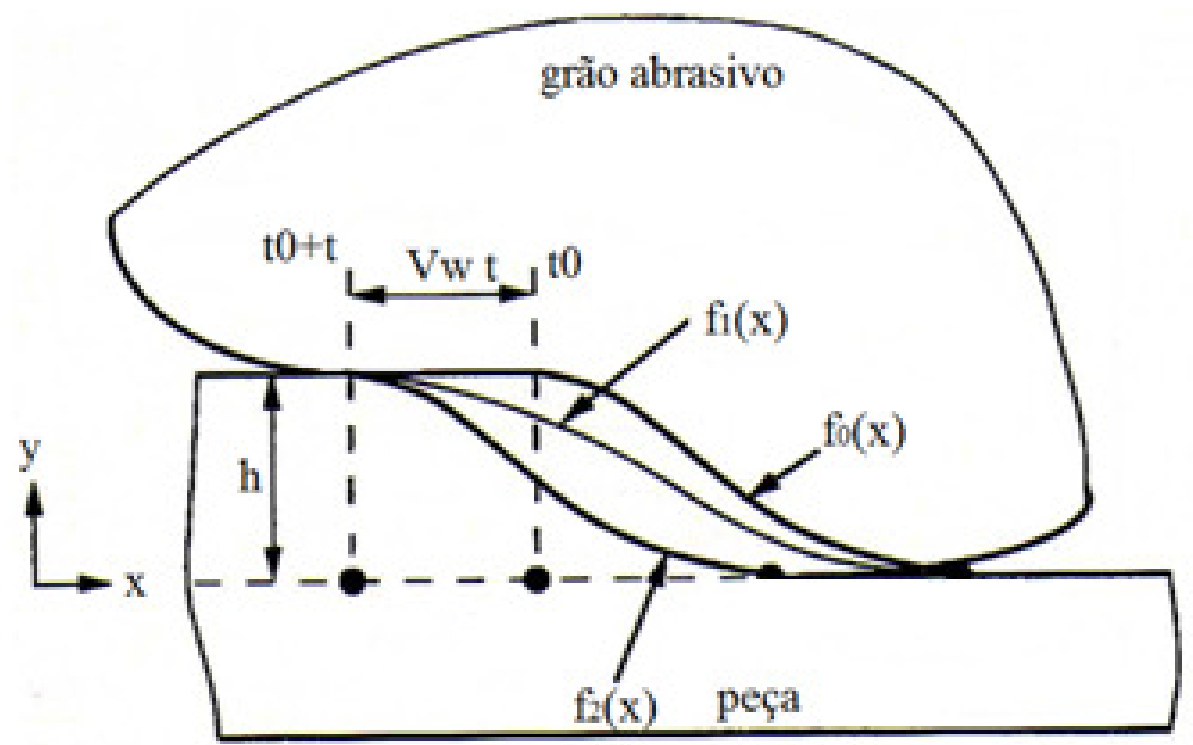

Figura 9 - Modelo teórico do estado de interface entre grão e a peça no processo de retificação. Fonte: Adaptado de Zhang et. al. (1993).

A peça desloca-se na direção do eixo $X$ representado na Figura 9. Considerando o deslocamento constante da peça em direção ao rebolo, ocorre o primeiro contato entre o grão e a peça indicado como $f_{0}(x)$, no instante $t_{0}$, neste estágio inicia-se o processo de deformação na zona de contato entre o grão e a peça. Este limite de contato desloca-se em função de $v w$, considerando o intervalo de tempo expresso em $t=t_{0}+t$, a posição $f_{2}(x)$ é atingida. Baseado neste estágio a deformação da peça pode ser dividida em duas partes para o intervalo de tempo $t=t_{0}+t$ : sendo a primeira a deformação plástica, com remoção de material por grãos ativos, entre as curvas de $f_{0}(x)$ e $f_{1}(x)$. A segunda parte apresenta deformação elástica compreendida entre as curvas de $f_{1}(x)$ e $f_{2}(x)$ (ZHANG et. al., 1993). 


\subsubsection{Fatores de deflexão no grão que influenciam a rigidez de contato}

Saini, Wager e Brown (1982), descrevem três componentes de deflexão, que afetam a rigidez de contato, tendo como referência a peça, conforme demonstrado nas Figuras 10 e 11.

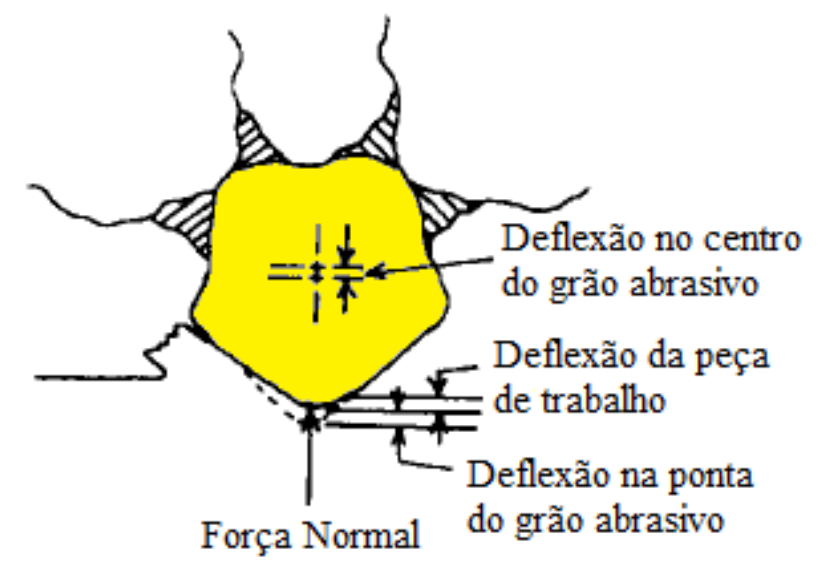

Figura 10 - Deflexão do grão aplicando a força normal durante o processo de retificação.

Fonte: Adaptado de Saini, Wager e Brown (1982).

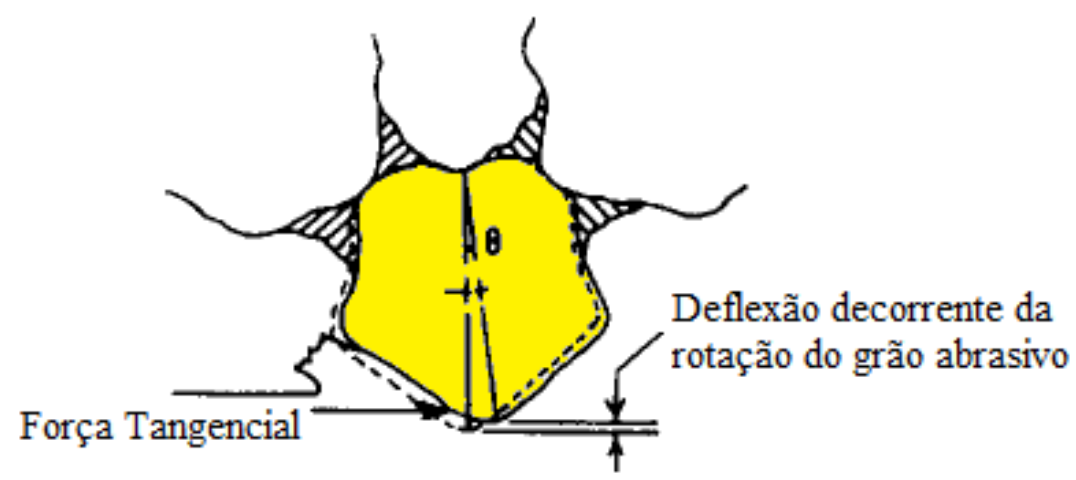

Figura 11 - Deflexão do grão aplicando a força tangencial durante o processo de retificação.

Fonte: Adaptado de Saini, Wager e Brown (1982).

Segundo Saini, Wager e Brown (1982), a deformação da peça, considerando na formação do cavaco a componente vertical de força de contato entre o grão e peça, resulta em deformações elásticas seguidas de plásticas. O retorno subsequente da fase elástica resulta em uma flexão na peça. Este fenômeno ocorre em função de vários fatores, tais como largura do corte, ângulo de cunha do grão, dureza da peça, etc. Esses fatores também afetam, por sua vez, a rigidez de contato. 
A deformação na ponta do grão durante a operação de retificação e a alta pressão de contato do grão com a peça causam deformação elástica local na ponta do grão, perpendicular à superfície de trabalho. Este fenômeno ocorre, principalmente, por dois fatores: a tensão gerada em função da largura da ponta do grão e a forma de ponta (SAINI, 1982).

Segundo Saini, Wager e Brown (1982), também ocorre deflexão no centro do grão, conforme ilustrado na Figura 10, devido à força normal exercida sobre o grão. A deformação é transmitida através do contato grão e peça, de forma direta ou indireta, pelo elemento ligante, o que provoca deslocamento radial do centro de grão. Tal fenômeno ocorre em função de vários fatores, como: a forma e perfil dos grãos, o número de grão ativos no ato do corte e a natureza intergranular da ligação dos grãos e elemento ligante.

Portanto, as deformações descritas por Saini, Wager e Brown (1982) podem afetar, de forma direta, o resultado diametral da peça, caso não sejam consideradas no processo de retificação. Uma das soluções comumente aplicada é deixar o rebolo usinando ao final da operação, sem avanço, no estágio denominado centelhamento, para que essas deformações sejam absorvidas e o diâmetro objetivo da peça seja alcançado. Determinar o tempo mínimo necessário de centelhamento para absorver tais deformações é o objetivo deste trabalho.

\subsubsection{Rigidez de processo}

A rigidez de processo pode ser definida como a relação entre a força normal e a deformação total sofrida pelo sistema MRP, incluindo o sistema de fixação e tudo o mais que por ventura causar uma diferença entre o diâmetro comandado e aquele efetivamente conseguido na peça.

Segundo Malkin (1981) e Malkin e Guo (2008), Chiu e Malkin (1993), Oliveira (1988), Hassui e Diniz (2003) e Rossi (2009), existem diferenças entre a curva de deslocamento radial do rebolo no tempo, comandada pelo sistema de controle da máquina (máquinas de avanço controlado) e a curva real obtida no processo, durante o avanço do rebolo sobre a peça. A Figura 12 demonstra todas as fases de um processo de retificação cilíndrica externa por mergulho, considerando as deformações elásticas durante a operação. 


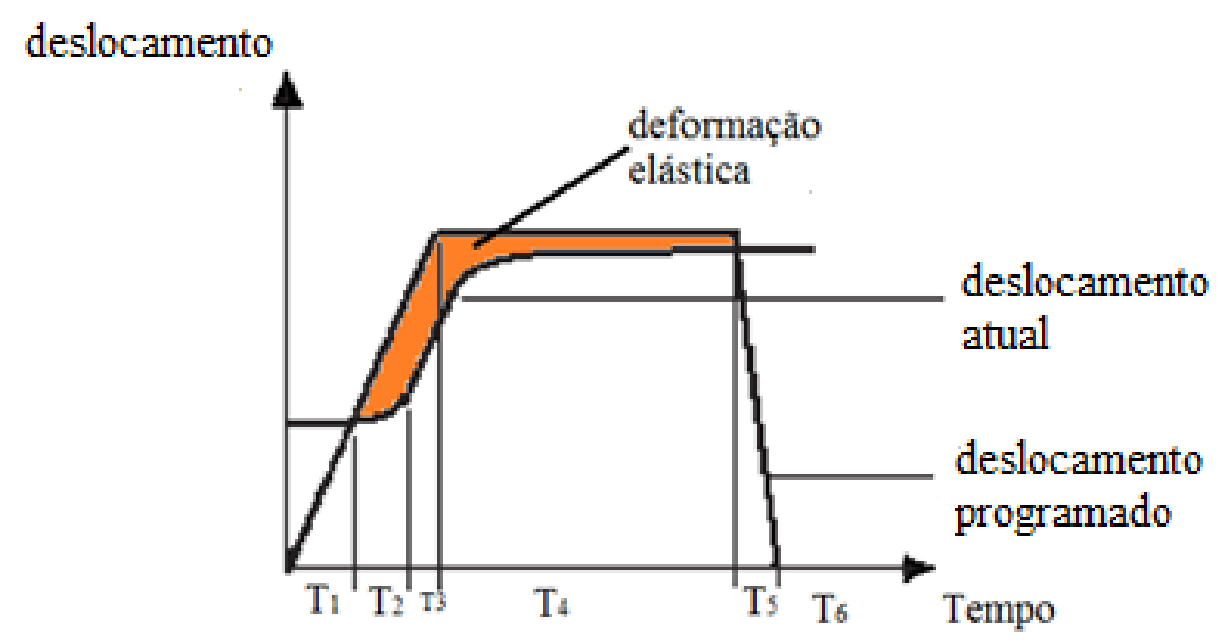

Figura 12 - Esquema teórico das fases de retificação cilíndrica externa tangencial de mergulho.

Fonte: Adaptado de Malkin (1981) e Oliveira (1988).

O intervalo de tempo $T_{1}$ indica a etapa de aproximação, com deslocamento do rebolo em direção à peça, antes do contato entre ambos. A seguir, durante o intervalo de tempo $\mathrm{T}_{2}$ ocorre o contato entre ambos, iniciando-se o corte, com início de geração de força. A partir desse momento, inicia-se a deformação do sistema MRP, com magnitude proporcional ao valor de rigidez do sistema e dos esforços de corte envolvidos, resultando num atraso entre o deslocamento efetivamente realizado pelo rebolo e o programado. Durante o intervalo de tempo $\mathrm{T}_{3}$, a profundidade de corte passa a ser igual ao avanço por volta. $\mathrm{O}$ intervalo de tempo $\mathrm{T}_{4}$ representa a fase do centelhamento (spark-out) onde não há mais avanço comandado pelo sistema de controle e a redução de diâmetro da peça ocorre devido à força elástica resultante do atraso de deslocamento do intervalo $\mathrm{T}_{2}$. Neste intervalo, o volume de cavacos removidos diminui continuamente, tendendo a zero, com a peça convergindo para o valor dimensional esperado caso seja programado um tempo de centelhamento adequado para essa recuperação elástica. $\mathrm{O}$ intervalo $\mathrm{T}_{5}$ indica o retorno do rebolo à posição de origem e o intervalo $\mathrm{T}_{6}$ indica $\mathrm{a}$ posição inicial para novo ciclo de retificação (KÖNIG, 1980 e OLIVEIRA 1988).

\subsubsection{Rigidez estática}

A rigidez estática de uma retificadora pode ser definida como a deformação do sistema MRP, na direção normal à superfície de trabalho do rebolo, causada pela força aplicada nessa 
mesma direção, sem o movimento rotacional do rebolo e peça, conforme exemplificado na Figura 13 (RAMOS, VINOLAS e NIETO (2000) e WANG et al., 2009).

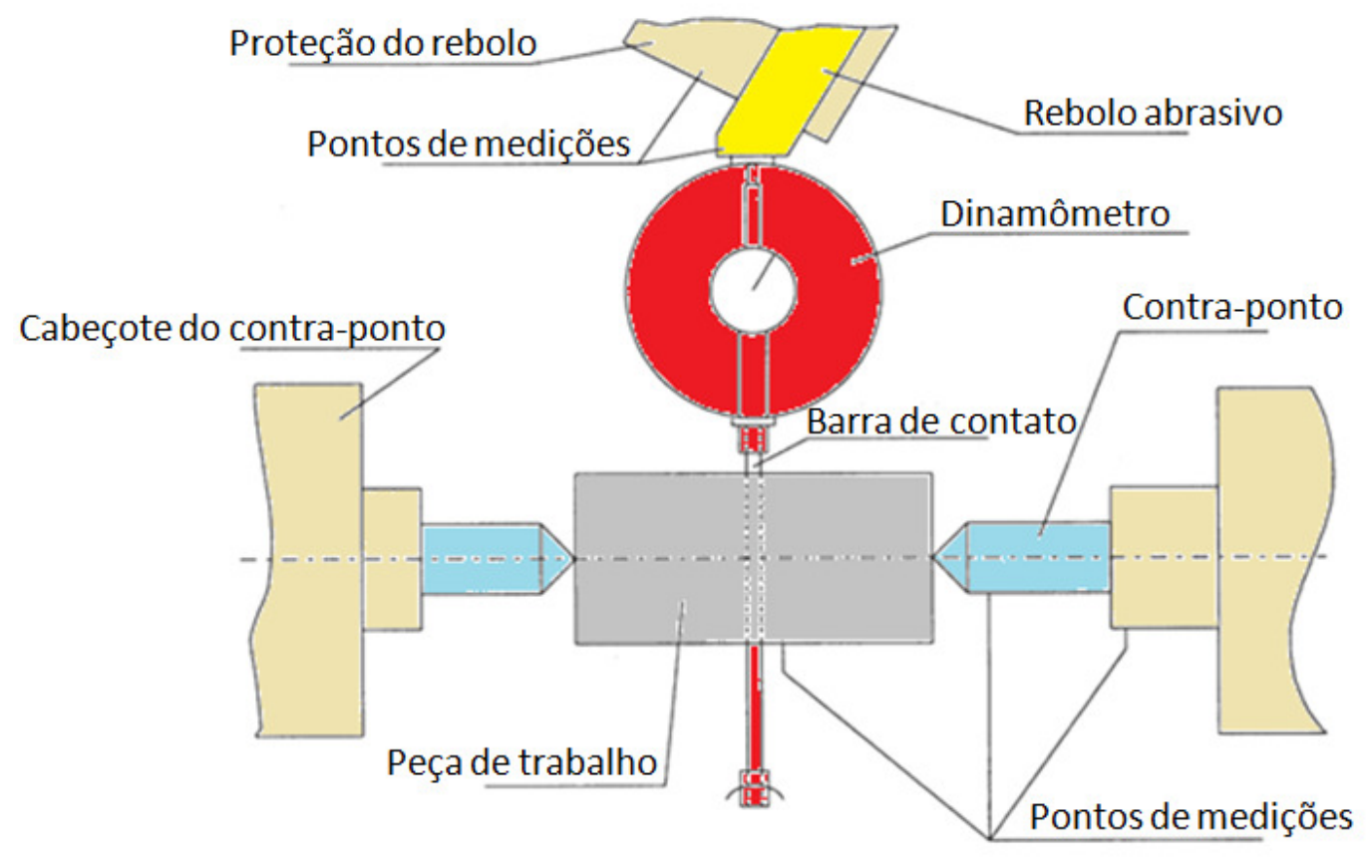

Figura 13 - Dispositivo de teste para determinar rigidez estática do sistema MRP Fonte: Adaptado de Ramos, Vinolas e Nieto (2000).

Os carregamentos na direção normal em relação à peça geralmente resultam em desalinhamentos e deslocamentos dos elementos guias, ocasionando assim inexatidões na retificadora. Neste contexto, a rigidez estática de uma operação de retificação pode ser medida a partir do deslocamento do rebolo, sem movimento rotacional, na direção da peça acoplada ao sistema de fixação, exercendo força normal e deformação de todo o sistema MRP (RAMOS, VINOLAS e NIETO, 2000).

Ramos, Vinolas e Nieto (2000), desenvolveram um sistema para determinar a rigidez estática de uma operação, que consistiu em adaptar um sensor LVDT (Linear Variable Differential Transformer), posicionado no contra-ponto de fixação da peça. O teste foi executado sem nenhum movimento relativo entre o rebolo e a peça, na direção tangencial de corte. A força estática e o deslocamento foram registrados usando-se uma célula de carga e sensor LVDT, conforme demonstrado nas Figuras 13 e 14. 


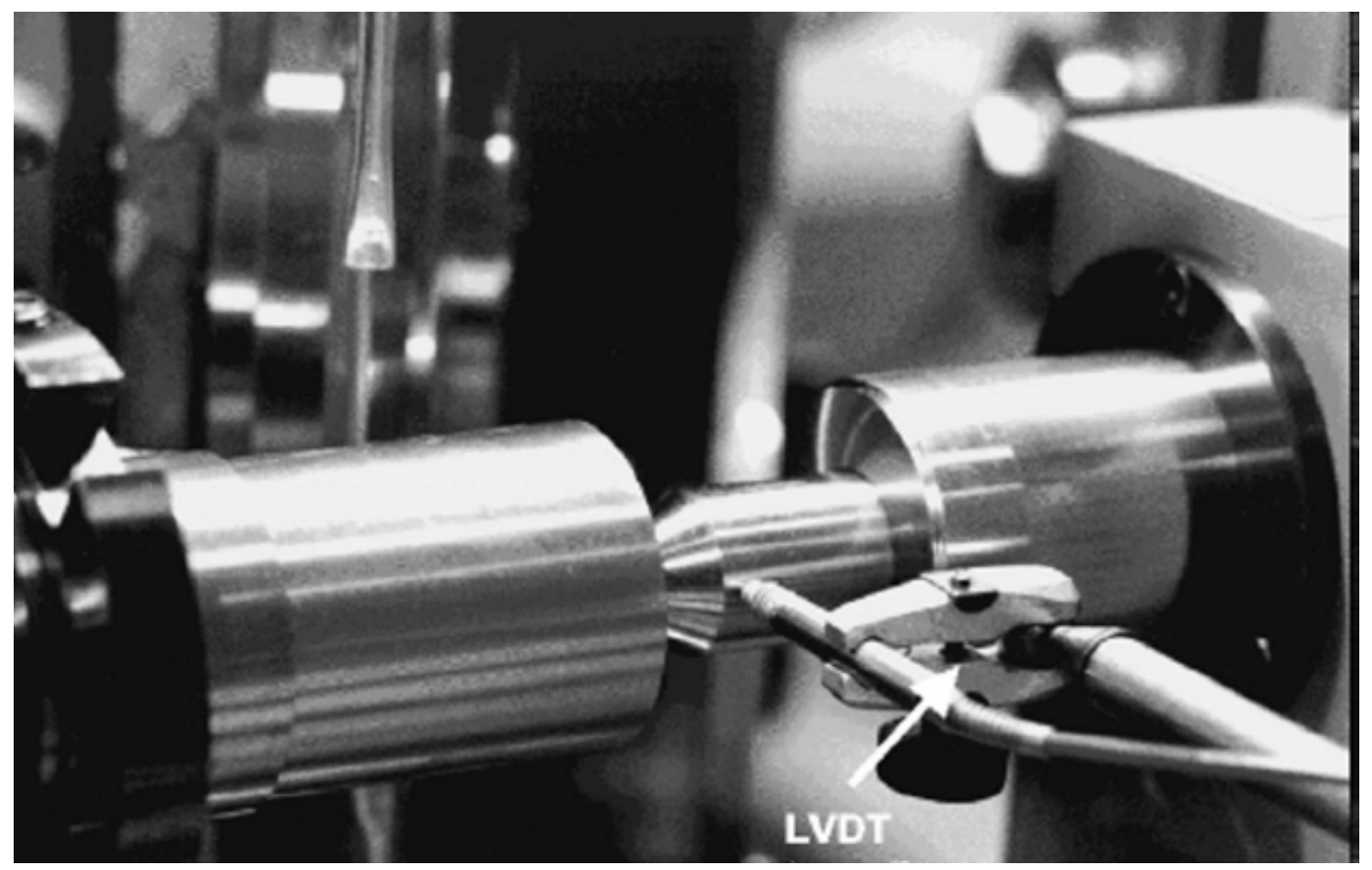

Figura 14 - Medição rigidez estática com sensor LVDT.

Fonte: Adaptado de Ramos, Vinolas e Nieto (2000).

O resultado deste experimento demonstrou uma relação linear entre a deformação e a força radial. Bertallucci e Lasini, em 1977 e Hashimoto em 1984, segundo Ramos, Vinolas e Nieto (2000), determinaram a rigidez estática com um arranjo similar ao demonstrado nas Figuras 13 e 14. O experimento consistiu em mover o rebolo na direção de mergulho sobre a peça. Os instrumentos de medições como célula de carga e transdutor linear de posição foram acoplados à retificadora para aquisição da força e o deslocamento, respectivamente. Os resultados também demonstraram relação linear entre a força e a deformação, sendo consideradas as deformações de todo o sistema MRP.

Inasaki e Yonetsu, em 1969, descrito posteriormente por Ramos, Vinolas e Nieto (2000), aplicaram a teoria de contato "Hertziana" indicado em Zhu (2012), Adams e Nosonovsky (2000) e Oliveira (1988), para determinar a rigidez estática, usando o método de contato entre corpos esféricos, conforme demonstrado na Figura 15. Os pesquisadores também concluíram que a relação entre deformação e a força é linear. 


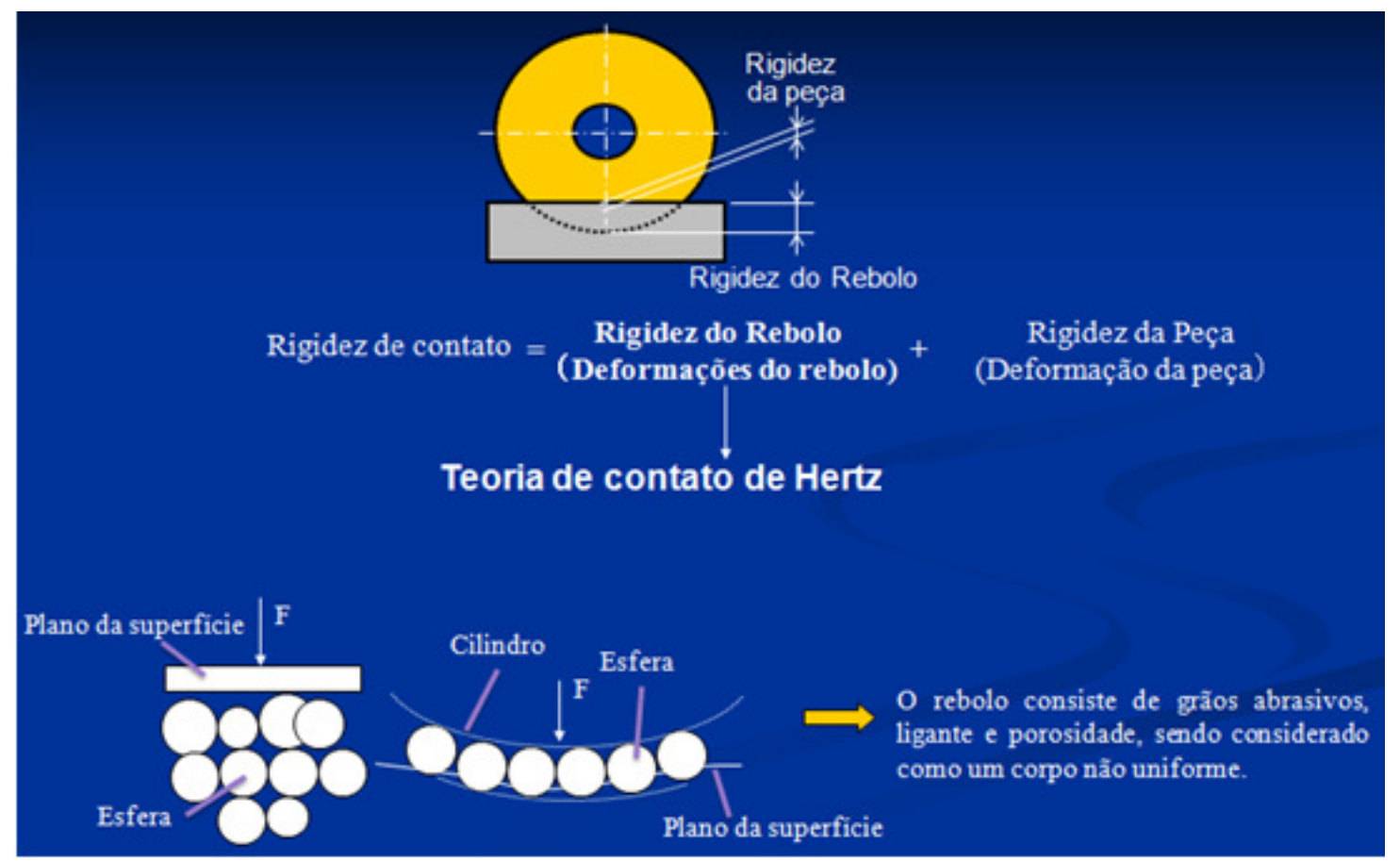

Figura 15 - Esquema para determinação da rigidez estática.

Fonte: Adaptado de Zhu. (2012).

\subsubsection{Rigidez dinâmica}

A rigidez dinâmica pode ser definida com a relação entre a carga e a deformação em função da frequência de aplicação das cargas. Segundo Zhang et al. (1993), rigidez dinâmica no processo de retificação pode determinar a estabilidade do processo. Considera-se também, o efeito de amortecimento "damping" o qual influencia os resultados dimensionais da peça e no tempo de ciclo para retificação. O efeito dinâmico da rigidez da máquina é frequentemente imprevisível, pois muda em função do número de grãos ativos em contato, do tipo de fluido e da própria ação do grão durante o processo de formação de cavacos. Normalmente, a análise da rigidez dinâmica de um processo de retificação é conduzida nos domínios da frequência e do tempo. No primeiro, a análise de estabilidade pode ser executada de maneira mais simples. Contudo, encontra duas limitações: é restrito a problemas lineares e não fornece uma solução quantitativa. No domínio do tempo pode-se superar estas limitações, embora poucas referências sejam encontradas na literatura. Além disso, no domínio do tempo, pode-se simular processos de retificação com problemas de instabilidade, devido à vibração nas diversas partes da máquina (OLIVEIRA, 1988). 
Segundo Oliveira, França e Wang (2008) e Wang et. al. (2009) um aspecto importante a ser considerado na determinação da rigidez dinâmica é a vibração à qual todo o sistema está sujeito. As vibrações de todo o sistema MRP estão relacionadas com fenômenos de autoexcitação, que ocorrem principalmente quando a força de retificação aumenta. O rebolo gira a altas rotações e sofre desgaste diferenciado ao longo de seu perímetro, o que provoca também variações das forças de corte ao longo de sua vida. Tais variações dinâmicas excitam o sistema, que começa vibrar, podendo chegar a níveis que inviabilizam a continuidade da operação (OLIVEIRA, 1988).

Segundo Oliveira, França e Wang (2008), as vibrações, de forma geral, são classificadas em dois tipos. O primeiro engloba as vibrações radiais, que tem origem no desbalanceamento do rebolo. Quando o rebolo atinge altas velocidades de corte, o desbalanceamento do eixoárvore, incluindo-se o rebolo, ocasiona forças centrífugas em sua direção radial, culminando em pequenas oscilações. O segundo tipo de vibração comumente observado é atribuído às excitações externas, devido ao ambiente onde a retificadora está instalada, causada por outros equipamentos adjacentes.

Alfares e Elsharkawy (2000) apresentaram um estudo onde foram demonstrados os efeitos da vibração no processo de retificação, com base nas tensões entre a aresta de corte do grão e a peça, sendo aumentada para além do limite elástico, onde ocorre a deformação plástica.

Pesquisadores como Zhou e Lutterwelt (1992) e Biera, Vinolas e Nieto (1997), explicam que fatores como: o comprimento de contato, temperatura e integridade da superfície da peça na zona de contato, são determinantes para a rigidez dinâmica, devido à interação mútua desses fatores durante o processo de retificação. Esses trabalhos apresentam um modelamento em função do domínio do tempo para retificação, demonstrando que o comprimento de contato pode variar de 22 a 50\%, considerando as deformações do sistema MRP. Esse fenômeno é causado por alguns fatores, como: a localização dos grãos ativos na superfície do rebolo, a porosidade e as diferentes deformações elásticas que o rebolo, a peça e a máquina estão submetidos durante o processo de retificação.

\subsection{As forças de retificação e a rigidez}

Segundo Malkin e Guo (2008), Oliveira (1988) e Wager e Saini (1986), no processo de retificação, a força atuante pode ser dividida em duas componentes, sendo a força tangencial " $F_{t}$ ", e a força normal " $F_{n}$ ", conforme representado na Figura 16. 


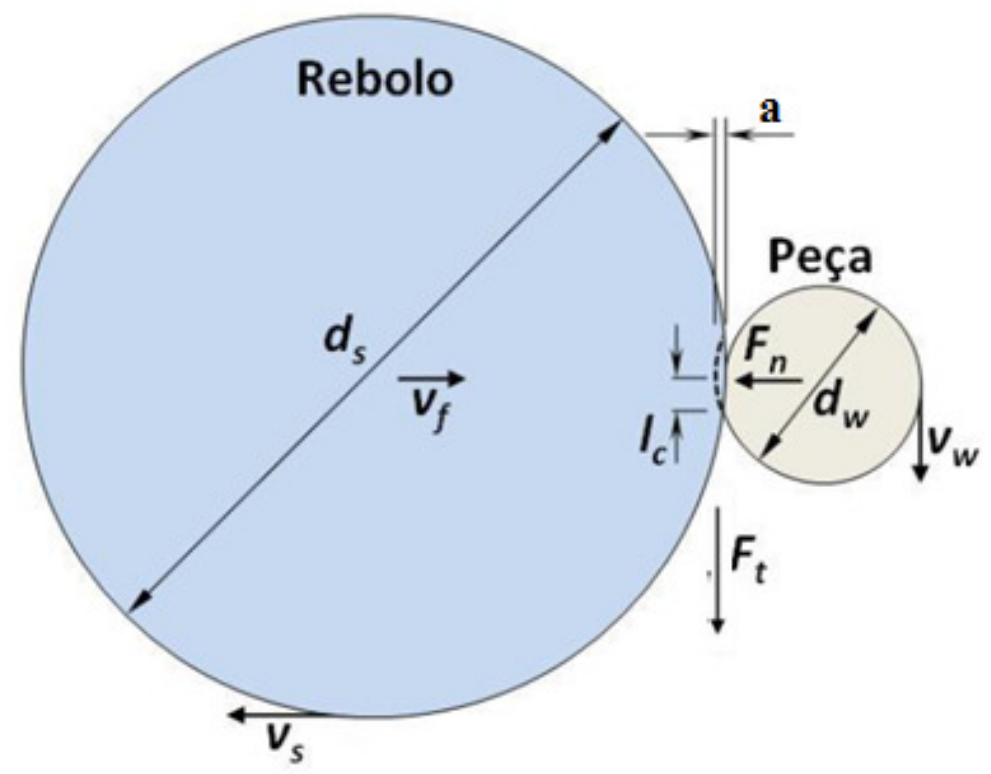

Figura 16 - Contato entre o rebolo e a peça durante a retificação Fonte: Adaptado de Malkin (1989).

Onde:

- $\quad \mathrm{F}_{\mathrm{n}}=$ Força normal de retificação;

- $\quad F_{t}=$ Força tangencial de retificação;

- $\mathrm{v}_{\mathrm{s}}=$ Velocidade de corte;

- $\mathrm{v}_{\mathrm{f}}=$ Velocidade de mergulho;

- $\mathrm{V}_{\mathrm{w}}=$ Velocidade periférica da peça;

- $\quad \mathrm{a}=$ Profundidade de penetração do rebolo por volta;

- $1_{\mathrm{c}}=$ Comprimento de contato;

- $\mathrm{d}_{\mathrm{s}}=$ Diâmetro do rebolo;

- $\mathrm{d}_{\mathrm{w}}=$ Diâmetro da peça;

A força tangencial " $F_{t}$ " tem papel fundamental na remoção de material. Pode ser considerada como a resistência que o rebolo encontra para remover material da superfície da peça. Engloba as parcelas gastas em atrito, sulcamento e remoção de cavaco propriamente dito. O produto força tangencial e velocidade de corte resulta no cálculo da potência de retificação. Pode-se então calcular facilmente a força tangencial de corte através da medição da potência de retificação, utilizando-se a Equação (8) MALKIN e GUO (2008): 


$$
F_{t}=\frac{P}{v s}
$$

Onde:

$$
\begin{aligned}
& \mathrm{F}_{\mathrm{t}}=\text { Força tangencial }[\mathrm{N}] \\
& \mathrm{P}=\text { Potência }[\mathrm{W}]
\end{aligned}
$$

Segundo Tönshoff et al. (1992), a força tangencial de retificação possui relação direta com o aumento da temperatura decorrente das condições de usinagem do processo de retificação. Durante o corte, o grão recebe a força tangencial " $\mathrm{F}_{t}$ ", e a força normal " $\mathrm{F}_{n}$ ", sendo que a magnitude destas forças depende da velocidade de corte “ $\mathrm{v}_{s}$ ”, e do ângulo “ $\alpha$ ”, de saída do grão em relação à superfície gerada conforme mostrado na Figura 17.

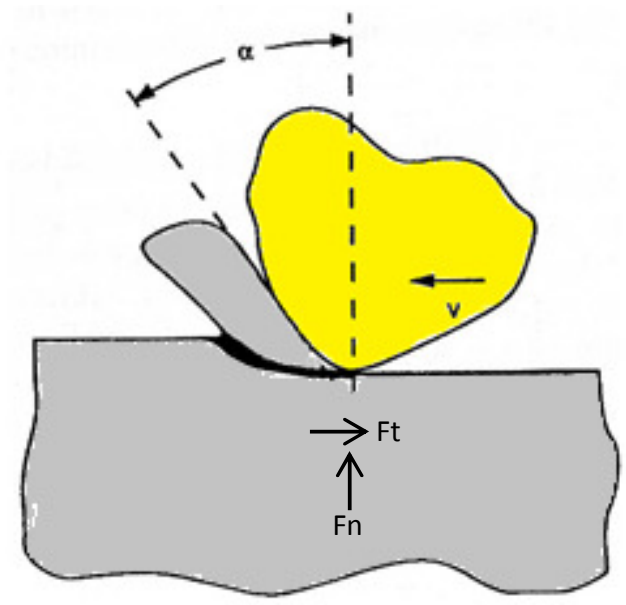

Figura 17 - Processo de corte para um grão abrasivo.

Fonte: Adaptado de Zhang (1993).

Durante o processo de retificação certa quantidade de energia é requerida para remoção de material. O consumo desta energia está associado à quantidade de material removido da peça pelo rebolo por unidade de tempo " $Q_{w}$ ". Bianchi, Silva e Aguiar (2001), relatam que um processo de corte abrasivo é considerado eficiente quando ocorre grande quantidade de material removido, " $Q_{w}$ ", e ao mesmo tempo o consumo de energia seja baixo.

Segundo Malkin e Xiao (1996), o desgaste efetivo do grão abrasivo, em termos de área, pode ser estimado através da variação da potência consumida no ato da retificação. A potência decorrente do processo de retificação, obtida na zona de contato do grão e peça é considerada como a potência específica " $P$ '", e está relacionada ao volume de material removido, neste 
caso, à taxa de remoção de material específica “ $Q{ }^{\prime}{ }_{w}$ ”. Então a potência específica “ $P$ ' ", é expressa pela Equação (9):

$$
P^{\prime}=\frac{P}{Q_{w}}
$$

Onde:

$\mathrm{P}^{\prime}=$ Potência específica;

$\mathrm{P}=$ Potência;

$\mathrm{Q}_{\mathrm{w}}{ }^{\prime}=$ Taxa de remoção de material específica;

Segundo Cai et. al. (2002) e Malkin e Xiao (1996), o atrito entre o grão e a peça tem influência direta nas forças de retificação, normal e tangencial, energia específica e potência, sobretudo, uma alta força de atrito pode intensificar a geração de calor entre grão e peça e proporcionar danos térmicos na microestrutura do material sendo retificado.

Durante o processo de retificação a força tangencial é responsável por uma ligeira rotação do grão resultando em uma flexão radial positiva ou negativa na ponta do grão conforme demonstrado na Figura 18 (MALKIN, 1989).
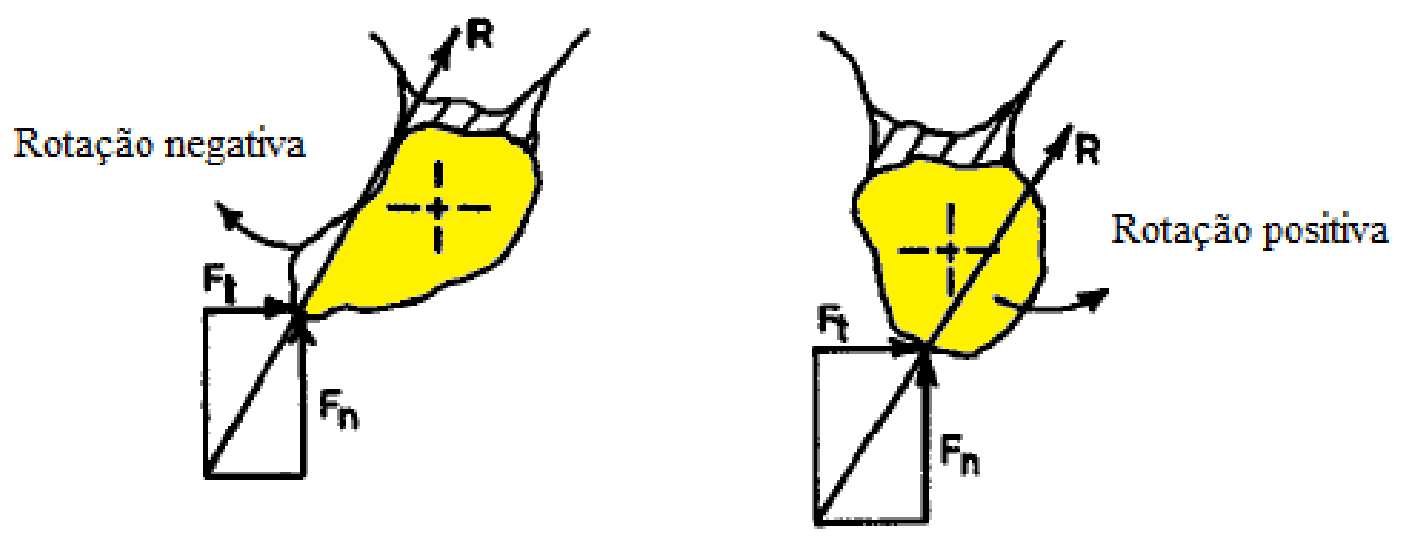

Figura 18 - Flexão de ponta no grão aplicando a força tangencial durante o processo de retificação.

Fonte: Adaptado de Saini (1982).

A recuperação elástica da peça e a flexão devido à rotação do grão, em particular para aços temperados são maiores em comparação a aços sem têmpera. Isto foi observado devido ao aumento da força normal de corte gerado pelo entupimento dos poros do rebolo. A rotação do grão é um fator importante dentro da análise do processo de retificação, tendo impacto direto no acabamento superficial da peça e na profundidade de corte, visto que sua resultante está 
ligada diretamente as forças normal e tangencial de corte (SAINI, WAGER e BROWN (1982) e SAINI e WAGER (1985)).

A força normal " $F_{n}$ ", atua de forma perpendicular à área de contato e é proporcional a profundidade de corte. A força normal " $F_{n}$ ", é necessária para manter a profundidade de corte do grão e é considerada uma das principais causas das flexões do sistema MRP (MALKIN, 1989).

Segundo Saini e Wager (1985) e Cai et. al. (2002), a força normal no rebolo, transmitida a cada grão torna-se o principal parâmetro que afeta a flexão durante a retificação, pois relaciona-se com a tensão em que todo sistema MRP está submetido.

Tlusty, apud Oliveira (1989) definiu o coeficiente " $\mu$ ", com um parâmetro adimensional que permite uma apreciação quantitativa do nível de influência da força normal de corte no conjunto MRP. Esse coeficiente é definido na Equação (10)

$\mu=\frac{R}{K_{r}}$

onde: $R$ é o coeficiente de proporcionalidade entre a força normal de corte por unidade de largura de retificação b quando se aumenta a profundidade de corte $a$.

O coeficiente R pode ser calculado através da Equação (11):

$$
R=\frac{F^{\prime} n * b}{a}
$$

onde: $\mathrm{F}^{\prime} \mathrm{n}$ é a força normal de corte por unidade de largura de retificação.

A Figura 19 traz uma representação do significado físico do coeficiente $\mu$. Pode-se verificar que uma configuração de coeficiente $\mu$ grande pode ocorrer, por exemplo, ao retificarse um material de difícil usinabilidade (DTG - difficult to grind material) ( $R$ grande), numa configuração de retificação cilíndrica interna, com alto valor de diâmetro equivalente $(R$ grande) e associada a uma baixa rigidez global do sistema MRP ( $K_{r}$ pequeno). Já um coeficiente $\mu$ baixo é obtido ao retificar-se uma peça de grande usinabilidade (ETG - easy to grind material) ( $R$ pequeno), numa retificação cilíndrica externa de mergulho, com menor diâmetro equivalente ( $R$ pequeno) e alta rigidez global do sistema MRP ( $K_{r}$ grande). 


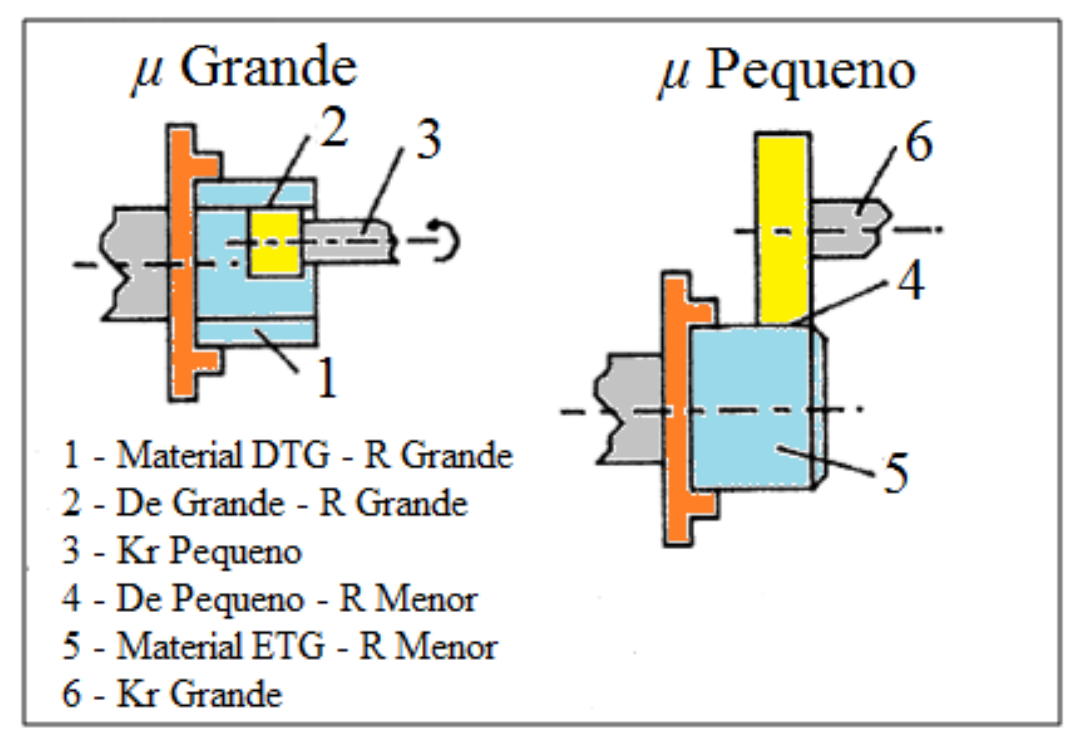

Figura 19 - Significado Físico de $\mu$.

Fonte: Adaptado de Saini (1982).

Segundo Oliveira (1989), o produto $\mu$ versus a penetração do rebolo por volta da peça, $S$, aqui denotado como $y$, determina a diferença entre a dimensão X mostrada no painel de uma máquina $\mathrm{CNC}$ e a real dimensão da peça após atingir-se um número de voltas $(n)$ igual aquele necessário $\left(n l_{i m}\right)$ para que o profundidade de corte $a$ seja igual a $S$., conforme demonstrado na Figura 20.

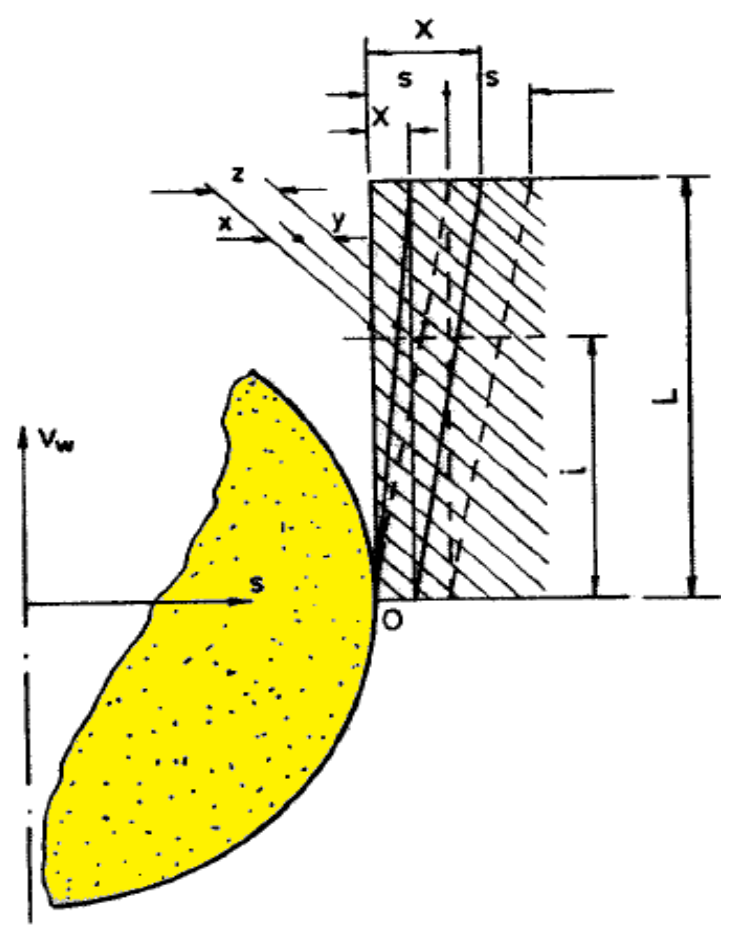

Figura 20 - Penetração do rebolo numa operação de mergulho Fonte: Adaptado de Oliveira (1989). 
Onde:

$\mathrm{Z}=$ Posição em que o rebolo estaria se não houvesse deformações;

$\mathrm{S}=$ Penetração do rebolo por volta da peça;

$\mathrm{x}=\mathrm{a}=$ Profundidade de corte;

$\mathrm{X}=$ Posição do rebolo;

$\mathrm{y}=$ Parcela de deformação do conjunto MRP

\subsection{Método prático para determinar a rigidez do processo descrito por Rossi (2009).}

Rossi (2009) em seu estudo desenvolveu método prático para determinar a deformação do sistema MRP em várias faixas de velocidades de cortes, comprovando a existência da relação entre a velocidade de mergulho do rebolo e variação no diâmetro final da peça, relatada inicialmente por Oliveira (1988), Malkin (1980) e Tlusty (1970).

O experimento ocorreu em uma retificadora cilíndrica tangencial externa, Zema, modelo Numerika G-800-HS. O corpo de prova foi de aço SAE 4340 normalizado com 52 HRc de dureza, representado na Figura 21. O rebolo utilizado foi óxido de alumínio, dureza K e granulometria 80. A taxa de remoção específica de material para este rebolo foi $100 \mathrm{~mm}^{3} /$ $\mathrm{mm} *$ min. A largura de corte foi de $15 \mathrm{~mm}$.

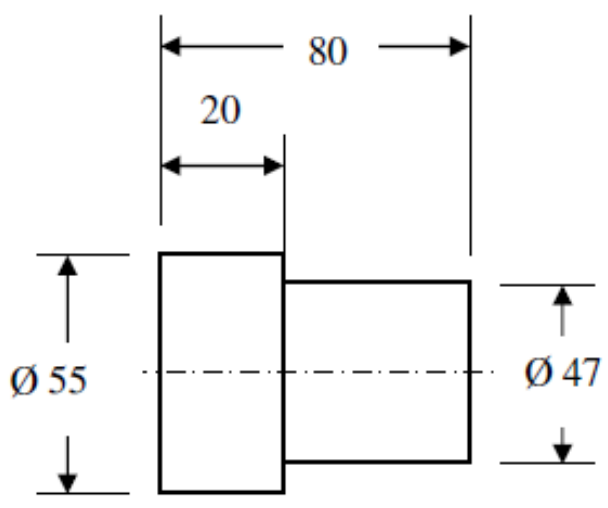

Figura 21 Corpo de prova utilizado no experimento

Fonte: Adaptado de Rossi (2009).

O sobremetal do corpo de prova foi de $0,050 \mathrm{~mm}$. Foram construídas 7 amostras para o experimento. O tempo de centelhamento foi ajustado para zero segundo. As velocidades de 
avanço foram crescentes de 0,1 à $2,5 \mathrm{~mm} / \mathrm{min}$. com incremento de $0,4 \mathrm{~mm} / \mathrm{min}$. em cada amostra.

Os diâmetros iniciais, antes da retificação e finais após a retificação foram coletados por intermédio de um micrometro, nos corpos de prova para tempo de centelhamento igual a zero segundo.

O mesmo procedimento foi repetido, porém com tempo de centelhamento em 10 segundos. Esse tempo foi determinado para que todas as deformações do sistema MRP sejam absorvidas.

A deformação do sistema MRP foi calculada a partir da diferença do diâmetro inicial das amostras com tempo de centelhamento em zero segundo e o diâmetro final encontrado nas amostras com tempo de centelhamento de 10 segundos, considerando que para ambos os experimentos o deslocamento programado no $\mathrm{CNC}$ foi o mesmo. O Gráfico 1 representa a deformação do sistema MRP determinada pelo método prático.

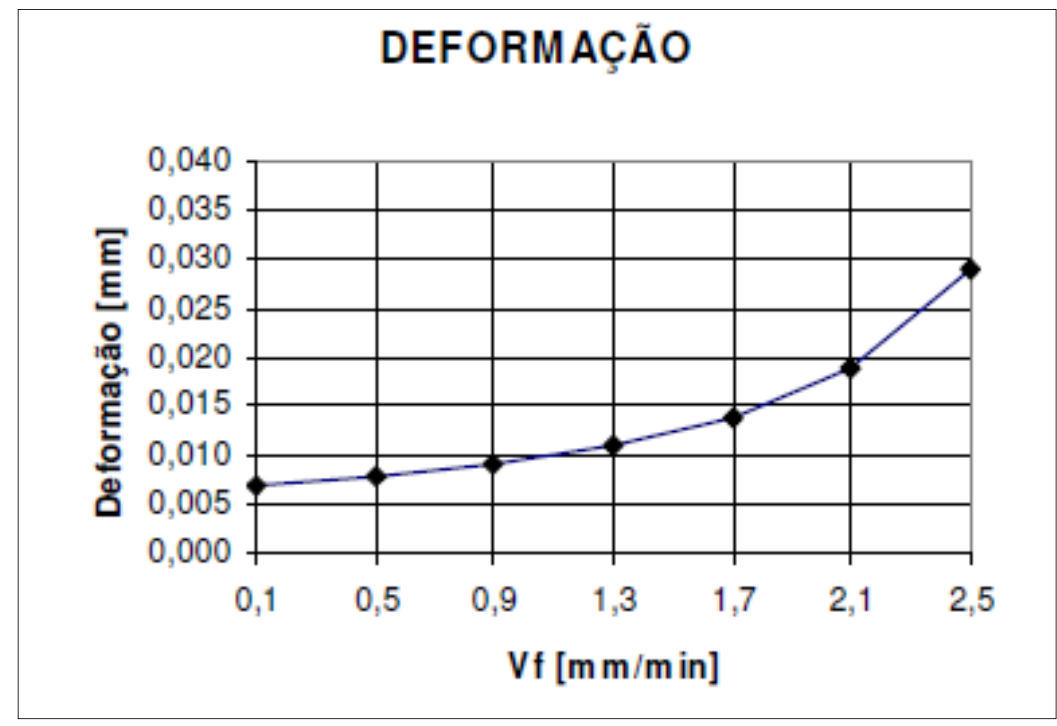

Gráfico 1 - Deformação sistema MRP

Fonte: Adaptado de Rossi (2009).

Rossi (2009) confirmou experimentalmente a relação diretamente proporcional entre a velocidade de avanço e a deformação encontrada no sistema MRP. Partido de 0,007 mm de deformação com velocidade de avanço em $0,1 \mathrm{~mm} / \mathrm{min}$. para $0,028 \mathrm{~mm}$ de deformação para velocidade de avanço $2,5 \mathrm{~mm} / \mathrm{min}$. Todavia, verifica-se que a relação observada não é linear, podendo sugerir, que o sistema MRP pode apresentar um distinto comportamento dependendo da força normal aplicada, especialmente em regiões de baixa solicitação, como o caso da velocidade de avanço $0,1 \mathrm{~mm} / \mathrm{min}$. 


\subsection{Modelos matemáticos para determinação da rigidez do sistema MRP}

A utilização de modelos matemáticos para prever ou controlar o comportamento do processo durante o ciclo de retificação tem apresentado grande desafio em sua aplicação, pois devem ser capazes de relacionar e predizer o comportamento do processo de retificação de forma eficaz tendo como objetivo alcançar o resultado dimensional esperado da peça. Os modelos devem ainda considerar fatores como: a dimensão final da peça, parâmetros de processo, deformações do sistema MRP gerados pelas forças normal e tangencial, desgaste do rebolo, aspectos térmicos, energia de retificação, espessura do cavaco entre outros. Neste sentido os vários modelos desenvolvidos passam a serem aplicados em softwares de simulações que são capazes de integrar tais modelos com o objetivo de prever o que acontece durante uma operação de retificação para que a qualidade dimensional requerida da peça seja atingida no processo (MALKIN e GUO, 2008) e (BRINKSMEIER, et. al., 2006).

Segundo Tönshoff et. al. (1992), a qualidade e eficácia de qualquer tipo de simulação empregado no processo de retificação dependem exclusivamente da eficácia do modelo aplicado. Fu, Xu e Xu (2002), afirmam que o processo de simulação deve resultar em um guia de processo considerando parâmetros ideias para aplicação.

Chiu e Malkin (1993) construíram um modelo virtual de simulação para retificação a partir de experimentos práticos, incluindo força normal, tangencial, potência de retificação, desgaste do rebolo, temperatura da zona de retificação, danos térmicos, expansão do grão e a qualidade da superfície ao final do ciclo de retificação.

Segundo Junkar e Filipic (1992), de forma geral são consideradas três abordagens para o estudo do processo de simulação. A primeira abordagem considera o processo como um sistema puro e determinístico, baseado nos parâmetros de processo de forma direta. A segunda considera uma abordagem probabilística, onde os parâmetros do processo são avaliados através da análise estatística dos resultados dimensionais encontrados na peça. A terceira é a abordagem da inteligência artificial, em que o processo é descrito com atributos simbólicos, baseado em medições quase em tempo real e corrigido de acordo com as medições encontradas, utilizando técnicas de autoaprendizado com dados provenientes dos ciclos de retificação anteriores.

Tönshoff e Friemuth (2002) e Chiu e Malkin (1993) indicam que a simulação do processo para prever o comportamento, de forma dependente ao tempo, requer integração de vários modelos durante o ciclo de retificação. Segundo Brinksmeier, et al., (2006) esses modelos são de caráter exclusivo a uma específica aplicação e ao ser replicado para outro processo de 
retificação deve ser adaptado. Portanto, não há um modelo de simulação universal e sim a necessidade de adaptação e ajuste de modelos de simulação para cada aplicação.

\subsubsection{Modelo determinado por Malkin e Guo (2008):}

\subsubsection{Análise para máquinas de avanço controlado}

A deformação elástica do sistema MRP faz com que a remoção real de material passe a ser menor do que o planejado no início do ciclo de retificação. O esquema demonstrado na Figura 22 modela, com efeito mola, a estrutura da máquina e o rebolo, determinando a rigidez " $\mathrm{k}_{\mathrm{s}}$ ", e a rigidez de contato peça-rebolo " $\mathrm{k}_{\mathrm{w}}$ ". Juntos estes dois efeitos compõem a rigidez estática da retificadora " $\mathrm{k}_{\mathrm{m}}$ ", no sentido de mergulho, de acordo com Equação (12) (MALKIN; GUO, 2008).

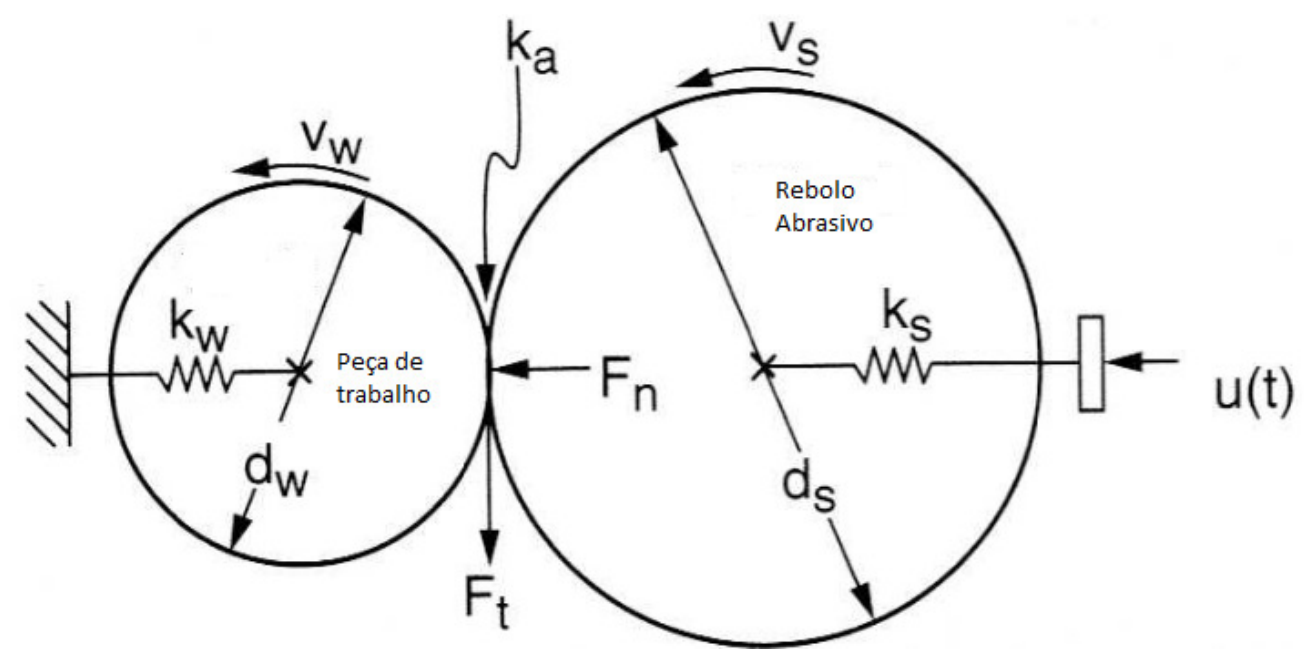

Figura 22 - Modelo idealizado de retificação cilíndrica

Fonte: Adaptado de Malkin e Guo (2008).

$k_{m}^{-1}=k_{s}^{-1}+k_{w}^{-1}$

Onde:

$k_{m}^{-1}=$ Rigidez estática; 
$k_{s}^{-1}=$ Rigidez maquina e rebolo;

$k_{w}^{-1}=$ Rigidez de contato rebolo peça;

Segundo Tönshoff et. al. (1992), durante a etapa de formação de cavaco, no processo de retificação, para materiais dúcteis, como os metais, o material está sujeito a deformações elásticas, em seguida, o material começa a ceder e a deformação plástica é observada.

A flexão do rebolo e a elasticidade da peça são consideradas como um contato flexível e modela-se a rigidez do processo, como “ $\mathrm{k}_{\mathrm{a}}$ ”, na zona de retificação. Esta combina-se com a rigidez de contato resultando na rigidez global “ $\mathrm{k}_{\mathrm{e}}$ ”, conforme demonstrado na Equação (13).

$k_{e}^{-1}=k_{m}^{-1}+k_{a}^{-1}=k_{s}^{-1}+k_{w}^{-1}+k_{a}^{-1}$

Onde:

$k_{e}^{-1}=$ Rigidez global da máquina

$k_{m}^{-1}=$ Rigidez estática

$k_{a}^{-1}=$ Rigidez de contato

Durante o processo de retificação cilíndrica externa de mergulho, em máquinas de avanço controlado, o rebolo avança em direção à peça, com velocidade de mergulho " $u(\mathrm{t})$ ". A real velocidade de mergulho do rebolo “ $v(\mathrm{t})$ ”, correspondendo a real taxa de redução radial da peça, é menor que a taxa teórica no mesmo instante de tempo. Essa diferença, negligenciando o desgaste do rebolo, pode ser classificada como a taxa de deformação elástica do sistema MRP, “ $\dot{\varepsilon} "$, do deslocamento previsto e a redução do diâmetro. A Equação (14) é proposta.

$u(t)-v(t)=\dot{\varepsilon}$

Segundo Zhang et. al. (1993), o módulo de elasticidade, " $\mathcal{E}$ ", é um parâmetro importante para análise de deformação. Sendo analisado no sistema MRP, torna-se um critério bem definido para determinar a flexão.

A deflexão do sistema segundo Malkin e Guo (2008), pode ser expressa pela Equação (15).

$\varepsilon=\frac{F_{n}}{k_{e}}$ 
Onde " $F_{n}$ " é a componente de força normal e " $k_{e}$ " é a rigidez efetiva global do processo, considerando todos os elementos deformáveis no sistema MRP.

Assumindo-se que a componente de força normal é proporcional a taxa volumétrica de remoção de material, conforme Equação (16).

$$
F_{n}=F_{0} Q_{w}
$$

Ou

$$
F_{n}=F_{0} b v_{w} a
$$

Para a velocidade da peça " $v_{w}$ ", e largura da retificação " $b$ ”, a força é proporcional à profundidade de penetração do rebolo por volta “ $a$ ”, atribuída ao rebolo, conforme demonstrado na Equação (18).

$$
F_{n}=k_{c} a
$$

Onde " $k_{c}$ " é a rigidez de corte, expresso pela Equação (19).

$$
k_{c}=F_{0} b v_{w}
$$

Considerando o processo de retificação cilíndrica externa por mergulho, objeto de estudo deste trabalho, é mais comum relacionar a taxa de remoção de material com a velocidade de mergulho " $v_{\mathrm{f}}$ ", conforme demonstrado na Figura 23 e expresso pela Equação (20).

$$
Q_{w}=\pi b d_{w} v_{\mathrm{f}}
$$




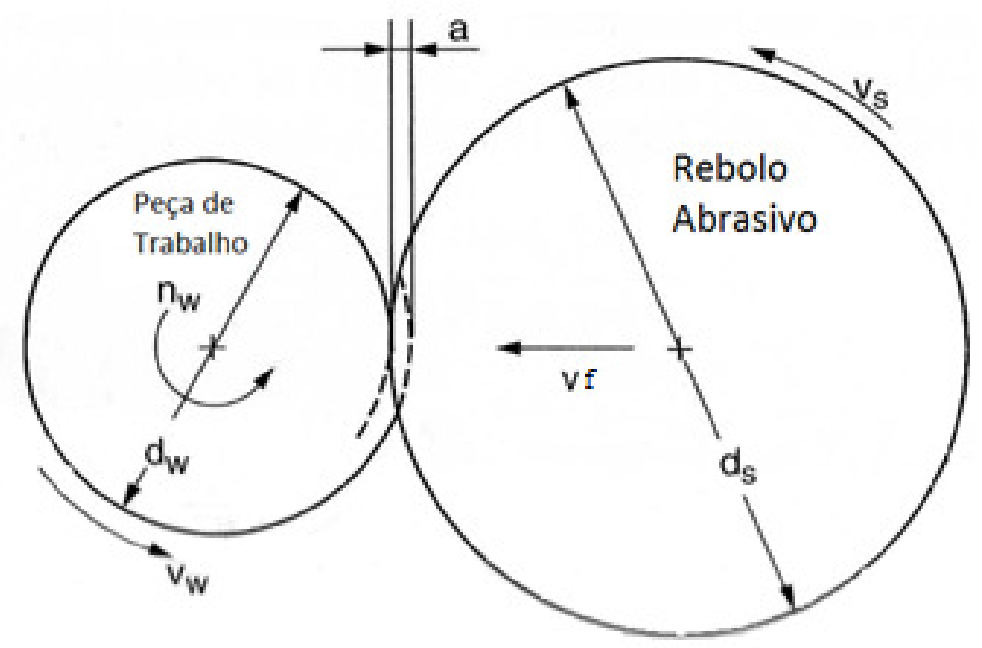

Figura 23 - Ilustração de retificação cilíndrica.

Fonte: Adaptado de Malkin e Guo (2008).

E a força normal descrita na Equação (17), tem-se a Equação (21).

$F_{n}=\left(\pi b d_{w} F_{0}\right) v_{\mathrm{f}}$

$\mathrm{Ou}$

$F_{n}=F_{v} v_{\mathrm{f}}$

Onde " $F_{v}$ " corresponde à multiplicação dos fatores na relação entre parêntesis descrita na Equação (21). Combinando as Equações (14), (15) e (22) tem-se a Equação diferencial.

$\dot{v}=\frac{1}{\tau}[u(t)-v(t)]$

Onde " $\tau$ " é chamado de constante de tempo.

$\tau \equiv \frac{F_{v}}{k_{e}}$

A taxa de redução do raio da peça é equivalente à velocidade de avanço atual.

$\dot{r}=v(t)$ 
Onde " $\dot{r}$ " é a redução acumulada do raio da peça. Para um controle da velocidade de avanço " $u(t)$ ”, como dado de entrada à máquina, o processo de redução do diâmetro é descrito pelas Equações (23) e (25), assumindo as seguintes condições iniciais:

$v(0)=v_{0}$

ou

$r(0)=r_{0}$

Considerando a mesma análise, incluindo o efeito do desgaste do rebolo, pode-se expressar a razão de retificação na Equação (28).

$G=\frac{d_{w} v(t)}{d_{s} w(t)}$

Onde " $w(t)$ " é o desgaste radial do rebolo, " $d_{w}$ " e " $d_{s}$ " correspondem à peça e ao diâmetro do rebolo respectivamente. Considerando-se o desgaste do rebolo analogamente temse:

$u(t)-v(t)-w(t)=\dot{\varepsilon}$

Combinando as Equações (27), (24), (14) e (15) obtêm-se a Equação (30):

$\dot{v}=\frac{1}{\tau^{\prime}}\left[u^{\prime}(t)-v(t)\right]$

Onde:

$\tau^{\prime}=\frac{\tau}{1+\frac{d_{w}}{d_{S} G}}$ 
$u^{\prime}=\frac{u(t)}{1+\frac{d_{w}}{d_{s} G}}$

A equação (30) é a mesma que a equação (23), mas com $\tau$ sendo substituído por $\tau^{\prime}$ e $u(t)$ por $u^{\prime}(t)$. Todavia, o efeito do desgaste radial do rebolo torna-se insignificante na análise proposta quando $G \gg d_{w} / d_{s}$.

\subsubsection{Comportamento do ciclo de retificação}

A análise apresentada no tópico anterior será utilizada para predizer a redução radial da peça em ciclos de retificação de mergulho de avanço controlado em peças cilíndricas. O ciclo de retificação, demonstrado na Figura 24, consiste em uma fase inicial de desbaste, com velocidade de avanço constante e controlada $\left(\mathrm{u}_{1}\right)$, seguida de fase de centelhamento (spark$o u t)$, com velocidade de avanço igual a zero $\left(\mathrm{u}_{2}=0\right)$. Resolvendo-se as Equações (23) e (25) no primeiro estágio com $v(0)$ e $r(0)=0$, conforme demonstrado nas Equações (33) e (34).

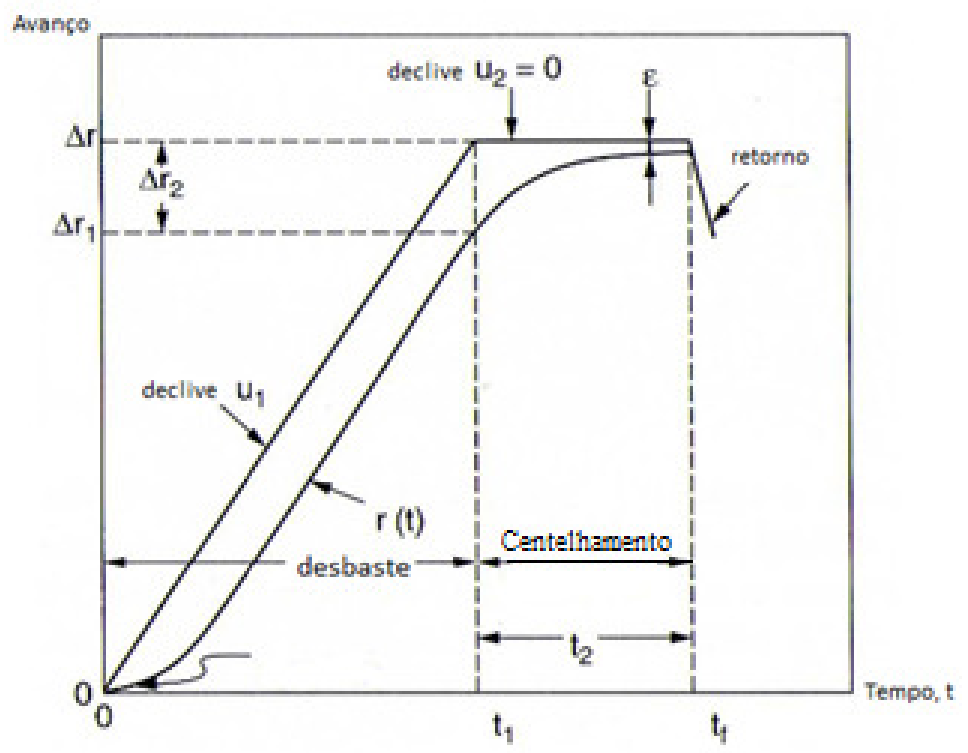

Figura 24 - Simplificação esquemática do ciclo de retificação com desbaste e centelhamento.

Fonte: Adaptado de Malkin e Guo (2008).

$v(t)=\left(1-e^{-t / \tau}\right) u_{1}$ 
$r(t)=\left(t+\tau e^{-t / \tau}-\tau\right) u_{1}$

A Figura 24 representa um ciclo de retificação compondo desbaste e centelhamento. Após um transiente inicial, a velocidade real de mergulho, correspondendo à inclinação da curva de $r(t)$ na primeira fase (desbaste) tende a se aproximar da velocidade de avanço comandada. A defasagem (flexão) entre a velocidade de avanço real e a comandada acumulada se aproxima de um valor estacionário. A quão rapidamente essa situação é atingida depende do valor da constante de tempo $\tau$ sendo " $u_{1} \tau$ ” o estado de defasagem (flexão) em relação à velocidade de avanço comandada. Para $t \gg \tau$, tem-se:

$$
v(t)=u_{1}
$$

$\mathrm{e}$

$$
r(t)=u_{1} t-u_{1} \tau
$$

O valor da constante de tempo $\tau$ pode ser estimado através da equação (24). Todavia, os valores precisos do parâmetro de força $F_{v}$ e da rigidez efetiva $k_{e}$ são de difícil determinação. Sendo assim, o valor de $\tau$ pode ser estimado medindo-se, durante o desbaste, a defasagem (no estado estacionário) entre os avanços real e comandado, utilizando-se um medidor em processo, dividindo o valor obtido por $u_{1}$. Valores típicos de $\tau$ para operações de retificação cilíndrica externa estarão entre 0,5 e $1 \mathrm{~s}$, podendo variar bastante, em função do valor obtido na rigidez efetiva do sistema $\left(k_{e}\right)$, para a configuração MRP adotada.

O processo de desbaste é seguido por uma fase de centelhamento (spark-out), $\operatorname{com} u(t)=$ 0 , durante o qual a remoção de material continua a uma taxa decrescente, até que o rebolo seja desengajado da peça, no tempo $t=t_{f}$. Resolvendo as Equações (23) e (25), para a etapa de centelhamento $\left(t_{1}<t<t_{f}\right)$ e adotando-se como condições iniciais correspondendo ao final da etapa de desbaste (isto é Equações (35) e (36) com $t=t_{1}$ e para $t_{1} \gg \tau$, possibilitando que a velocidade final no desbaste $v_{1}$ seja muito próxima da velocidade comandada da máquina $\mathrm{CNC}$, $u_{1}$, tem-se: 
$v_{2}(t)=u_{1} \mathrm{e}\left(-\frac{t-t_{1}}{\tau}\right)$

e

$r(t)=u_{1} t_{1}-u_{1} \tau \mathrm{e}\left(-\frac{t-t_{1}}{\tau}\right)$

Onde o primeiro termo da Equação (38) é penetração radial " $\Delta r$ " durante a etapa de desbaste, enquanto o segundo termo é a deflexão elástica " $E$ ”, com decréscimo exponencial em direção a zero. Segundo Malkin e Guo (2008) e Machado et. al. (2011), a mesma análise e o equacionamento podem ser aplicados em ciclos de retificação mais complexos, com mais etapas, o que normalmente ocorre nas indústrias, conforme demonstrado na Figura 25.

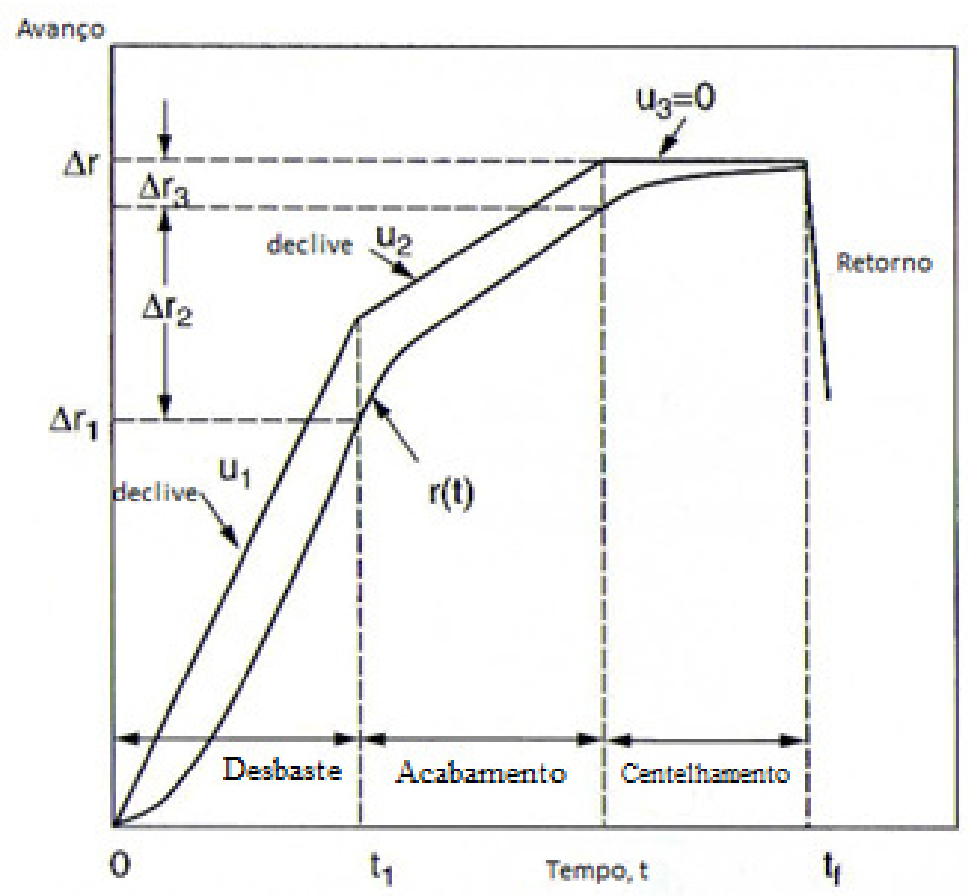

Figura 25 - Ciclo de retificação com desbaste, acabamento e centelhamento.

Fonte: Adaptado de Malkin e Guo (2008).

No caso de ciclos com fases intermediárias de avanço, conforme apresentado na Figura 25, em cada estágio, a velocidade de avanço instantânea tende a se aproximar da velocidade de avanço controlada, a uma taxa caracterizada pela constante de tempo $\tau$. A defasagem acumulada (deflexão) entre a velocidade de avanço real e a comandada se aproxima de um valor estacionário, de valor igual ao produto entre a velocidade programada da máquina versus a 
constante de tempo. A comutação entre estágios dentro do ciclo pode ser executada, de forma prática, pela quantidade de sobremetal a ser removida em cada estágio, utilizando-se um medidor em processo ou através da adoção de outro critério para essa comutação.

\subsubsection{Modelo determinado por Tlusty (1970):}

Neste modelo define-se um coeficiente " $R$ " como sendo a relação entre a força normal "Fn", e a profundidade de penetração por volta do rebolo na peça "a", conforme a Equação (39).

$R=\frac{F_{n}}{a}$

Portanto, o coeficiente " $R$ " representa o acréscimo que tem a força normal quando aumenta-se a profundidade de corte, representando uma parâmetro de rigidez de corte, análogo ao apresentado na equação (19) (MALKIN; GUO, 2008).

A velocidade de avanço é responsável pelo mergulho do rebolo em direção à peça. Essa velocidade sendo constante permite manter, teoricamente, uma profundidade de penetração em função do tempo "t”, também constante. A Equação (40) mostra essa relação (TLUSTY, 1970).

$a=v_{f} \cdot t$

Combinando as Equações (39) e (40) é definida a Equação (41):

$R=\frac{F_{n}}{V_{f}^{* t}}$

Segundo Oliveira (1988), levando-se em consideração a deformação do sistema MRP sob a influência da força normal e o parâmetro adimensional, " $\mu$ ”, definido por Tlusty (1970), que relaciona o coeficiente " $\mathrm{R}$ " com a rigidez radial " $\mathrm{K}_{\mathrm{r}}$ " do sistema MRP, tem-se:

$\mu=\frac{R}{K_{r}}$ 
Combinando as Equações (41) e (42) é definida a Equação (43):

$\mu=\frac{F_{n}}{V_{f} * t * K_{r}}$

Segundo Oliveira (1988), pode-se estabelecer uma relação entre o valor de $\mu$ e a rigidez do sistema MRP. Sistemas rígidos apresentam pequenos valores de $\mu$, já que não ocorre um aumento significativo da força normal com o aumento da profundidade de corte. De forma oposta, sistemas pouco rígidos geram um valor alto de $\mu$, com elevado aumento de força normal com aumento da profundidade de corte. A análise do parâmetro $\mu$ para diferentes sistemas MRP foi analisada de forma detalhada no item 2.5.

\subsection{Sistemas de aquisição de dados em processo de retificação}

A aquisição de dados é considerada uma excelente ferramenta para aperfeiçoar o ciclo de retificação e parâmetros de corte, com base no complexo relacionamento entre os parâmetros de processo e os resultados obtidos na peça (BRINKSMEIER, et. al., 2006).

Sistemas construídos para coletar dados e monitorar o processo de retificação devem ter como objetivo detectar com alta confiabilidade os problemas que podem ocorrer durante o processo de retificação, tais como, vibração, queima e deterioração da textura superficial do rebolo, de forma que a produção de peças fora do padrão estabelecido por projeto seja reduzido (INASAKI; KARPUSCHEWSKI e LEE (2001) e TÖNSHOFF, et. al., 1992). Já MALKIN; XIAO (1996), além destes fatores adicionam que usualmente os sistemas de monitoramento do processo de retificação visam à redução do tempo de processamento sem perder os requisitos qualitativos da peça.

Segundo Choi et al., (2007), o sistema de aquisição de dados deve abranger vários aspectos, tais como a aplicabilidade que consiste na forma de utilização do sistema, a sensibilidade no que diz respeito ao nível de precisão e comunicação necessária para aquisição de dados, a robustez do sistema para aplicação industrial, o comportamento ao longo do tempo e o tempo de resposta.

As grandezas mais relevantes no processo de retificação a serem medidas são: forças, aceleração (vibração), temperatura e emissão acústica (TÖNSHOFF, FRIEMUTH e 
BECKERM (2002), BRINKSMEIER, et al., 2006, CHOI, et al., 2007 e OLIVEIRA, FRANÇA e WANG (2008)). Outro aspecto de grande influência para sistema de monitoramento do processo de retificação é o tipo de material a ser utilizado na peça e as características relativas ao tipo de rebolo, tamanho do grão, estrutura aberta ou fechada de poros, etc. (TÖNSHOFF, et. al., 1992 e OLIVEIRA 1988).

O processo de retificação representa uma grande interação de vários modelos matemáticos, parâmetros de processo, tipo de ferramental (rebolos convencional ou superabrasivos), topografia do rebolo, cinemática do processo, aos quais são considerados componentes chaves no monitoramento de processo para predizer o comportamento de desgaste do rebolo e qualidade da peça (BRINKSMEIER, et. al., 2006).

Neste trabalho será desenvolvido um sistema de aquisição para coletar dados de posicionamento do rebolo e redução diametral da peça durante o processo de retificação. Esses dados serão utilizados para determinar a constante de tempo $\tau$, e a partir dela, através de um novo modelo matemático, prever o tempo mínimo necessário de centelhamento para absorver as deformações do sistema MRP durante o processo de retificação. 


\section{PROPOSTA DE APRIMORAMENTO DO MODELAMENTO PARA A DETERMINAÇÃO DA RIGIDEZ DE UM SISTEMA MRP PARA RETIFICAÇÃO EXTERNA DE MERGULHO}

\subsection{Dedução do modelo}

No modelo proposto por Malkin e Guo (2008), item 2.7.1, assume-se que o ciclo de desbaste será projetado com duração suficiente para que, ao seu final, a velocidade de avanço real do rebolo sobre a peça, $v(t)$, seja muito próxima da velocidade de avanço programada, $u_{1}$. Assim, sempre assume-se que a curva real de deslocamento do rebolo em função do tempo tenha a mesma inclinação que a curva de deslocamento teórico do rebolo, comandada pela máquina. Isso somente será verdadeiro se o tempo de desbaste $\left(t_{1}\right)$ for suficiente para que tal equilíbrio seja alcançado, ou seja sendo $t_{1} \gg \tau$. Em processos rápidos, nos quais se busca uma significativa redução de tempo de ciclo, essa condição pode não ser alcançada. Por outro lado, se a constante de tempo do processo, $\tau$, não for baixa o suficiente, muitas vezes devido à falta de rigidez do sistema MRP, isso não acontecerá e o modelo ficará limitado. Na proposta atual, assume-se que a velocidade real no final do estágio de desbaste seja a inicial do início do ciclo de centelhamento.

Partindo das Equações (33) e (34) de Malkin e Guo (2008) e considerando que o final da fase de desbaste como início do centelhamento tem-se:

$$
v(t)=\left(1-e^{\left(\frac{-t}{\tau}\right)}\right) * u_{1}
$$

$\mathrm{e}$

$$
r(t)=\left(t+\tau e^{-t / \tau}-\tau\right) u_{1}
$$

A Equação (37) expressa o comportamento no centelhamento da velocidade real $v_{2}(t)$ :

$$
v_{2}(t)=v_{1} e^{-\left(\frac{t-t 1}{\tau}\right)}
$$

onde $v_{1}$ é a velocidade de avanço real ao final do estágio de desbaste, no tempo $t_{1}$ 
Substituindo a Equação (33) em (37), tem-se:

$$
v_{2}(t)=\underbrace{\left(1-e^{\left(\frac{-t 1}{\tau}\right)}\right) * u_{1}}_{v_{1}(t 1)} * e^{-\left(\frac{t-t 1}{\tau}\right)}
$$

Para obter-se a redução radial durante o centelhamento, $r_{2}(t)$, integra-se a Equação (44).

$$
r_{2}(t)=\int\left(1-e^{\left(\frac{-t 1}{\tau}\right)}\right) * u_{1} * e^{-\left(\frac{t-t 1}{\tau}\right)}
$$

Resolvendo a integral da equação 45, tem-se a Equação (46).

$$
r_{2}(t)=-\left(1+e^{\left(\frac{-t 1}{\tau}\right)}\right) * u_{1} * \tau * e^{-\left(\frac{t-t 1}{\tau}\right)}+C
$$

Sendo " $C$ " a constante de integração.

Partindo da igualdade do deslocamento do eixo do rebolo ao final da fase de desbaste $t=$ $t_{1}$ ), definido de forma geral pela equação (34) ao início da fase de centelhamento, tem-se a Equação (47).

$$
r_{1}\left(t_{1}\right)=r_{2}\left(t_{1}\right)
$$

Sendo $r_{1}\left(t_{1}\right)$ a redução radial no diâmetro ao final do desbaste e $r_{2}\left(t_{1}\right)$ a redução radial no início da fase de centelhamento.

Usando as Equações (34) e (46) e substituindo na Equação (47) tem-se:

$$
u_{1} * t_{1}+u_{1} * \tau * e^{\left(\frac{-t 1}{\tau}\right)}-u_{1} * \tau=-\left(1+e^{\left(\frac{-t 1}{\tau}\right)}\right) * u_{1} * \tau+C
$$

Isolando a constante $\mathrm{C}$, tem-se:

$$
u_{1} * t_{1}+u_{1} * \tau * e^{\left(\frac{-t 1}{\tau}\right)}-u_{1} * \tau+u_{1} * \tau+e^{\left(\frac{-t 1}{\tau}\right)} * u_{1} * \tau=C
$$


Simplificando tem-se:

$$
u_{1} * t_{1}+2 u_{1} * \tau * e^{\left(\frac{-t 1}{\tau}\right)}=C
$$

Com o valor de "C", substituindo na Equação (46) tem-se a equação geral da redução radial na fase de centelhamento $\left(r_{2}(t)\right)$ :

$$
r_{2}(t)=-\left(1+e^{\left(\frac{-t 1}{\tau}\right)}\right) * u_{1} * \tau * e^{-\left(\frac{t-t 1}{\tau}\right)}+u_{1} * t_{1}+2 u_{1} * \tau * e^{\left(\frac{-t 1}{\tau}\right)}
$$

Simplificando tem-se:

$$
\begin{aligned}
& r_{2}(t)=\left[t_{1}+2 \tau * e^{-\left(\frac{t-t 1}{\tau}\right)}-\left(1+e^{\left(\frac{-t 1}{\tau}\right)}\right) * \tau * e^{-\left(\frac{t-t 1}{\tau}\right)}\right] * u_{1} \\
& r_{2}(t)=\left[2 \tau * e^{-\left(\frac{t-t 1}{\tau}\right)}+t_{1}-\left(1+e^{\left(\frac{-t 1}{\tau}\right)}\right) * \tau * e^{-\left(\frac{t}{\tau}\right)}\right] * u_{1}
\end{aligned}
$$

Através da Equação (51), conhecendo os valores de $\tau$ e a velocidade de mergulho do rebolo $u_{1}$ comandada pela máquina durante o desbaste, pode-se obter a redução radial da peça ao longo do centelhamento. A equação (51), se comparada com a equação (38), que permite o cálculo da redução radial da peça proposta inicialmente por Malkin e Guo (2008), possibilita calcular a redução radial da peça para os casos em que o tempo no ciclo de desbaste é inferior a constante de tempo $\tau$, seja pela adoção de um ciclo extremamente rápido de desbaste ou por uma condição de rigidez do sistema MRP desfavorável. Malkin e Guo (2008) sugerem que para processos de retificação externa possuem valores de $\tau$, entre 0,5 e $1 \mathrm{~s}$, sendo que esses valores serão verificados na parte experimental dessa pesquisa, de acordo com o modelamento descrito nesse capítulo. 


\section{MATERIAIS E EQUIPAMENTOS}

A metodologia de experimentação para avaliar a rigidez do processo de retificação, medindo-se a constante de tempo $\tau$, consiste na realização de ensaios laboratoriais de retificação cilíndrica externa de mergulho, monitorando-se variáveis-chave do processo. Os ensaios foram realizados em uma empresa multinacional Norte-Americana, do ramo de autopeças, localizada na região de Limeira-SP, pertencente ao seguimento de produtos para direção elétrica de automóveis.

\subsection{Retificadora}

Os experimentos foram realizados em uma retificadora cilíndrica externa, marca BONELI, modelo “Angle" 500. A Figura 26 mostra à retificadora e uma visão geral do banco de ensaios montado.

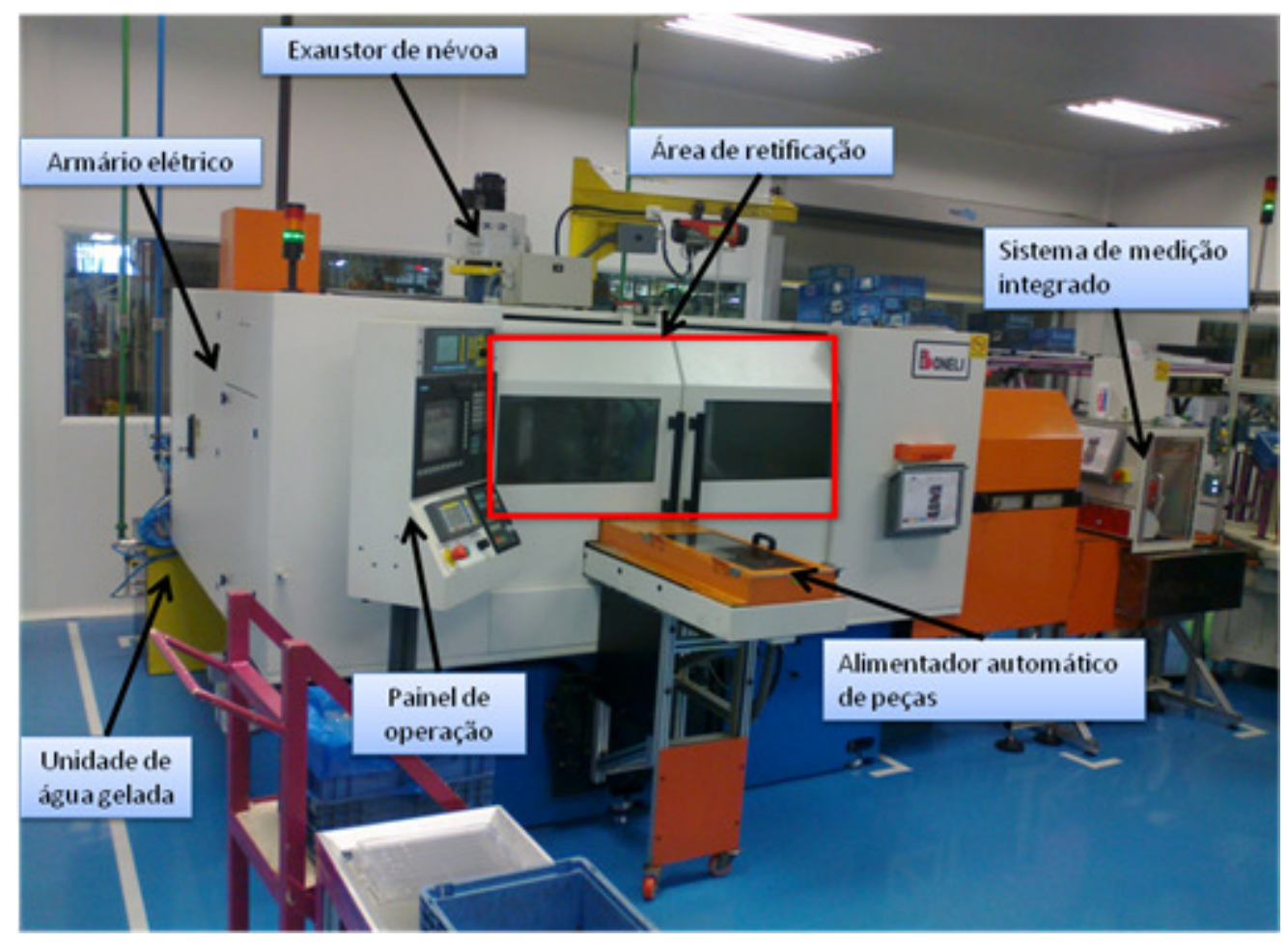

Figura 26 - Esquema geral do Banco de Teste 
A retificadora possui comando numérico SIEMENS ${ }^{\circledR}$ modelo $802 \mathrm{D} / \mathrm{SL}$, equipada com motor de acionamento do rebolo de 7,35 KW (10 cv), inversor de frequência SIEMENS, balanceador magnético automático, marca SBS, modelo SB-5500 acoplado diretamente ao centro do eixo do rebolo, posicionador axial com encoder no eixo X. A retificadora possui ainda medidor de diâmetro da peça em processo, marca MOVOMATIC ${ }^{\circledR}$, modelo ES400. A movimentação de carga e descarga da peça ocorre por um manipulador pneumático automático, sem a inferência humana. Outro ponto relevante a ser considerado para este experimento é o fato de ser uma retificadora com operação industrial há pouco tempo (cerca de 2 anos de utilização).

Sobre a retificadora destacam-se as informações a seguir:

- Dimensões do rebolo abrasivo (diâmetro externo x altura e diâmetro interno do furo): $610 \times 13 \times 254 \mathrm{~mm}$;

- Máxima velocidade de corte: $60 \mathrm{~m} / \mathrm{s}$;

- Comprimento máximo retificável: $100 \mathrm{~mm}$, entre pontas;

- Máxima potência disponível (motor do rebolo): 7,35 kW (10 cv);

- Balanceador magnético com leitura em 0,0001g/mm;

- Sistema de filtragem do fluido de corte;

A Figura 27 mostra uma visão geral da preparação da máquina utilizada para retificação em mergulho, com medição de diâmetro em processo, posicionamento axial e medição de vibração do rebolo.

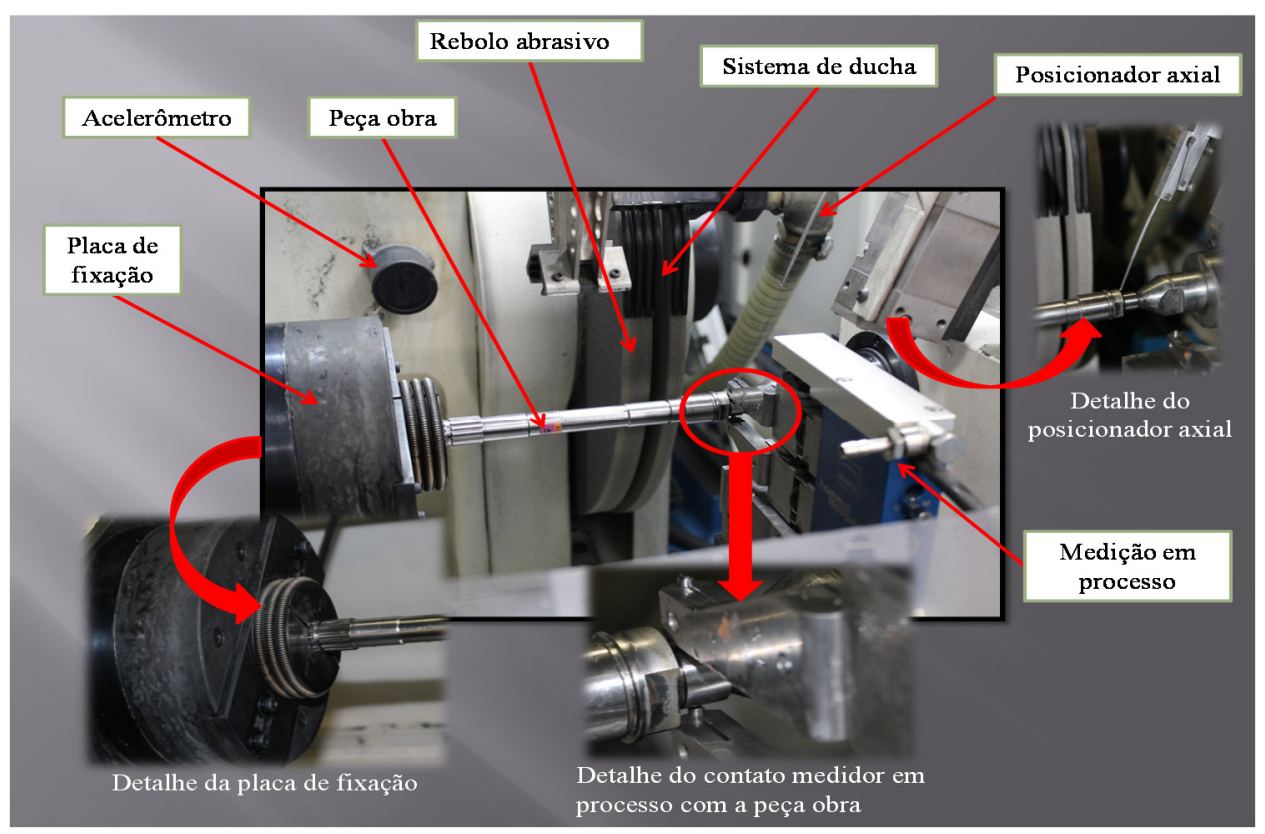

Figura 27 - Set up utilizado para o processo de retificação por mergulho na retificadora BONELI 


\subsection{Rebolo}

O rebolo utilizado para retificação em mergulho do fornecedor NORTON $^{\circledR}$, cuja especificação é 5 NQK 100 K V HB, onde "5" indica a concentração de grão cerâmico (classe 1 a 5 , sendo 1 menor e 5 maior concentração de grãos), "NQK" indica que é um rebolo Quantum de óxido de alumínio $\left(\mathrm{Al}_{2} \mathrm{O}_{3}\right)$ com grão especial, o número "100" indica a granulometria, "K" indica a dureza do rebolo (sendo A - macio, $\mathrm{N}$ - dureza média e $\mathrm{Z}$ para rebolos mais duros), "V" indica liga vitrificada e "HB" indica a qualidade da liga, segundo o fabricante. A máxima velocidade periférica admissível ao rebolo é de $60 \mathrm{~m} / \mathrm{s}$ como especificação do fabricante.

\subsection{Sistema de balanceamento do rebolo}

A retificadora BONELI está equipada com sistema de balanceamento magnético automático acoplado diretamente ao centro do eixo árvore, com precisão de balanceamento em $0,0001 \mathrm{~g} / \mathrm{mm}$.

\subsection{Dressador}

O dressador utilizado é do tipo FLIESE $^{\circledR}$ do fornecedor WINTER ${ }^{\circledR}$, modelo FAS90. Este tipo de dressador possui diamantes posicionados de forma ordenada na vertical em pastilhas ao longo corpo, a largura de atuação é de $1 \mathrm{~mm}$ com 1 fileira de barras conforme representado na Figura 28. 

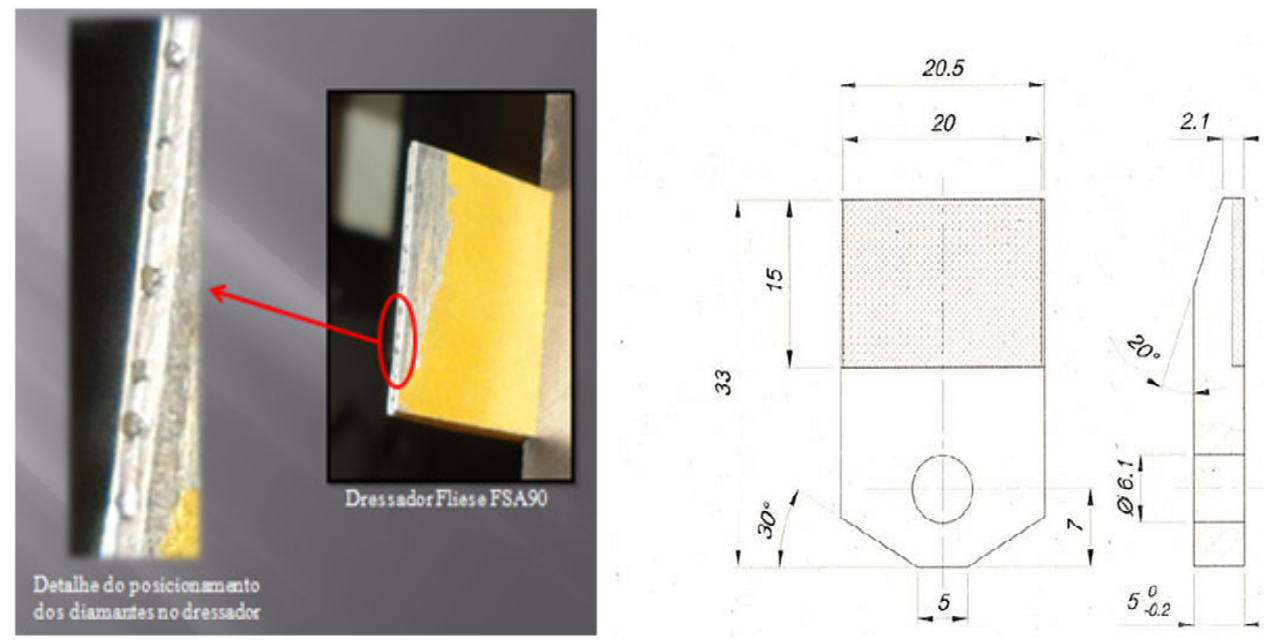

Figura 28 - Dressador utilizado no experimento de retificação

\subsection{Sistema de refrigeração e filtragem do fluido de corte}

A retificadora BONELI $^{\circledR}$ possui um sistema de filtragem acoplado, marca MACHSYSTEM $^{\circledR}$, modelo SFU, com potência de $1,5 \mathrm{KW}$, vazão de 80 1/min. e pressão de 2,5

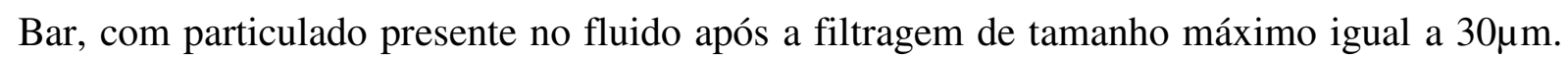
Este sistema elimina a utilização do filtro em papel, utilizando o método de deposição de partículas por hidrociclone.

O fluido utilizado para o processo de retificação é classificado como sintético, fornecido pela empresa FUCHS ${ }^{\circledR}$ com a nomenclatura ECOCOOL P1978.

\subsection{Corpo de prova}

A peça retificada é um componente utilizado no sistema de direção elétrico com diâmetro de $14,15 \mathrm{~mm}$ e comprimento de 202,10mm conforme demonstrado nas Figuras 29 e 30. O material do eixo é o aço ABNT 1045 endurecido por indução com 38 a 42 HRc de dureza. A caracterização da composição química deste material foi realizada no espectrômetro da marca "SPECTRO - analytical instruments". Os principais elementos químicos identificados na peça estão na Tabela 1. 


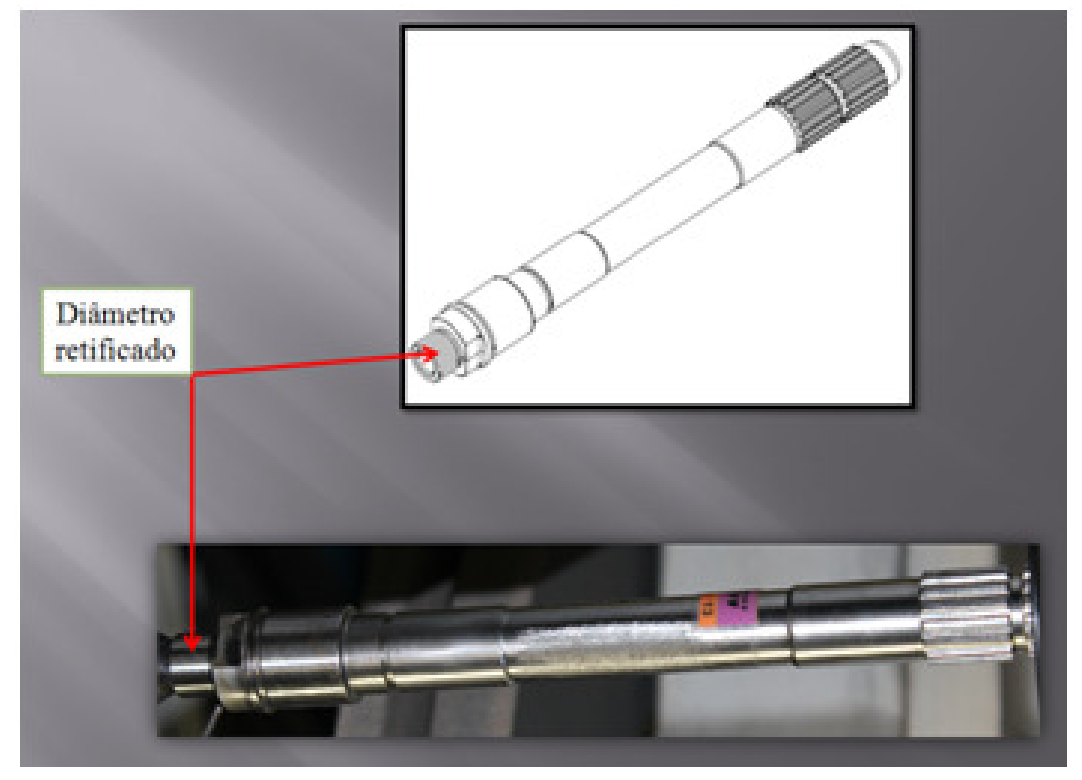

Figura 29 - Peça utilizada no experimento de retificação

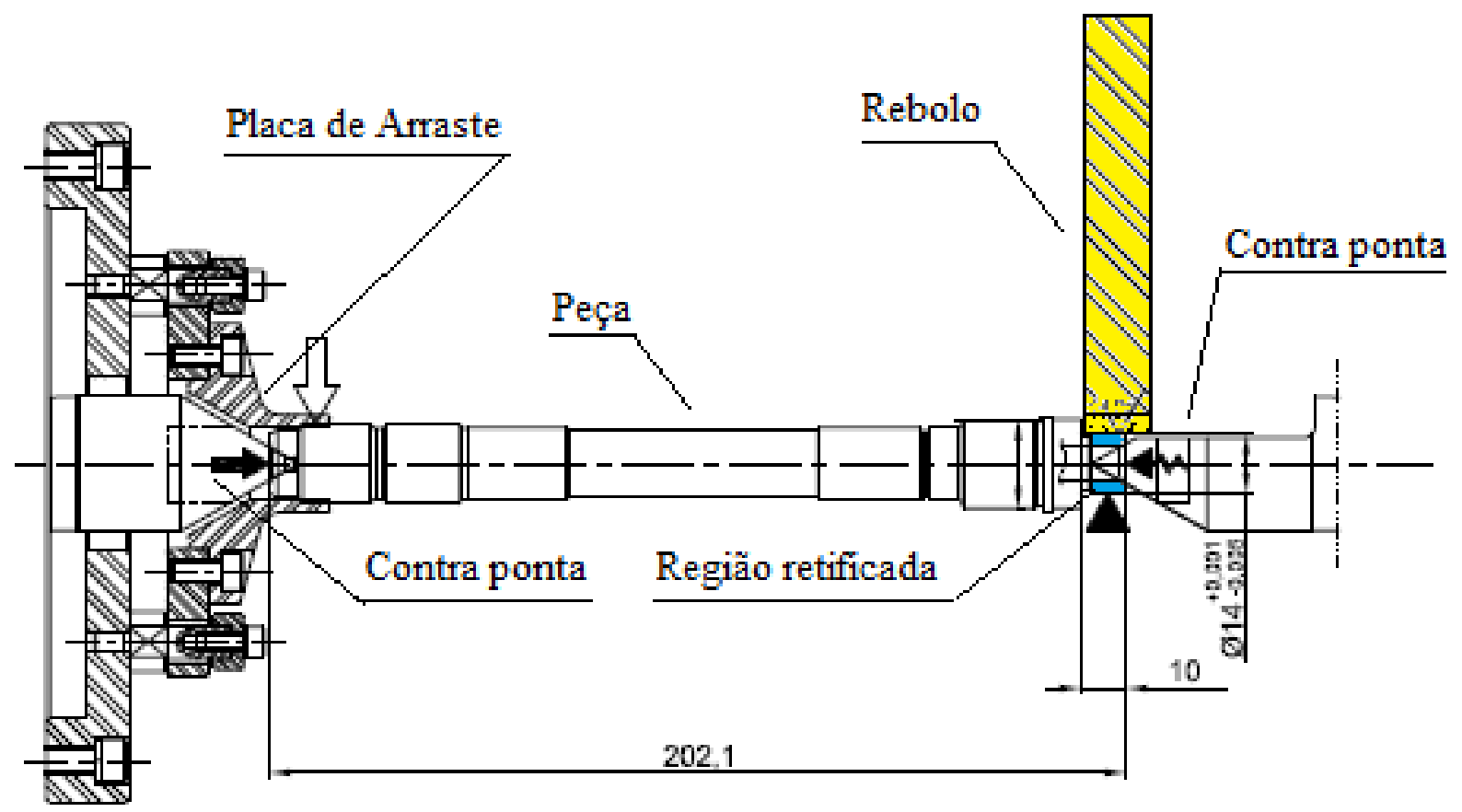

Figura 30 - Esquema de fixação da peça no sistema de arraste e contra pontas 
Tabela 1 - Resultados obtidos da composição química do material SAE 1045.

\begin{tabular}{cc}
\hline Composição Química & {$[\%]$} \\
\hline $\mathrm{C}$ & 0,4180 \\
$\mathrm{Si}$ & 0,1200 \\
$\mathrm{Mn}$ & 1,2600 \\
$\mathrm{P}$ & 0,0130 \\
$\mathrm{~S}$ & 0,1530 \\
$\mathrm{Cr}$ & 0,1200 \\
$\mathrm{Mo}$ & 0,0500 \\
$\mathrm{Ni}$ & 0,1200 \\
$\mathrm{Al}$ & 0,0223 \\
$\mathrm{Cu}$ & 0,1810 \\
$\mathrm{Nb}$ & 0,0020 \\
$\mathrm{Ti}$ & 0,0042 \\
$\mathrm{~V}$ & 0,0030 \\
$\mathrm{C}$ equivalente & 0,7100 \\
$\mathrm{Fe}$ & 97,5400 \\
\hline
\end{tabular}

O processo de retificação cilíndrica externa de mergulho foi realizado no diâmetro de 14 $\mathrm{mm}$, cujo comprimento é igual a $10 \mathrm{~mm}$. A tolerância dimensional no diâmetro retificado é de $+0,001 /-0,005 \mathrm{~mm}$ e a rugosidade média (Ra) especificada é de $0,4 \mu \mathrm{m}$.

\subsection{Sistema de aquisição para coleta de dados de diâmetro instantâneo da peça e coordenada $X$ do rebolo}

O sistema de aquisição utilizado neste trabalho consistiu em adquirir, na menor taxa de aquisição possível, os dados decorrentes do posicionamento do eixo "X", responsável pelo mergulho do rebolo e os dados referentes ao decréscimo do diâmetro da peça durante o processo de retificação. Para tal, foram utilizadas duas placas de aquisição marca NATIONAL INSTRUMENTS $^{\circledR}$, código NI-9421 e NI-9426, instaladas em um controlador lógico CompactRIO $^{\circledR}$ da NATIONAL INSTRUMENTS, modelo 9075. Utilizou-se ainda um " $D P / D P$ Coupler”, modelo 6ES7 158-0AD01-0XA0, para a comunicação com o inversor de frequência do eixo de posicionamento do cabeçote porta rebolo. 


\section{MÉTODOS}

\subsection{Matriz experimental}

A matriz de testes para obter a constante de tempo $\tau$ consistiu-se em dois conjuntos de testes. Os experimentos foram conduzidos sempre após o aquecimento da retificadora, com no mínimo 6 horas de utilização.

O ciclo de retificação para o processo de retificação cilíndrica externa de mergulho consistiu em 2 fases distintas: desbaste e centelhamento. As velocidades de mergulho do rebolo $\left(v_{f}\right)$ adotadas foram de 3,$0 ; 2,5 ; 1,6 ; 0,8$ e $0,08 \mathrm{~mm} / \mathrm{min}$, com tempo de centelhamento $\left(t_{2}\right)$ de 0s. Para cada velocidade, foram adquiridos dados do processo em 5 amostras seguidas.

A taxa de remoção específica de material é demonstrada na tabela 2.

Tabela 2 - Taxa de Remoção específica adotado nos experimentos

\begin{tabular}{ccc}
\hline $\begin{array}{c}\text { vf } \\
{[\mathbf{m m} / \mathbf{m i n} .]}\end{array}$ & $\begin{array}{c}\mathbf{Q} \mathbf{w} \\
{\left[\mathbf{m m}^{\mathbf{3}} /(\mathbf{m m} * \mathbf{s})\right]}\end{array}$ & $\begin{array}{c}\mathbf{t}_{2} \\
{[\mathbf{s}]}\end{array}$ \\
\hline 3 & 2,199 & 0 \\
2,5 & 1,833 & 0 \\
1,6 & 1,173 & 0 \\
0,8 & 0,586 & 0 \\
0,08 & 0,059 & 0 \\
\hline
\end{tabular}

A velocidade de mergulho máxima de $3,0 \mathrm{~mm} / \mathrm{min}$ foi determinada por testes práticos, observando-se a máxima potência consumida pelo motor durante a retificação, a qual atingiu 98\%. A Tabela 3 mostra os demais parâmetros de corte adotados, comuns a todos os experimentos. Na Tabela 4 estão detalhados os parâmetros de dressagem adotados nos ensaios. 
Tabela 3 - Parâmetros de processo adotados nos bancos de testes

\begin{tabular}{lcl}
\hline Parâmetros de processo & Valores adotados & Unidade \\
\hline Velocidade de corte & 60 & {$[\mathrm{~m} / \mathrm{s}]$} \\
Diâmetro inicial do rebolo & 553 & {$[\mathrm{~mm}]$} \\
Rotação da peça & 650 & {$[\mathrm{RPM}]$} \\
Sobremetal & $0,15+/-0,03$ & {$[\mathrm{~mm}]$} \\
Amostras para cada experimento & 5 & {$[\mathrm{pç}]$} \\
Largura de corte "b" & 10 & {$[\mathrm{~mm}]$} \\
\hline
\end{tabular}

Tabela 4 - Parâmetros de processo de dressagem

\begin{tabular}{ccc}
\hline $\begin{array}{c}\text { Parâmetros de } \\
\text { dressagem }\end{array}$ & $\begin{array}{c}\text { Valores } \\
\text { Adotados }\end{array}$ & Unidades \\
\hline bd & 1 & {$[\mathrm{~mm}]$} \\
sd & 1,4 & {$[\mathrm{~mm} / \mathrm{rot}]$} \\
$\mathrm{ad}$ & 0,02 & {$[\mathrm{~mm}]$} \\
$\mathrm{Ud}$ & 0,714 & {$[\mathrm{~mm}]$} \\
\hline
\end{tabular}

Para cada velocidade de mergulho foi retificada uma peça calibrada, com tempo de centelhamento de 60 segundos. Objetivou-se eliminar toda a deformação do sistema MRP após esse tempo $\left(t_{2}\right)$, adotando-se como premissa que ao final desse seria possível obter-se o diâmetro conhecido e padronizado antes de cada experimento. A forma de medição deu-se por um medidor de processo instalado na retificadora. O procedimento adotado para os experimentos é detalhado a seguir:

1) Ajustou-se todos os parâmetros de corte para condição de processo previstas na Tabela 2 , inserindo no programa CNC da retificadora o valor correspondente de $v_{f}$ e $t_{2}$ para o ensaio em questão;

2) Realizou-se a dressagem do rebolo adotando-se as condições descritas na Tabela 4;

3) Retificou-se a peça calibrada com tempo de centelhamento $\left(t_{2}\right)$ de 60 segundos.

4) Retificou-se 5 corpos de provas utilizando-se os parâmetros de corte introduzidos no passo 1.

5) Coletou-se os dados sincronizados do início ao final do processo de retificação através do software de aquisição de dados do processo de retificação, desenvolvido em LabView ${ }^{\circledR}$. 
6) Considerou-se o diâmetro inicial da peça com a média de todos os pontos adquiridos no software de monitoramento antes do decréscimo do diâmetro da peça, ou seja, antes do toque efetivo do rebolo na peça.

7) Considerou-se o diâmetro final da peça como a média dos dois últimos pontos adquiridos no software de monitoramento, exceto quando o tempo de centelhamento foi nulo. Neste caso, o valor do diâmetro final considerado foi o último ponto adquirido.

Desta forma o sobremetal para cada peça retificada é obtido com a diferença entre os passos 6 e 7 descritos acima. Sendo em média $0,15 \mathrm{~mm}$ por peça.

\subsection{Método para coleta de dados de diâmetro instantâneo da peça e coordenada $\mathrm{X}$ do rebolo}

O esquema de instrumentação utilizado para a coleta dos dados de diâmetro instantâneo da peça e coordenada X do rebolo pode ser visualizado na Figura 31.

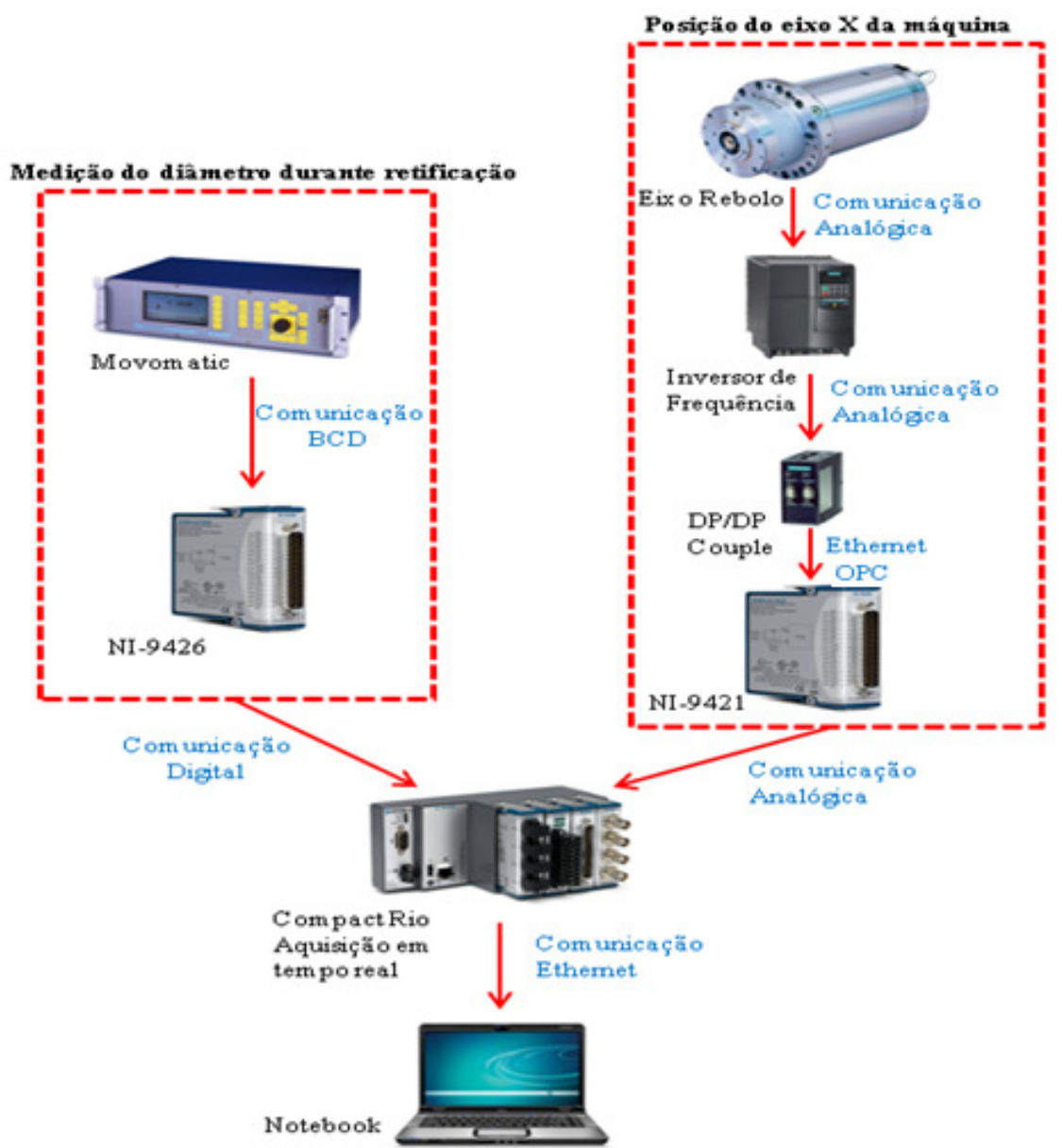

Figura 31 - Tipologia utilizada na instrumentação para aquisição dos dados 
A aquisição da rotação do eixo do rebolo foi obtida adquirindo-se um sinal de saída do inversor de frequência, marca SIEMENS ${ }^{\circledR}$, modelo Mm 420, na porta codificada como P0311, através da qual pode-se obter também a variação da tensão (porta P0304) e corrente elétrica (porta P0305) durante o processo de retificação. Foi utilizada uma placa de aquisição da marca NATIONAL INSTRUMENTS ${ }^{\circledR}$, código NI-9421. O sinal de tensão e corrente são adquiridos, de forma analógica do inversor de frequência, a uma taxa de $5 m s$ para serem processadas e posteriormente enviadas ao programa de aquisição dos dados de processo desenvolvido em LabView $^{\circledR}$.

A aquisição do posicionamento do rebolo em mergulho ocorre por comunicação " $D P / D P$ Coupler” diretamente do controlador lógico programável - CLP SIEMENS ${ }^{\circledR}$, modelo 802D/SL, por variável digital de 32 Bits, com ligação via Ethernet e OPC (“OLE for Process Control”) a uma taxa de transferências de dados em 100ms, aproximadamente. Já a aquisição do diâmetro da peça durante o processo ocorre pela saída X31 do sistema de controle MOVOMATIC ${ }^{\circledR}$. O sinal digital é adquirido e processado pela placa NI 9426 da NATIONAL INSTRUMENTS ${ }^{\circledR}$ a uma taxa de $100 \mathrm{~ms}$. Neste caso é a menor taxa que a saída X31 do MOVOMATIC ${ }^{\circledR}$ permite adquirir.

A título de facilitar a leitura, as aquisições do sistema de monitoramento neste experimento são classificadas como: OPC para posição do eixo X do rebolo e MOVOMATIC ${ }^{\circledR}$ para aquisição do diâmetro durante o processo de retificação. São gerenciadas e processadas por um controlador lógico CompactRIO ${ }^{\circledR}$, modelo 9075 da NATIONAL INSTRUMENTS ${ }^{\circledR}$. Esse hardware opera fora da plataforma Windows ${ }^{\circledR}$, portanto, o processamento das informações recebidas ocorre em tempo real, já que são realizadas no processador dedicado do referido controlador lógico. É um sistema embarcado e configurável de aquisição e controle. A arquitetura de hardware do sistema CompactRIO ${ }^{\circledR}$ é formada por módulos e um chassi com FPGA “field-programmable gate array”. Além disso, o CompactRIO ${ }^{\circledR}$ é programado com o uso das ferramentas de programação gráficas do software LabVIEW ${ }^{\circledR}$. Sua função no monitoramento da operação de retificação é receber os dados enviados pelos dois sistemas, chamados aqui em MOVOMATIC ${ }^{\circledR}$ e OPC.

Para realizar a análise de forma sincronizada, respeitando a maior taxa de aquisição de dados, o software de programação gráfica LabView ${ }^{\circledR}$, foi utilizado. Com o objetivo de reduzir os ruídos provenientes de aterramento, contato e outros, foi incluído um filtro tipo passa baixa nas aquisições no valor de $55 \mathrm{kHz}$. Este valor foi determinado mediante testes preliminares.

A comunicação do MOVOMATIC ${ }^{\circledR}$ com o comando numérico ocorre por meio de um conjunto de entradas digitais. Através de uma porta serial com 15 pinos formando um código 
BCD “Binary-Coded Decimal”. A comunicação BCD baseia-se em um número de bits, onde para cada bit é atribuído um valor diferente e inteiro. A soma do valor de todos os bits no nível lógico representa o valor do sinal desejado.

\subsection{Curvas de aquisição típicas}

Os dados de deslocamento do eixo "x" responsável pelo mergulho do rebolo em direção à peça e o decréscimo do diâmetro da peça durante o contato do rebolo, foram adquiridos de forma simultânea e sincronizados pelo programa de aquisição de dados desenvolvido neste trabalho. O Gráfico 2 representa uma saída típica do sistema de aquisição de dados durante o processo de retificação. A curva Diâmetro representa os valores obtidos do medidor em processo, indicados no eixo y à esquerda. A curva Eixo " $X$ ” representa o conjunto de valores obtidos para a coordenada $\mathrm{X}$ do eixo porta rebolo, cujos resultados são indicados na escala y à direita no referido gráfico. O cabeçalho do gráfico indica ainda a amostra analisada (1 a 5), a velocidade de mergulho $\left(v_{f}\right)$ adotada e o tempo de centelhamento utilizado. Os demais gráficos obtidos como dados de saída do sistema de aquisição desenvolvido estão no "Apêndice I" deste trabalho.

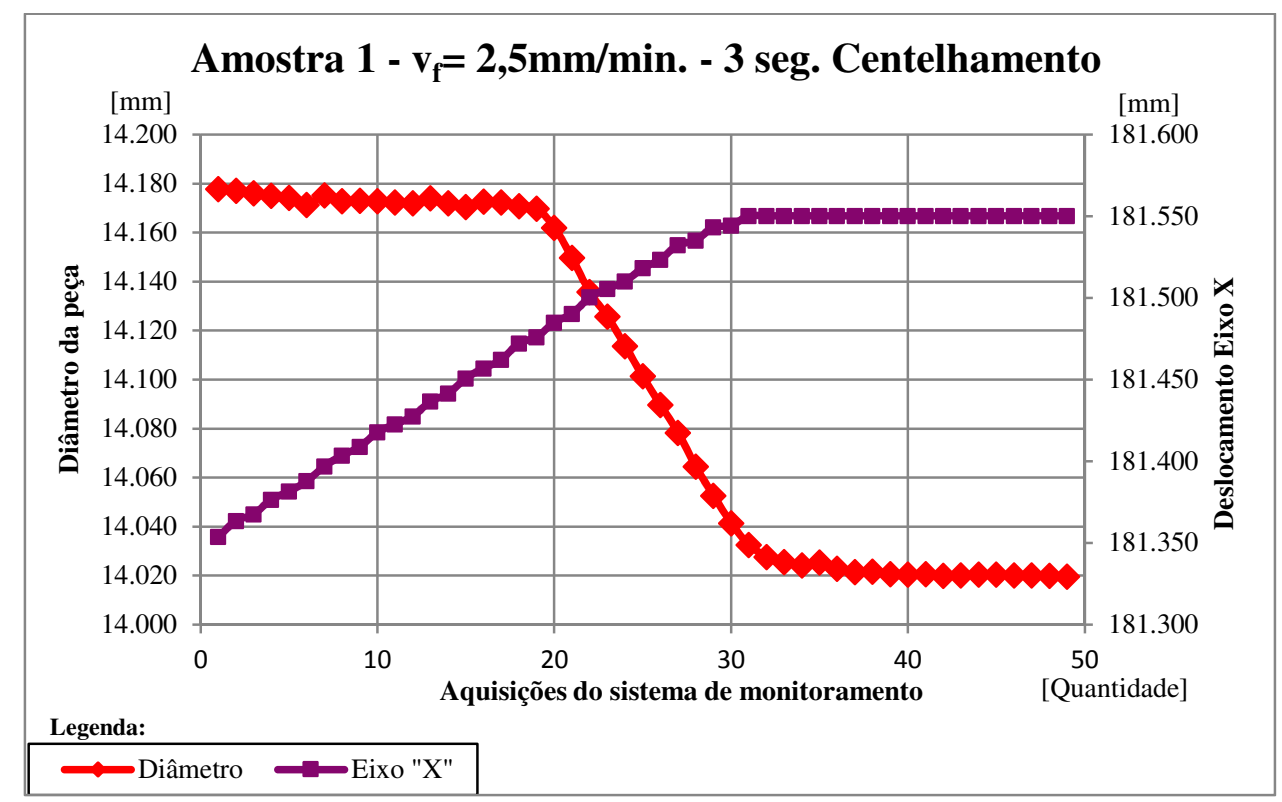

Gráfico 2 - Aquisição dados durante o processo retificação 
Deste tipo de gráfico processou-se os dados de forma a produzir outro gráfico, na mesma escala e usando-se o tempo de aquisição de aproximadamente $100 \mathrm{~ms}$ para as velocidades de mergulho iguais a 3,0;2,5;1,6; 0,8 e $0,08 \mathrm{~mm} / \mathrm{min}$, com cinco repetições e diferentes valores de tempo de centelhamento. O Gráfico 3 representa a curva processada para a condição Amostra $1-v_{f}=2,5 \mathrm{~mm} / \mathrm{min}$. e tempo de centelhamento de 3 segundos.

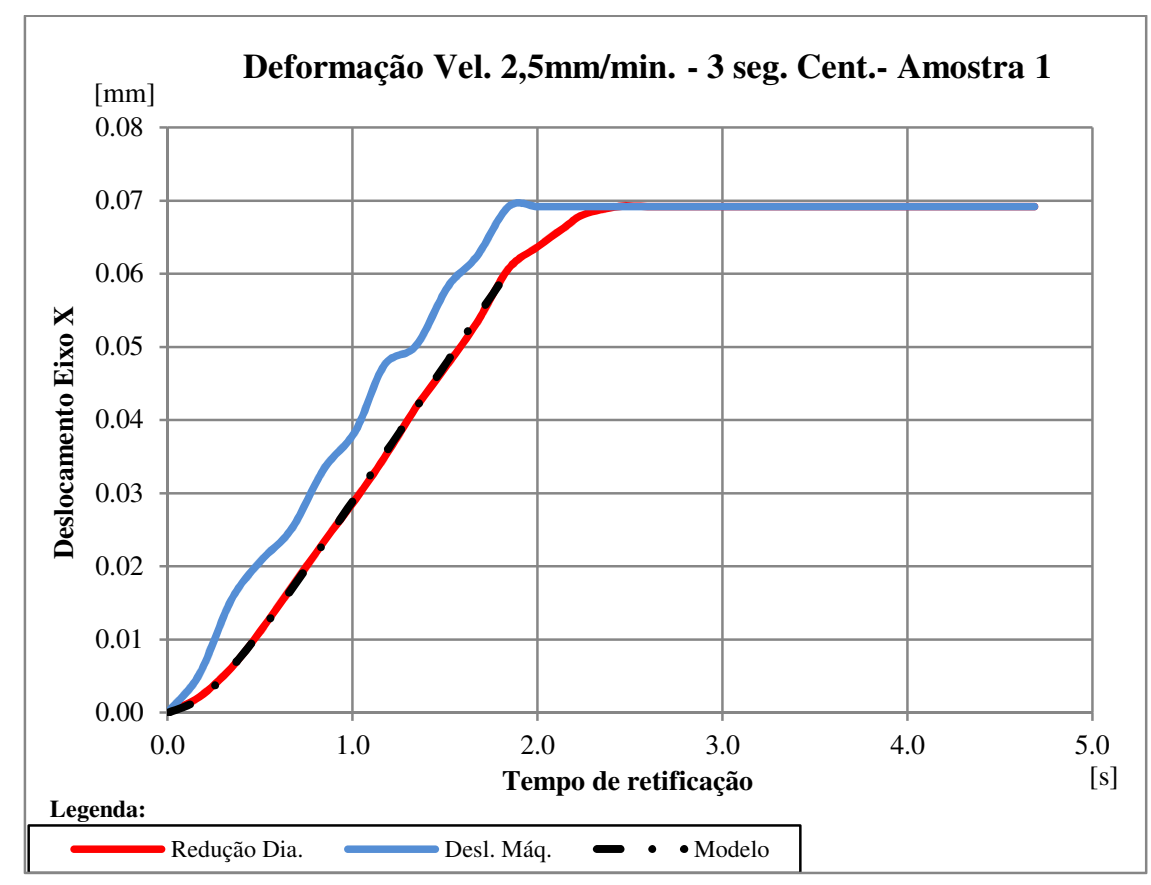

Gráfico 3 - Curva de deformação no processo de retificação

A linha nomeada como "Desl. Máq." no Gráfico 3 indica o deslocamento programado da retificadora para remoção do material no raio da peça em $0,07 \mathrm{~mm}$. A linha nomeada como "Redução Dia." representa a redução do raio na peça em 0,06 mm no instante em que cessou o deslocamento do eixo X e a linha nomeada como "Modelo" indica a aplicação da Equação (34) de Malkin e Guo (2008) com o $\tau$ de menor desvio encontrado na Equação (34) processada no MatLab $^{\circledR}$.

Os demais gráficos obtidos estão no "Apêndice I" deste trabalho após o processamento. Com esse tipo de gráfico foi obtido a constante tempo $\tau$, descrita a seguir. 


\subsection{Tratamento dos dados no MatLab ${ }^{\circledR}$.}

Os dados coletados para construção da curva de deslocamento do eixo X da retificadora foram tratados utilizando a técnica de minimização da soma dos quadrados dos resíduos. Essa técnica permite a aproximação por mínimos quadrados, consistindo em encontrar a função que melhor se ajuste ao conjunto de dados, minimizando o erro resultante do ajustamento. Isso permite a linearização dos dados e a construção de uma reta às curvas de deslocamento do eixo $\mathrm{X}$ no tempo, durante a fase de desbaste.

\subsection{Experimento 1: Determinação da constante de tempo $\tau$ em função de $v f$.}

Partindo dos dados de posição do eixo X e da redução diametral em função do tempo, coletados pelo programa de aquisição de dados descrito no item 5.2, foi desenvolvido uma rotina para ajuste de curvas no MatLab ${ }^{\circledR}$. A Tabela 5 mostra os dados típicos coletados com velocidade de mergulho de $3,0 \mathrm{~mm} / \mathrm{min}$ como exemplo.

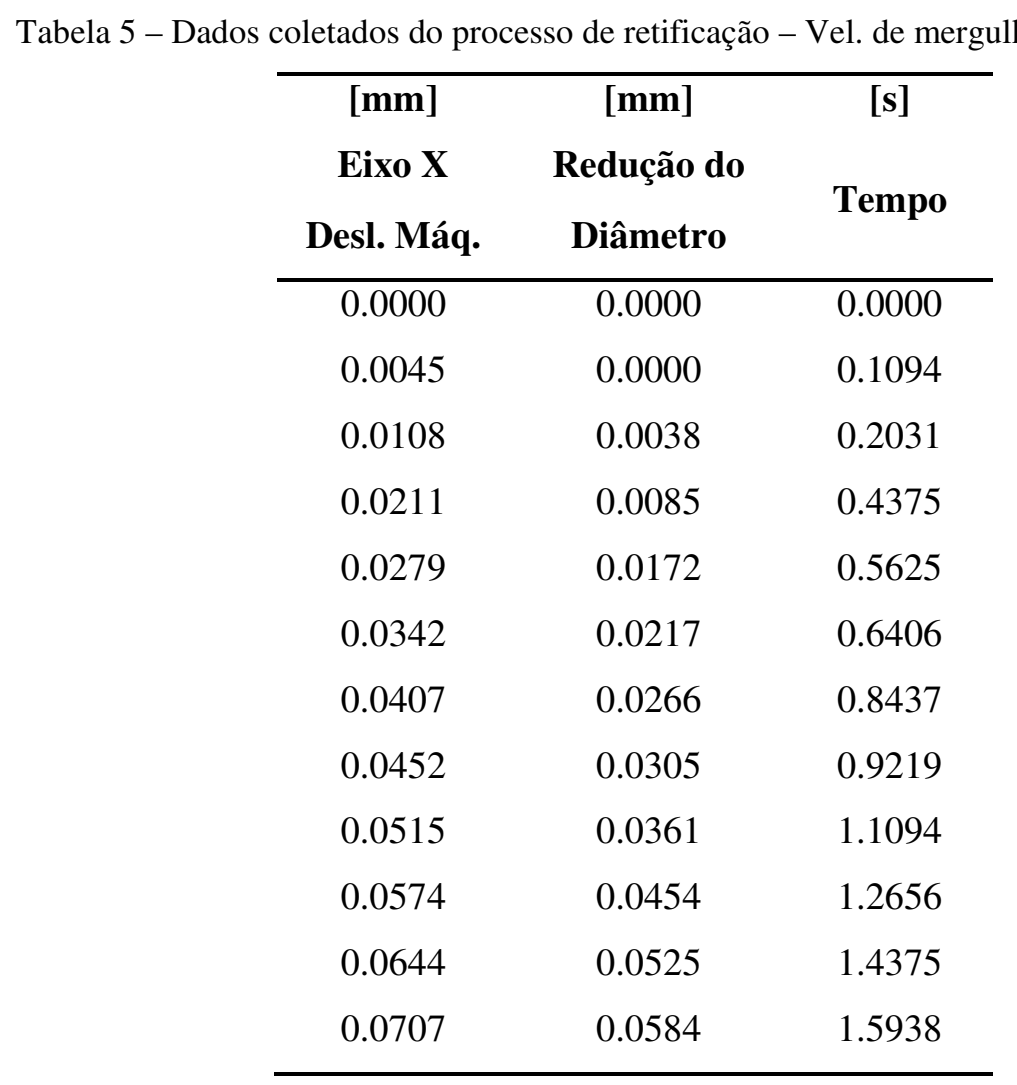


O próximo passo é aplicar a técnica de mínimos quadrados, descrita no item 5.4, na Equação (34) de Malkin e Guo (2008) com os dados coletados pelo programa de monitoramento para encontrar qual o menor desvio de $\tau$. O intervalo estabelecido no programa MatLab para determinar o menor desvio de $\tau$ foi de 0 a $0,5 \mathrm{~s}$, com incremento de $0,001 \mathrm{~s}$. O Gráfico 4 mostra a curva de estimativas de $\tau$ para velocidade de $3,0 \mathrm{~mm} / \mathrm{min}$.

$r(t)=\left(t+\tau e^{-t / \tau}-\tau\right) u_{1}$

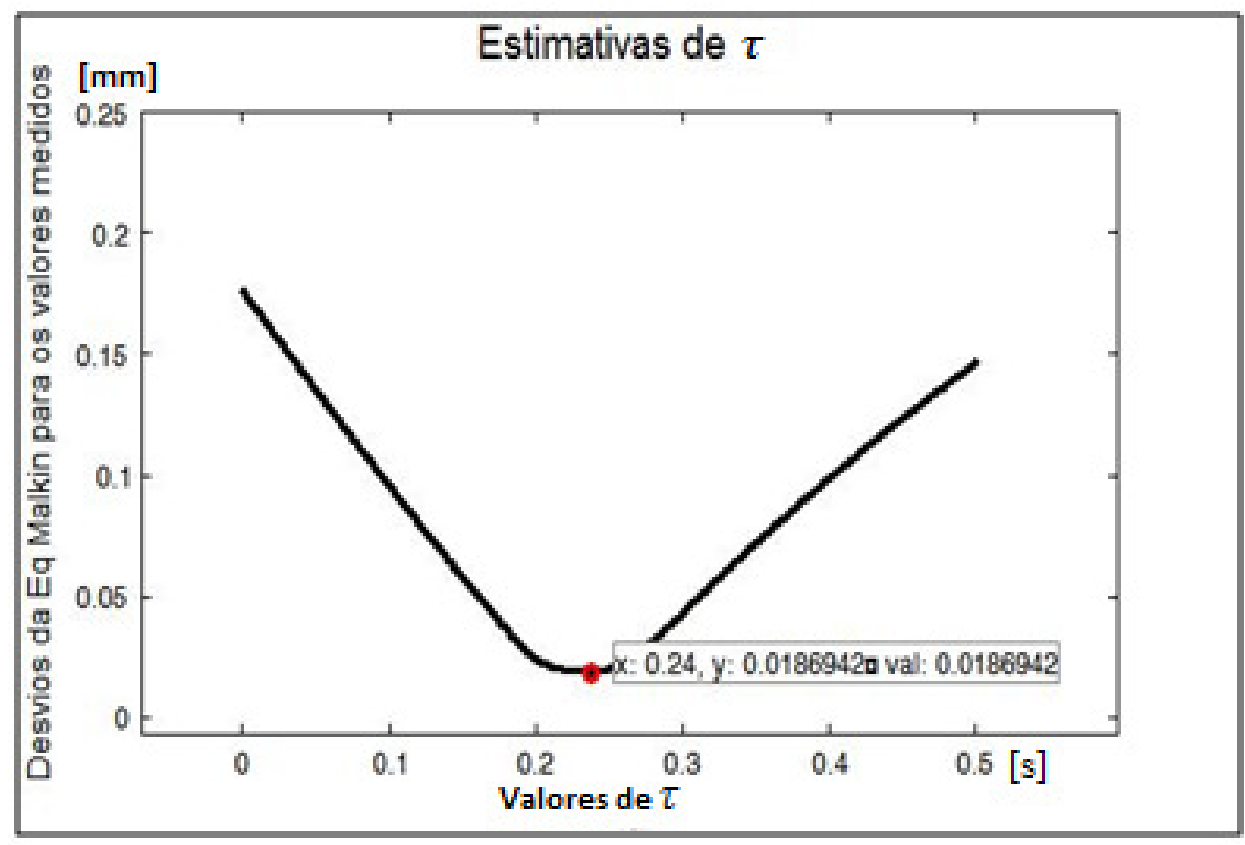

Gráfico 4 - Curvas características de estimativa de $\tau$ - MatLab ${ }^{\circledR}$

Após determinar o menor desvio de $\tau$ aplicou-se a Equação (34) de Malkin e Guo (2008) para cada tempo coletado no programa de monitoramento. A Tabela 6 mostra os resultados de $\tau$ em função do tempo de aquisição. 
Tabela 6 - Dados do processo de retificação aplicando Equação (34) Malkin e Guo (2008)

\begin{tabular}{|c|c|c|c|}
\hline $\begin{array}{c}\text { [mm] } \\
\text { Eixo X } \\
\text { Desl. Máq. }\end{array}$ & $\begin{array}{c}\text { [mm] } \\
\text { Redução do } \\
\text { Diâmetro }\end{array}$ & $\begin{array}{c}\text { [s] } \\
\text { Tempo }\end{array}$ & $\begin{array}{c}\text { [mm] } \\
\text { Equação } \\
(34)\end{array}$ \\
\hline 0.0000 & 0.0000 & 0.0000 & 0.0000 \\
\hline 0.0045 & 0.0000 & 0.1094 & 0.0009 \\
\hline 0.0108 & 0.0038 & 0.2031 & 0.0029 \\
\hline 0.0211 & 0.0085 & 0.4375 & 0.0104 \\
\hline 0.0279 & 0.0172 & 0.5625 & 0.0152 \\
\hline 0.0342 & 0.0217 & 0.6406 & 0.0184 \\
\hline 0.0407 & 0.0266 & 0.8437 & 0.0269 \\
\hline 0.0452 & 0.0305 & 0.9219 & 0.0303 \\
\hline 0.0515 & 0.0361 & 1.1094 & 0.0385 \\
\hline 0.0574 & 0.0454 & 1.2656 & 0.0454 \\
\hline 0.0644 & 0.0525 & 1.4375 & 0.0530 \\
\hline 0.0707 & 0.0584 & 1.5938 & 0.0599 \\
\hline
\end{tabular}

Após determinar qual o menor desvio de $\tau$ construiu-se a curva de deformação do sistema MRP pela Equação (34) de Malkin e Guo (2008). O Gráfico 5 representa curvas típicas para determinar o melhor ajuste para o valor de $\tau$. As demais curvas de ajustes para as velocidades de mergulho 3,0 , 2,5 , 1,6 , 0,8 e 0,08mm/min. no MaLab ${ }^{\circledR}$ e Excel $^{\circledR}$ são demonstradas nos gráficos 6 a 15 .

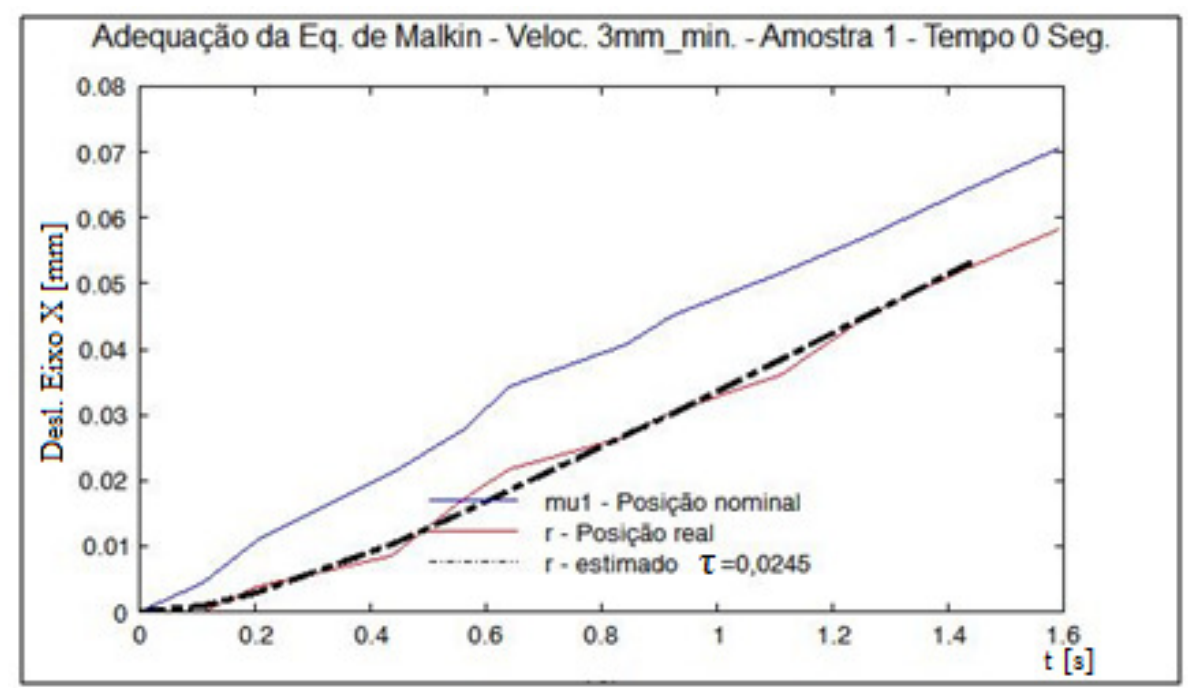

Gráfico 5 - Curvas características de estimativa de $\tau$ - MatLab ${ }^{\circledR}$ 
Curvas experimentais velocidade de mergulho $=3,0 \mathrm{~mm} / \mathrm{min}$. - amostras 1 a 5 :
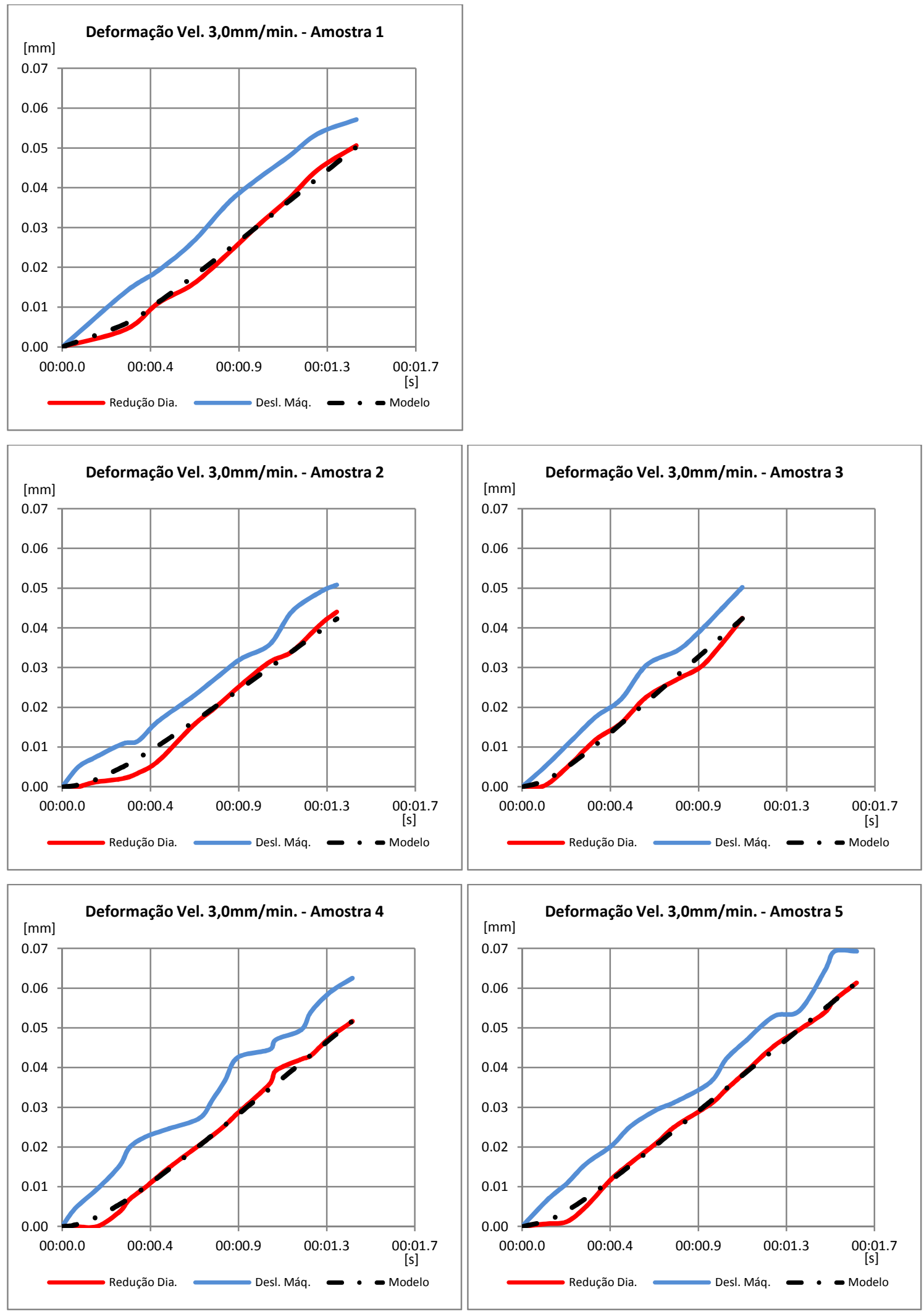

Gráfico 6 - Curvas Experimentais Excel ${ }^{\circledR}-$ Vel. de mergulho $=3,0 \mathrm{~mm} / \mathrm{min}$. Tempo de Centelhamento $=0 \mathrm{~s}$ 
Ajuste das curvas experimentais MatLab ${ }^{\circledR}$ velocidade de mergulho $=3,0 \mathrm{~mm} / \mathrm{min}$. - amostras 1 a 5:
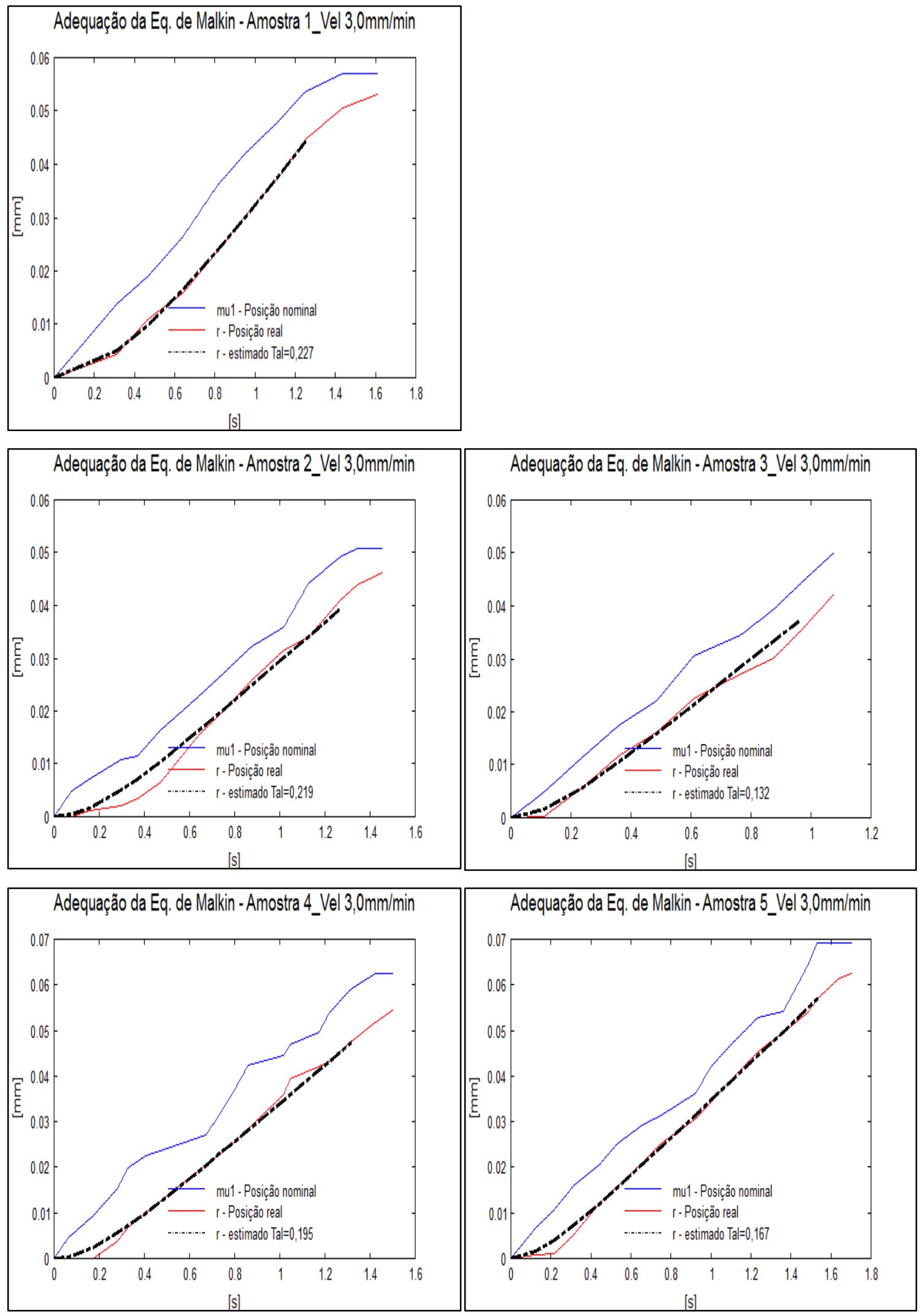

Gráfico 7 - Curvas Experimentais MatLab ${ }^{\circledR}-$ Vel. de mergulho $=3,0 \mathrm{~mm} / \mathrm{min}$. Centelhamento $=0 \mathrm{~s}$ 
Curvas experimentais velocidade de mergulho $=2,5 \mathrm{~mm} / \mathrm{min}$. - amostras 1 a 5 :
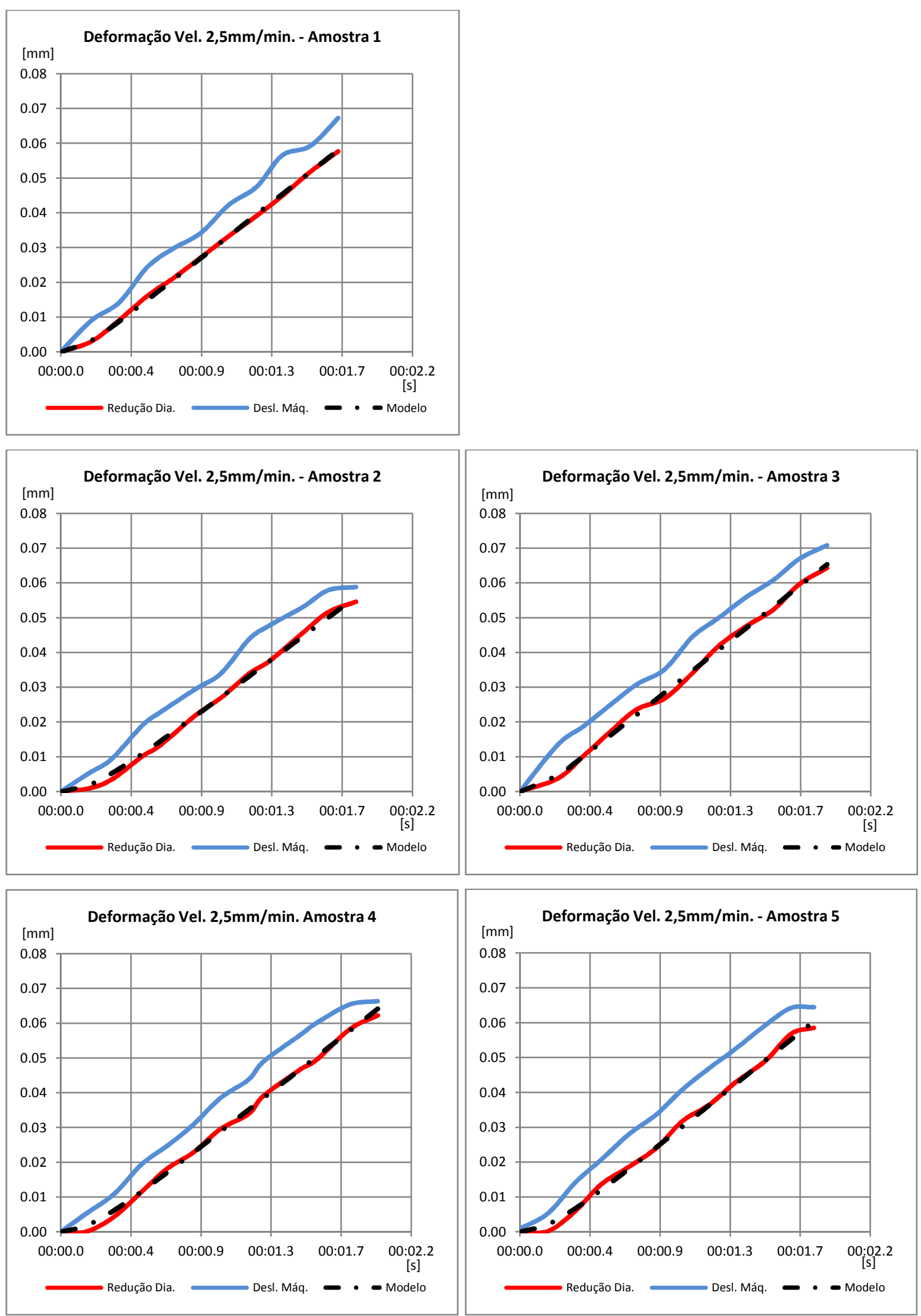

Gráfico 8 - Curvas Experimentais Excel ${ }^{\circledR}-$ Vel. de mergulho $=2,5 \mathrm{~mm} / \mathrm{min}$. centelhamento $=0 \mathrm{~s}$ 
Ajuste das curvas experimentais MatLab ${ }^{\circledR}$ velocidade de mergulho $=2,5 \mathrm{~mm} / \mathrm{min}$. - amostras 1 a 5:
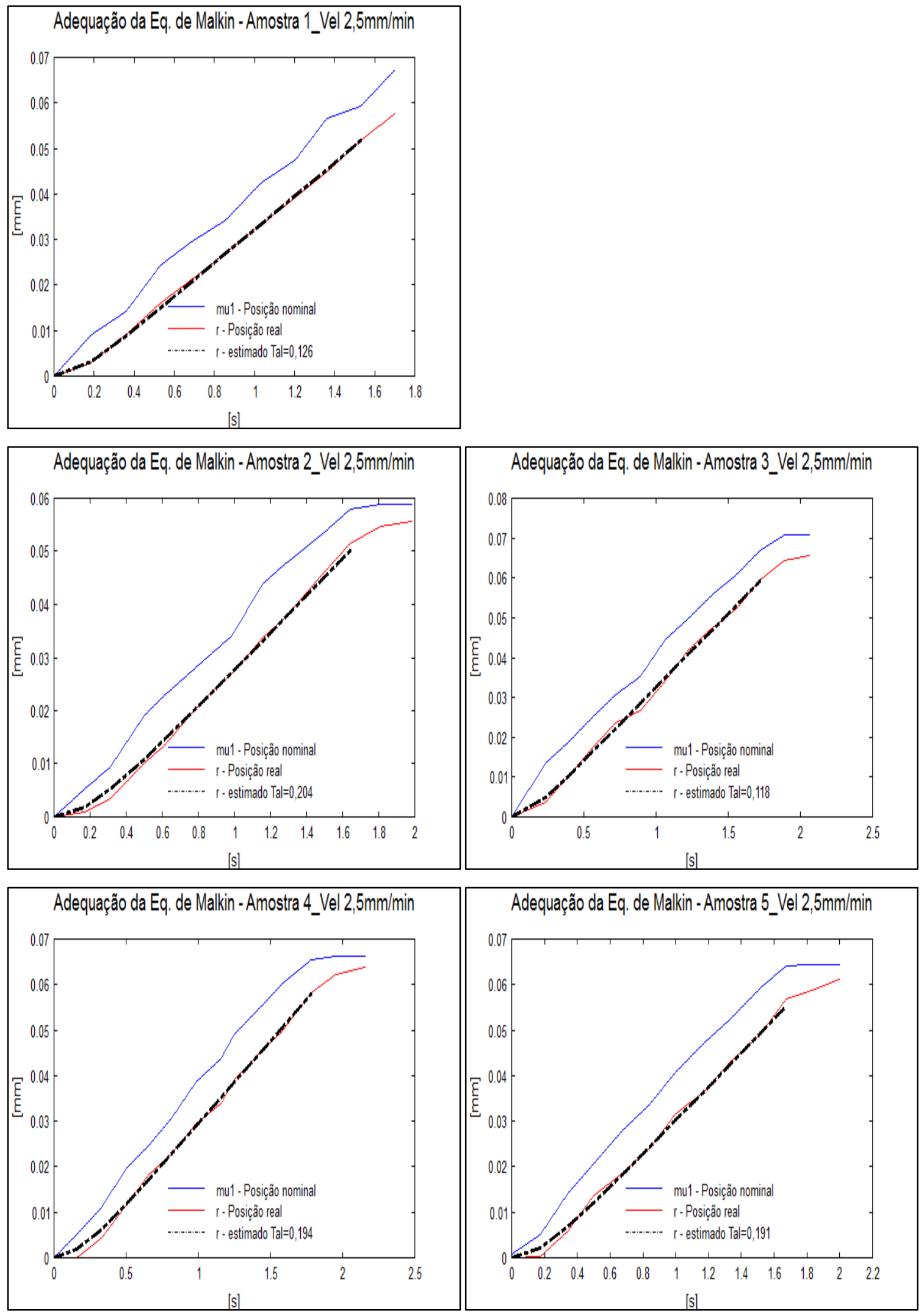

Gráfico 9 - Curvas Experimentais MatLab ${ }^{\circledR}-$ Vel. de mergulho = 2,5mm $/ \mathrm{min}$. 
Curvas experimentais velocidade de mergulho $=1,6 \mathrm{~mm} / \mathrm{min}$. - amostras 1 a 5 :
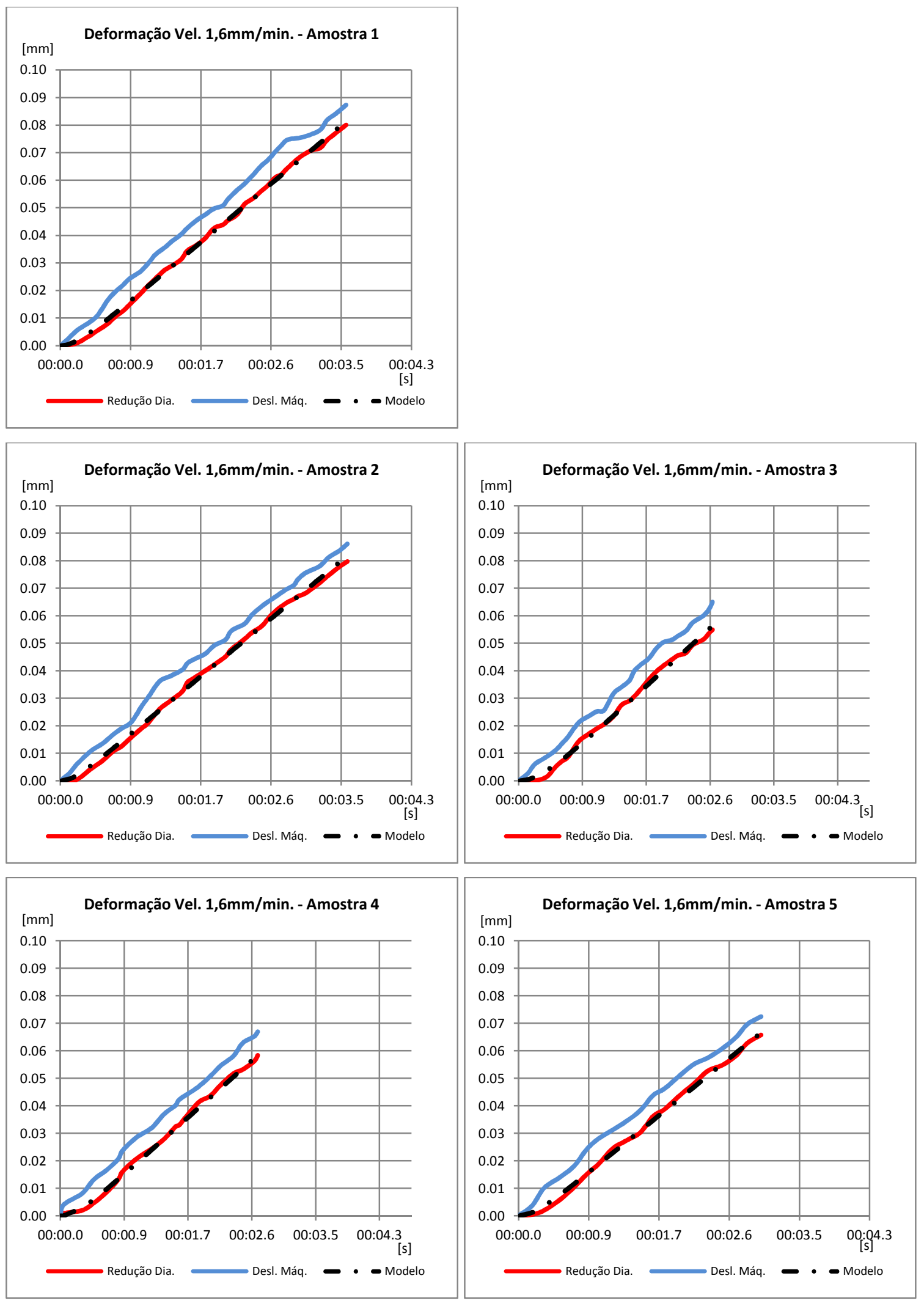

Gráfico 10 - Curvas Experimentais Excel ${ }^{\circledR}-$ Vel. de mergulho $=1,6 \mathrm{~mm} / \mathrm{min}$. 
Ajuste das curvas experimentais MatLab ${ }^{\circledR}$ velocidade de mergulho $=1,6 \mathrm{~mm} / \mathrm{min}$. - amostras 1 a 5:
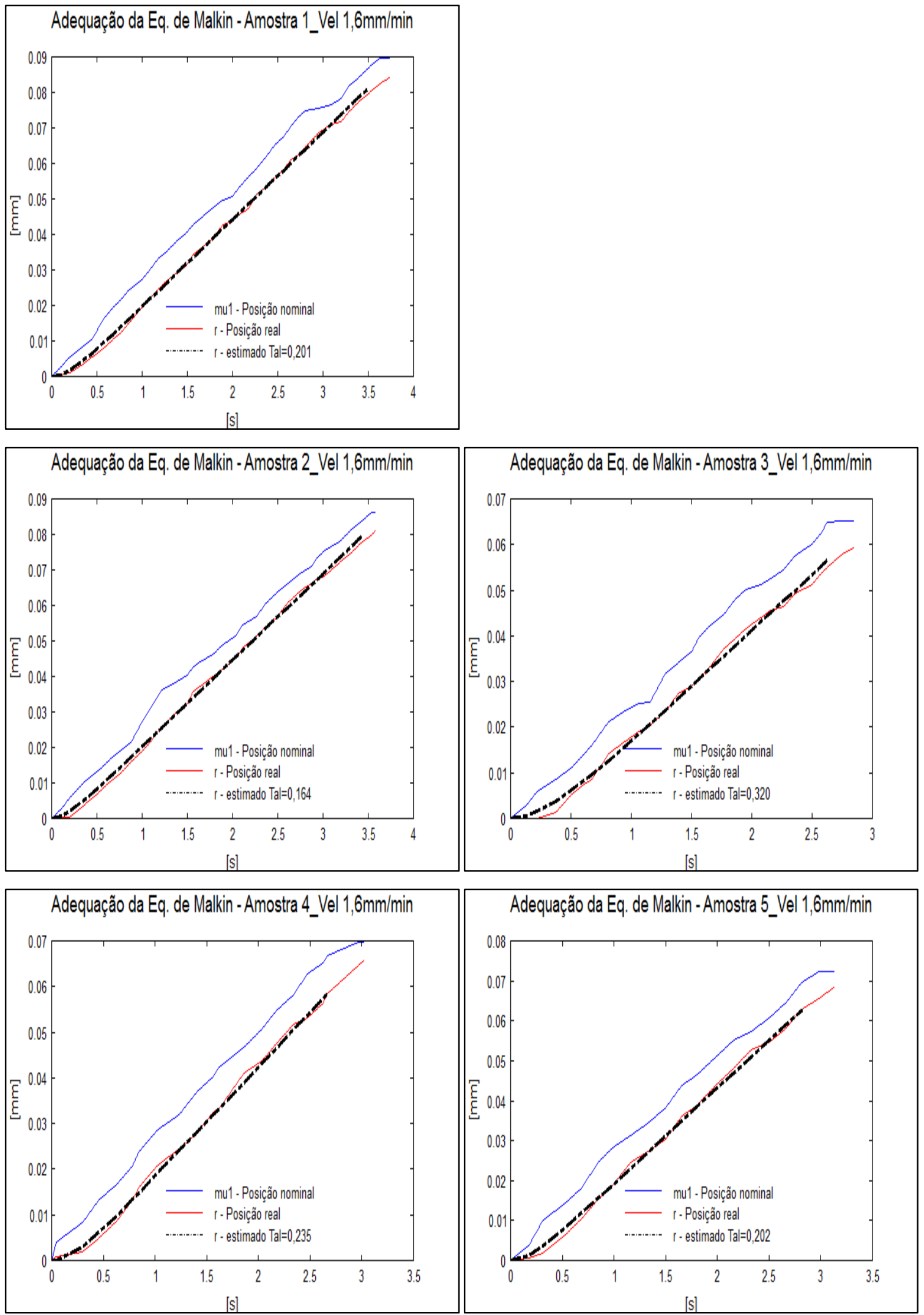

Gráfico 11 - Curvas Experimentais MatLab ${ }^{\circledR}-$ Vel. de mergulho = 1,6mm $/ \mathrm{min}$. 
Curvas experimentais velocidade de mergulho $=0,8 \mathrm{~mm} / \mathrm{min}$. - amostras 1 a 5 :
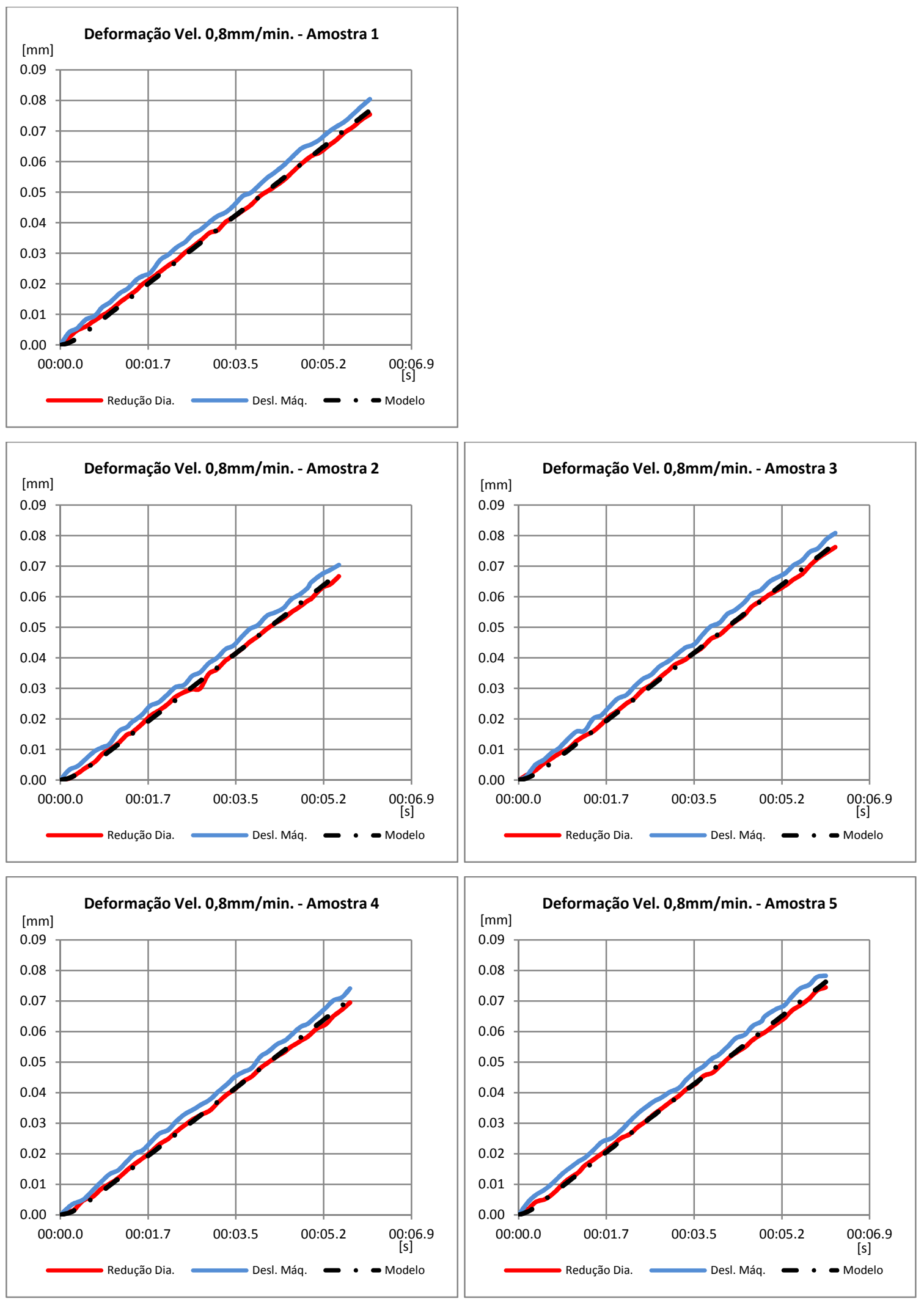

Gráfico 12 - Curvas Experimentais Excel ${ }^{\circledR}-$ Vel. de mergulho $=0,8 \mathrm{~mm} / \mathrm{min}$. 
Ajuste das curvas experimentais MatLab ${ }^{\circledR}$ velocidade de mergulho $=0,8 \mathrm{~mm} / \mathrm{min}$. - amostras 1 a 5:
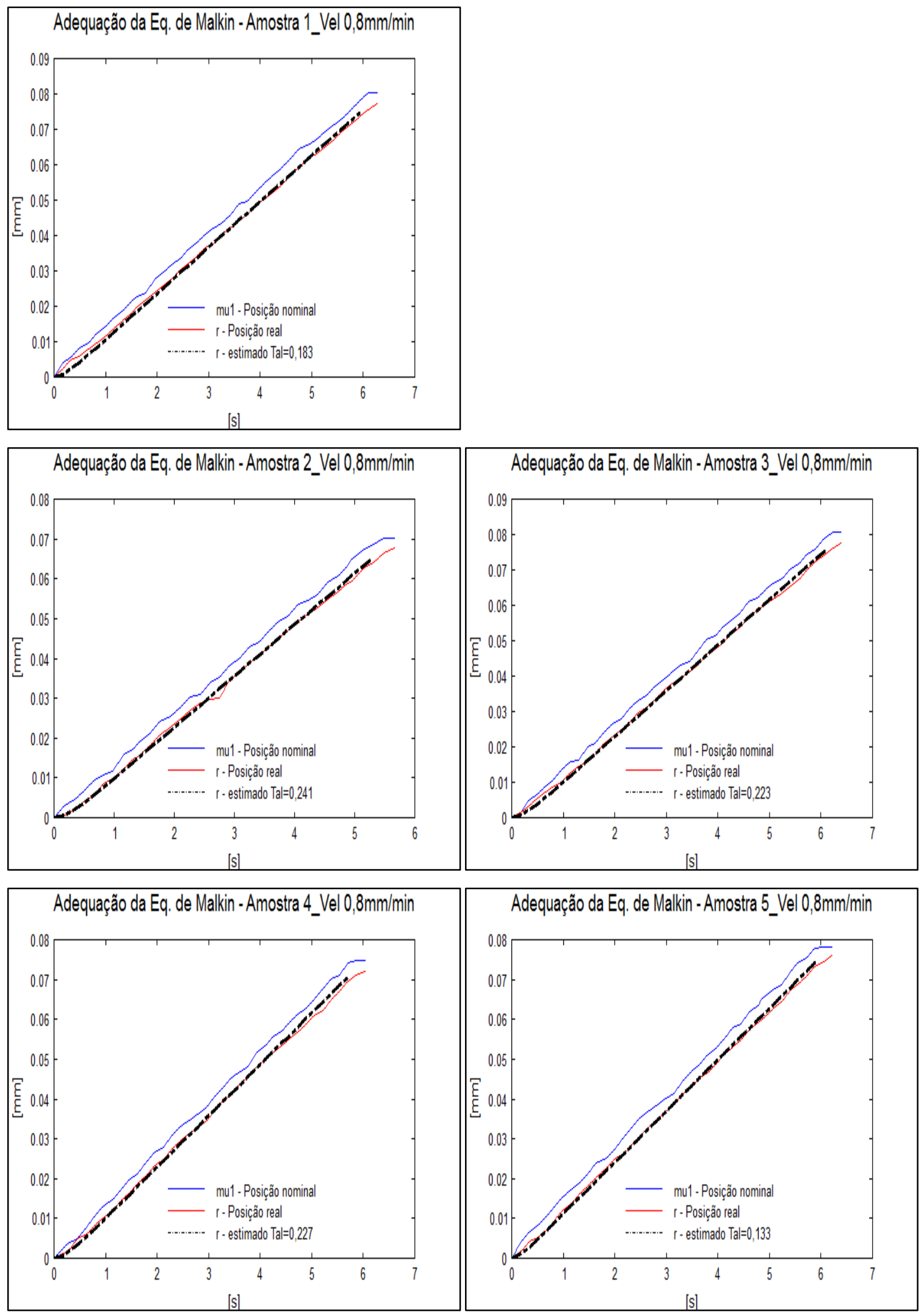

Gráfico 13 - Curvas Experimentais MatLab ${ }^{\circledR}-$ Vel. de mergulho = 0,8mm $/ \mathrm{min}$. 
Curvas experimentais velocidade de mergulho $=0,08 \mathrm{~mm} / \mathrm{min}$. - amostras 1 a 5 :
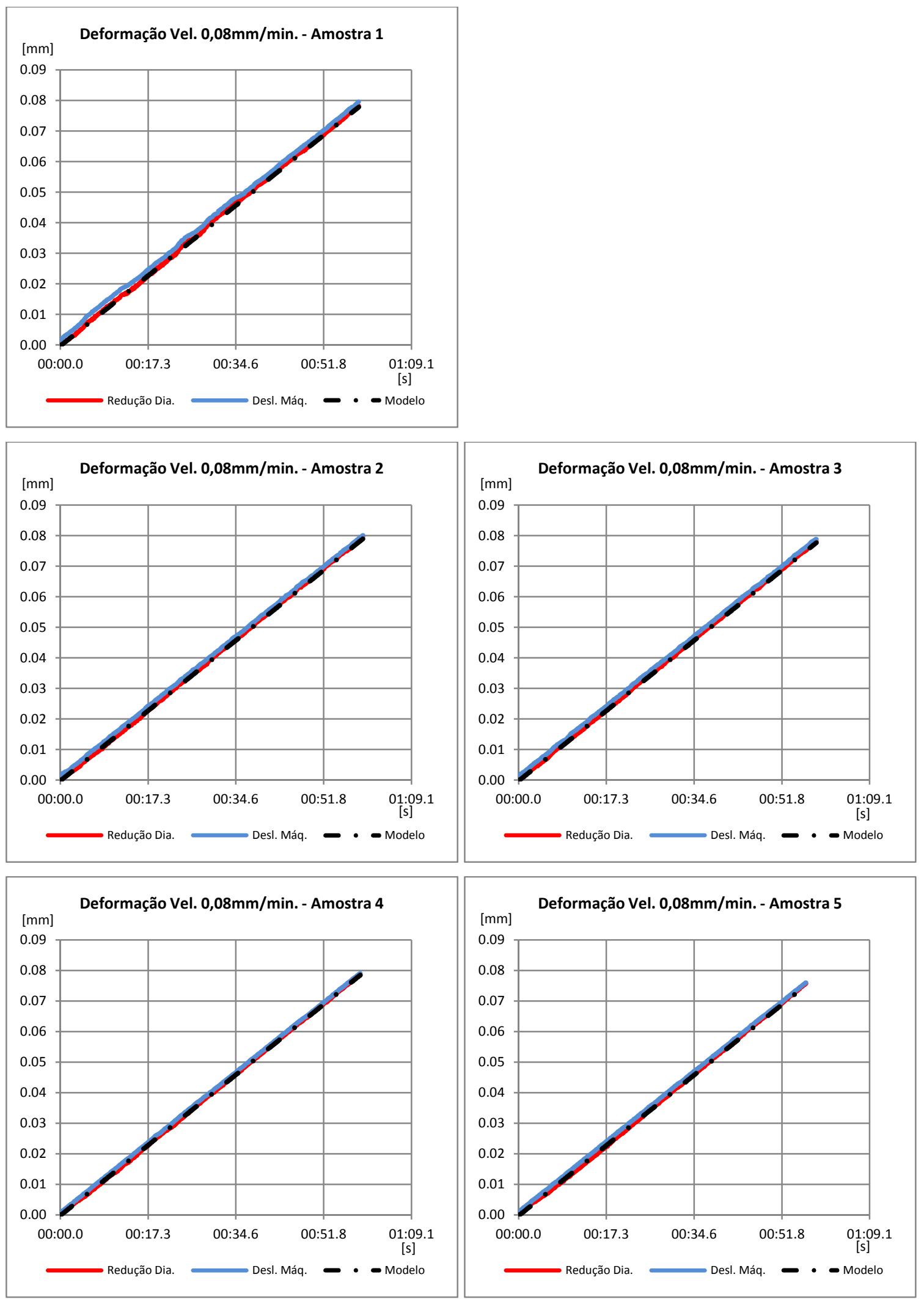

Gráfico 14 - Curvas Experimentais Excel ${ }^{\circledR}-$ Vel. de mergulho = 0,08mm/min. 
Ajuste das curvas experimentais MatLab ${ }^{\circledR}$ velocidade de mergulho $=0,08 \mathrm{~mm} / \mathrm{min}$. - amostras 1 a 5 :
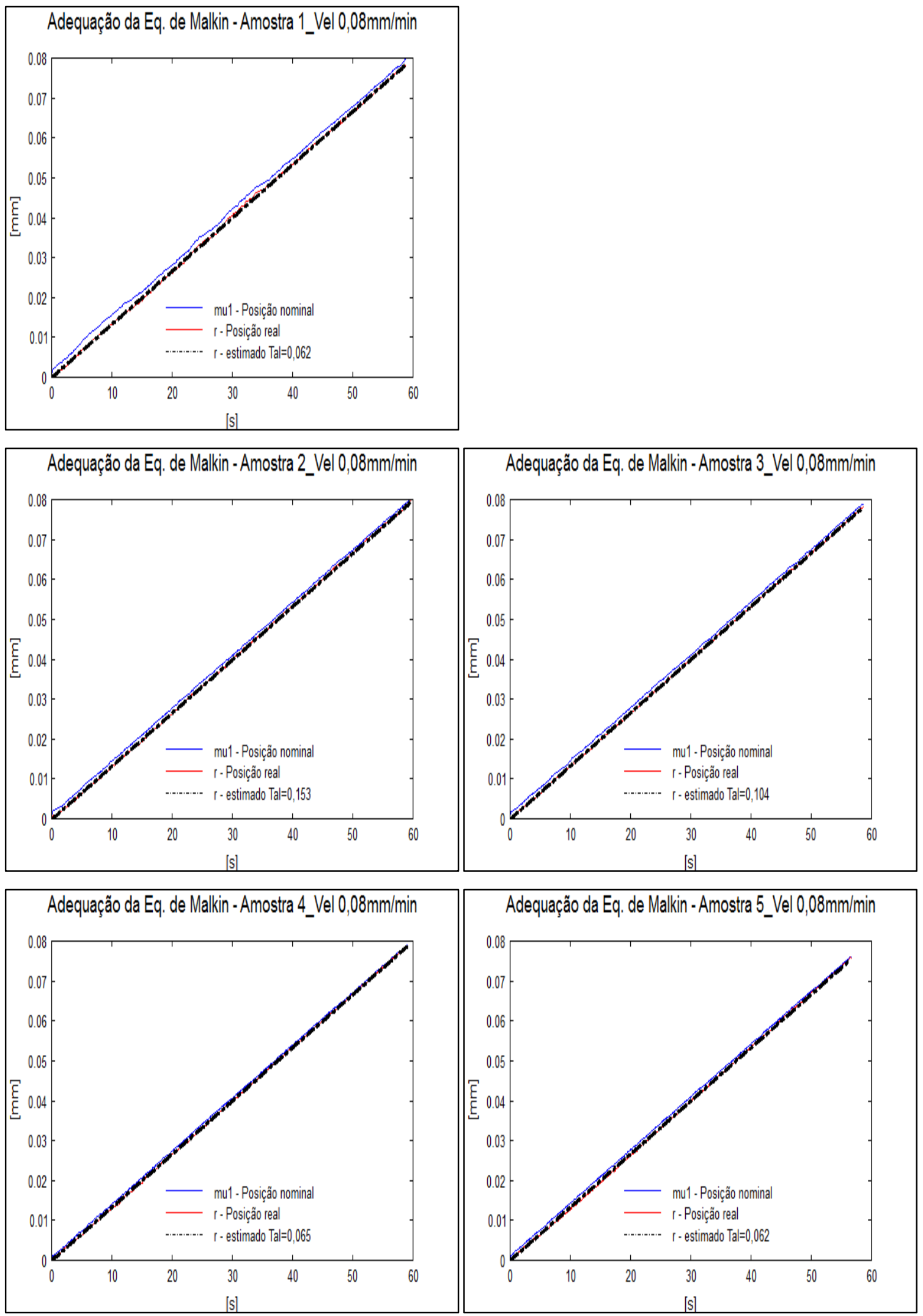

Gráfico 15 - Curvas Experimentais MatLab ${ }^{\circledR}$ - Vel. de mergulho $=0,08 \mathrm{~mm} / \mathrm{min}$. 


\subsection{Experimento2: Avaliação do tempo de centelhamento}

Partindo-se do equacionamento de Malkin e Guo (2008) apresentado no Capítulo 2, do método prático proposto por Rossi (2009) e adicionando o modelamento descrito no Capítulo 3 deste trabalho, são comparados os resultados teóricos do modelo com os resultados práticos obtidos nos experimentos. Buscou-se definir o menor tempo de centelhamento necessário para que as deformações do sistema MRP sejam absorvidas e o diâmetro objetivo alcançado.

Os parâmetros de processos adotados para os experimentos foram apresentados na Tabela 2. O procedimento para obtenção do $\tau$ foi o mesmo descrito no item 5.5 deste trabalho. A seguir será apresentado um exemplo de aplicação da Equação (51) com velocidade de mergulho de $2,5 \mathrm{~mm} / \mathrm{min}$. e $\tau$ de $0,204 \mathrm{~s}$. A Tabela 7 mostra os dados coletados no processo de retificação para deslocamento e diâmetro da peça e os dados de redução de diâmetros calculados a partir das Equações (34) e (51), para o desbaste e centelhamento, respectivamente.

Tabela 7 - Dados calculados deformação sistema MRP

\begin{tabular}{|c|c|c|c|c|}
\hline $\begin{array}{c}{[s]} \\
t \\
\text { tempo }\end{array}$ & $\begin{array}{c}\text { [mm] } \\
\mathbf{u 1} \\
\text { Desl. Eixo X }\end{array}$ & $\begin{array}{c}\text { [mm] } \\
\text { Equação (34) } \\
\text { Redução Dia. } r(t)\end{array}$ & $\begin{array}{c}\quad[\mathrm{mm}] \\
\text { Equação }(51) \\
\text { Modelo } r_{2}(t)\end{array}$ & $\begin{array}{c}\text { [mm] } \\
\text { Sobremetal } \\
\text { Centelham. }\end{array}$ \\
\hline 0 & 0.0000 & 0.0000 & 0.0748 & 0.0085 \\
\hline 0.1 & 0.0042 & 0.0009 & 0.0781 & 0.0052 \\
\hline 0.2 & 0.0083 & 0.0030 & 0.0801 & 0.0032 \\
\hline 0.3 & 0.0125 & 0.0060 & 0.0814 & 0.0020 \\
\hline 0.4 & 0.0167 & 0.0094 & 0.0821 & 0.0012 \\
\hline 0.5 & 0.0208 & 0.0131 & 0.0826 & 0.0007 \\
\hline 0.6 & 0.0250 & 0.0169 & 0.0829 & 0.0004 \\
\hline 0.7 & 0.0292 & 0.0209 & 0.0831 & 0.0003 \\
\hline 0.8 & 0.0333 & 0.0250 & 0.0832 & 0.0002 \\
\hline 0.9 & 0.0375 & 0.0291 & 0.0832 & 0.0001 \\
\hline 1 & 0.0417 & 0.0332 & 0.0833 & 0.0000 \\
\hline 1.1 & 0.0458 & 0.0374 & 0.0833 & 0.0000 \\
\hline 1.2 & 0.0500 & 0.0415 & 0.0833 & 0.0000 \\
\hline 1.3 & 0.0542 & 0.0457 & 0.0833 & 0.0000 \\
\hline 1.4 & 0.0583 & 0.0498 & 0.0833 & 0.0000 \\
\hline 1.5 & 0.0625 & 0.0540 & 0.0833 & 0.0000 \\
\hline 1.6 & 0.0667 & 0.0582 & 0.0833 & 0.0000 \\
\hline 1.7 & 0.0708 & 0.0623 & 0.0833 & 0.0000 \\
\hline 1.8 & 0.0750 & 0.0665 & 0.0833 & 0.0000 \\
\hline 1.9 & 0.0792 & 0.0707 & 0.0833 & 0.0000 \\
\hline 2 & 0.0833 & 0.0748 & 0.0833 & 0.0000 \\
\hline
\end{tabular}


A coluna tempo corresponde à taxa de aquisição do sistema para velocidade de mergulho de 2,5mm/min. A partir desses dados aplicou-se a Equação (34) de Malkin e Guo (2008) e calculou-se a defasagem da redução diametral durante a fase de desbaste em função do tempo. No exemplo da Tabela 7, tem-se para o instante $2 \mathrm{~s}$ a posição do eixo X em 0,0833 mm e a posição obtida na Equação (34) é 0,0748 mm. Para o estágio de centelhamento, aplicou-se a Equação (51). No instante 0s tem-se o valor de 0,0748 mm. Considerando-se a posição final do eixo $\mathrm{X}$ em 0,0833mm, calcula-se a diferença entre ambas, que corresponde a 0,0085 $\mathrm{mm}$ de deformação do sistema MRP, expresso na coluna de "sobremetal centelham.”. O Gráfico 16 representa curvas típicas para deformação do sistema MRP construídas a partir do modelo proposto.

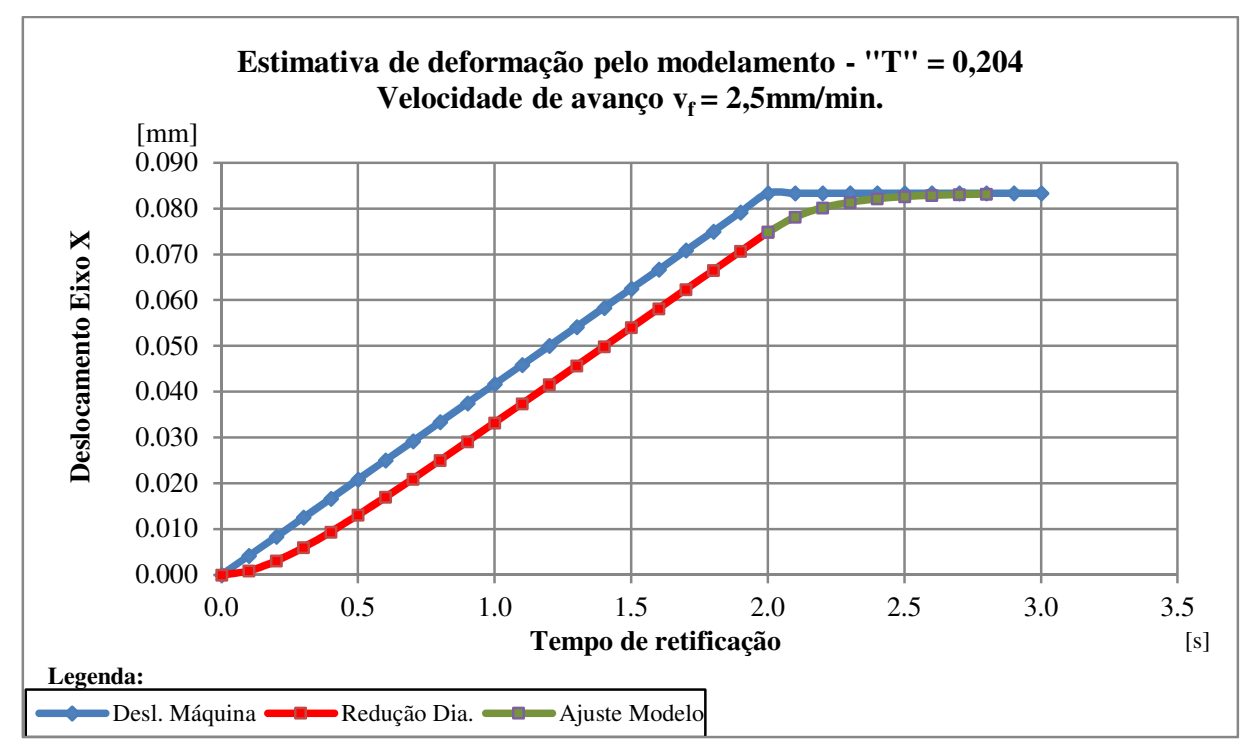

Gráfico 16 - Curvas teóricas de deformação do sistema MRP.

Considerando-se a deformação do sistema MRP calculado pela Equação (34) e o mínimo tempo de centelhamento necessário calculado pela Equação (51) obteve-se o Gráfico 17 de variação diametral da peça. Nele, observa-se o decréscimo de redução diametral com o decorrer do tempo de centelhamento. Observa-se que o mínimo tempo de centelhamento necessário para que a deformação do ciclo de desbaste possa ser suprimida é de 1,0 s. Esse valor é válido para a constante de tempo $\tau=0,204$ (característica do sistema MRP em questão) e a velocidade de mergulho de $2,5 \mathrm{~mm} / \mathrm{min}$ adotada. 


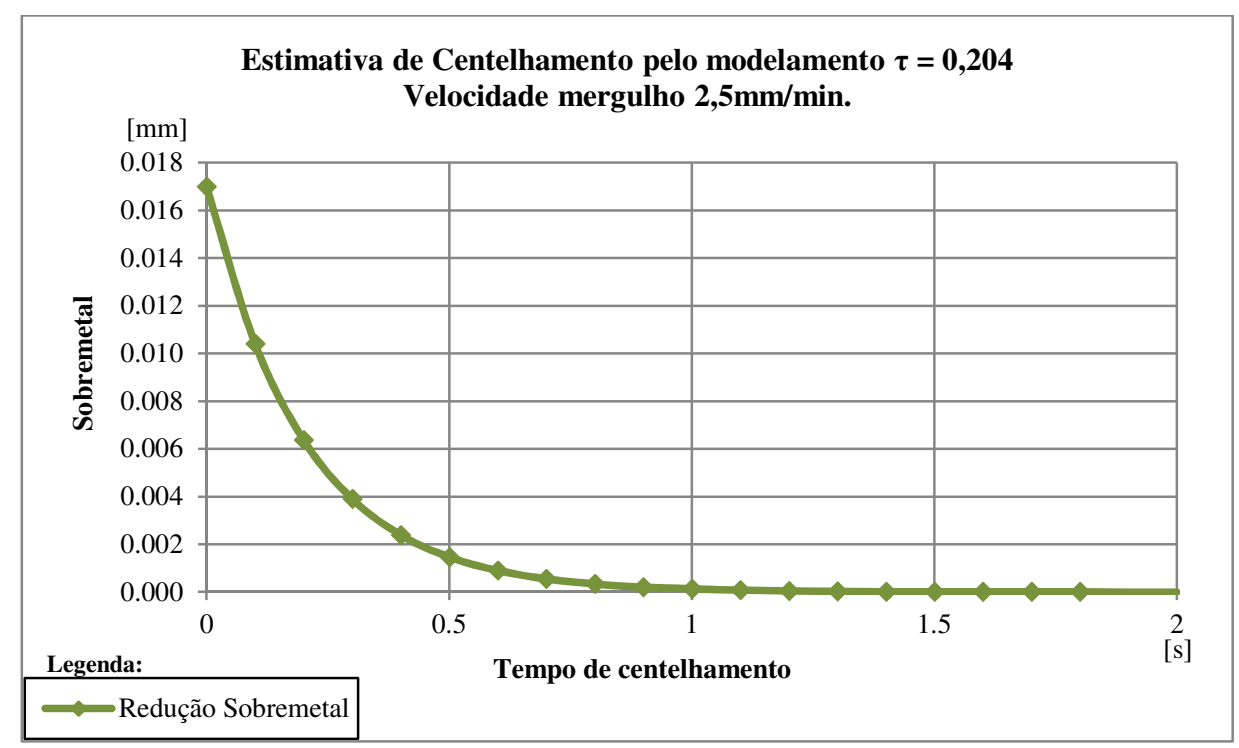

Gráfico 17 - Curva teórica - Tempo mínimo de centelhamento. 


\subsection{Experimento 1: Determinação dos valores de $\tau \times v_{f}$}

Segundo Malkin e Guo (2008) aplicando a Equação (24) seria possível determinar a rigidez da retificadora usando os valores de $\mathrm{F}_{\mathrm{v}}$ e $\mathrm{K}_{\mathrm{e}}$. Esses normalmente não são disponíveis e o caminho escolhido foi determinar experimentalmente a faixa de valores correspondentes ao $\tau$ através de medições em processo do diâmetro real versus deslocamento do eixo durante a fase de desbaste.

$\tau \equiv \frac{F_{v}}{k_{e}}$

O procedimento de ensaio foi descrito no capítulo 5, itens 5.1 a 5.5 deste trabalho. Os Gráficos 18 (a), 18 (b), 18 (c), 18 (d) e 18 (e) representam curvas características de deslocamento do eixo X da máquina e redução diametral para velocidades de mergulho de 3,0, 2,5, 1,6, 0,8 e $0,08 \mathrm{~mm} / \mathrm{min}$. com 30 repetições.

(a)

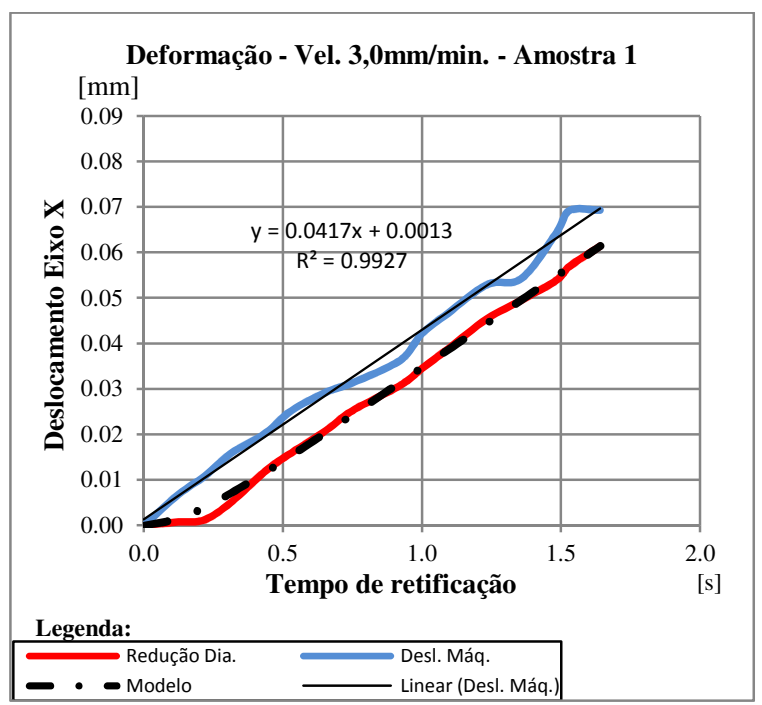

(b)

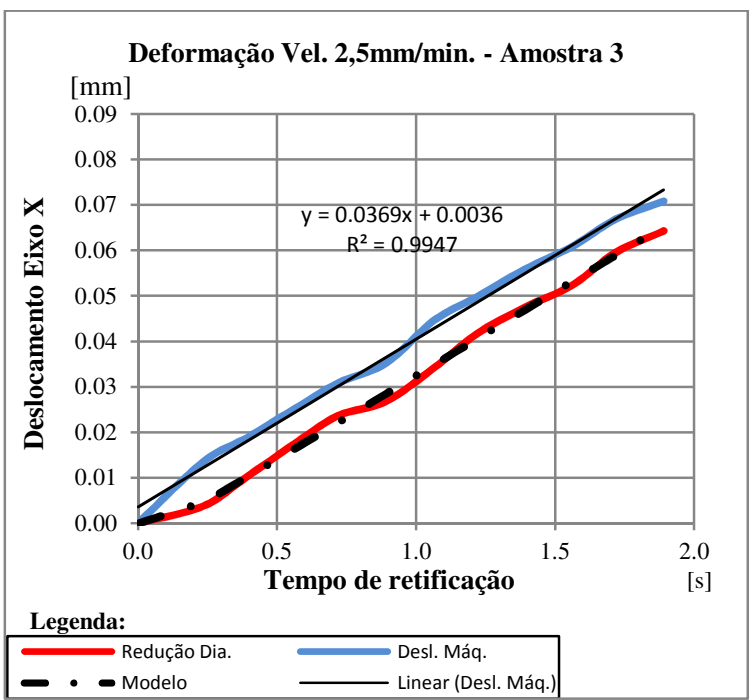


(c)

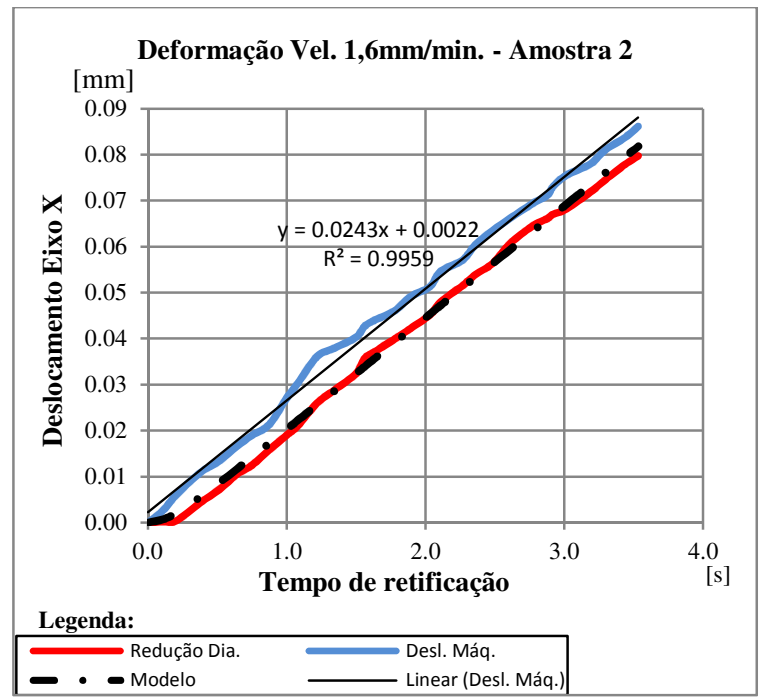

(e)

- - Modelo

(Desl. Máq.)

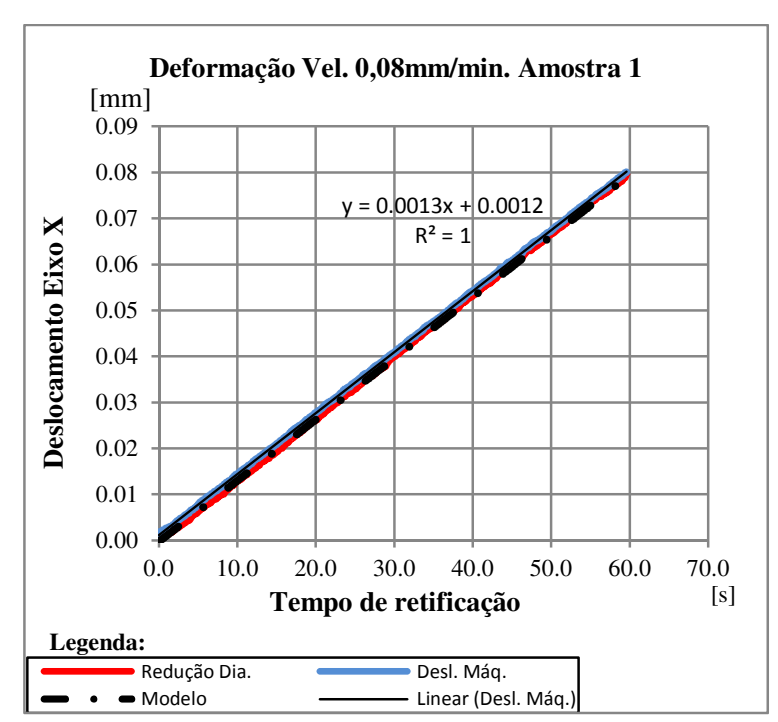

(d)

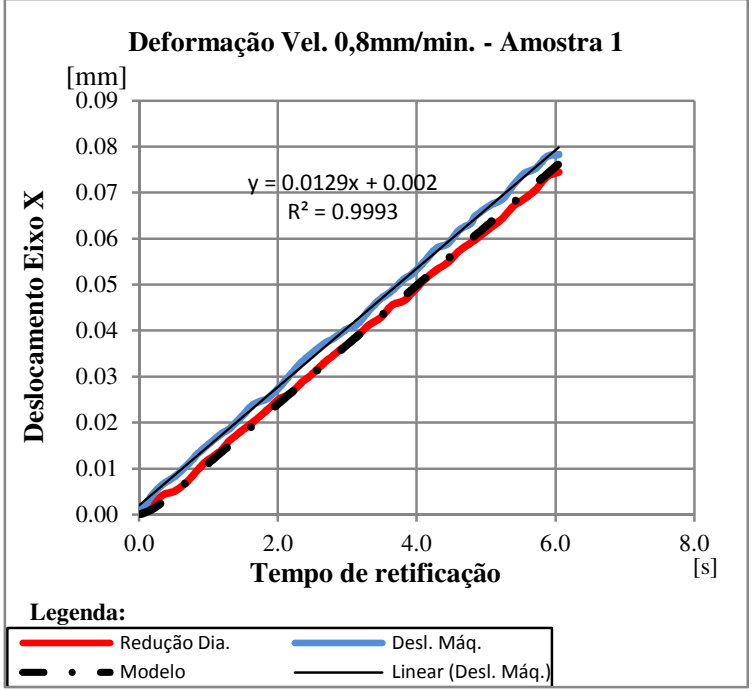

- - Modelo L Linear (Desl. Máq.

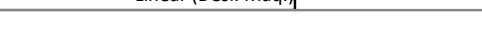

Gráfico 18 - Ciclo convencional processo usinagem - Veloc. de mergulho = 3, 2,5, 1,6, 0,8 e 0,08 mm/min.

Diante desses dados pode-se observar que durante o movimento de mergulho da retificadora, o eixo X não se desloca linearmente no tempo. Esse fato sugere uma variação de velocidade de mergulho mais acentuadamente para os valores das velocidades de 3,0, 2,5, e 1,6 mm/min. Para que o modelo de Malkin e Guo (2008) seja válido, é necessário que a velocidade de deslocamento do eixo X, neste caso $u_{1}$, seja constante. Desta forma, considerouse a velocidade média encontrada em todos os pontos de aquisição do deslocamento do eixo X. Esse procedimento para tratamento dos dados foi descrito no item 5.4, sendo utilizada a técnica de mínimos quadrados para ajustar uma reta às curvas de deslocamento no tempo, durante a fase de desbaste. 
Após a determinação dos valores de $\tau$ para cada velocidade de mergulho, considerando 30 repetições para cada velocidade de mergulho, exceto para velocidade de $0,08 \mathrm{~mm} / \mathrm{min}$. que foi coletado 5 repetições devido ao tempo de recuperação da deformação elástica ser muito próximo ao tempo de deslocamento do eixo. Os intervalos de confiança para $95 \%$ foram calculados e demonstrados no Gráfico 19.

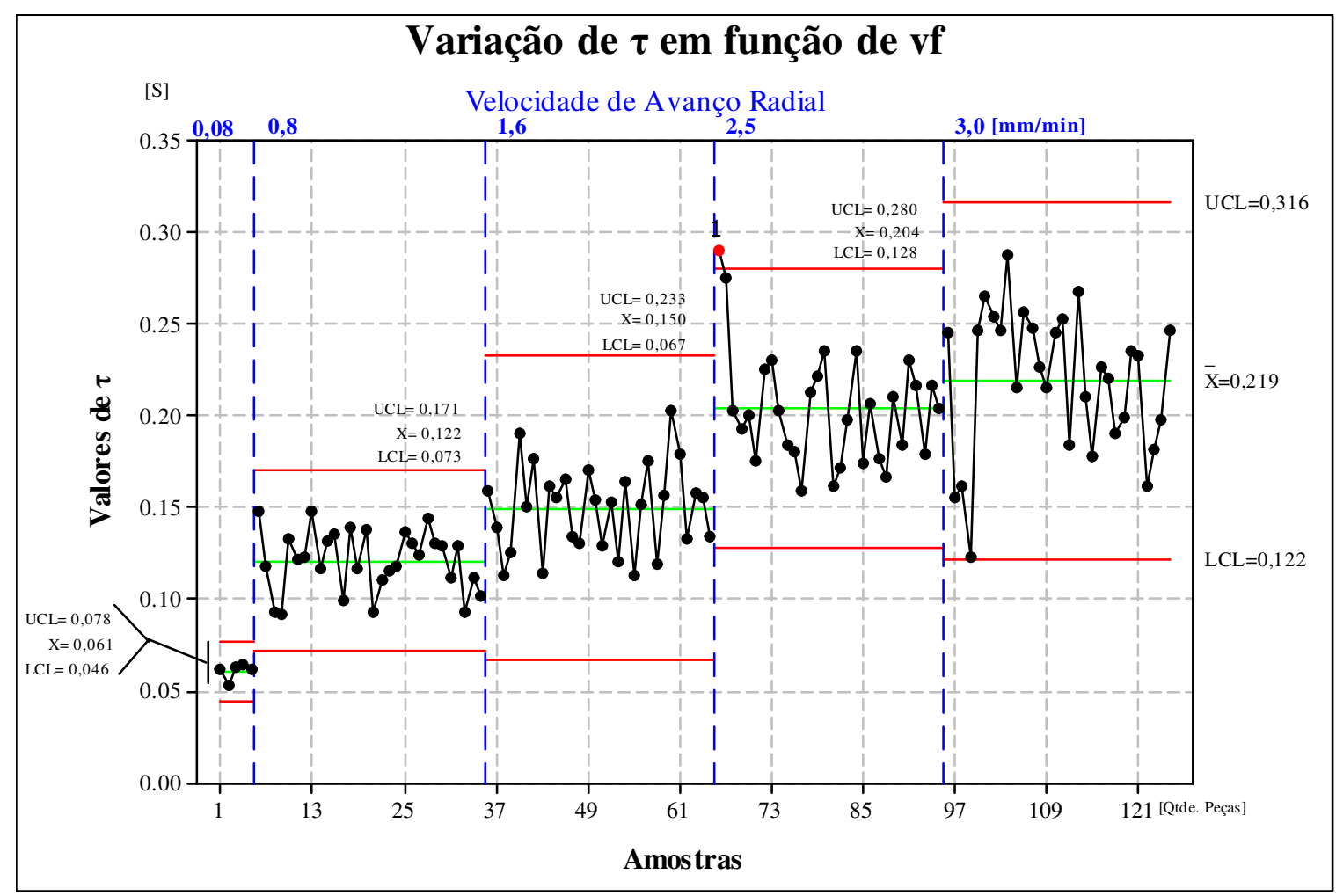

Gráfico 19 - Valores de $\tau$ para Veloc. de mergulho $=3,2,5,1,6,0,8$ e $0,08 \mathrm{~mm} / \mathrm{min}$.

O Gráfico 19 representa a variação do $\tau$ para as velocidades de mergulho $0,08,0,8,1,6$, 2,5 e 3,0 $\mathrm{mm} / \mathrm{min}$. As linhas indicadas em vermelho no gráfico situadas acima e abaixo de cada velocidade representam os limites de controle considerando 3 desvios padrões acima e abaixo da linha média. Para velocidade de $0,08 \mathrm{~mm} / \mathrm{min}$. os limites inferior e superior de controle foram de 0,046 e $0,078 \mathrm{~s}$ respectivamente e o $\tau$ médio de $0,061 \mathrm{~s}$. Um valor de $\tau$ baixo indica uma retificadora muito rígida, ou seja, para velocidades de avanço muito baixas para o sistema MRP em questão, praticamente não há atraso de tempo entre o deslocamento do eixo e o diâmetro especificado da peça. Tal fato já havia sido mencionado por Rossi (2009), ou seja, uma variação na rigidez do sistema, com faixas de avanço para as quais a máquina poderia apresentar um comportamento mais rígido, decorrente de suas características construtivas. 
A velocidade de mergulho de $0,8 \mathrm{~mm} / \mathrm{min}$ apresentou como limites de controles inferior e posterior 0,073 e $0,171 \mathrm{~s}$ com $\tau$ médio de $0,122 \mathrm{~s}$. Para velocidade de mergulho de 1,6 os limites inferior e posterior são 0,067 e 0,233 respectivamente com $\tau$ médio de 0,150 s. A velocidade de mergulho de $2,5 \mathrm{~mm} / \mathrm{min}$ apresentou limites inferior e superior de 0,128 e 0,280 s respectivamente e $\tau$ médio de $0,204 \mathrm{~s}$. Já à velocidade de mergulho $3,0 \mathrm{~mm} / \mathrm{min}$ tem seus limites inferior de 0,122 e superior de 0,316 e $\tau$ médio de $0,219 \mathrm{~s}$, de acordo com o método proposto de medição neste trabalho: modelo de Malkin e Guo (2008).

Malkin e Guo (2008) também modelaram o sistema MRP como um sistema dinâmico de primeira ordem, onde não se leva em conta uma constante relativa à velocidade de mergulho. Neste modelo, a constante de tempo $\tau$ é independente da velocidade. Tal limitação do modelo fica evidente quando se usam velocidades de avanço muito distintas. Se as faixas de velocidades de mergulho fossem mais restritas, os valores de $\tau$ teriam menores variações.

Segundo Rossi (2009), existe relação proporcional entre a velocidade de mergulho e a deformação que o mesmo sistema MRP apresenta. Isto pode ser observado para velocidade de mergulho de $0,8 \mathrm{~mm} / \mathrm{min}$, onde $\tau$ médio é de $0,122 \mathrm{~s}$ e para velocidade de $3,0 \mathrm{~mm} / \mathrm{min}$, onde o $\tau$ médio é $0,219 \mathrm{~s}$.

De acordo com o modelo de Malkin e Guo (2008) o valor de $\tau$ deveria estar entre 0,5 e 1 $\mathrm{s}$ tipicamente, mas isto pode variar de acordo com a rigidez efetiva do sistema $k_{e}$. Quanto maior for o $\tau$ maior será a deformação, pois indica um sistema MRP menos rígido. Com base nos resultados do Experimento 1, o sistema MRP em questão é mais rígido, estando abaixo da faixa considerada por Malkin e Guo (2008).

\subsection{Experimento2: Avaliação do centelhamento}

Os Gráficos 20 (a), 20 (b), 20 (c) e 20 (d) representam curvas típicas do ciclo de retificação para o sistema MRP com velocidade de mergulho de 3,0, $\mathrm{mm} / \mathrm{min}$ e tempo de centelhamento de $0,0,6,1$ e $2 \mathrm{~s}$. As demais curvas para as velocidades de mergulho 2,5, 1,6 e 0,8, ajustes do MatLab ${ }^{\circledR}$ e Excel $^{\circledR}$ estão no “Apêndice II" deste trabalho. 
(a)

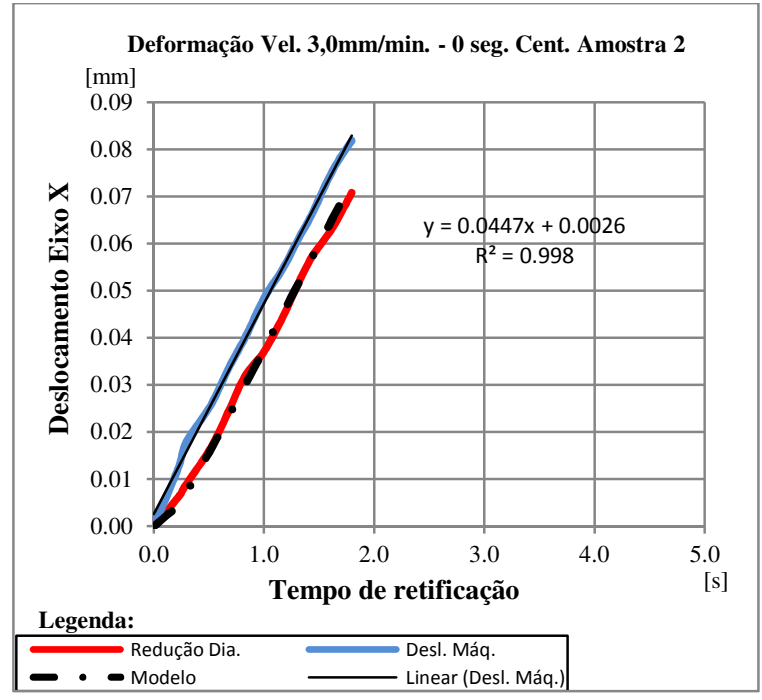

(c)

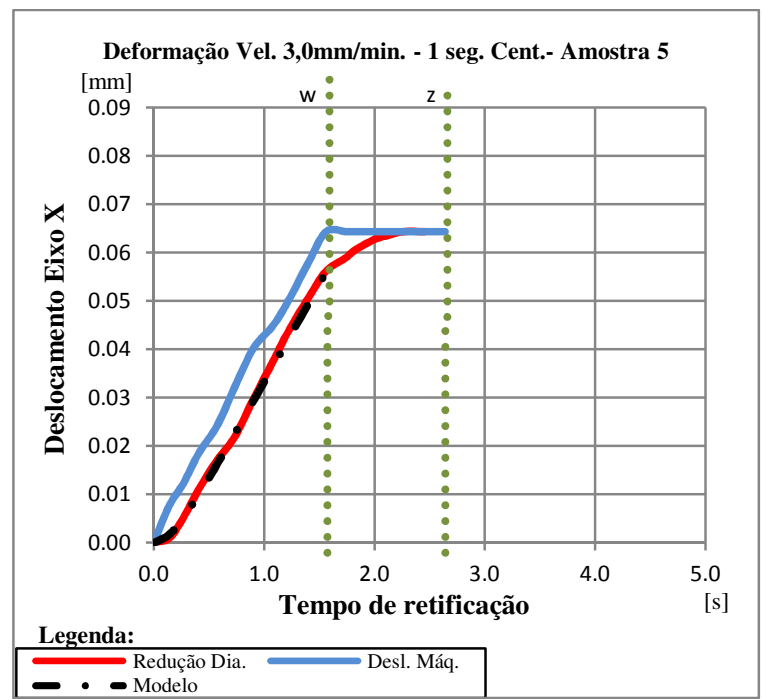

(b)

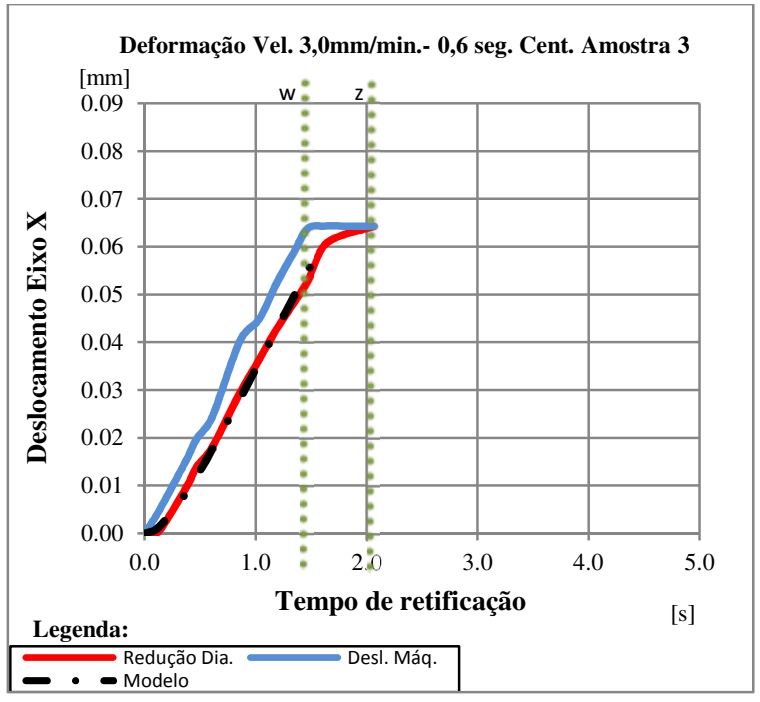

(d)

Gráfico 20 - Ciclo convencional processo usinagem - velocidade de mergulho $=3,0 \mathrm{~mm} / \mathrm{min}$.

As retas pontilhadas $w$ e $z$, indicadas nos Gráficos 20 (b), 20 (c) e 20 (d), representam, respectivamente, o início e o fim do tempo de centelhamento para cada ensaio. No Gráfico 20 (a) observa-se que o tempo de centelhamento $0 \mathrm{~s}$ foi insuficiente para que as deformações do sistema MRP fossem absorvidas. Os Gráficos 20 (b), 20 (c) e 20 (d) representam tempo de centelhamento de 0,6, 1 e 2 segundos, respectivamente. Nestes casos, observa-se que 0,6 segundo de centelhamento foi insuficiente para absorver as deformações; já o tempo de 2 segundos de centelhamento foi excessivo.

Os Gráficos 21 (a) e 21 (b) representam, respectivamente, a medição do ciclo de retificação do Experimento 2 e a estimativa do ciclo de retificação com o tempo mínimo para 
centelhamento. Essa análise foi realizada de acordo com o modelo apresentado no Capítulo 3, Equação (51) deste trabalho.

$r_{2}(t)=-\left(1+e^{\left(\frac{-t 1}{\tau}\right)}\right) * u_{1} * \tau * e^{-\left(\frac{t-t 1}{\tau}\right)}+u_{1} * t_{1}+2 u_{1} * \tau * e^{\left(\frac{-t 1}{\tau}\right)}$

(a)

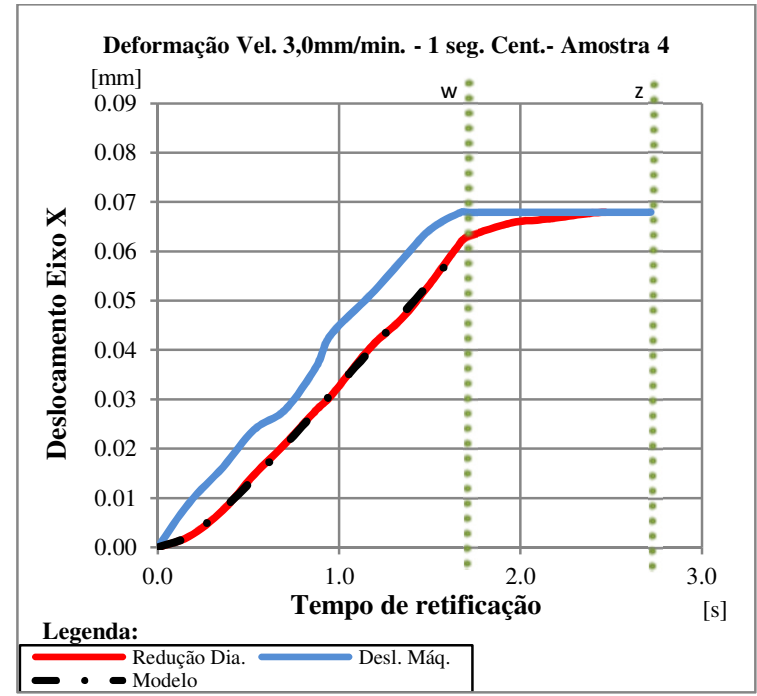

(b)

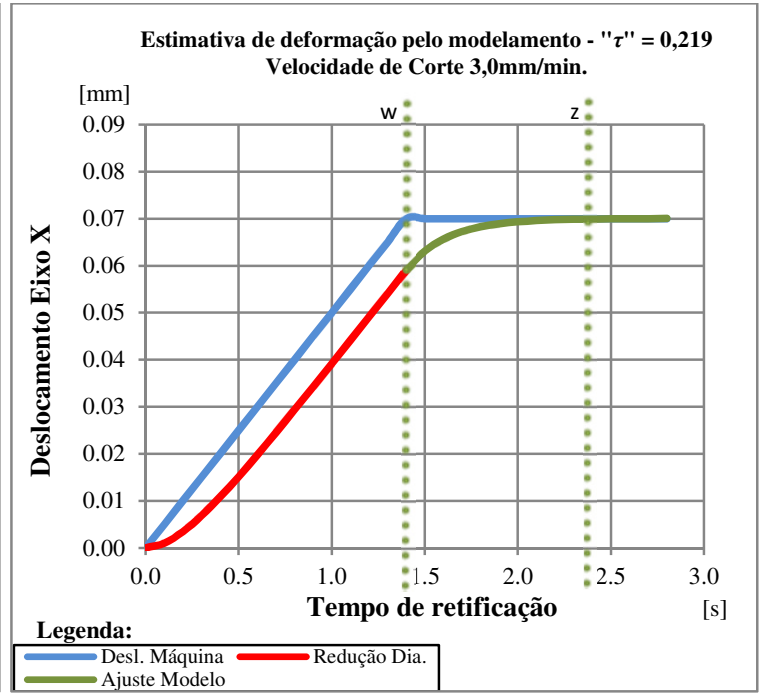

Gráfico 21 - Curvas experimental e teórica do ciclo convencional processo usinagem - velocidade de mergulho $=3,0 \mathrm{~mm} / \mathrm{min}$.

O tempo de centelhamento utilizado no Gráfico 21 (a) foi de 1 s. Esse tempo está delimitado no referido gráfico pela subtração dos trechos $z$ e $w$, correspondendo aos tempos 2,7 e 1,7 s, respectivamente. No marco $z$, as deformações no sistema MRP foram absorvidas. O Gráfico 21 (b) traz a estimativa de deformação do sistema MRP em função do $\tau$ médio adquirido nas 30 repetições (Apêndice II). Aplicando a Equação (51) tem-se também o tempo de 1s para centelhamento como o mínimo necessário para absorver as deformações do sistema MRP. A mesma análise gráfica foi realizada paras as velocidades de mergulho 2,5, 1,6 e $0,8 \mathrm{~mm} / \mathrm{min}$ disponível no Apêndice II deste trabalho.

Malkin e Guo (2008) através da Equação (38) propõem a estimativa de tempo para centelhamento a partir do valor de $\tau$ para um determinado sistema MRP. O Gráfico 22 mostra a comparação dos modelos de Malkin e Guo (2008), a Equação (51) e o resultados experimentais para a velocidade de mergulho $3,0 \mathrm{~mm} / \mathrm{min}$.

$$
r(t)=u_{1} t_{1}-u_{1} \tau \mathrm{e}\left(-\frac{t-t_{1}}{\tau}\right)
$$




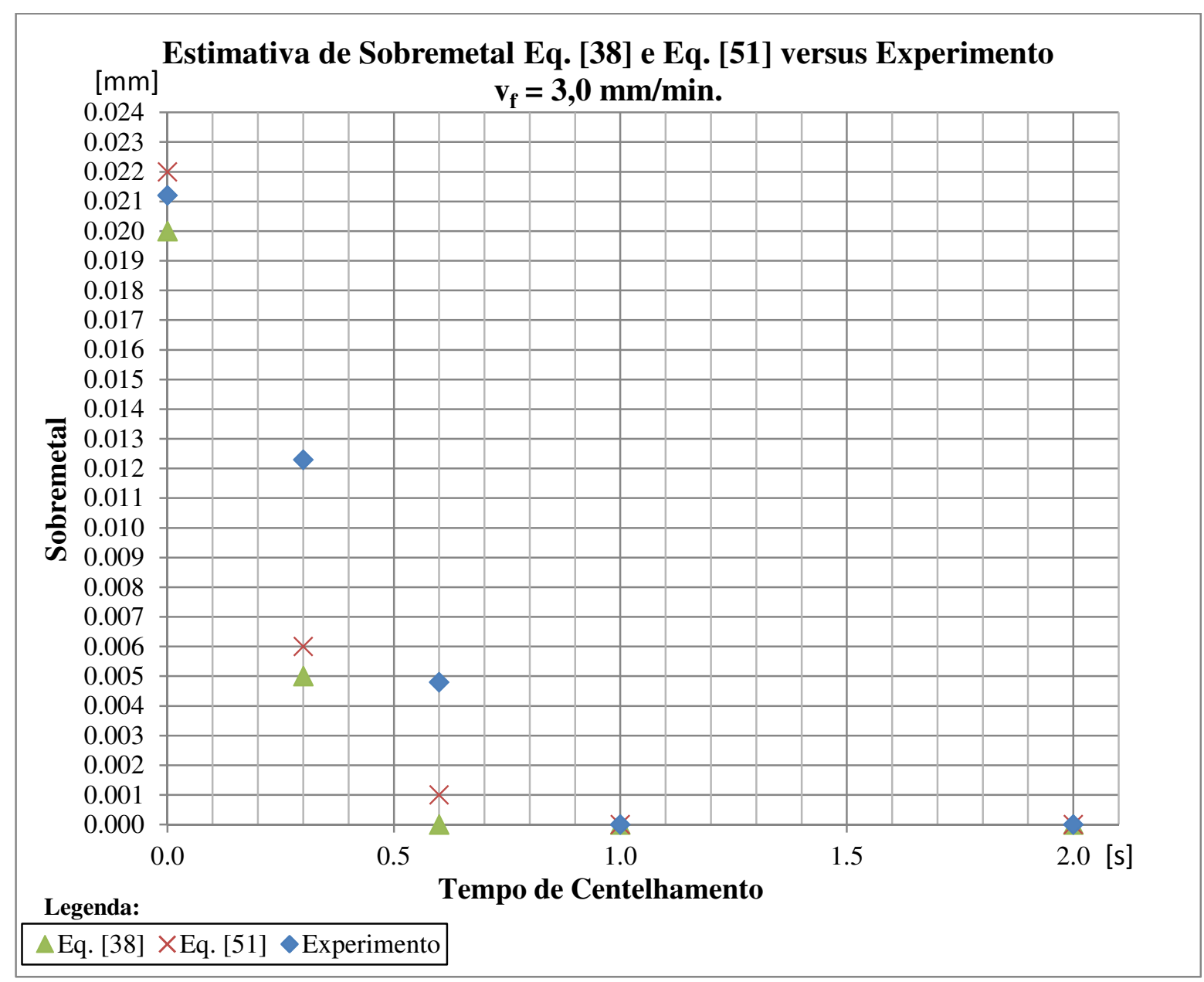

Gráfico 22 - Resultado teórico Equação (38), (51) e Experimento - velocidade de mergulho = 3,0 mm/min.

No Gráfico 22, considerando o tempo de centelhamento $0 \mathrm{~s}$ aplicando Equação (38) o sobremetal na peça é de $0,020 \mathrm{~mm}$, para Equação (51) é de 0,022 e o experimento foi de 0,021 mm. Para os tempos de centelhamentos 0,3 e 0,6 as Equações (38) e (51) mantiveram a diferença de $0,001 \mathrm{~mm}$ entre os resultados com 0,005 e $0,006 \mathrm{~mm}$ e 0,000 e $0,001 \mathrm{~mm}$, respectivamente. As Equações (38), (51) e o experimento, para os instantes 1,0 e 2,0 s de centelhamento apresentaram os mesmos resultados.

Considerando a Equação (38) o processo de retificação poderia ser interrompido no instante 0,6 s, pois as deformações elásticas do sistema MRP teriam sido suprimidas e o diâmetro objetivo da peça atingido. Já para Equação (51) em 0,6 s restam 0,001 mm para ser retificado na peça. Para o tempo de 1 segundo, torna-se excessivo para absorver toda deformação do sistema MRP.

Os sobremetais encontrados na peça para o tempo de 0,0,3 e 0,6 s de centelhamento foram 0,021, 0,012 e 0,005 $\mathrm{mm}$, respectivamente. O Gráfico 23 demonstra os desvios 
encontrados nas Equações (38) e (51) em relação ao dimensional da peça para os tempos de centelhamento de $0,0,3,0,6,1$ e 2 s.

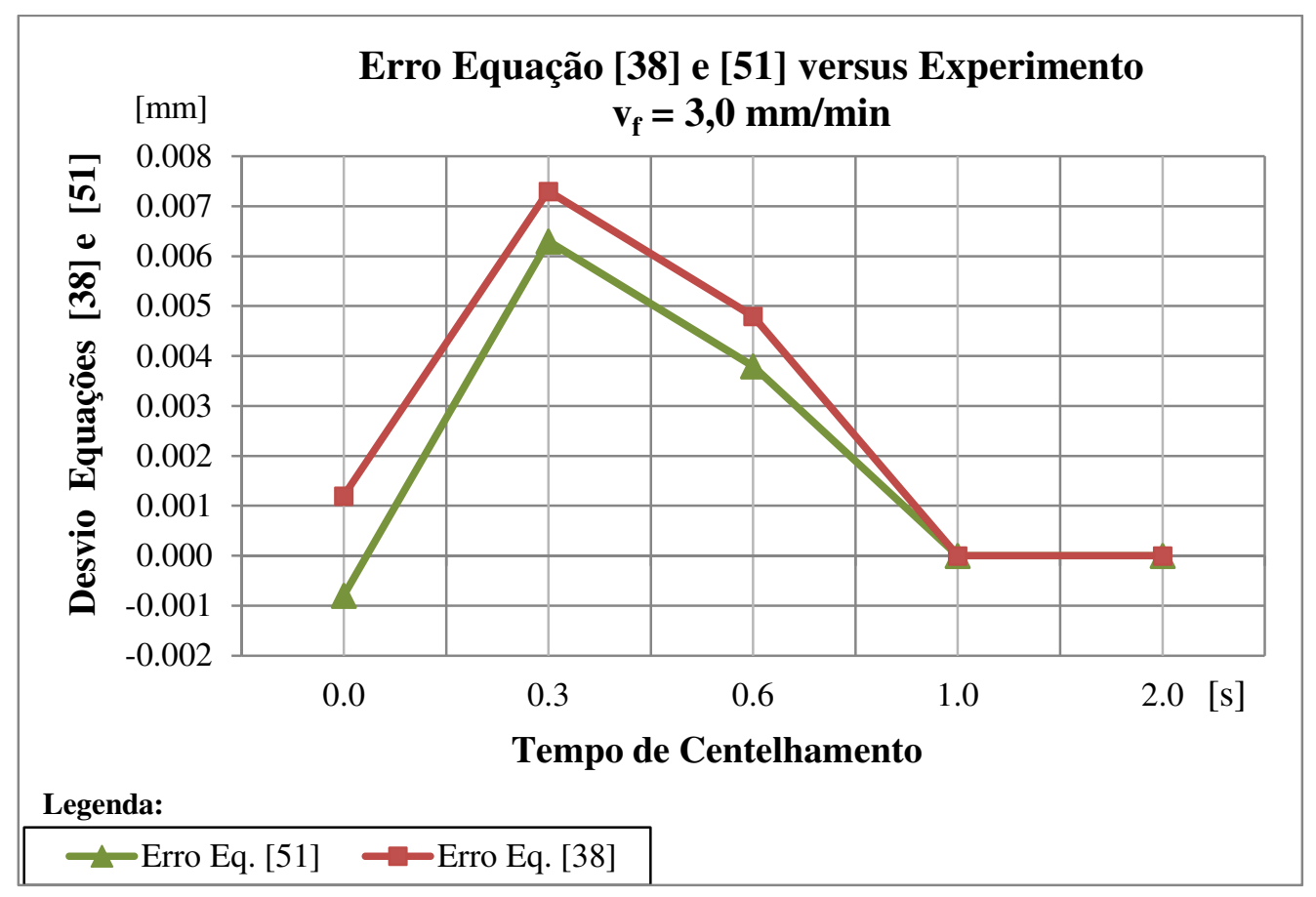

Gráfico 23 - Comparação dos erros entre os modelos Equação (38) e Equação (51) velocidade de mergulho =3,0 mm/min

Para o instantes $0 \mathrm{~s}$ de centelhamento, considerando a velocidade de mergulho 3,0 $\mathrm{mm} / \mathrm{min}$, o erro entre as Equações (38) e (51) foi de 0,001 mm. Nos tempos de 0,3 e 0,6 s de centelhamento, os erros em relação a peça foram de 0,007, 0,006, 0,005 e 0,004 mm para as Equações (38) e (51), respectivamente. A Equação (51) apresenta menor erro em relação a Equação (38) pois aproxima-se mais do valor referência 0 no eixo da ordenada indicado no Gráfico 23. Para os instantes 1 e 2 s de centelhamento, as Equações (38) e (51) em relação a resultado dimensional da peça não apresentaram diferenças, no entanto sabe-se que as deformações do sistema MRP foram absorvidas entre os tempos de 0,6 e $1 \mathrm{~s}$. Como o sistema de aquisição de dados desenvolvido neste trabalho opera a uma taxa de aquisição média de 100 ms, não foi possível determinar experimentalmente o tempo exato em que as deformações do sistema MRP foram absorvidas. A Equação (38) considera que o tempo de 0,6 $\mathrm{s}$ de centelhamento é suficiente para absorção das deformações do sistema MRP, já a Equação (51) indica que 0,6 s é insuficiente para que as deformações elásticas sejam absorvidas.

A mesma análise foi realizada para as velocidades $2,5,1,6$ e $0,8 \mathrm{~mm} / \mathrm{min}$ representadas nos Gráficos 24 a 29. 


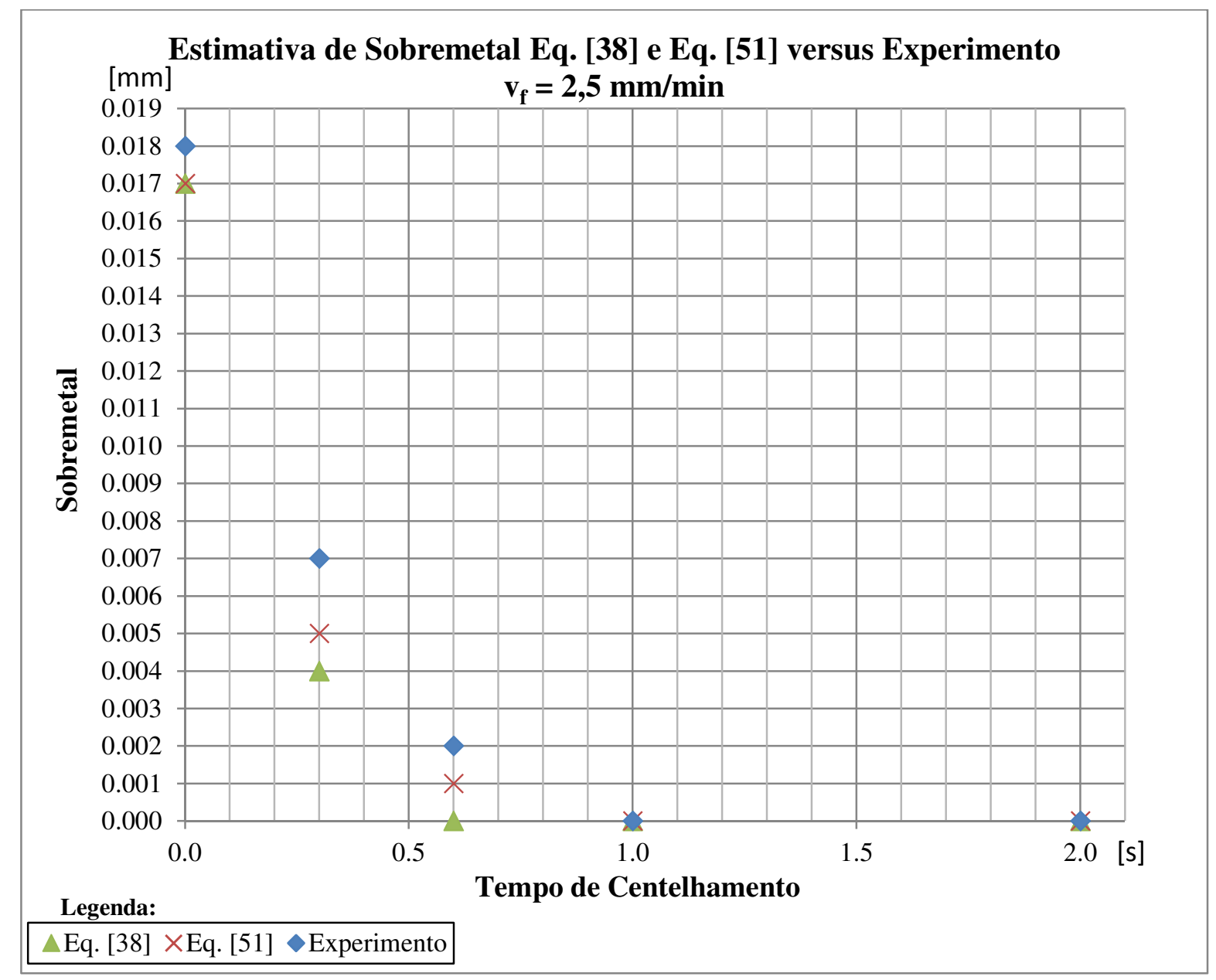

Gráfico 24 - Resultado teórico Equação (38), (51) e Experimento - velocidade de mergulho = 2,5 mm/min.

O Gráfico 24 representa a comparação entre os modelos descritos por Malkin e Guo (2008) Equação (38) e o modelo proposto neste trabalho Equação (51) comparando-os ao resultado experimental encontrado na peça. Para o instante $0 \mathrm{~s}$ de centelhamento as Equações (38) e (51) indicam sobremetal de 0,017 $\mathrm{mm}$ enquanto o dimensional da peça é $0,018 \mathrm{~mm}$. No instante 0,3 s de centelhamento as Equações (38) e (51) apresentaram diferenças entre si em $0,001 \mathrm{~mm}$ com valores de 0,004 e $0,005 \mathrm{~mm}$, respectivamente; já o dimensional da peça indicou sobremetal de 0,007 mm. Para o instante 0,6 s, a Equação (38) representa 0,000 mm de sobremetal indicando que as deformações do sistema MRP foram suprimidas; a Equação (51) indica $0,001 \mathrm{~mm}$ de sobremetal e o dimensional da peça no experimento representa $0,002 \mathrm{~mm}$ de sobremetal. Nos instantes 1 e $2 \mathrm{~s}$ as Equações (38) e (51) e o resultado dimensional da peça no experimento convergem para o $0,000 \mathrm{~mm}$ de sobremetal, indicando que as deformações elásticas do sistema MRP foram suprimidas. 
O Gráfico 25 indica a comparação dos erros encontrados entre as Equações (38) e (51) em relação ao dimensional da peça no experimento para velocidade de mergulho de 2,5 $\mathrm{mm} / \mathrm{min}$.

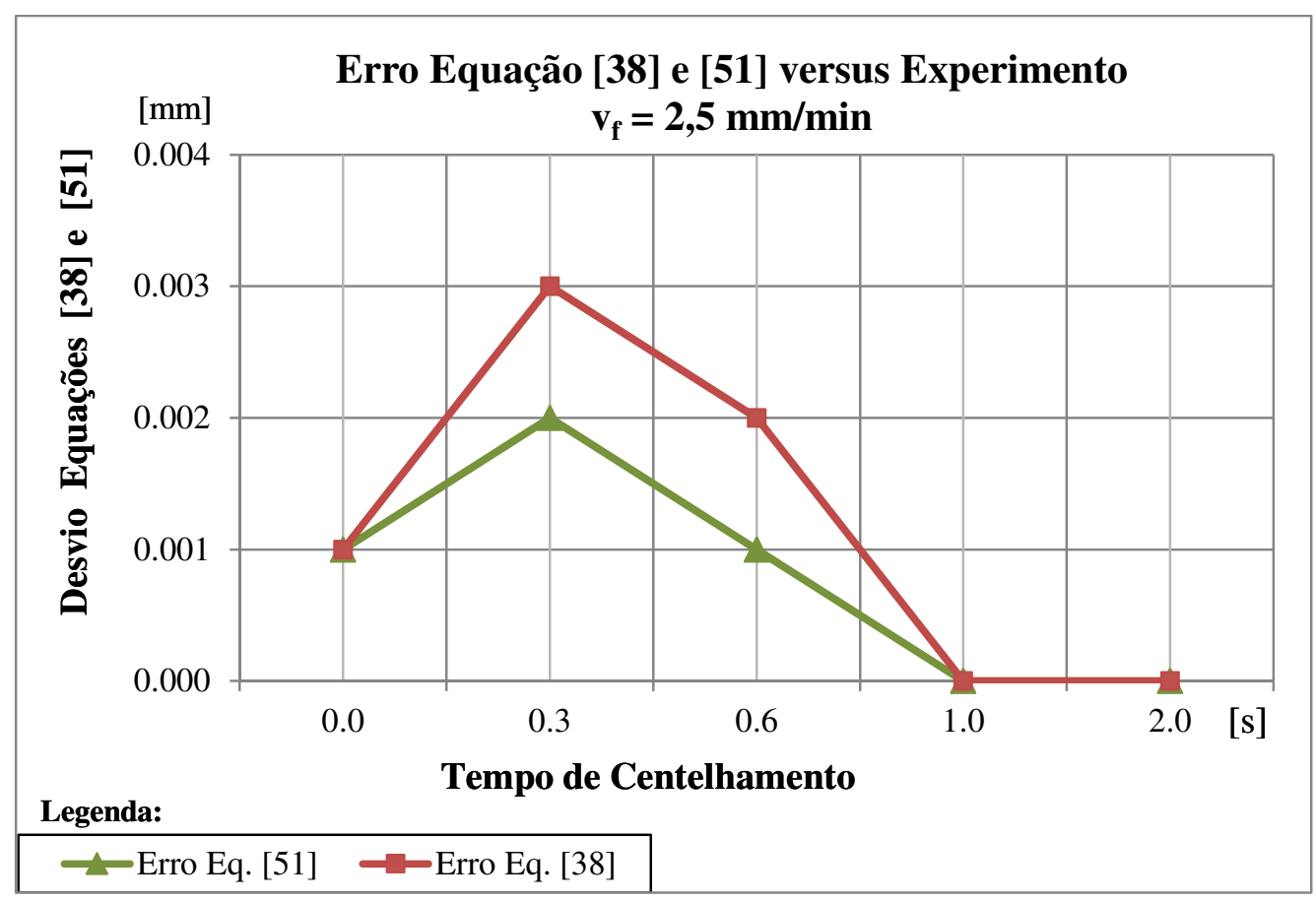

Gráfico 25 - Comparação dos erros entre os modelos Equação (38) e Equação (51) velocidade de mergulho = 2,5 $\mathrm{mm} / \mathrm{min}$

Para o tempo de centelhamento $0 \mathrm{~s}$, tanto a Equação (38) quanto a Equação (51) representam diferença de $0,001 \mathrm{~mm}$ em relação ao dimensional da peça no experimento. Para os tempos 0,3 e 0,6 s de centelhamento, a diferença entre as Equações foi de 0,001 mm. Já a Equação (51) apresentou menor erro em relação ao dimensional encontrado na peça, indicando diferença de 0,002 $\mathrm{mm}$ no instante $0,3 \mathrm{~s}$ e 0,001 $\mathrm{mm}$ no instante 0,6 s. Em contrapartida, a Equação (38) representou resultados de $0,003 \mathrm{~mm}$ e $0,002 \mathrm{~mm}$ nos tempos de centelhamento 0,3 e 0,6 s, respectivamente. Para os tempos de 1 e 2 s de centelhamento, as Equações (38) e (51) representam $0,000 \mathrm{~mm}$ de erro.

Os Gráficos 26 e 27 representam a mesma análise para a velocidade de mergulho de 1,6 $\mathrm{mm} / \mathrm{min}$. 


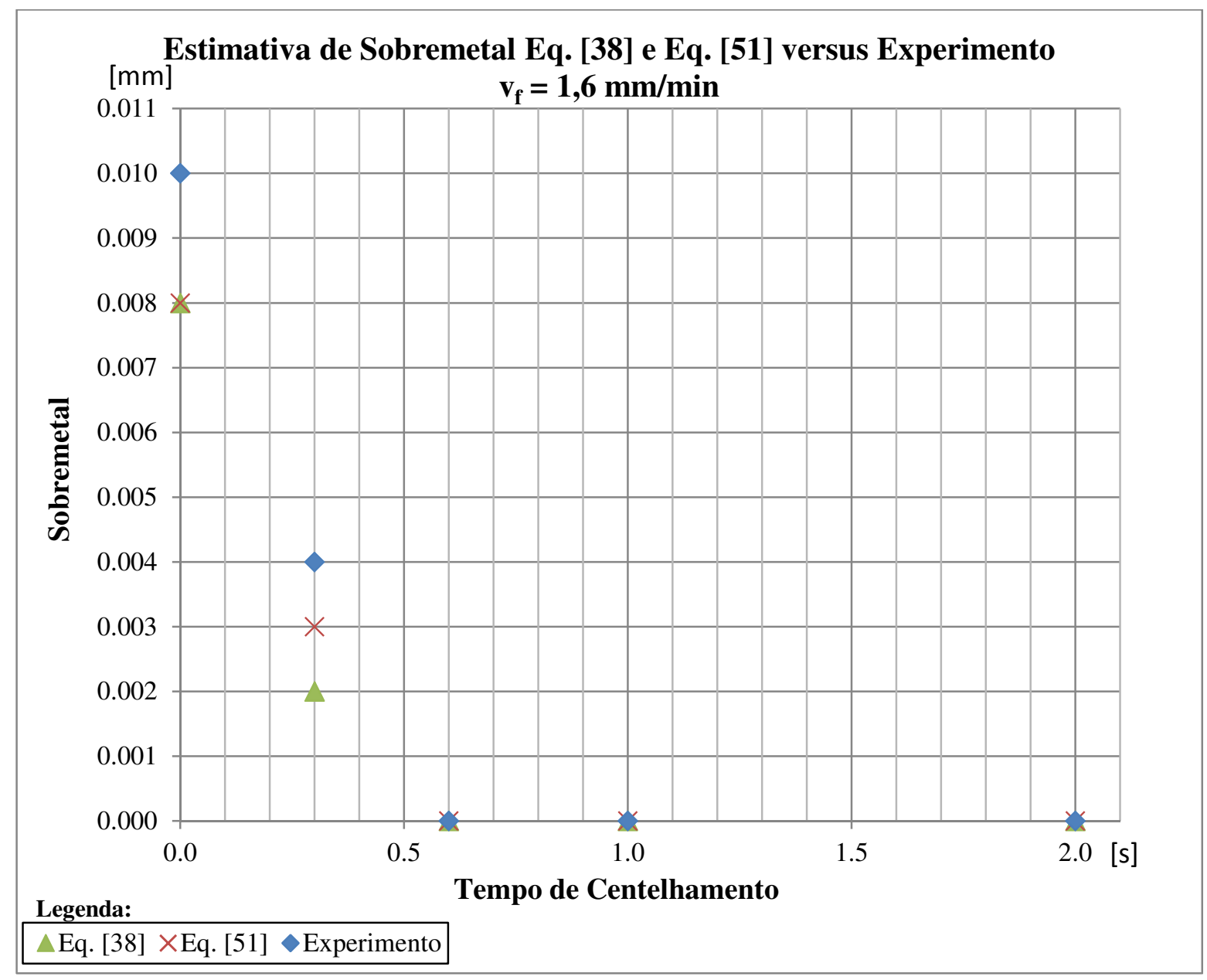

Gráfico 26 - Resultado teórico Equação (38), (51) e Experimento - velocidade de mergulho = 1,6 mm/min.

Da análise do Gráfico 26, as Equações (38) e (51) para o instante 0 s de centelhamento convergem para o valor de $0,008 \mathrm{~mm}$ de sobremetal, enquanto o valor encontrado na peça é de $0,010 \mathrm{~mm}$. Para o instante $0,3 \mathrm{~s}$, o sobremetal da peça no experimento foi de $0,004 \mathrm{~mm}$ e as Equações (38) e (51) indicam 0,002 e 0,003 mm, respectivamente. Para os instantes 0,6, 1 e 2 s de centelhamento o erro foi de 0,000 mm para as Equações (38) e (51) em comparação com o resultado encontrado na peça. 


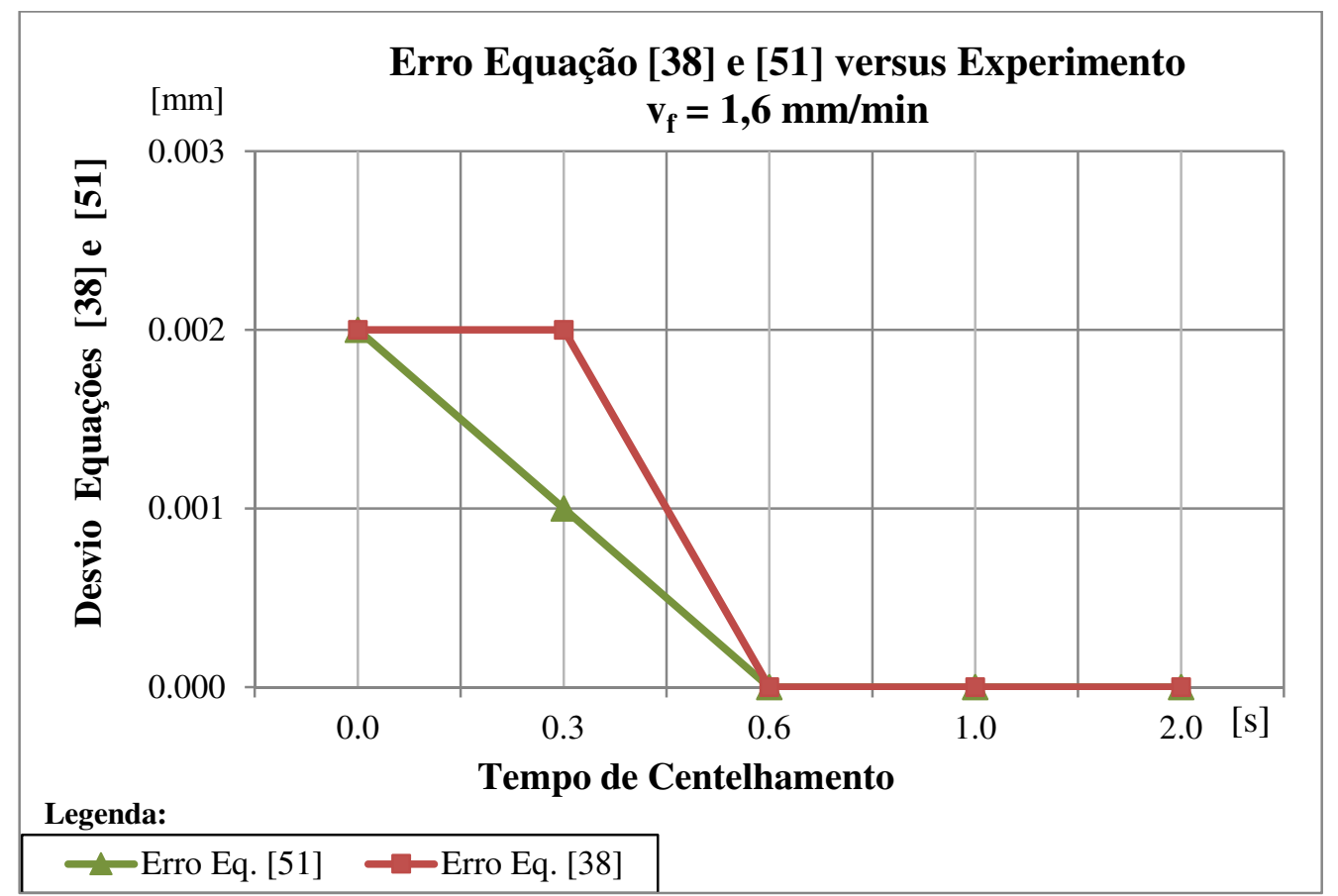

Gráfico 27 - Comparação dos erros entre os modelos Equação (38) e Equação (51) velocidade de mergulho = 1,6 mm/min

A avaliação do erro apresentada no Gráfico 27 indica para o instante $0 \mathrm{~s}$ de centelhamento um erro em relação a peça para as Equações (38) e (51) de 0,002 mm. Para o instante 0,3s, a diferença entre as Equações (38) e (51) é de 0,001 mm, indicando valores de 0,002 e 0,001 mm, respectivamente. Para os tempos de centelhamento de 0,6, 1 e 2 s, as Equações (38) e (51) convergem para $0,000 \mathrm{~mm}$ de erro. 


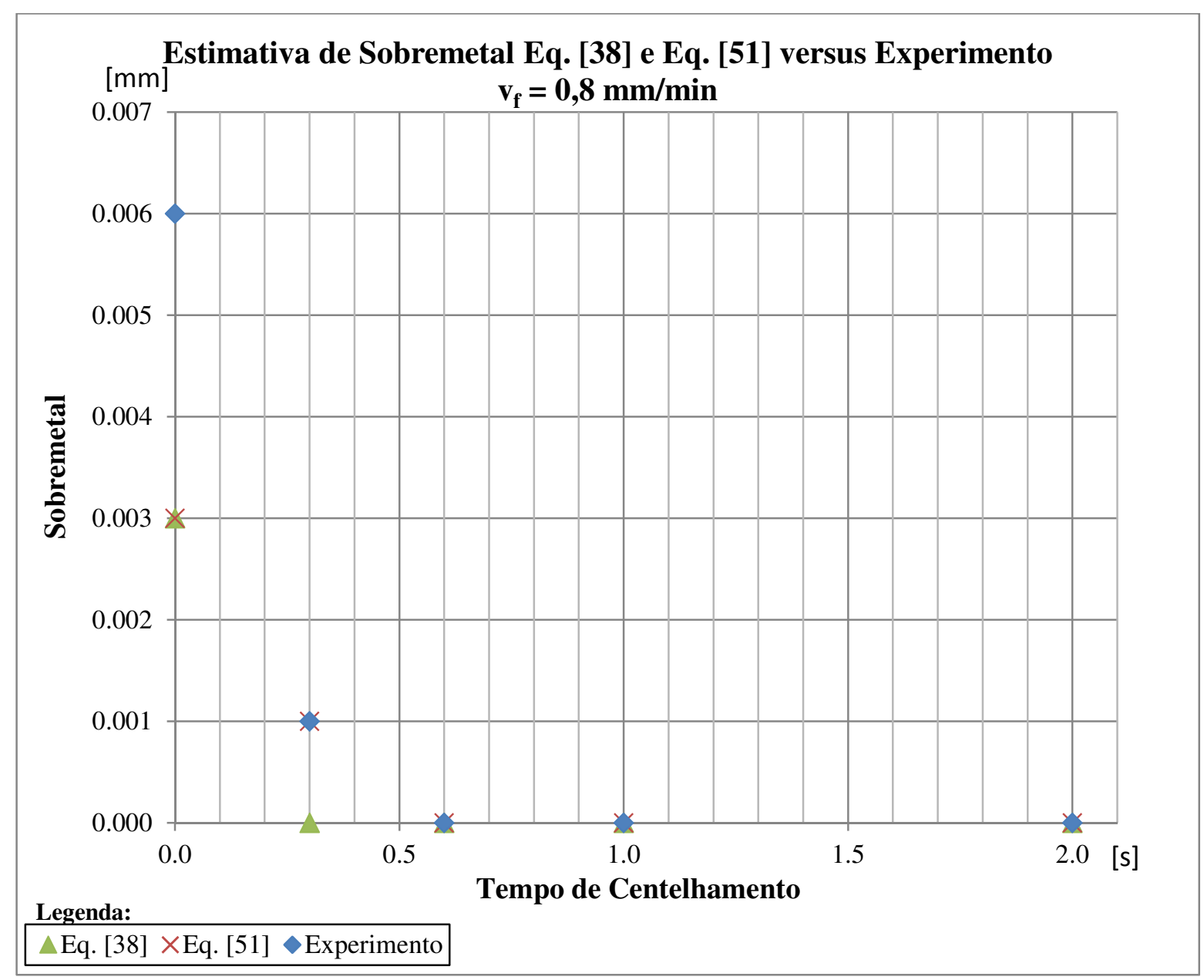

Gráfico 28 - Resultado teórico Equação (38), (51) e Experimento - velocidade de mergulho = 0,8 mm/min.

Para o Gráfico 28, tempo de centelhamento $0 \mathrm{~s}$, o sobremetal encontrado na peça foi de 0,006 mm, enquanto os resultados das Equações (38) e (51) indicam 0,003 mm de sobremetal. Para o tempo de 0,3 s de centelhamento, a Equação (51) e o sobremetal da peça indicam 0,001 mm, já a Equação (38) indica sobremetal de 0,000 mm. Para o instante 0,6 s de centelhamento, os modelos e o experimento representam $0,000 \mathrm{~mm}$ de sobremetal. 


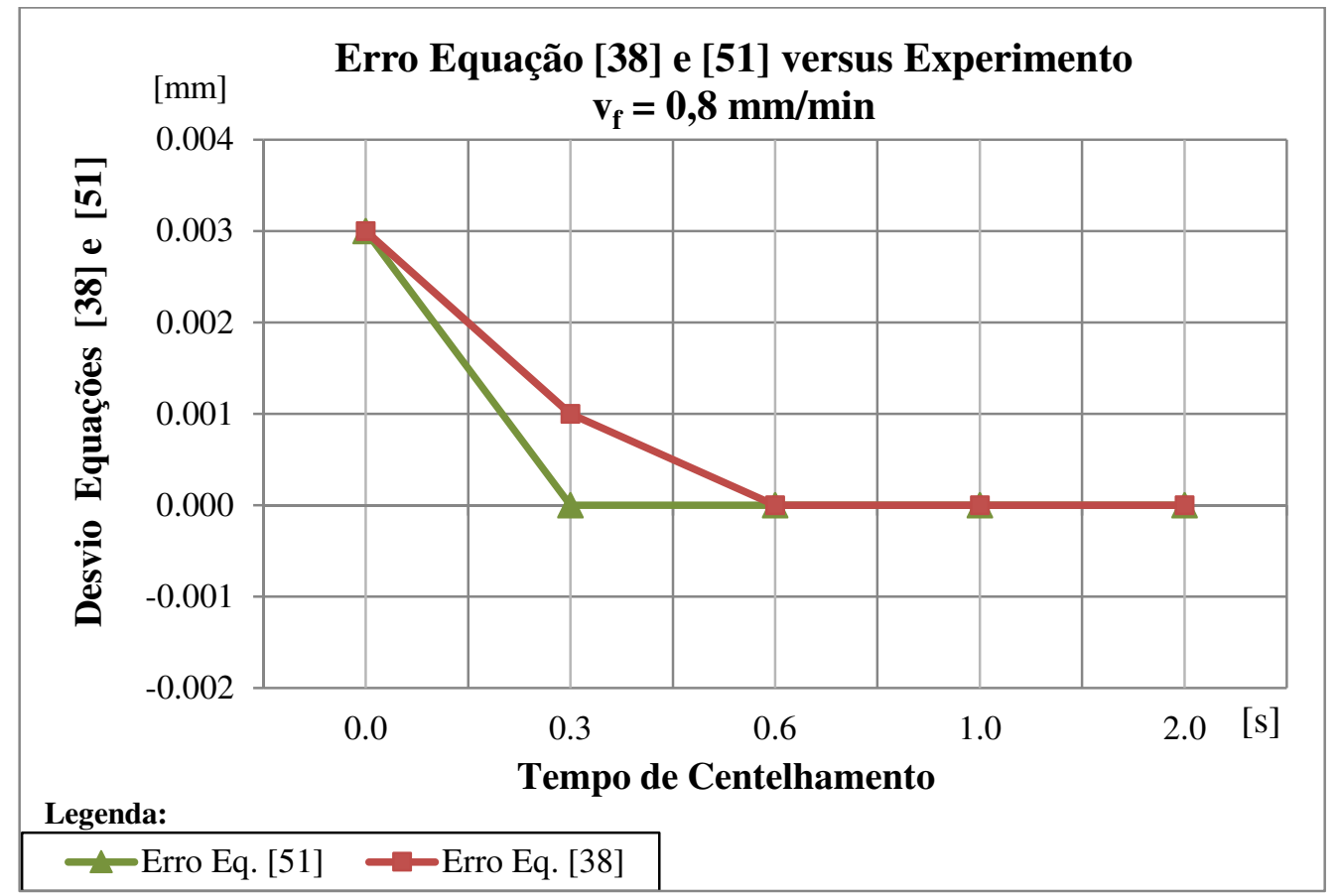

Gráfico 29 - Comparação dos erros entre os modelos Equação (38) e Equação (51) velocidade de mergulho = 0,8 mm/min

No Gráfico 29, para o instante $0 \mathrm{~s}$ de centelhamento, o erro encontrado nas Equações (38) e (51) foi de 0,003 mm em relação a peça. Em 0,3 s de centelhamento, a Equação (51) apresenta erro de 0,000 mm enquanto a Equação (38) apresenta 0,001 $\mathrm{mm}$. No tempo de centelhamento 0,6 s, os modelos de Malkin e Guo (2008), Equação (38) e a Equação (51) proposta neste trabalho apresentaram erro de $0,000 \mathrm{~mm}$ em relação ao valor obtido na peça.

A Tabela 8 mostra a relação $t_{1} / \tau$ para as velocidades de mergulho de 3,0, 2,5, 1,6, 0,8 e $0,08 \mathrm{~mm} / \mathrm{min}$ com os valores de $\tau$ médios obtidos em 30 repetições no experimento 1 . Os tempos de centelhamentos foram obtidos aplicando-se as Equações (38) e (51) e medindo-se o tempo real gasto no experimento. Esse tempo corresponde ao momento em que todas as deformações elásticas do sistema MRP foram plenamente absorvidas.

Tabela 8 - Relação $t_{1} / \tau$ para as velocidades radiais $3,0,2,5,1,6,0,8$ e $0,08 \mathrm{~mm} / \mathrm{min}$ em função do $\tau$

\begin{tabular}{ccccccc}
\hline $\mathbf{v f}$ & $\boldsymbol{\tau}$ & $\mathbf{t}_{1}$ & $\mathbf{t}_{\mathbf{1}} / \boldsymbol{\tau}$ & $\begin{array}{c}\text { Tempo Centelh. } \\
\text { Equação 38 } \\
{[\mathbf{s}]}\end{array}$ & $\begin{array}{c}\text { Tempo Centelh. } \\
\text { Equação 51 } \\
{[\mathbf{s}]}\end{array}$ & $\begin{array}{c}\text { Tempo Centelh. } \\
\text { Experimento } \\
{[\mathbf{m m} / \mathbf{m i n}]}\end{array}$ \\
\hline$[\mathbf{s}]$ & {$[\mathbf{s}]$} & & 0.6 & 1.0 & 1.0 \\
\hline 3.00 & 0.219 & 1.4 & 6.4 & 0.6 & 1.0 & 1.0 \\
2.50 & 0.204 & 2.0 & 9.8 & 0.6 & 0.6 & 0.6 \\
1.60 & 0.150 & 3.0 & 20.0 & 0.6 & 0.6 & 0.6 \\
0.80 & 0.122 & 6.1 & 50.0 & 0.0 & 0.0 & 0.0 \\
0.08 & 0.061 & 60.0 & 983.6 & & \\
\hline
\end{tabular}


No modelo proposto por Malkin e Guo (2008) - Equação (38) parte-se do princípio que a fase de desbaste terá duração suficiente para que, ao final, a velocidade de avanço real do rebolo sobre a peça, $v(t)$, seja muito próxima da velocidade de avanço programada, $u_{1}$. Assim, sempre assume-se que a curva real de deslocamento do rebolo em função do tempo tenha a mesma inclinação que a curva de deslocamento teórico do rebolo, comandada pela máquina. Isso somente será verdadeiro se o tempo de desbaste $\left(t_{1}\right)$ for suficiente para que tal equilíbrio seja alcançado, ou seja, sendo $t_{1} \gg \tau$. Malkin e Guo (2008) não quantificam qual a relação de $\mathrm{t}_{1} / \tau$ deve ser considerada para que as deformações do sistema MRP sejam absorvidas ao aplicar a Equação (38). O Gráfico 30 representa essa análise comparando os dados experimentais com as Equações (38) (Modelo Malkin e Guo, 2008) e (51) (modelo proposto - velocidade real no final do estágio de desbaste seja a inicial do início do ciclo de centelhamento).

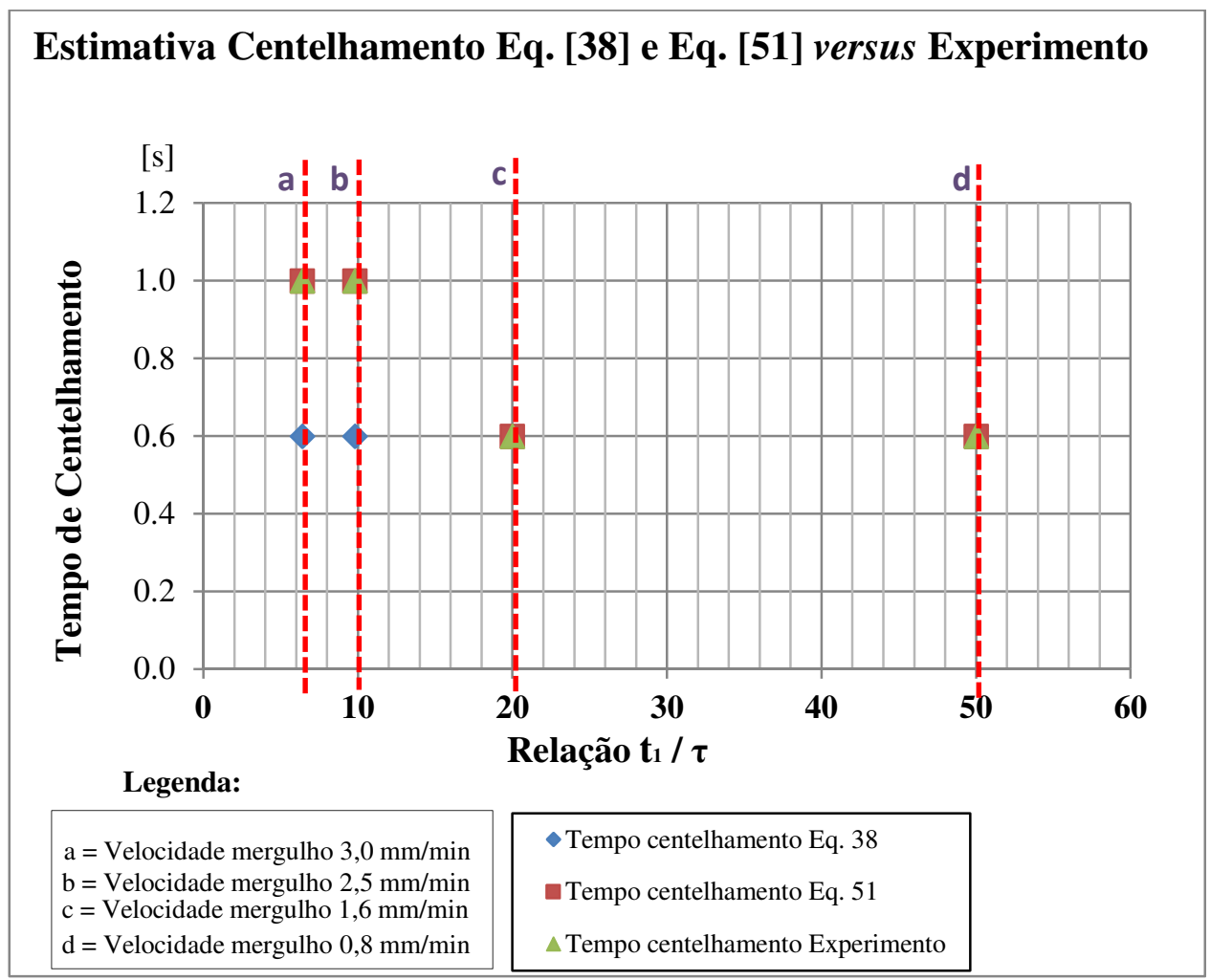

Gráfico 30 - Relação $t_{1} / \tau$ para velocidades de mergulho = 3,0, 2,5, 1,6 e 0,8 mm/min

No Gráfico 30, os marcos $a, b, c, d$ indicam as velocidades de mergulho de 3,0, 2,5, 1,6 e $0,8 \mathrm{~mm} / \mathrm{min}$ respectivamente. A Equação (51) para as velocidades de mergulho de 3,0 e 2,5 $\mathrm{mm} / \mathrm{min}$ mostra-se mais eficaz na predição do tempo de centelhamento, pois o tempo calculado e o real correspondem a $1 \mathrm{~s}$, enquanto a Equação (38) indica tempo de 0,6 s para supressão das deformações elásticas do sistema MRP estudado. Já para as velocidades de 1,6 e 0,8 mm/min. 
o tempo total de centelhamento calculado pelas Equações (38) e (51) comparadas ao experimento não apresentaram diferenças, ou seja, quando a relação $t_{1} / \tau$ for 20 ou mais, os modelos representados pelas Equações (38) e (51) se assemelham. Já quando a relação $t_{1} / \tau$ foi inferior a 20, a Equação (51) mostrou-se com menor erro para calcular o tempo de centelhamento para o sistema MRP analisado. Oliveira (1988) e Rossi (2009) relataram em suas pesquisas que a deformação do sistema MRP está relacionada a velocidade de mergulho de forma proporcional. Considerando as deformações do sistema MRP encontradas no experimento e no modelo proposto neste trabalho comprovou-se a proximidade do modelo teórico proposto pela Equação (51) com os resultados obtidos no experimento. Desta forma, aplicando o modelo proposto, torna-se possível determinar o tempo mínimo de centelhamento para que o diâmetro objetivo da peça seja alcançado de forma mais eficaz, comprovando assim a hipótese deste trabalho. 


\section{CONCLUSÕES}

- O modelo proposto neste trabalho para as velocidades de mergulho de 3,0; 2,5; 1,6 e $0,8 \mathrm{~mm} / \mathrm{min}$ comparado aos testes práticos realizados no experimento mostrou-se eficaz para prever o tempo mínimo necessário para centelhamento, uma vez obtido o valor da constante de tempo $\tau$ de forma experimental. Confirmada a hipótese deste trabalho.

- Verificou-se que, para um dado sistema máquina-rebolo-peça (MRP), o valor da constante de tempo $\tau$ não é único como ora suposto, sendo dependente da velocidade de mergulho. O sistema estudado mostrou-se mais rígido para menores velocidades de avanço. Os valores observados foram inferiores aos os valores tipicamente encontrados na literatura para retificação cilíndrica externa tangencial de mergulho.

- Ao adotar a velocidade real no final do desbaste como sendo a de início do ciclo de centelhamento, o modelo proposto nesse trabalho mostrou-se mais eficaz na determinação do erro diametral e do tempo de centelhamento necessário, se comparado ao modelo tradicional. Esse fato ocorreu para relações $t_{1} / \tau$ menores ou iguais a 20 , sendo $t_{1}$ o tempo em segundos da fase de retificação em desbaste. 


\section{SUGESTÕES PARA TRABALHOS FUTUROS}

Torna-se importante a continuidade de pesquisas focadas no estudo da rigidez do processo de retificação, pois ainda muitas lacunas estão abertas e disponíveis para futuros estudos.

Aplicar o modelo proposto neste trabalho em diferentes tipos de materiais e rebolos com o propósito de conhecer as variações da rigidez de processo e as limitações do modelo.

Desenvolver novo modelamento, partindo do proposto neste trabalho para retificação cilíndrica interna com o propósito de aprofundar o conhecimento da rigidez do processo de retificação interna.

Aplicar o modelo proposto neste trabalho em rebolos de CBN e comparar os resultados do mínimo tempo de centelhamento com os rebolos convencionais com o propósito de comparar os resultados entre rebolos convencionais de óxido de alumínio e ou carbeto de silício com o rebolos especiais em CBN. 
Adams G. G. e Nosonovsky M. Contact modeling — forces [Artigo]// Tribology International 33 (2000) 431-442.- New Jersey: Elsevier, 2000.

Alfares M. e Elsharkawy A. Effect of grinding forces on the vibration of grinding machine spindle system [Artigo]// International Journal of machine tools \& manufacture.- [s.1.]: Elsevier Science Ltd. Pergamon, 2000.- 40.- pp. 2003-2030.- PII:S0890-6955(00)00044-4.

Bianchi E. C. [et al.] Estudo comparativo entre a agressividade superficial obtida na retificação com rebolos de óxido de alumínio e $\mathrm{CBN}$, fabricados com ligantes resinóides e vitrificado, Cerâmica [Artigo].- São Paulo: [s.n.], 2011.- 344.- pp. 431-437.

Bianchi E. C., Aguiar P. R. e Piubeli B. A. Aplicação e Utilização dos Fluídos de Corte nos Processos de Retificação [Livro].- São Paulo: Artliber, 2004.- Vol. I.

Bianchi E. C., Silva J. C. E. e Aguiar P. R. Evaluation of the mechanism of stock removal and ground surface quality [Artigo]// Advanced Ceramics.- 2001.- 23.

Bianchi Eduardo Carlos Dissertação: Ação das Condições de Dressagem na Vida de Rebolos na Retificação de Precisão - São Carlos: Escola de Engenharia São Carlos - USP, 1990.

Biera J., Vinolas J. e Nieto F. J. Time-domain dynamic modelling of the external plunge grinding process [Artigo]// Int. J. Mach. Tools Manufacture - [s.1.]: Pergamon - Elsevier Science Ltd., 1997.- 11: Vol. 37.- pp. 1555-1572.- PII: S0890-6955(97)00024-2. 
Brinksmeier E. [et al.] Advances in modeling and simulation of grinding processes [Artigo]// Annals of the CIRP.- 2006.- 2: Vol. 55.- pp. 667-696.- Doi:10.1016/j.cirp.2006.10.003.

Cai G. Q. [et al.] Study on the friction coefficient in grinding [Artigo]// Journal of Materials Processing Technology.- [s.1.]: Elsevier Science B.V., 2002.- 129.- pp. 25-29.

Capelli A. Inversores de frequência - Mecatrônica atual [Livro].- São Paulo: Saber, 2002.- Vol. 1 .

Chiu N. e Malkin S. Computer simulation for cylindrical plunge grinding [Artigo]// Annals of the CIRP.- 1993.- 1: Vol. 42. - pp. 383-387.

Choi T. J. [et al.] Generalized practical models of cylindrical plunge grinding processes [Artigo]// International journal of machine tools \& manufacture - [s.1.]: Elsevier Ltd., 2007.Vol. 48.- pp. 61-72.- Doi: 10.1016/j.ijmachtools.2007.07.010.

Coelho Reginaldo [et al.] Innovative method for improving the dimensional capability of CNC grinding machines [Artigo]// Abrasive Engineering Soc.- Butlerto, PA, United States: [s.n.], 1999.

Coelho Reginaldo Teixeira Dissertação: Estudo Experimental da Profundidade de Dressagem de Rebolos na Retificação de Precisão Usando Método do Disco Retificado - São Carlos: Escola de Engenharia São Carlos - USP, 1991.

Doman D., Warkentin A. e Bauer R. Finite element modeling approaches in grinding [Artigo]// International Journal of Machine Tools \& Manufacture. - Halifax, Canadá: Elsevier, 2009 - 49: Vol. 1. 
Fu Y. C., Xu H. J. e Xu J. H. Optimization desing of grinding wheel topography for high efficiency grinding [Artigo]// Journal of materials processing technology - [s.1.]: Elsevier Science B. V., 2002 - Vol. 129 - pp. 118-122.

Furutani K. [et al.] Automatic compensation for grinding wheel wear by pressure based inprocess measurement in wet grinding [Artigo]// Precision Engineering - [s.1.]: Elsevier Science Inc., 2003 - Vol. 27 - pp. 9-13.

Hahn R. S. e Lindsay R. P. The wheel removal parameter [Artigo]// Principles of Grinding [s.1.]: Machinery, 1971 - Parte III - pp. 33-39.

Hashimoto F. [et al.] Sequential estimation of growth rate of chatter vibration in grinding processes [Artigo]// Annals of the CIRP - 1984 - 33: Vol. 1.

Hassui A. e Diniz A., E. Correlating surface roughness and vibration on plunge cylindrical grinding of steel [Artigo]// Internation Journal of Machine Tools \& Manufacture - [s.1.]: Pergamon - Elsevier Science Ltd., 2003 - 43 - pp. 855-862 - DOI: 10.1016/S08906955(03)00049-X.

Hassui A. e Diniz A.,E. Correlating surface roughness and vibration on plunge cylindrical grinding of steel [Artigo]// Internation Journal of Machine tools \& Manufacture - [s.l.]: Pergamon - Elsevier Science Ltd., 2003 - 43 - pp. 855-862 - doi: 10.1016/S08906955(03)00049-X.

Hitchiner M. P. Advantages in production grinding with $\mathrm{CBN}$ and their influence on machine tool desing [Artigo]// Saint Gobain Grinding Conference - São Carlos: [s.n.], 2001. 
Inasaki I. e Karpuschewski B. Abrasive process In: TÖNSHOFF, H.K. [Artigo] - 2001.

Junkar M. e Filipic B. Grinding process control through monitoring and machine learning [Artigo]// Competitive performance through advanced technology - 1992 - pp. 77-80 - Third International Conference.

Konig W. Retificação, brunimento e lapidação [Livro]/ trad. Weingaerther) (Direitos de tradução reservados por Prof. Walter L. - 1980 - Vol. 2.

Inasaki I., Karpuschewski B. e Lee H. S. Grinding Chatter - Origin and Suppression [Artigo]// CIRP Annals - Manufacturing Technology - 2001 - 2: Vol. 50 - pp. 515-534.

Machado Álisson R. [et al.] Teoria da Usinagem dos Materiais [Livro] - São Paulo: Blucher, 2011 - Vol. 2.

Malkin S. e Guo C. Grinding Technology - Theory and Applications of Machining with Abrasives [Livro] - New York: Industrial Press, 2008 - Second Edition.

Malkin S. e Koren Y. Optimal infeed control for accelerated spark-out in grinding [Artigo]// Trans. ASME, J. of Eng. for Ind. - 1984 - 106 - p. 70.

Malkin S. e Xiao G. On-line optimization for internal plunge grinding [Artigo]// Annals of the CIRP - 1996 - 1: Vol. 45 - pp. 287-292. 
Malkin S. Grinding cycle optimization [Artigo]// Annals of the CIRP - 1981 - 1: Vol. 30 - pp. 223-226.

Malkin S. Grinding review of materials processing literature [Artigo]// ASME Trans. Journal - 1977 - 99 - p. 901.

Malkin S. Grinding technology [Livro] - [s.1.]: Ellis Horwood Limited, 1989 - $1^{\circ}$ Edition.

Marconi M. A. e Lakatos E. M. Metodologia científica [Livro] - São Paulo: Atlas, 2000.

Marinescu I. D. [et al.] Tribology of abrasive machining processes [Artigo]// William Andrew Publishing Norwich - New York: [s.n.], 2004.

Milacron Cincinnati Grinding principles and practice [Livro] - Ohio, United State of American: [s.n.], 1996.

Nadolny K. The effect of integrating the structural modifications of the grinding wheel upon the internal cylindrical grinding process [Artigo]// Archives of civil and mechanical engineering - [s.l.]: Elsevier Urban \& Parther Sp. z.o.o., 2012 - 12 - pp. 60-67.

Nakayama K Sharpness evaluation of grinding wheel face by the grinding of steel ball [Artigo]// Annals of the CIRP - 1980 - 29: Vol. 1 - pp. 227-228.

Neto L., M., G. Dissertação: Estudo das correlações dos parâmetros e fenômenos do processo de retificação centerless de passagem com a circularidade da peça. Apresentada à Universidade de Taubaté - Taubate - SP: [s.n.], 2008. 
Oliveira J. F. G., França T. V. e Wang J. P. Experimental analysis of wheel / workpiece dynamic interactions in grinding [Artigo]// CIRP Annals - Manufacturing Technology - [s.1.]: Elsevier, 2008 - 57 - pp. 329-332 - doi:10.1016/j.cirp2008.03.096.

Oliveira João Fernando Gomes de Tese: Análise da Ação do Macroefeito de Dressagem de Rebolos no Desempenho do Processo de Retificação - São Carlos: Escola de Engenharia São Carlos - USP, 1988.

Ramos J. C., Vinolas J. e Nieto F. J. A simplified methodology to determine the cutting stiffness and the contact stiffness in the plunge grinding process [Artigo]// International jurnal of Machine Tools \& Manufacture - Design, research and application - [s.1.]: Pergamon, 2000 p 33-49.

Rossi Moacir Aparecido Dissertação: Método Prático para Otimização do Ciclo de Retificação Transversal de Precisão - São Carlos: Escola de Engenharia São Carlos - USP, 2009.

Rowe W. Brian Principles of Modern Grinding Technology [Livro] - Linacre House, Jordan Hill, Oxford OX2 8DP, UK: Willian Andrew, 2009 - First Edition.

Saini D. P. e Wager J. G. Local Contact Deflections and Forces in Grinding [Artigo]// CIRP Annals - Manufacturing Technology - 1985 - 1: Vol. 34 - pp. 281-285.

Saini D.P. e Brown R.H. Elastic Deflections in Grinding [Artigo]// CIRP Annals Manufacturing Technology - 1980 - 1: Vol. 29 - pp. 189-194. 
Saini D.P. Wheel hardness and local elastic deflections in grinding [Artigo]// International Journal of Machine Tools and Manufacture - 1990 - 4: Vol. 30 - pp. 637-649.

Saini D.P., Wager J.G. e Brown R.H. Practical Significance of Contact Deflections in Grinding [Artigo]// CIRP Annals - Manufacturing Technology - 1982 - 1: Vol. 31 - pp. 215219.

Shaw M. C. Principles of Abrasive Processing [Livro] - Arizona - EUA: Oxford University Press, 1996.

Shaw M.,C. Energy conversion in cutting and grinding [Artigo]// Annals of the CIRP - 1996 45 - pp. 101-104.

Sinha J. P., Sahay B. e Lal G. K. Forces produced during cutting with single abrasive grains [Artigo]// Elsevier Sequoia S.A. - Printed in The Netherlands: [s.n.], 1981 - 66 - pp. 133-144.

Souza M. V. Dissertação: Projeto robusto de parâmetros (PRP) aplicado na otimização de retificação cilíndrica com multiplas respostas - Itajuba: Universidade Federal de Itajubá, 2012.

Sushant K. B. e Mishra B. K. Optimization of variables in grinding brass particles for paint and pigment industry [Artigo]// Journal powder technology - [s.l.]: Elsevier Ltd., 2011 - Vol. 214 - pp. 349-355 - Doi: 10.1016/j.powtec.2011.08.030.

Thompson R., A. On the doubly regenerative stability of a grinder: The effect os contact stifness and wave filtering [Artigo]// Winter Annual Meeting ASME - São Francisco: [s.n.], 1989 - pp. 153-165. 
Tlusty J. Static and dynamic stiffness [Periódico] - [s.1.]: Oxford, Pergamon Press, 1970 - 519 p.p. 72-87: Vol. 1.

Tönshoff H. K. [et al.] Modeling and simulation of grinding processes [Artigo]// Annals of the CIRP - 1992 - 2: Vol. 42 - pp. 677-688.

Tönshoff H. K., Friemuth T. e Beckerm J. C. Process monitoring in grinding [Artigo]// Annals of the CIRP - 2002 - 2: Vol. 52 - pp. 551-571.

Wager J. G. e Saini D. P. Local contact deflections in grinding - Groups of grains and single grains [Artigo]// Annals of the CIRP - 1986 - 35 - pp. 245-248.

Wang P. J. Dissertação de Mestrado: Avaliação da retificação com rebolo de CBN aplicada em ligas de alto desempenho- São Carlos: Escola de Engenharia de São Carlos, Universidade de São Paulo, 2008.

Wang Z. [et al.] The static and dynamic stiffness analysis and strengthening desing of internal grinder shaper based on the CAE [Artigo]// Mechanics and Materials - Switzerland: Trans Tech Publications, 2009 - 16-19 - pp. 836-841 - doi:10.4028.

Warnecke G. e Barth C. Optmization of the dynamic behavior of grinding wheels for grinding of hard and brittle materials using the finite element method [Artigo]// Annals of the CIRP 1999 - 1: Vol. 48 - pp. 262-264.

Webster J. A., Cui C. e Mindek Jr R. B. Grinding fluid application system desing [Artigo]// Annals of CIRP - 1995 - 1: Vol. 44 - pp. 333-338. 
Wegener K. [et al.] Conditioning and monitoring of grinding wheels [Artigo]// Annals of the CIRP - [s.1.]: Elsevier - Science direct, 2011 - Vol. 60 - pp. 757-777 - DOI: 10.1016/1.cirp.2011.05.003.

Woodbury Robert S. History of the grinding machine [Livro] - Massachusetts: Massachusetts Institute of Technology Cambrigde, 1964 - Vol. I.

Yin R. K. Estudo de caso: Planejamento e métodos [Livro] - Porto Alegre : Bookman, 2010.

Zhang L., C. [et al.] Applied mechanics in grinding part II: Modelling of elastic modulus of wheels and interface forces [Artigo] = Pergamon Press Ltd// Int. J. Mach Tools Manufact Great Britain: [s.n.], 1993 - 2: Vol. 33 - pp. 245-255 - 0890-6955/93.

Zhou Z. X. e Lutterwelt C. A. The real contact length between grinding wheel and workpiece - A new concept and a new measuring method [Artigo]// Annals of the CIRP - 1992 - 1: Vol. 41 - pp. 387-391.

Zhu Xiaoyin Tutorial on Hertz Contact Stress [Artigo]// OPTI 521 - 2012. 


\section{APÊNDICE I-GRÁFICOS DAS AQUISIÇÕES}

Gráficos das amostras 1 a 5 para 0 segundo de centelhamento:
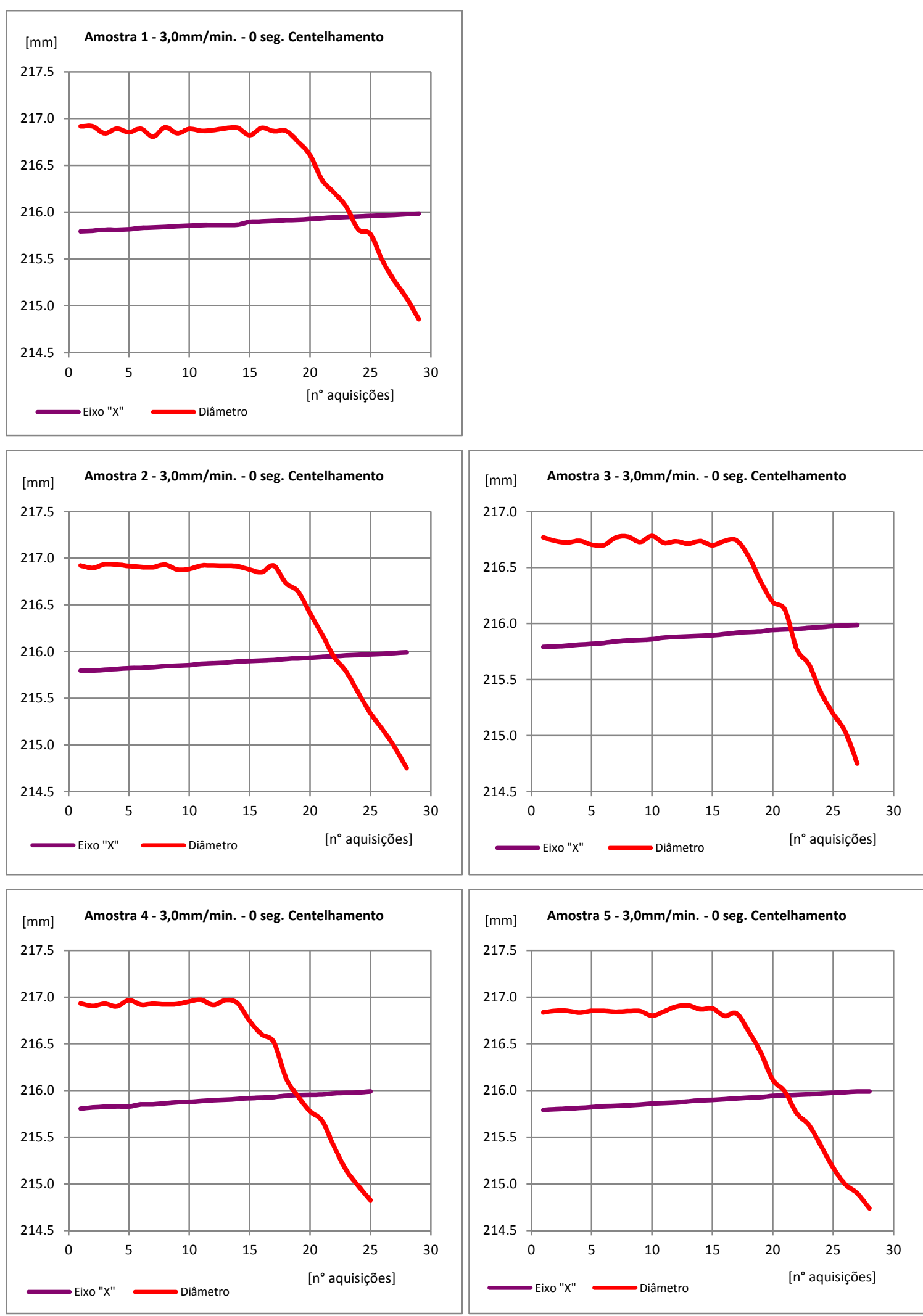

Gráfico 31 - Aquisição dados processo retificação - Vel. 3,0mm/min. 0seg. Centelhamento 
Gráficos das amostras 1 a 5 para 0,3 segundo de centelhamento:
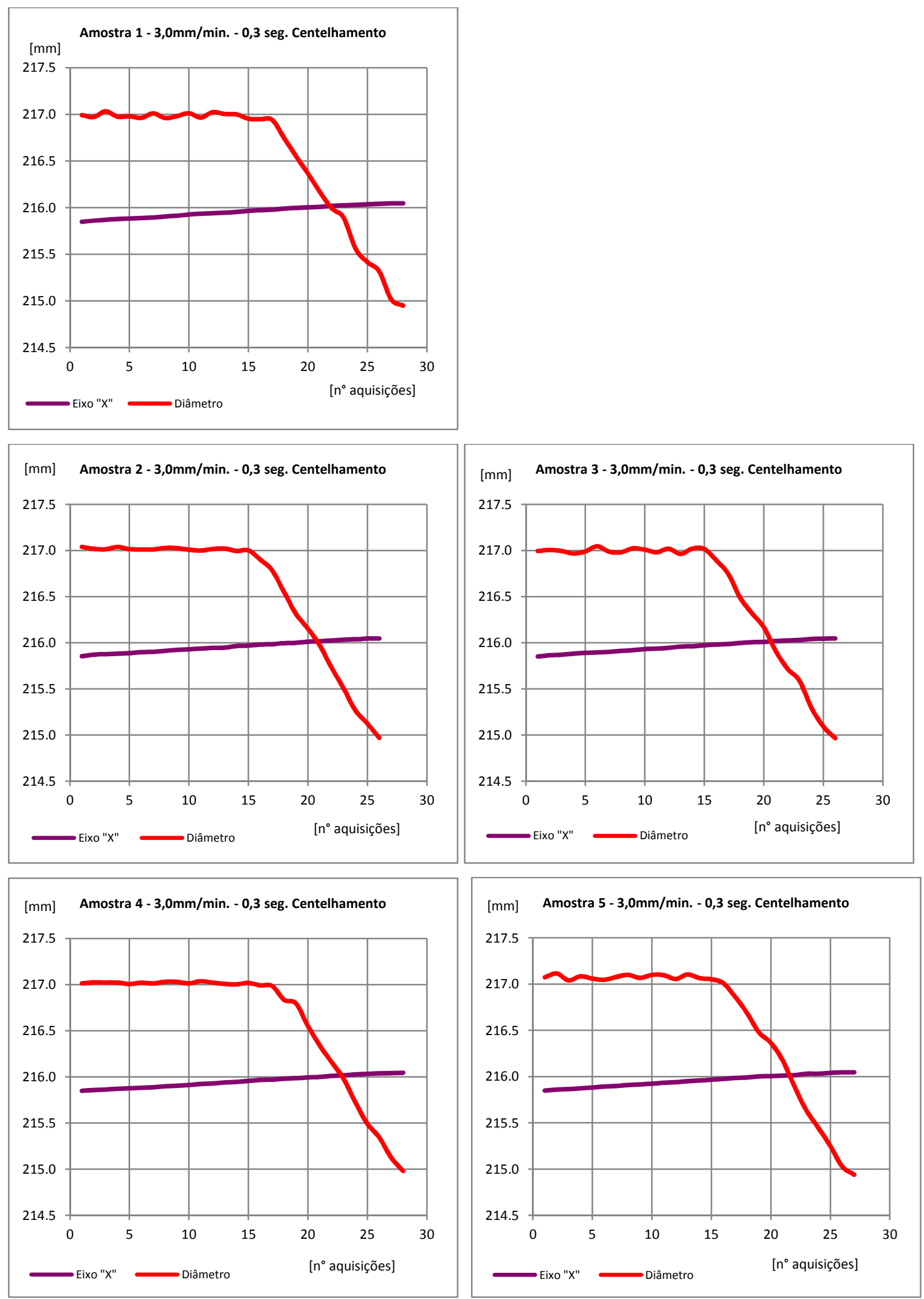

Gráfico 32 - Aquisição dados processo retificação - Vel. 3,0mm/min. 0,3seg. Centelhamento 
Gráficos das amostras 1 a 5 para 0,6 segundo de centelhamento:
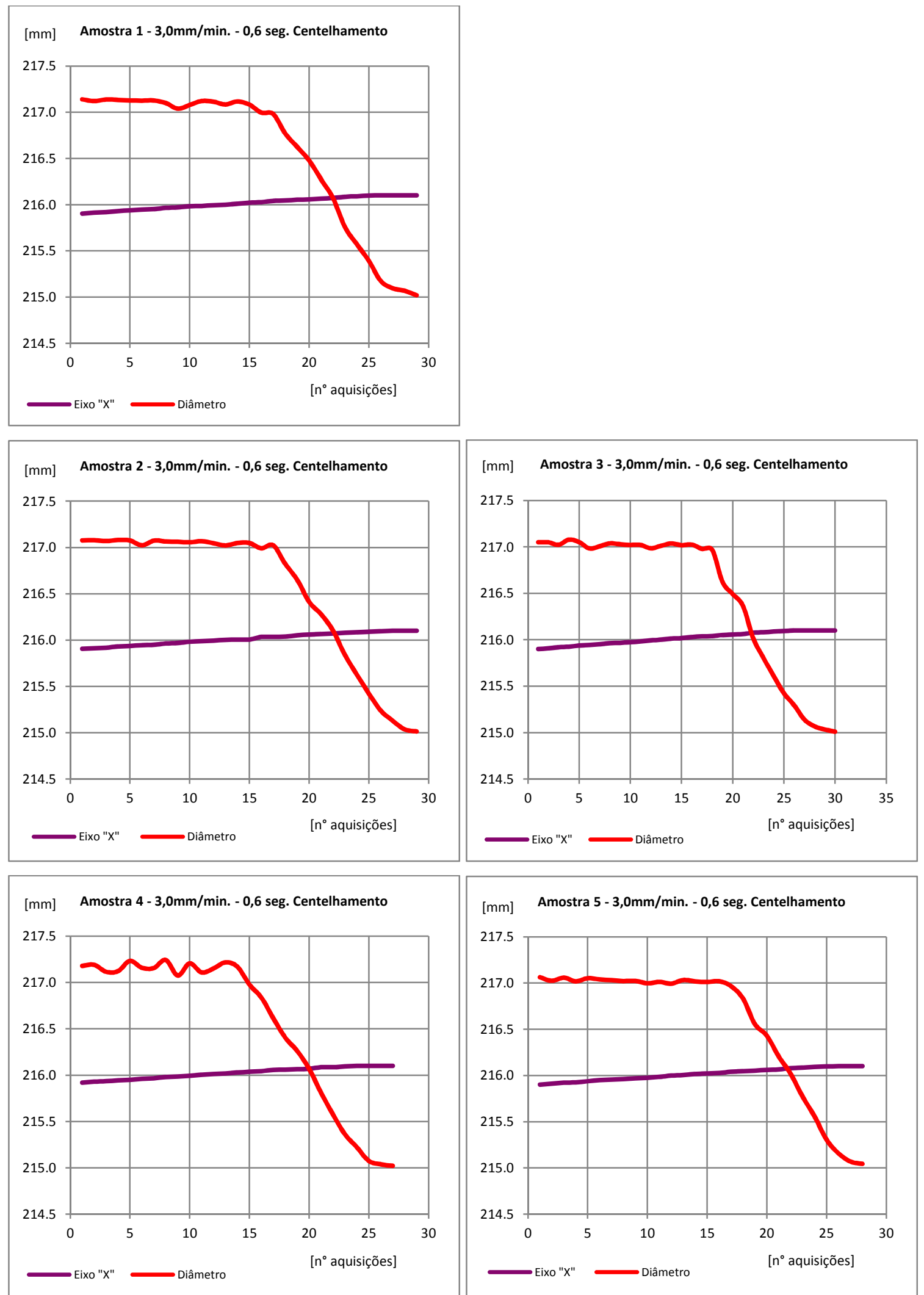

Gráfico 33 - Aquisição dados processo retificação - Vel. 3,0mm/min. 0,6seg. Centelhamento 
Gráficos das amostras 1 a 5 para 1 segundo de centelhamento:
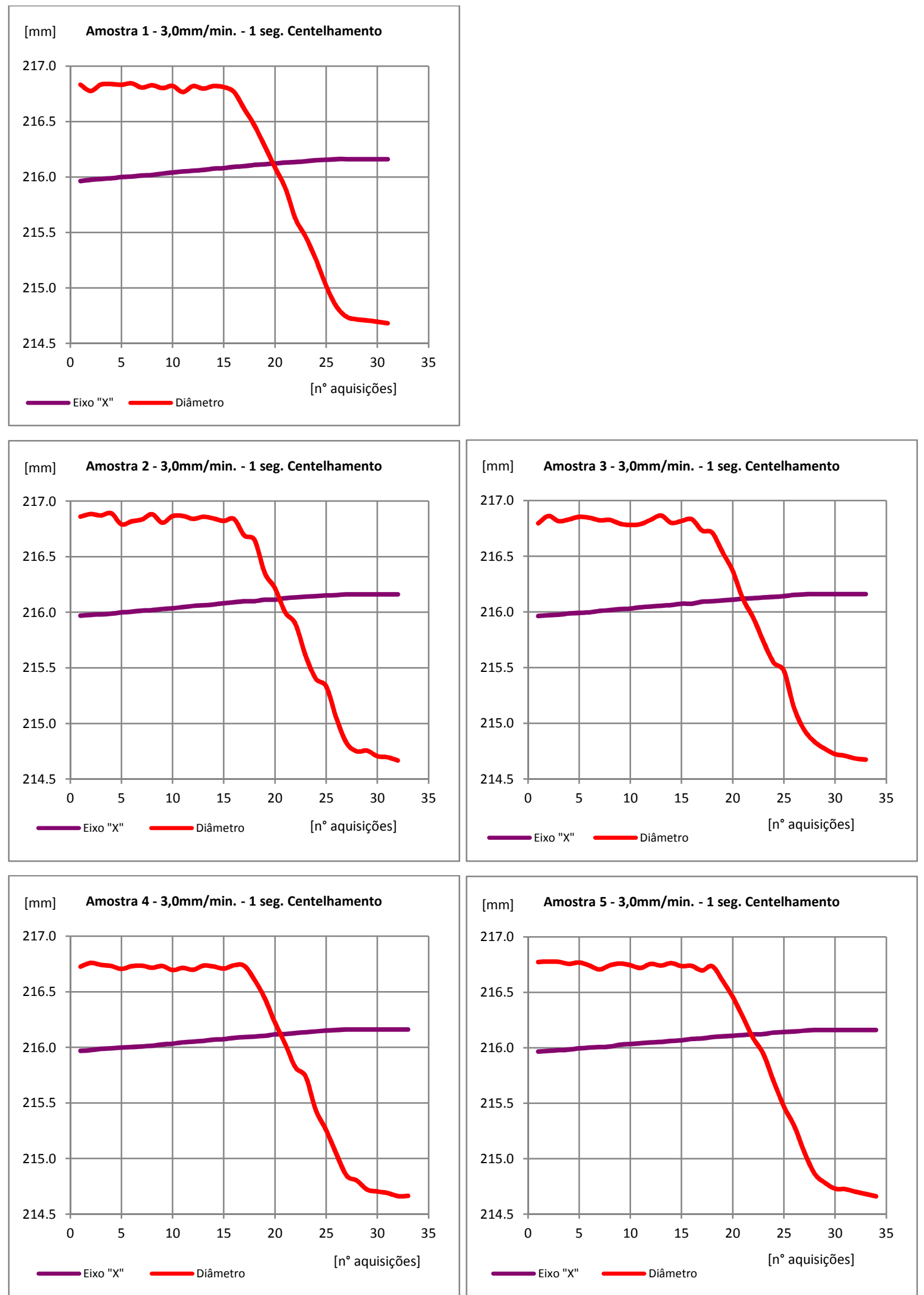

Gráfico 34 - Aquisição dados processo retificação - Vel. 3,0mm/min. 1seg. Centelhamento 
Gráficos das amostras 1 a 5 para 2 segundos de centelhamento:
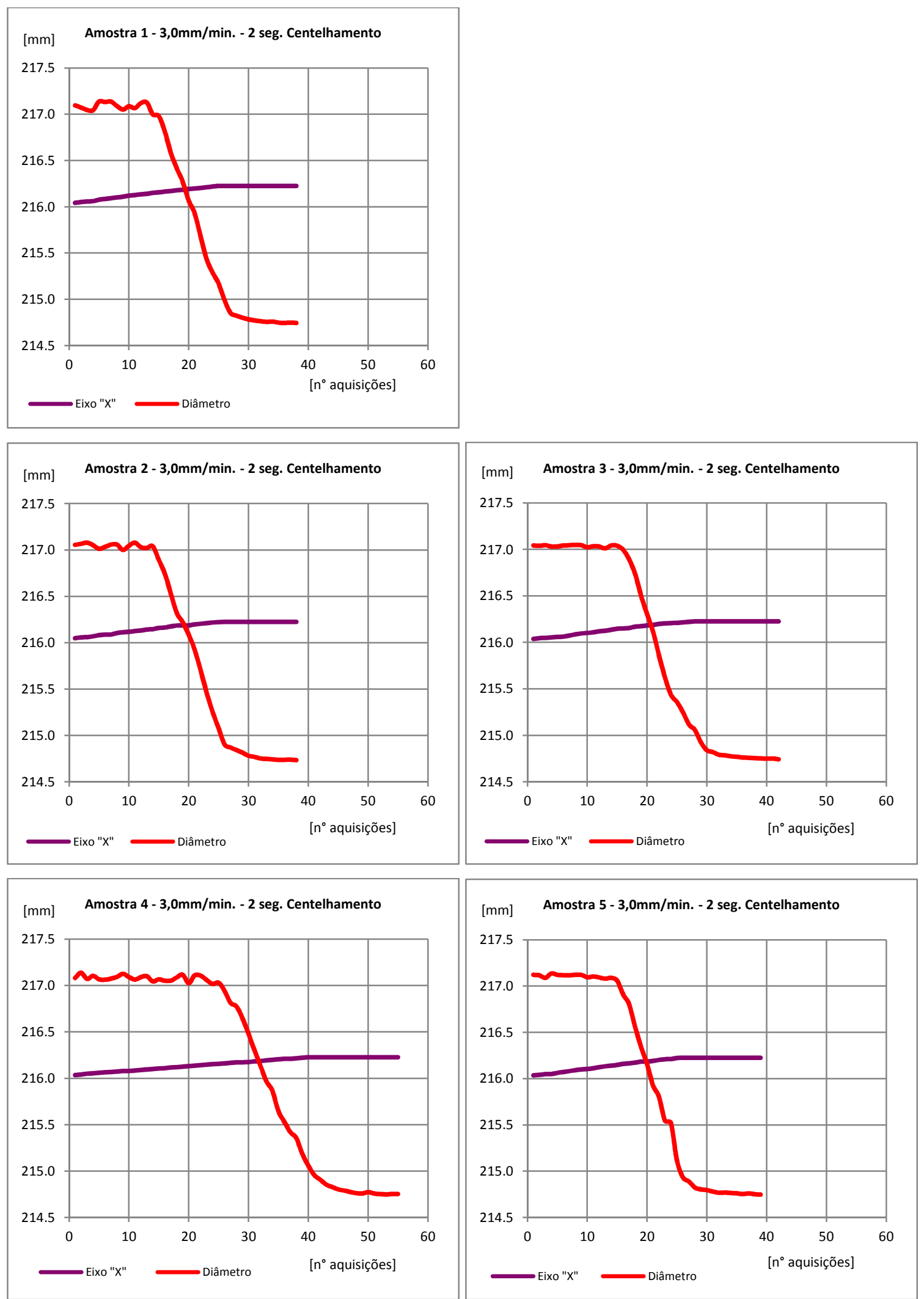

Gráfico 35 - Aquisição dados processo retificação - Vel. 3,0mm/min. 2 seg. Centelhamento 
Gráficos das amostras 1 a 5 para 3 segundos de centelhamento:
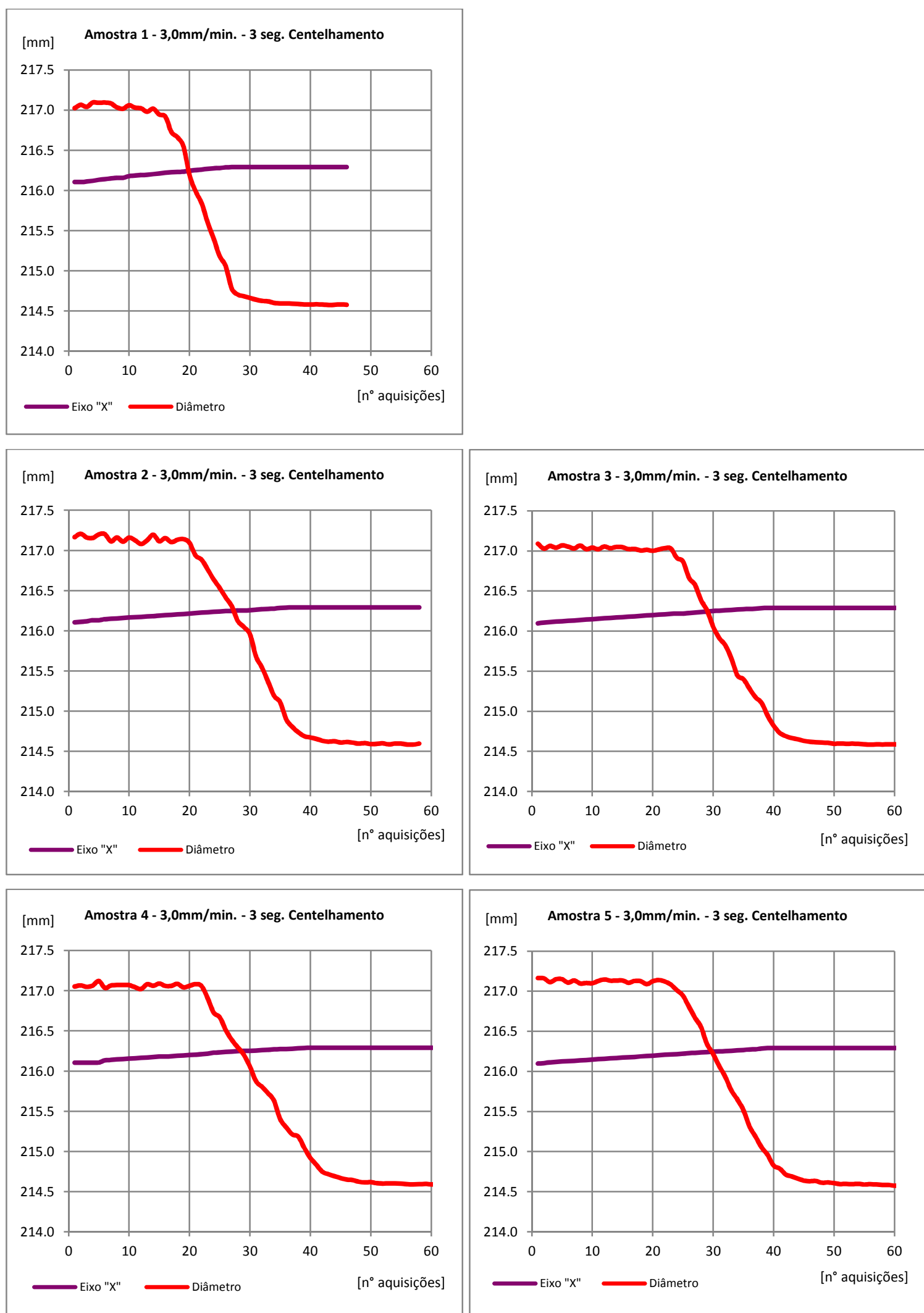

Gráfico 36 - Aquisição dados processo retificação - Vel. 3,0mm/min. 3 seg. Centelhamento 
Gráficos das amostras 1 a 5 para 0 segundo de centelhamento:
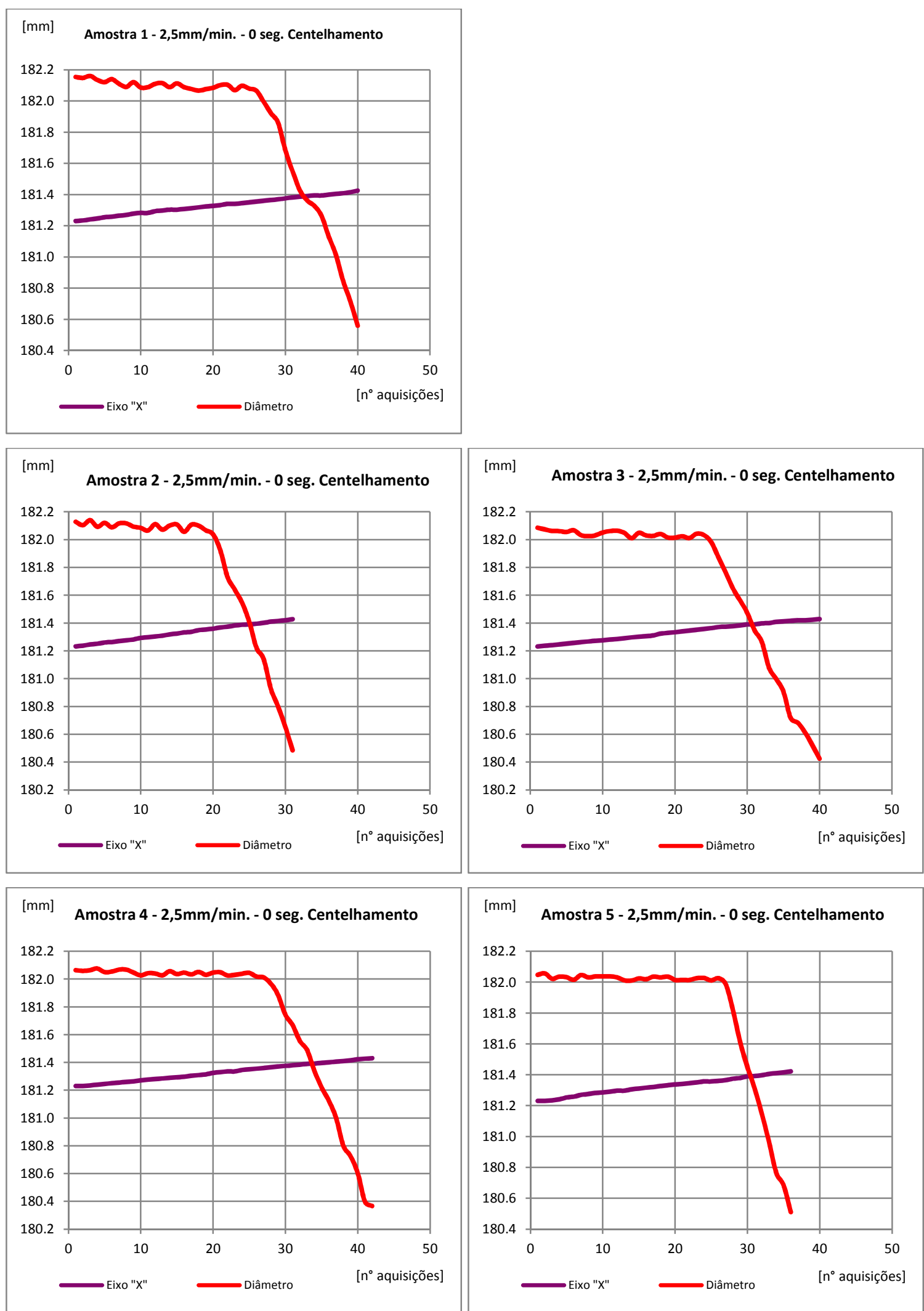

Gráfico 37 - Aquisição dados processo retificação - Vel. 2,5mm/min. 0seg. Centelhamento 
Gráficos das amostras 1 a 5 para 0,3 segundo de centelhamento:
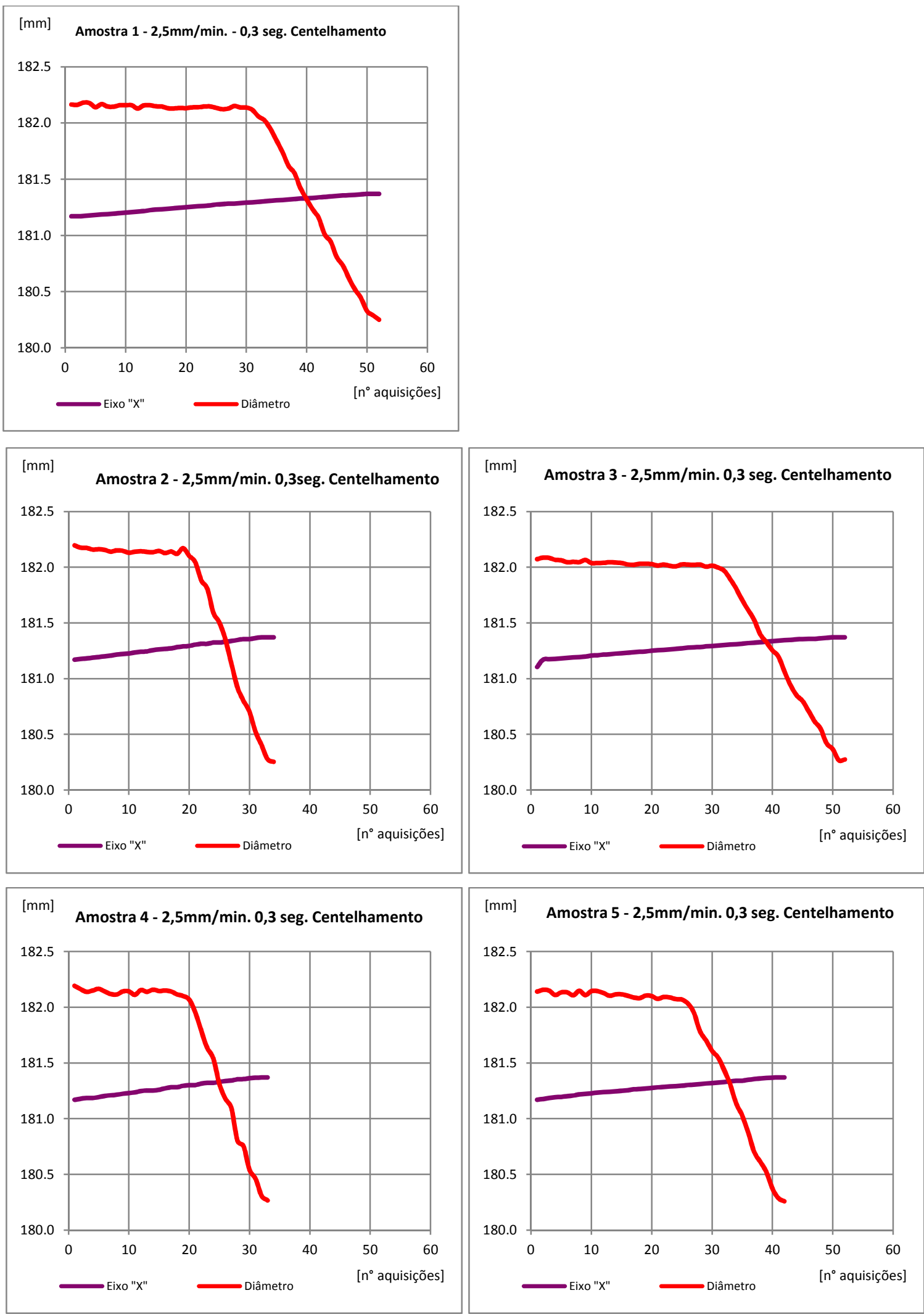

Gráfico 38 - Aquisição dados processo retificação - Vel. 2,5mm/min. 0,3seg. Centelhamento 
Gráficos das amostras 1 a 5 para 0,6 segundo de centelhamento:
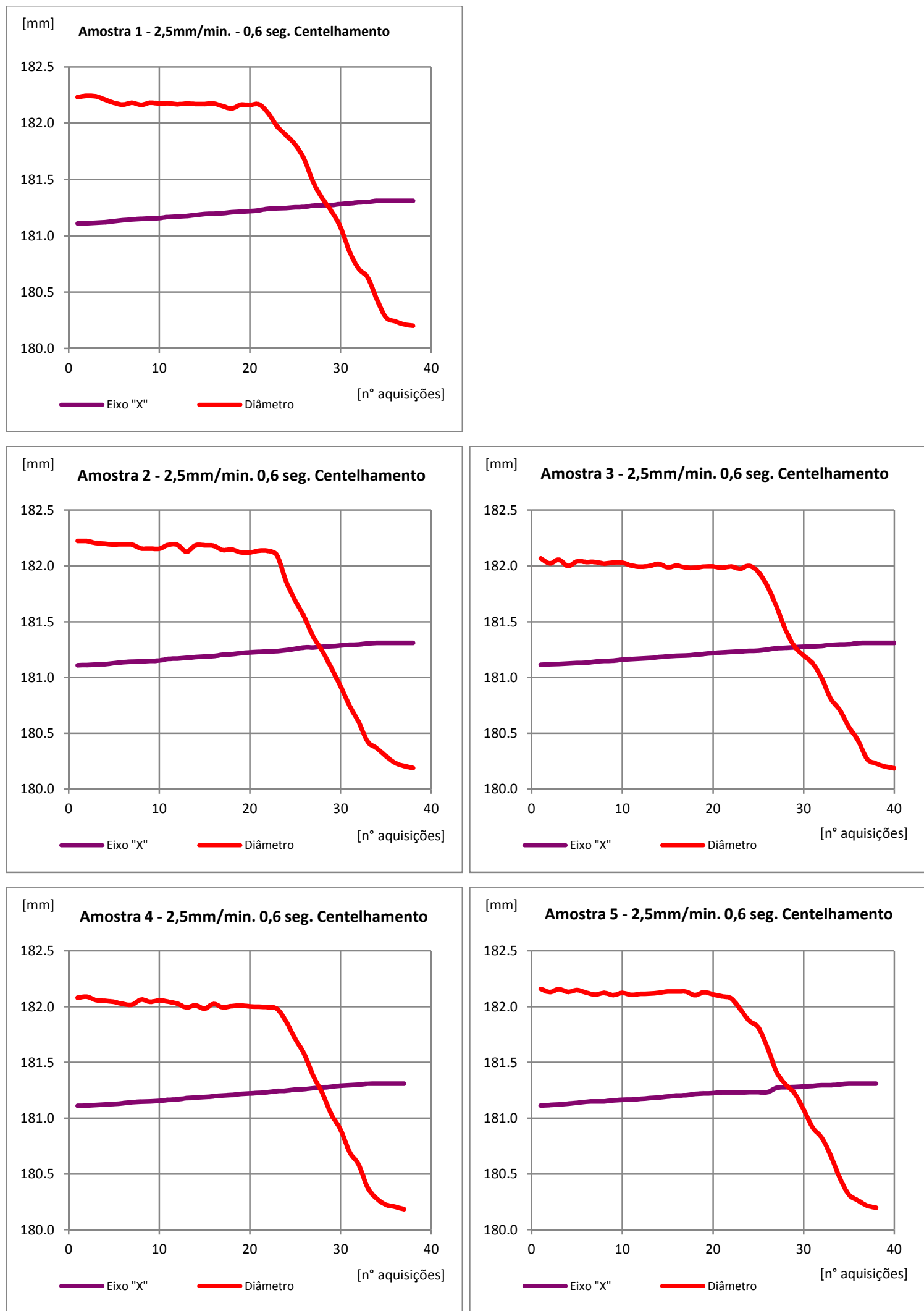

Gráfico 39 - Aquisição dados processo retificação - Vel. 2,5mm/min. 0,6seg. Centelhamento 
Gráficos das amostras 1 a 5 para 1 segundo de centelhamento:
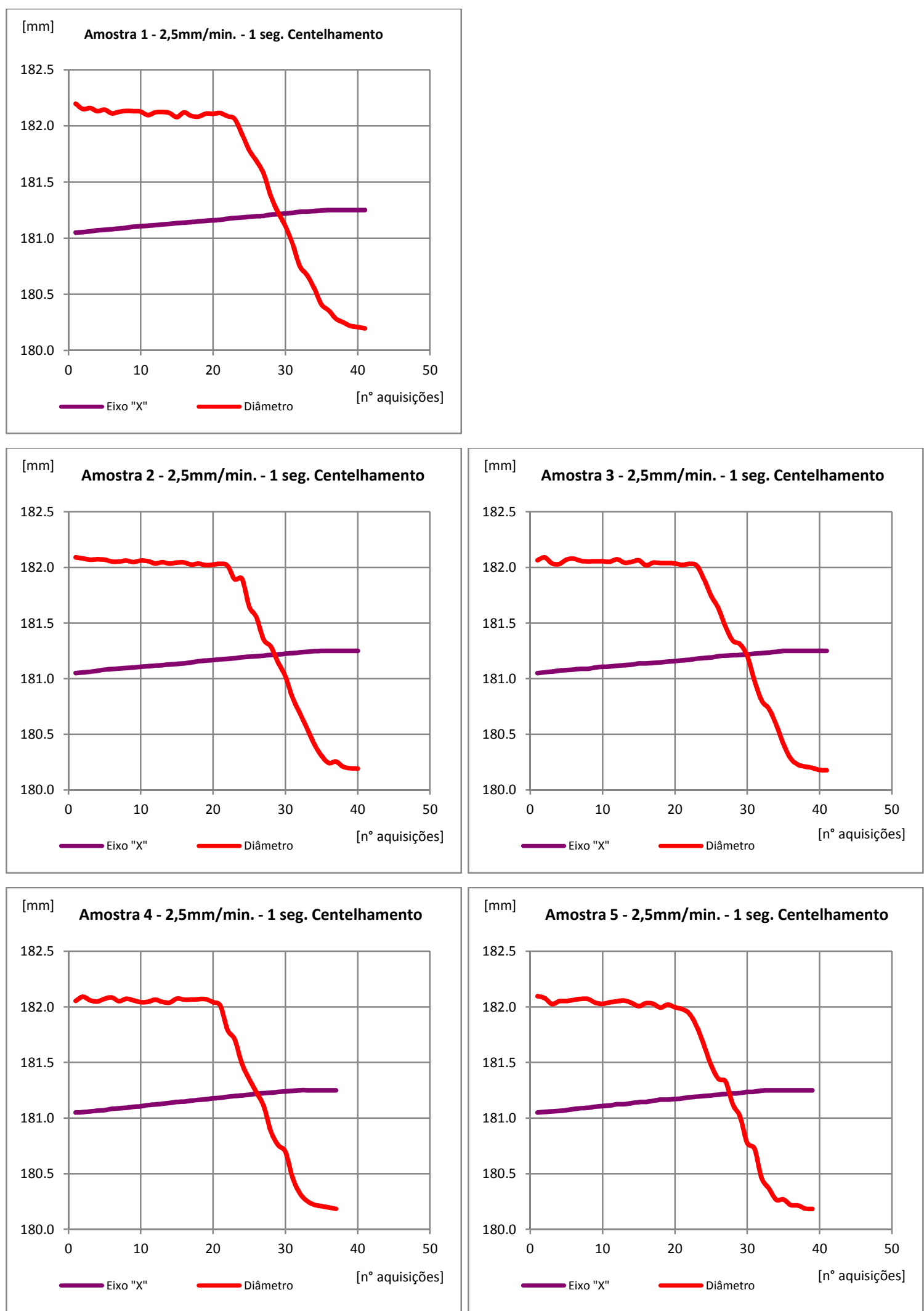

Gráfico 40 - Aquisição dados processo retificação - Vel. 2,5mm/min. 1seg. Centelhamento 
Gráficos das amostras 1 a 5 para 2 segundos de centelhamento:


Gráfico 41 - Aquisição dados processo retificação - Vel. 2,5mm/min. 2seg. Centelhamento 
Gráficos das amostras 1 a 5 para 3 segundos de centelhamento:
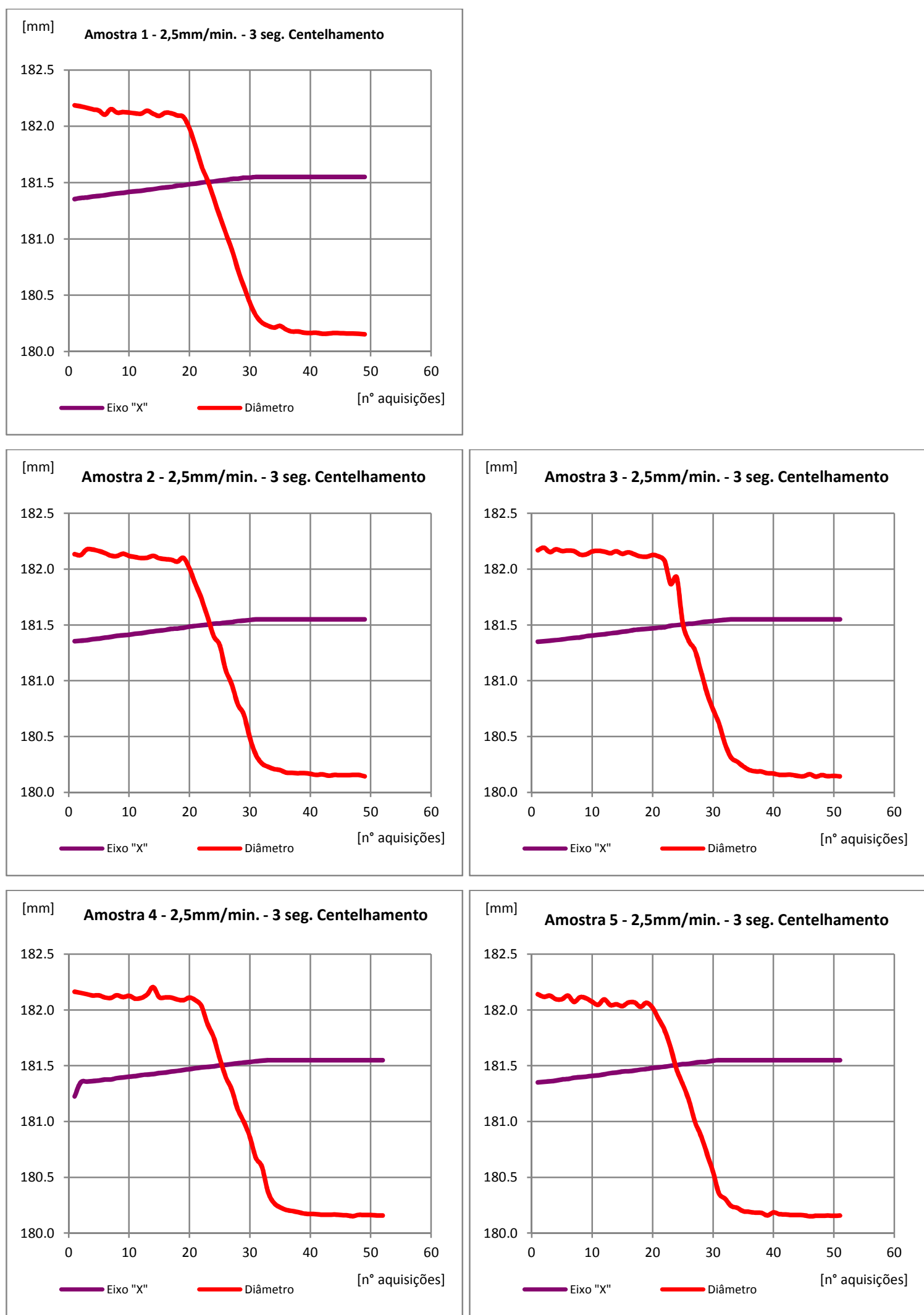

Gráfico 42 - Aquisição dados processo retificação - Vel. 2,5mm/min. 3seg. Centelhamento 
Gráficos das amostras 1 a 5 para 0 segundo de centelhamento:
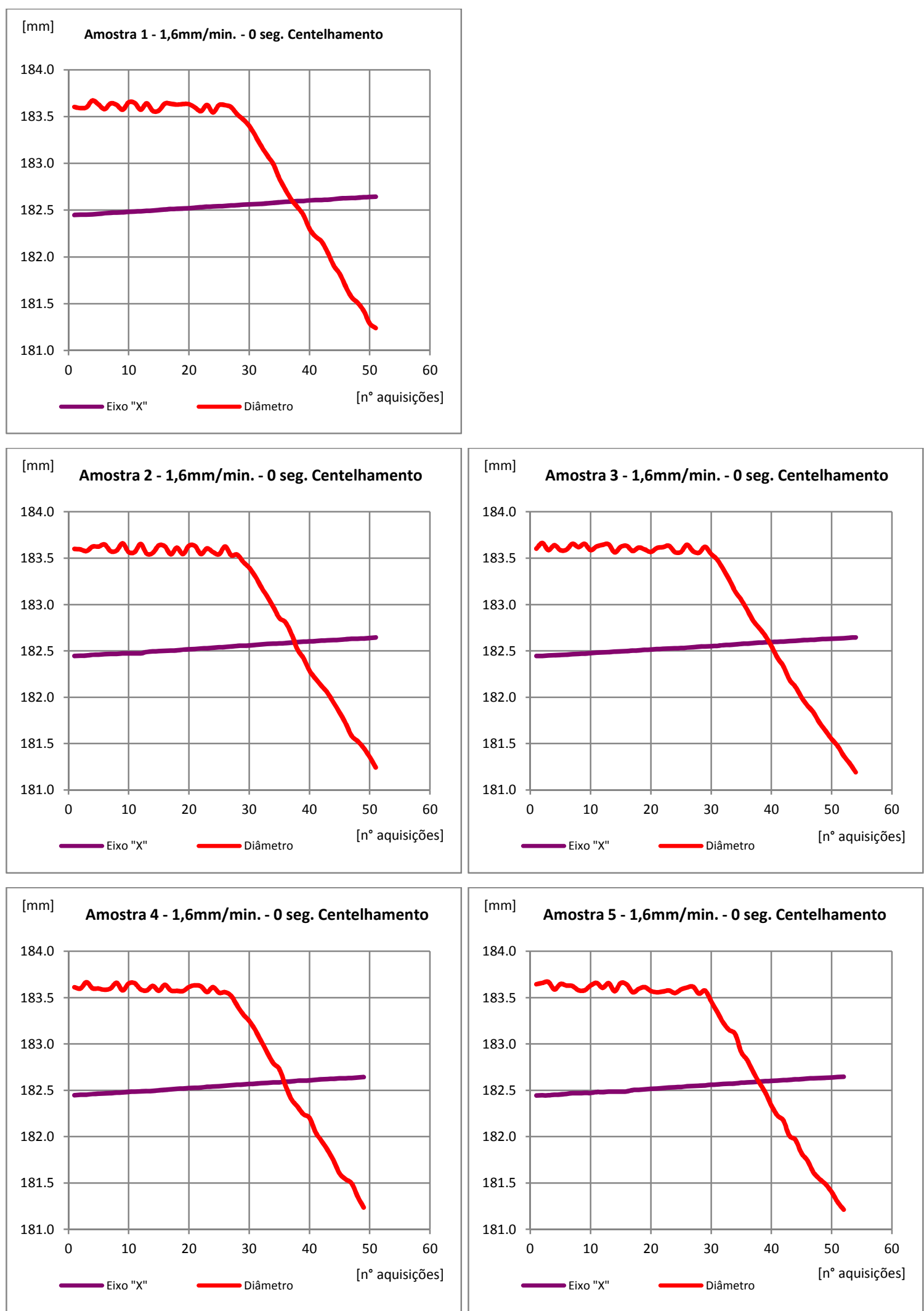

Gráfico 43 - Aquisição dados processo retificação - Vel. 1,6mm/min. 0seg. Centelhamento 
Gráficos das amostras 1 a 5 para 0,3 segundo de centelhamento:
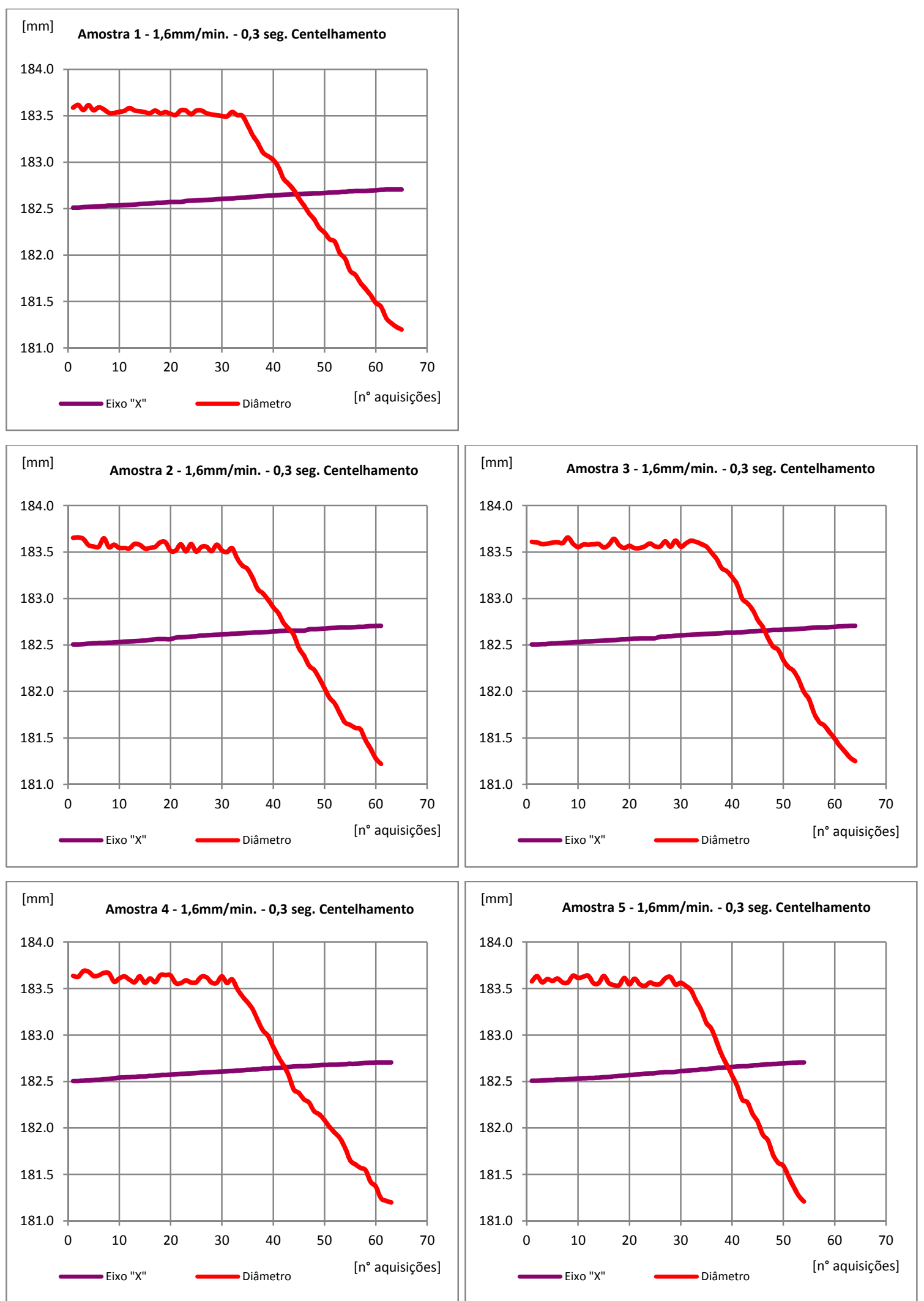

Gráfico 44 - Aquisição dados processo retificação - Vel. 1,6mm/min. 0,3 seg. Centelhamento 
Gráficos das amostras 1 a 5 para 0,6 segundo de centelhamento:
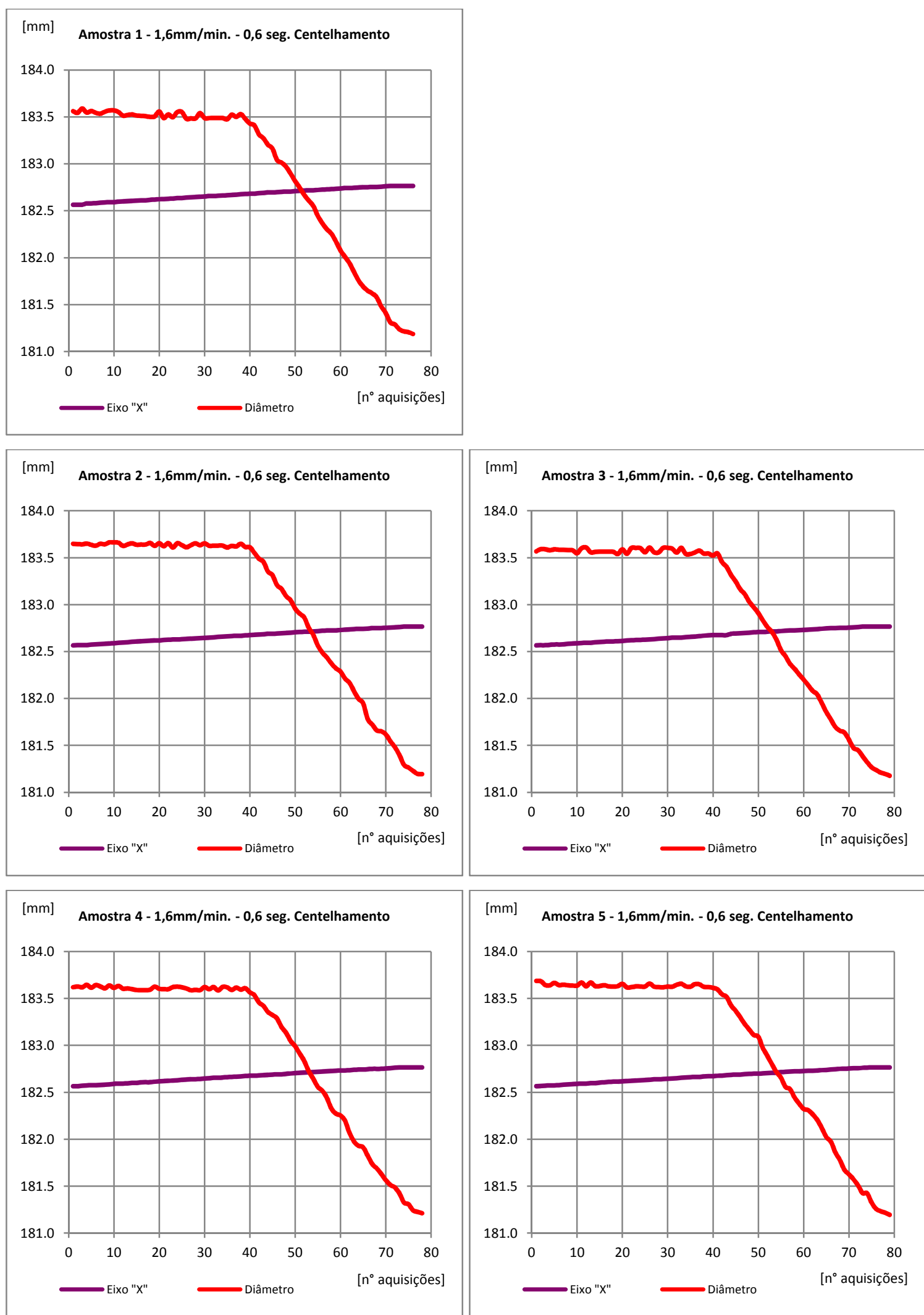

Gráfico 45 - Aquisição dados processo retificação - Vel. 1,6mm/min. 0,6 seg. Centelhamento 
Gráficos das amostras 1 a 5 para 1 segundo de centelhamento:
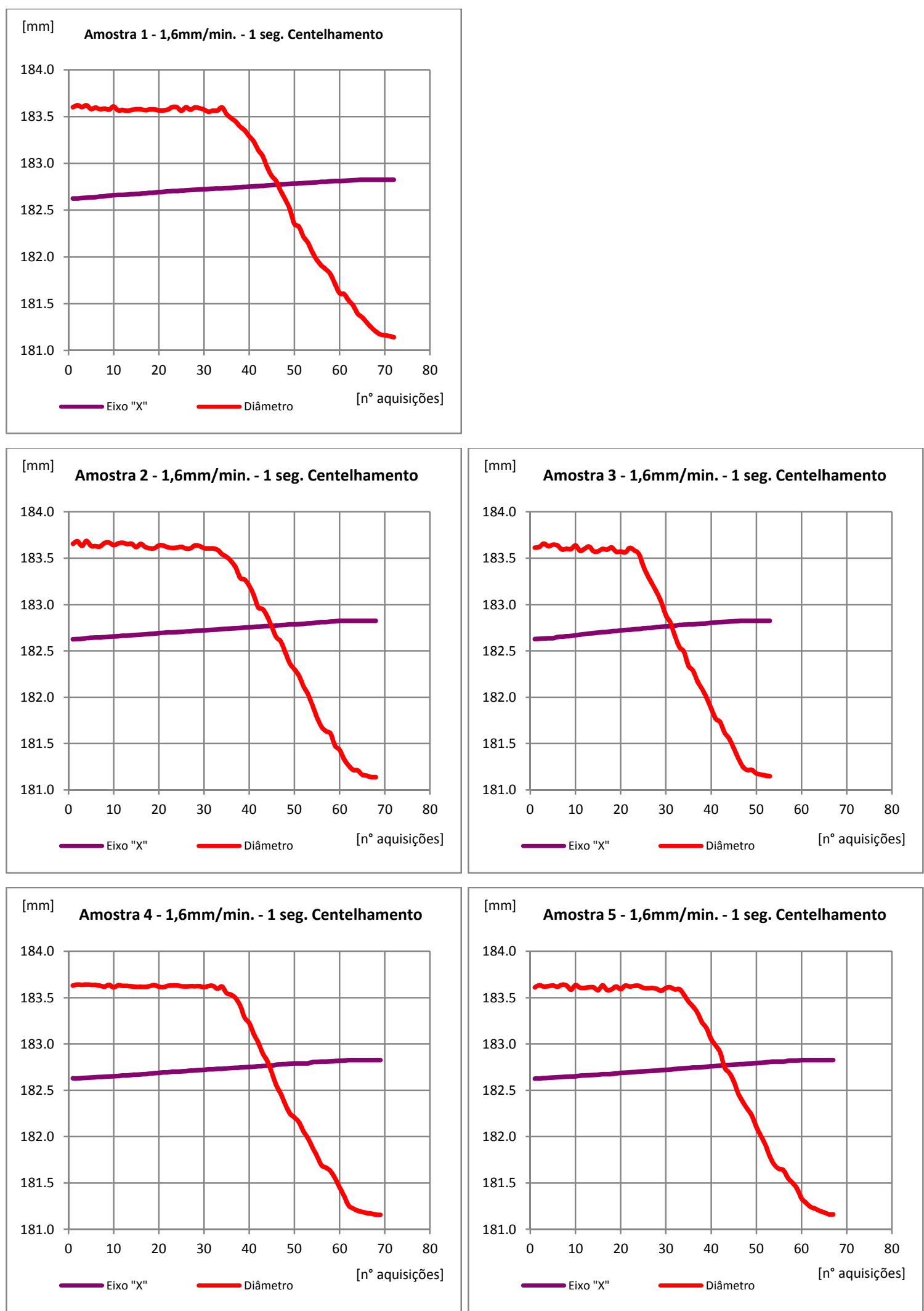

Gráfico 46 - Aquisição dados processo retificação - Vel. 1,6mm/min. 1 seg. Centelhamento 
Gráficos das amostras 1 a 5 para 2 segundos de centelhamento:
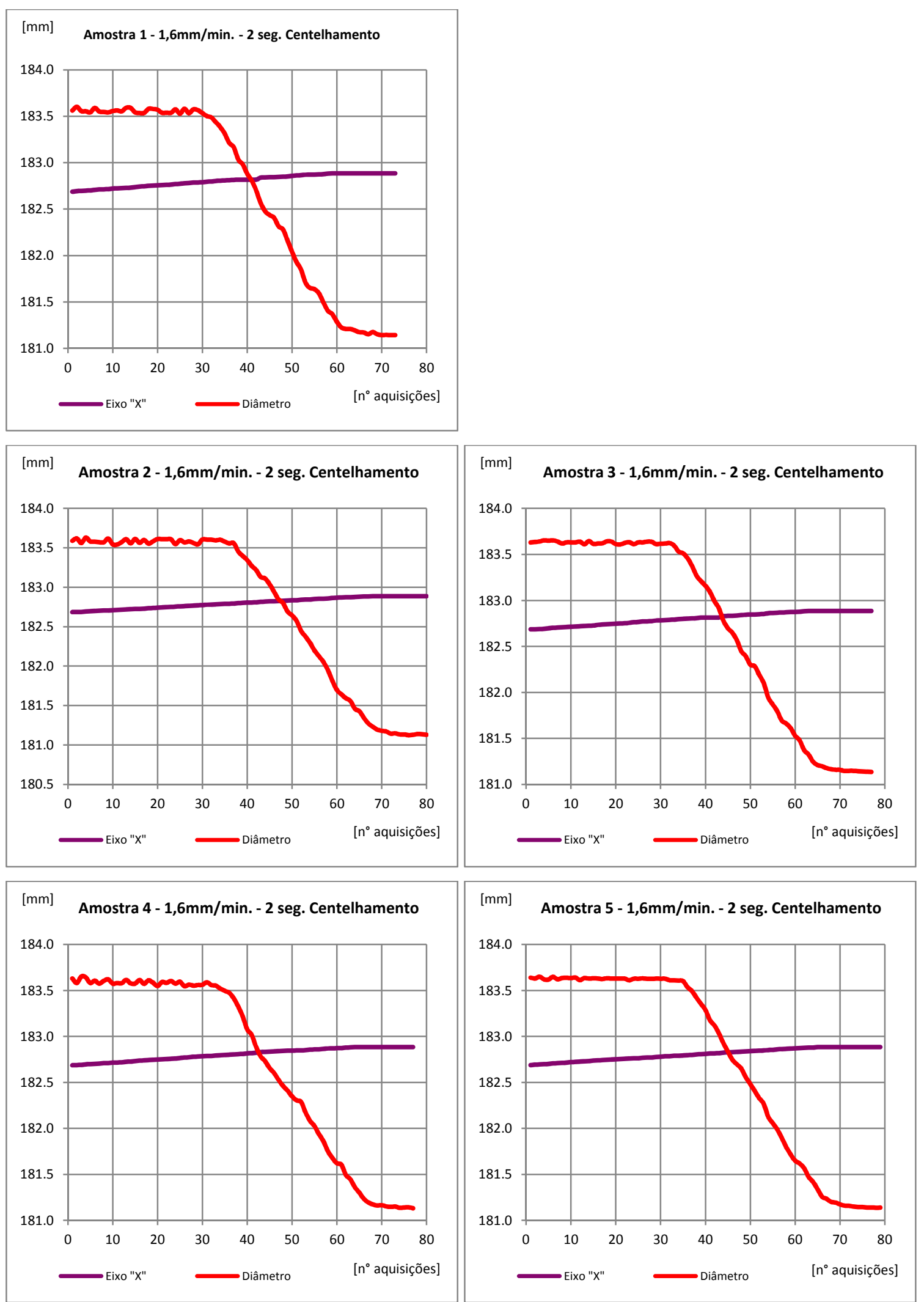

Gráfico 47 - Aquisição dados processo retificação - Vel. 1,6mm/min. 2 seg. Centelhamento 
Gráficos das amostras 1 a 5 para 3 segundos de centelhamento:
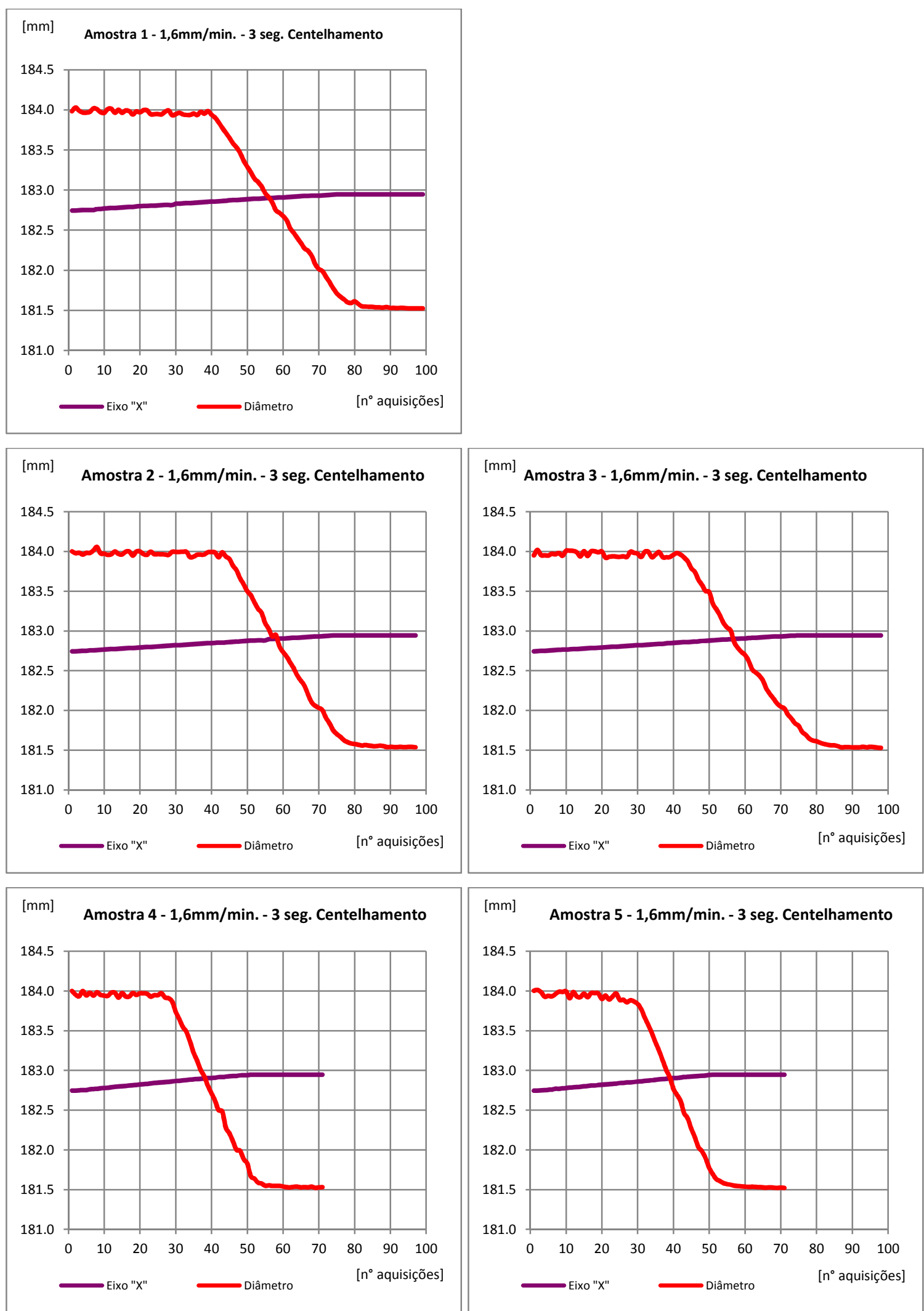

Gráfico 48 - Aquisição dados processo retificação - Vel. 1,6mm/min. 3 seg. Centelhamento 
Gráficos das amostras 1 a 5 para 0 segundo de centelhamento:
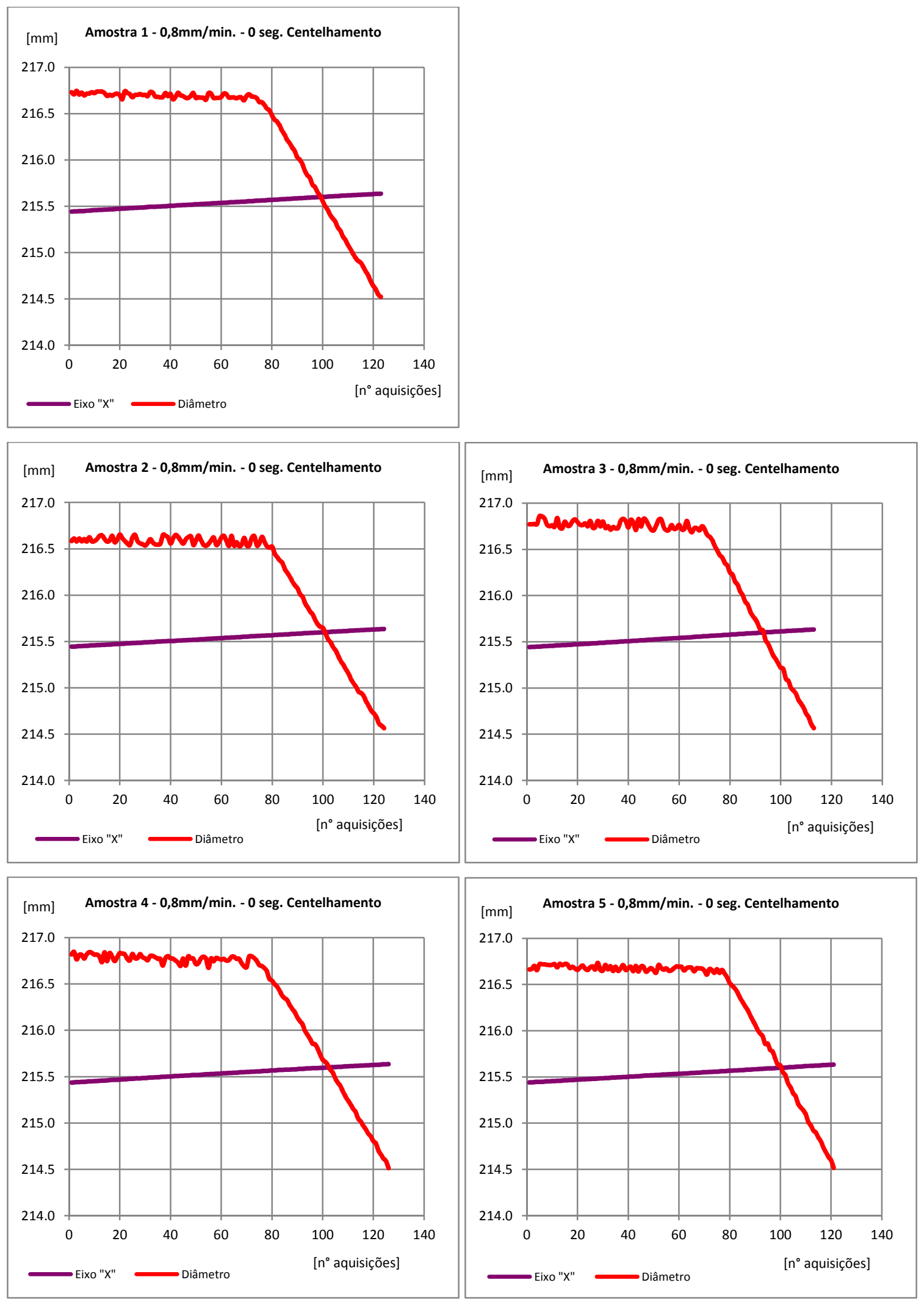

Gráfico 49 - Aquisição dados processo retificação - Vel. 0,8mm/min. 0 seg. Centelhamento 
Gráficos das amostras 1 a 5 para 0,3 segundo de centelhamento:
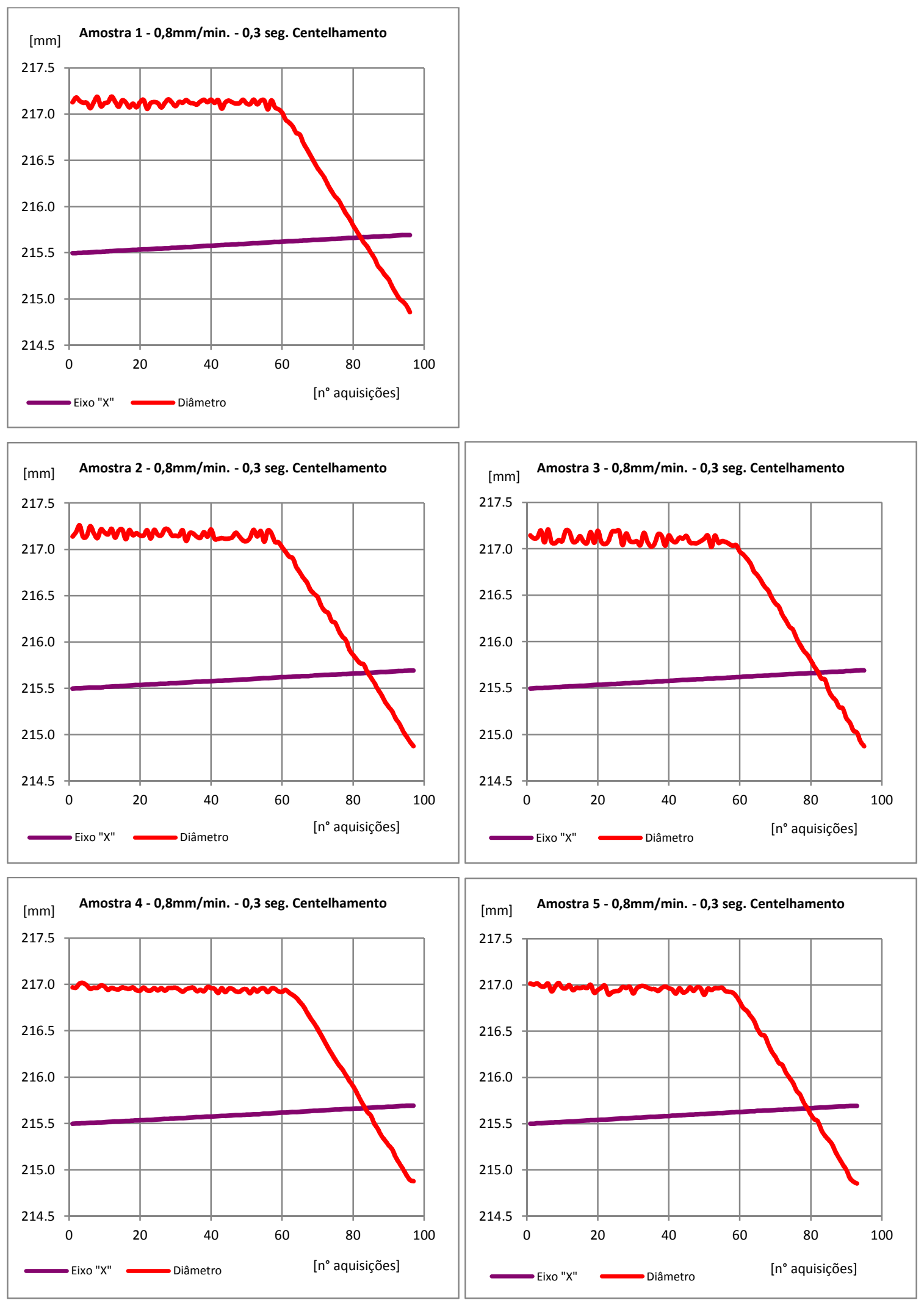

Gráfico 50 - Aquisição dados processo retificação - Vel. 0,8mm/min. 0,3 seg. Centelhamento 
Gráficos das amostras 1 a 5 para 0,6 segundo de centelhamento:
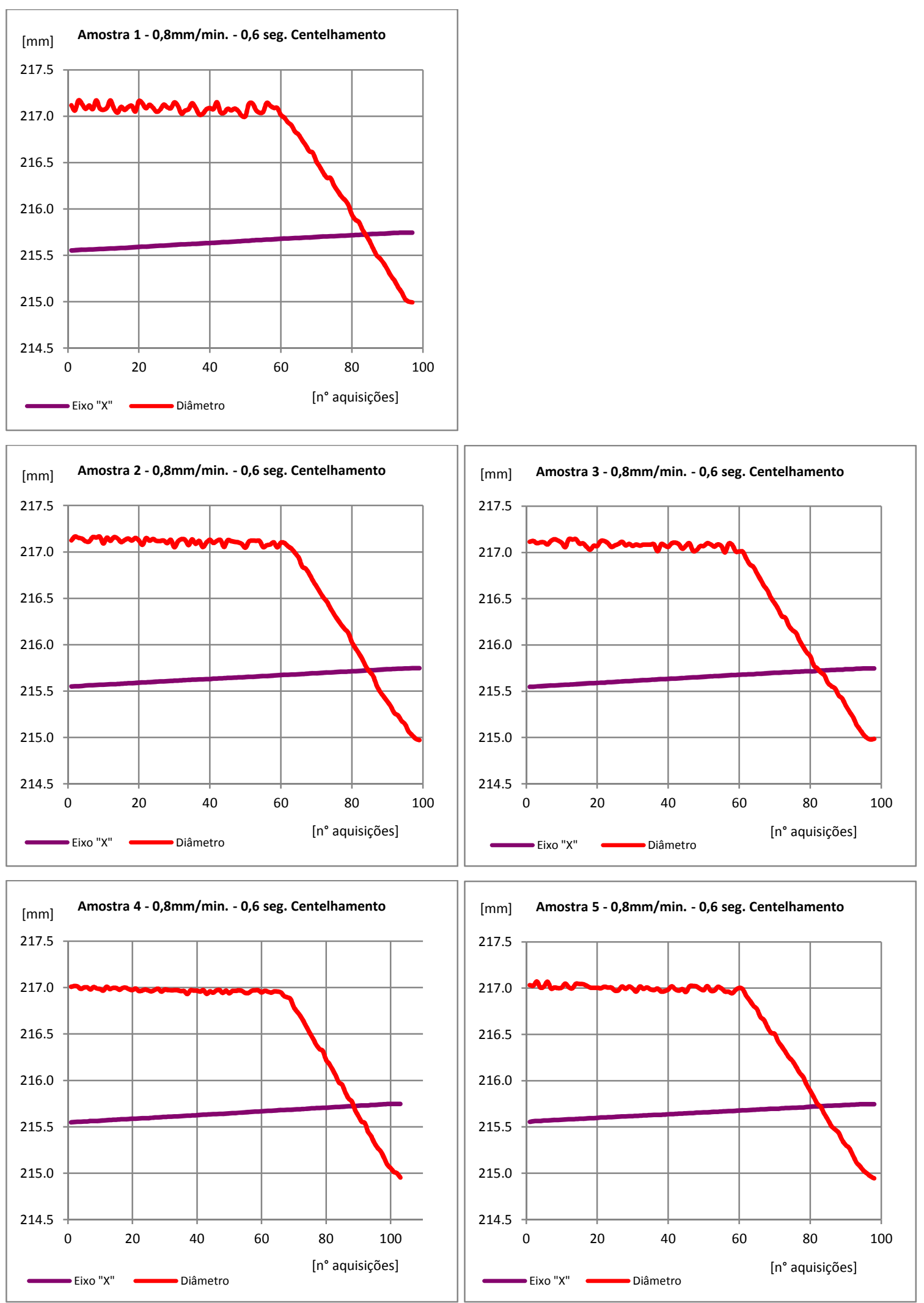

Gráfico 51 - Aquisição dados processo retificação - Vel. 0,8mm/min. 0,6 seg. Centelhamento 
Gráficos das amostras 1 a 5 para 1 segundo de centelhamento:
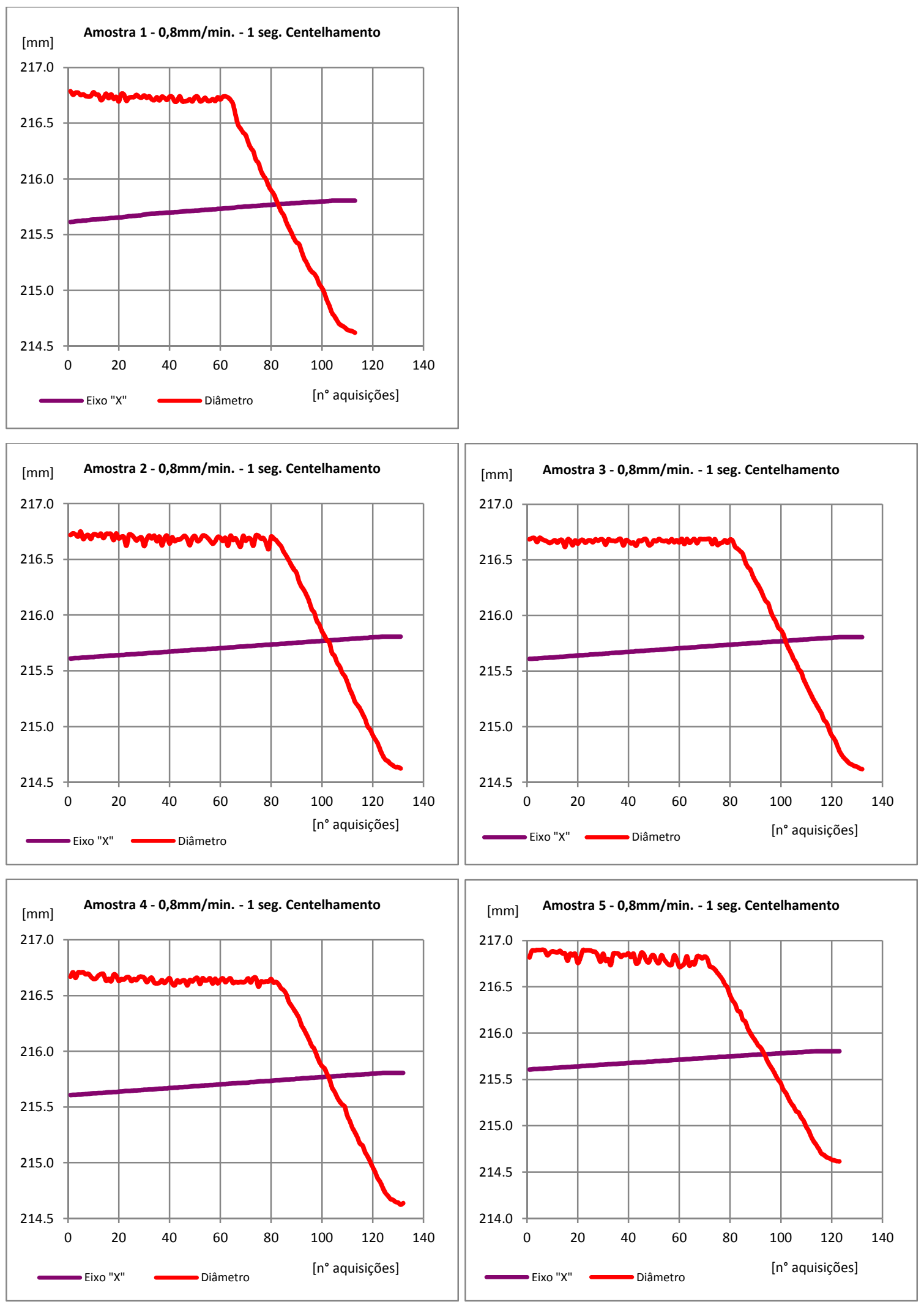

Gráfico 52 - Aquisição dados processo retificação - Vel. 0,8mm/min. 1 seg. Centelhamento 
Gráficos das amostras 1 a 5 para 2 segundos de centelhamento:
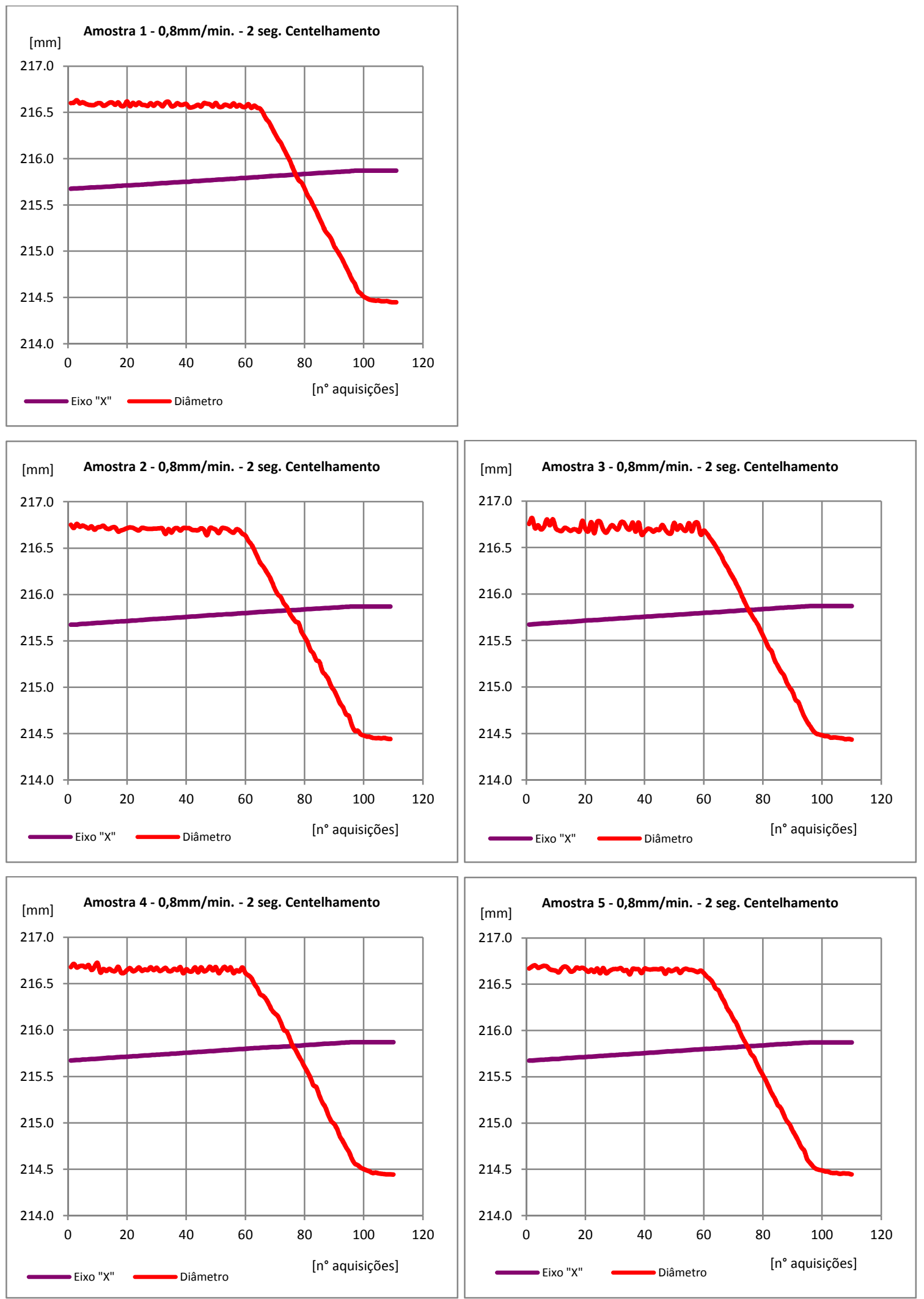

Gráfico 53 - Aquisição dados processo retificação - Vel. 0,8mm/min. 2 seg. Centelhamento 
Gráficos das amostras 1 a 5 para 3 segundos de centelhamento:
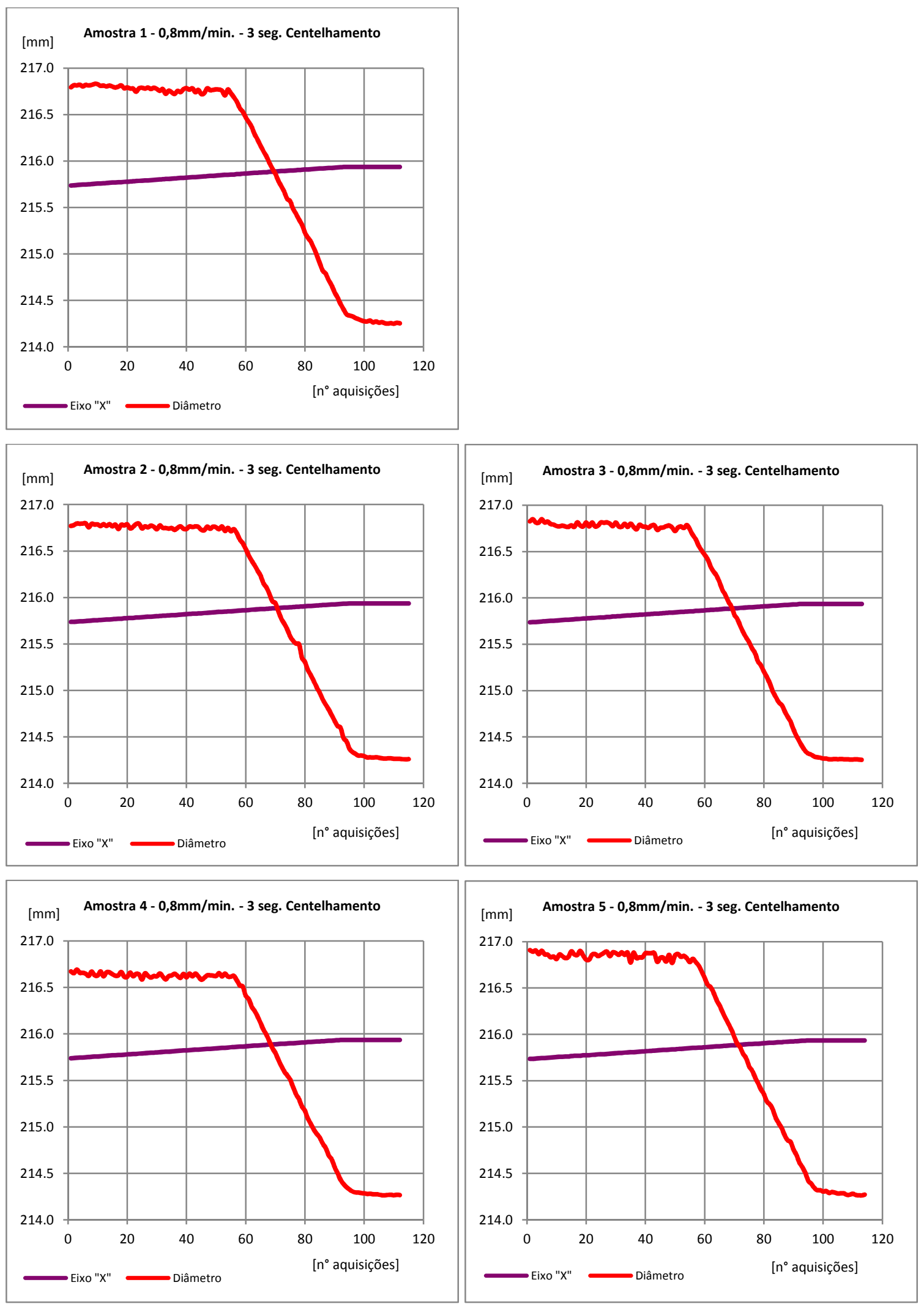

Gráfico 54 - Aquisição dados processo retificação - Vel. 0,8mm/min. 3 seg. Centelhamento 
Gráficos das amostras 1 a 5 para 0 segundo de centelhamento:
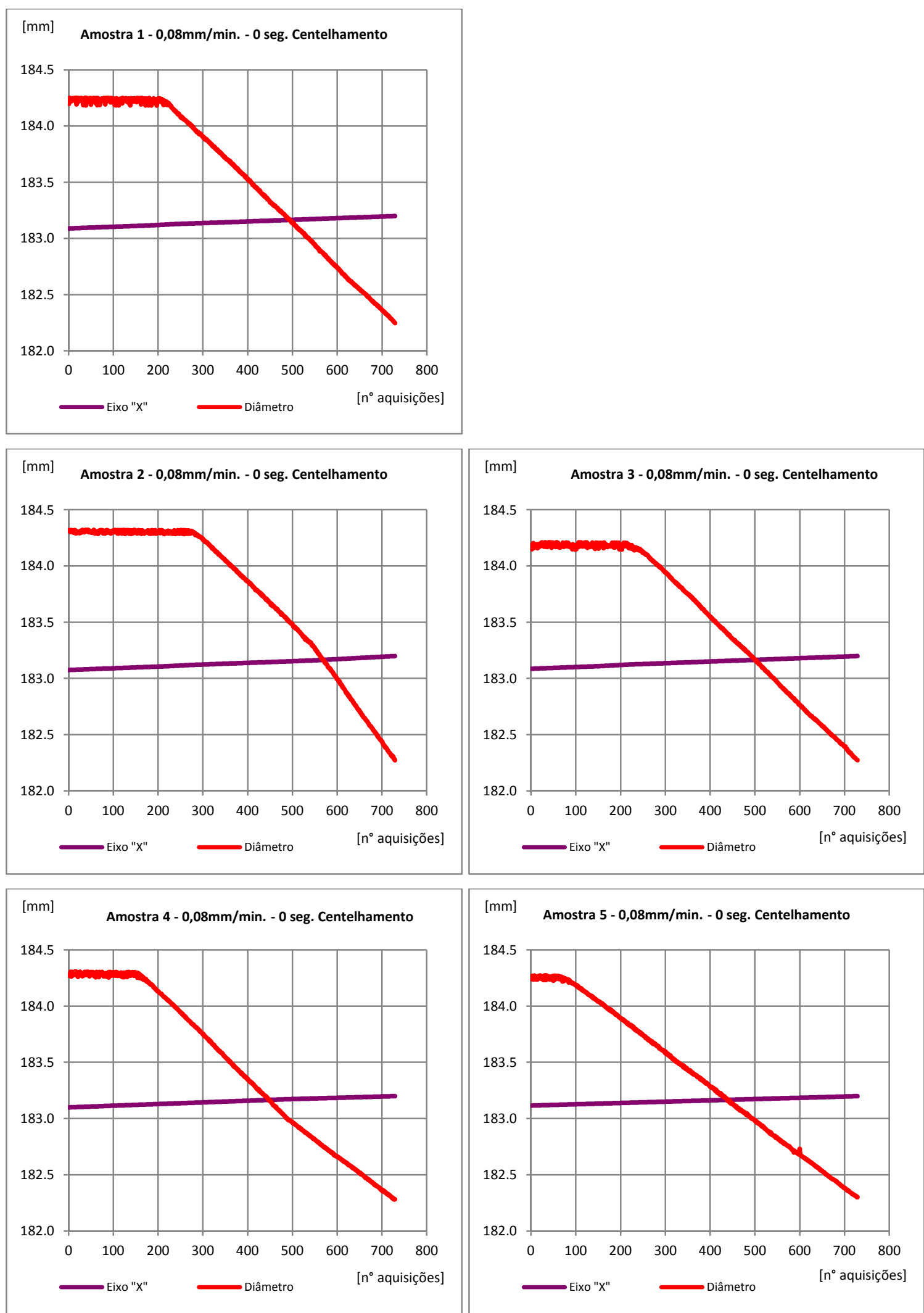

Gráfico 55 - Aquisição dados processo retificação - Vel. 0,08mm/min. 0 seg. Centelhamento 
Gráficos das amostras 1 a 5 para 0,3 segundo de centelhamento:
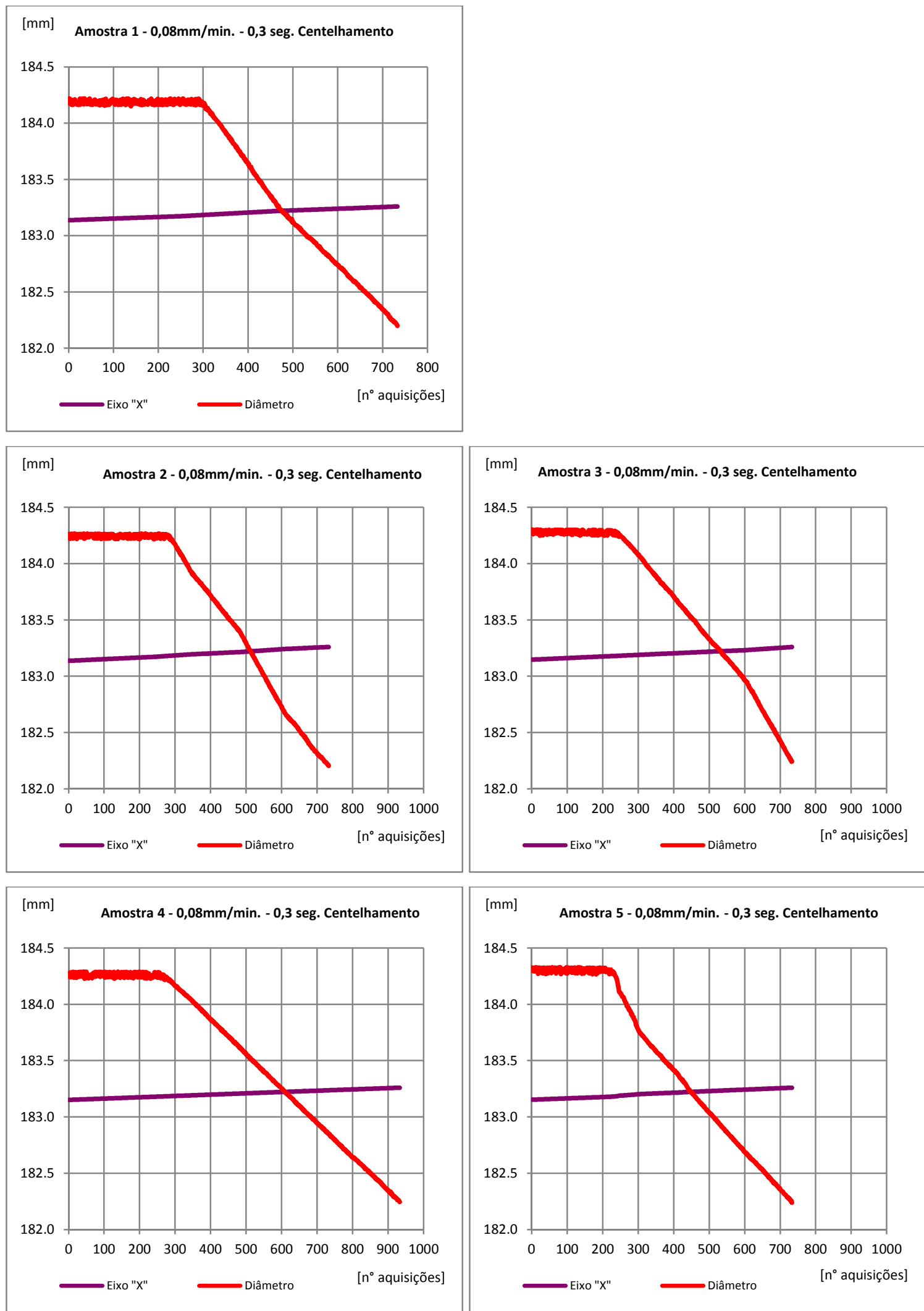

Gráfico 56 - Aquisição dados processo retificação - Vel. 0,08mm/min. 0,3 seg. Centelhamento 
Gráficos das amostras 1 a 5 para 0,6 segundo de centelhamento:
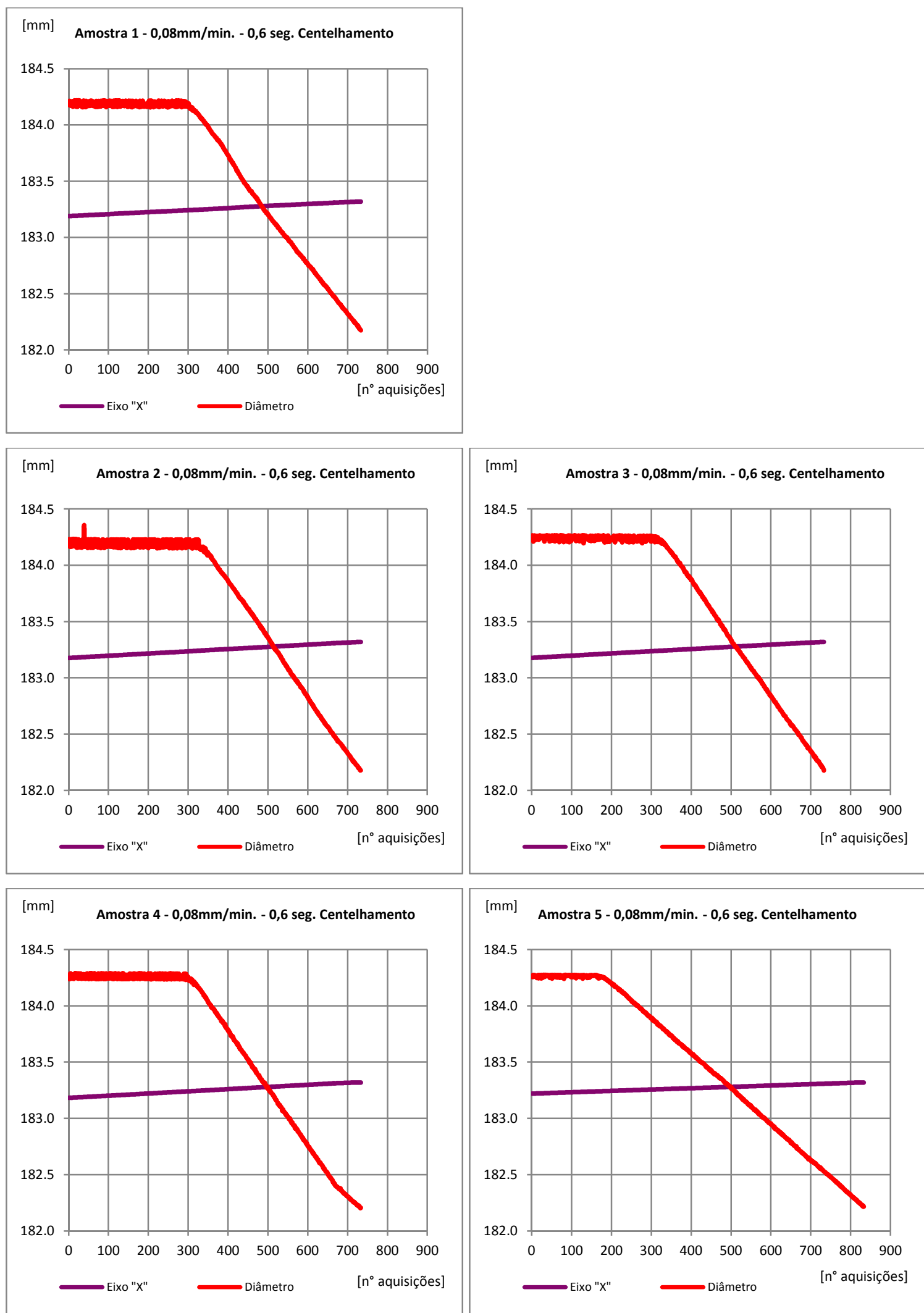

Gráfico 57 - Aquisição dados processo retificação - Vel. 0,08mm/min. 0,6 seg. Centelhamento 
Gráficos das amostras 1 a 5 para 1 segundo de centelhamento:
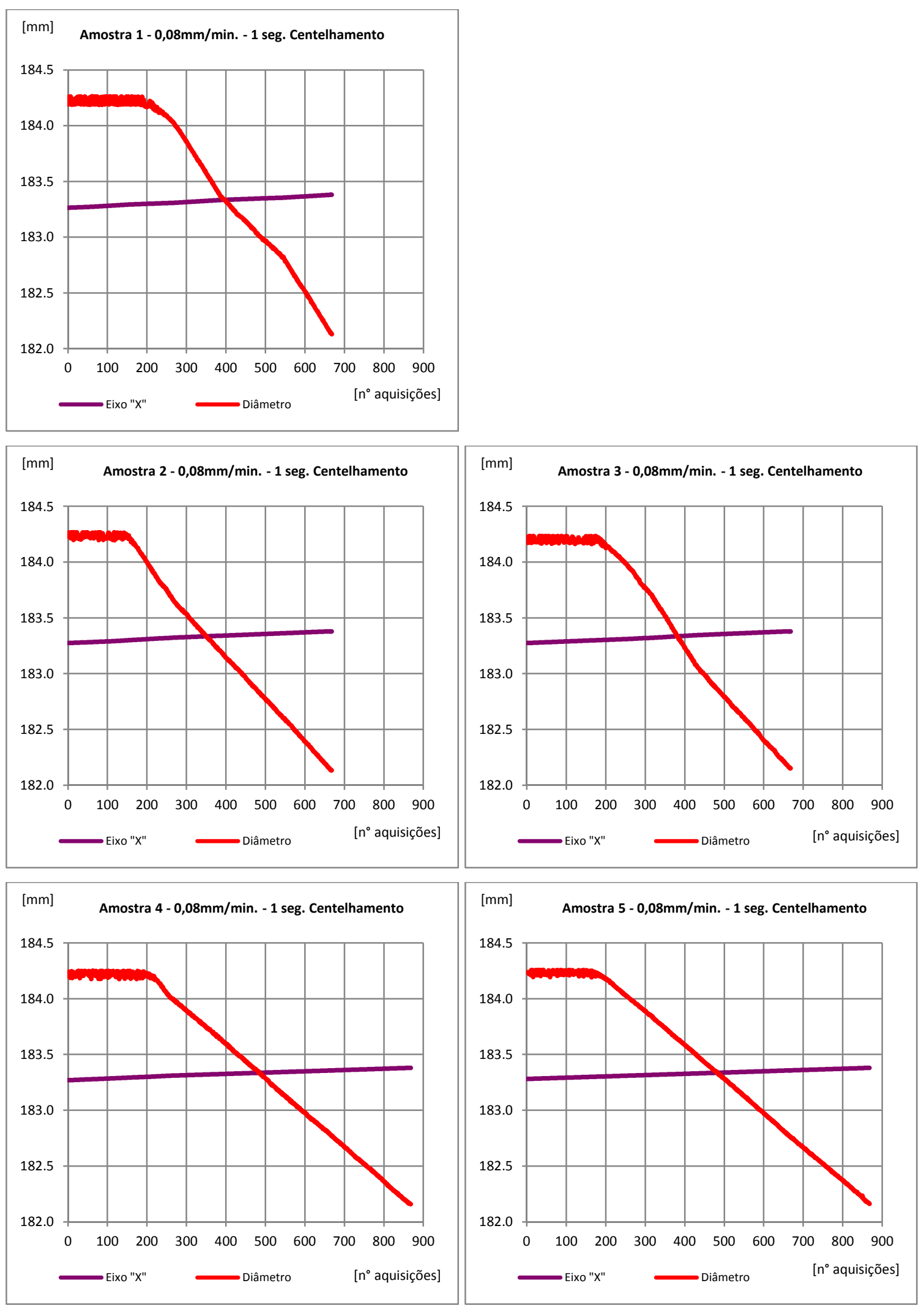

Gráfico 58 - Aquisição dados processo retificação - Vel. 0,08mm/min. 1 seg. Centelhamento 
Gráficos das amostras 1 a 5 para 2 segundos de centelhamento:
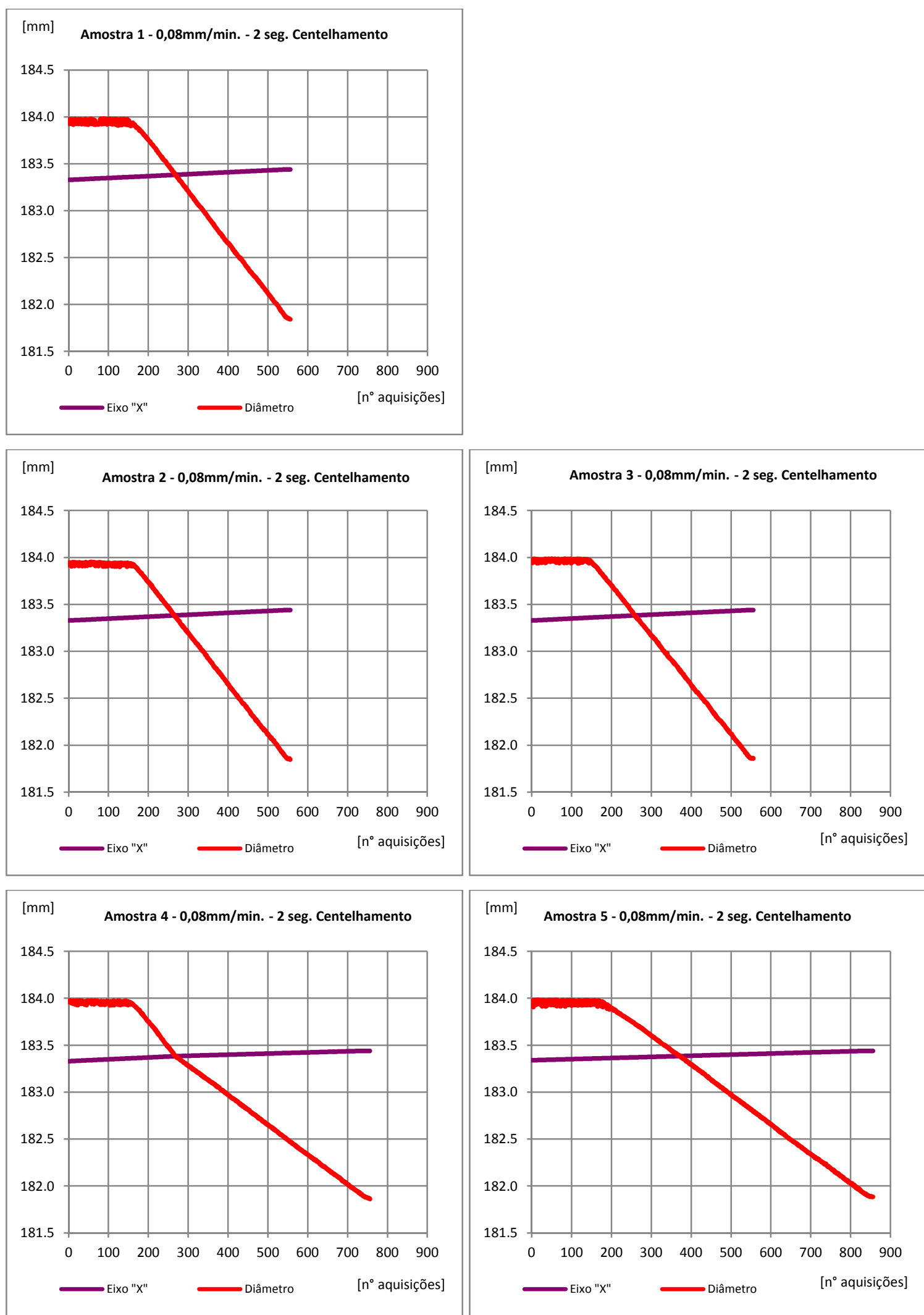

Gráfico 59 - Aquisição dados processo retificação - Vel. 0,08mm/min. 2 seg. Centelhamento 
Gráficos das amostras 1 a 5 para 3 segundos de centelhamento:
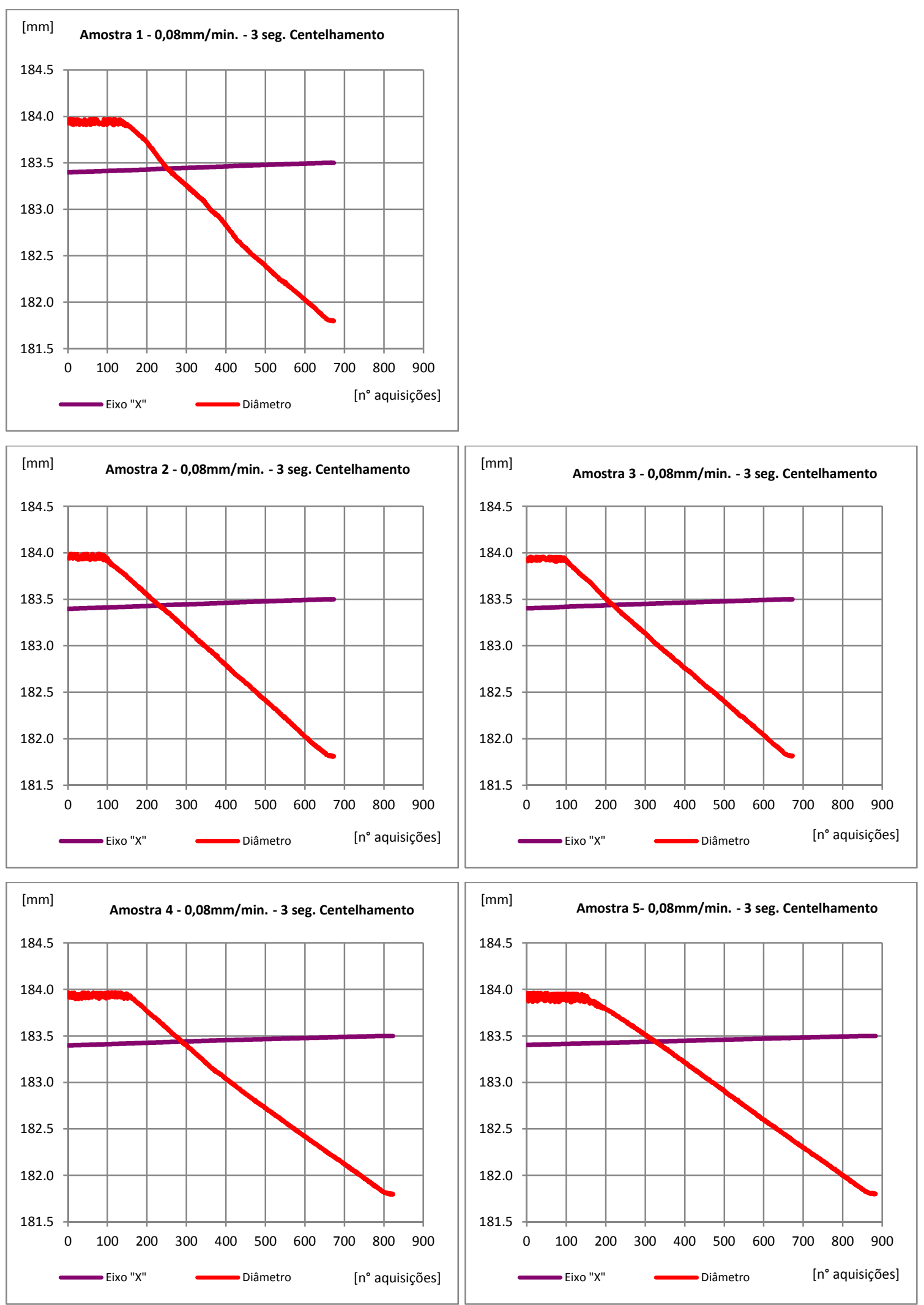

Gráfico 60 - Aquisição dados processo retificação - Vel. 0,08mm/min. 3 seg. Centelhamento 


\section{APÊNDICE II - CURVAS EXPERIMENTAIS EXCEL ${ }^{\circledR}$ E MATLAB ${ }^{\circledR}$ T X "CENT."}

Curvas experimentais veloc. $3,0 \mathrm{~mm} / \mathrm{min}$. - Tempo de centelhamento $0 \mathrm{seg}$. - amostras 1 a 5:
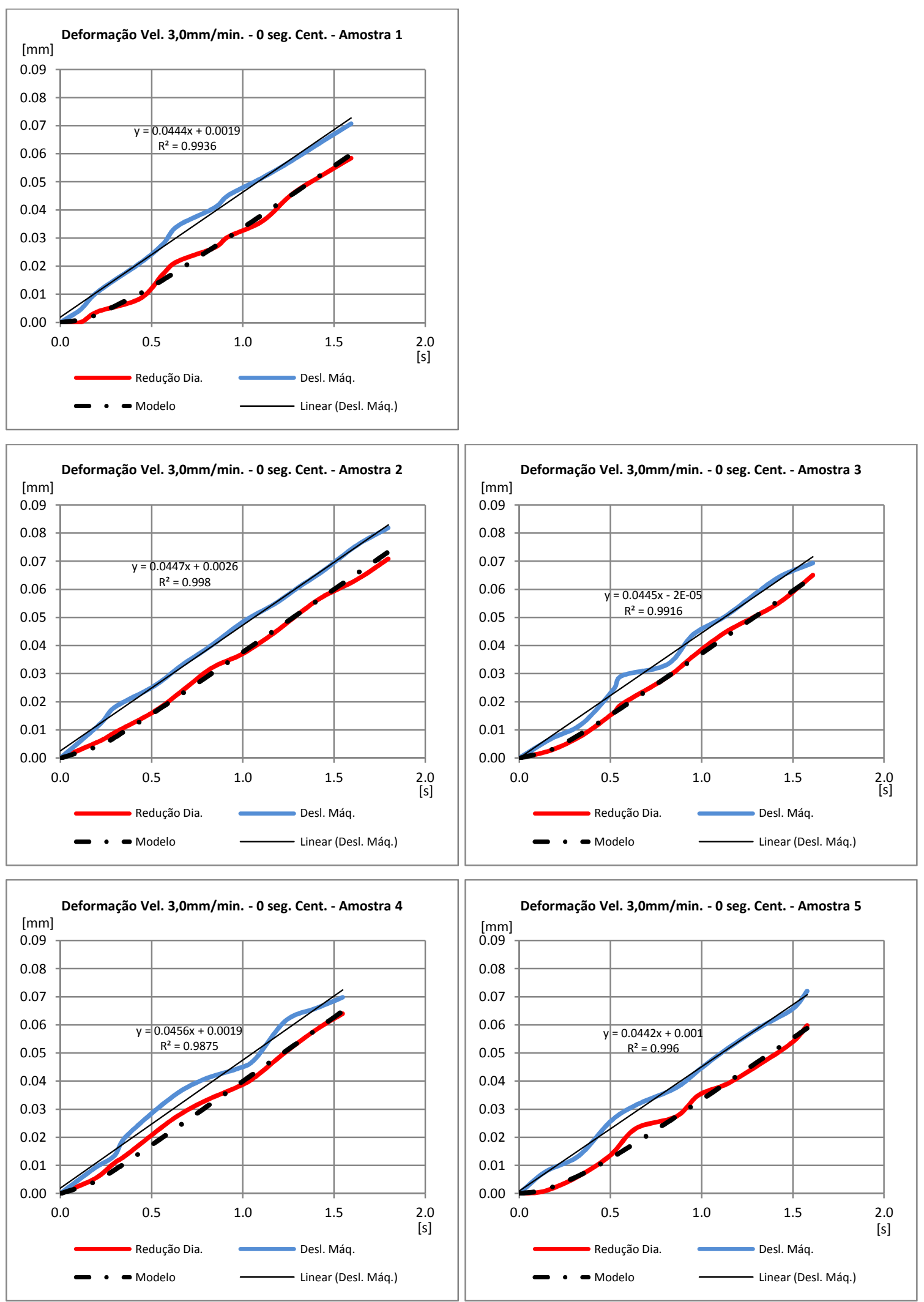

Gráfico 61 - Curvas Experimentais Excel ${ }^{\circledR}$ - Vel. 3,0mm/min. - 0 seg. Centelhamento 
Ajuste curvas MatLab ${ }^{\circledR}$ veloc. 3,0 mm/min.- Tempo de centelhamento 0 seg. - amostras 1 a 5:
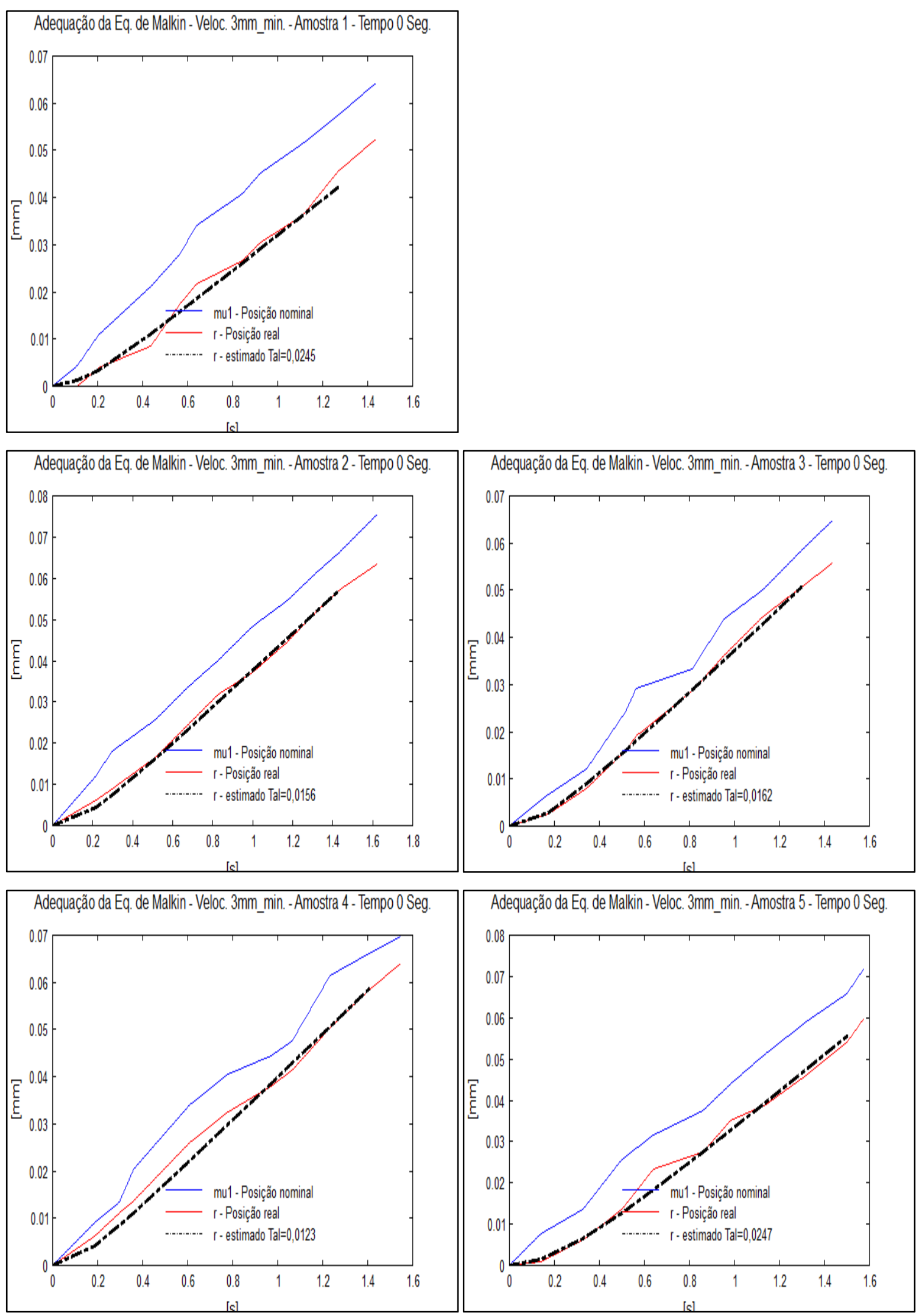

Gráfico 62 - Curvas Experimentais MatLab ${ }^{\circledR}$ - Vel. 3,0mm/min. - Tempo 0 Seg. Centelhamento. 
Curvas experimentais veloc. 3,0 mm/min.- Tempo de centelhamento 0,6 seg. - amostras 1 a 5:
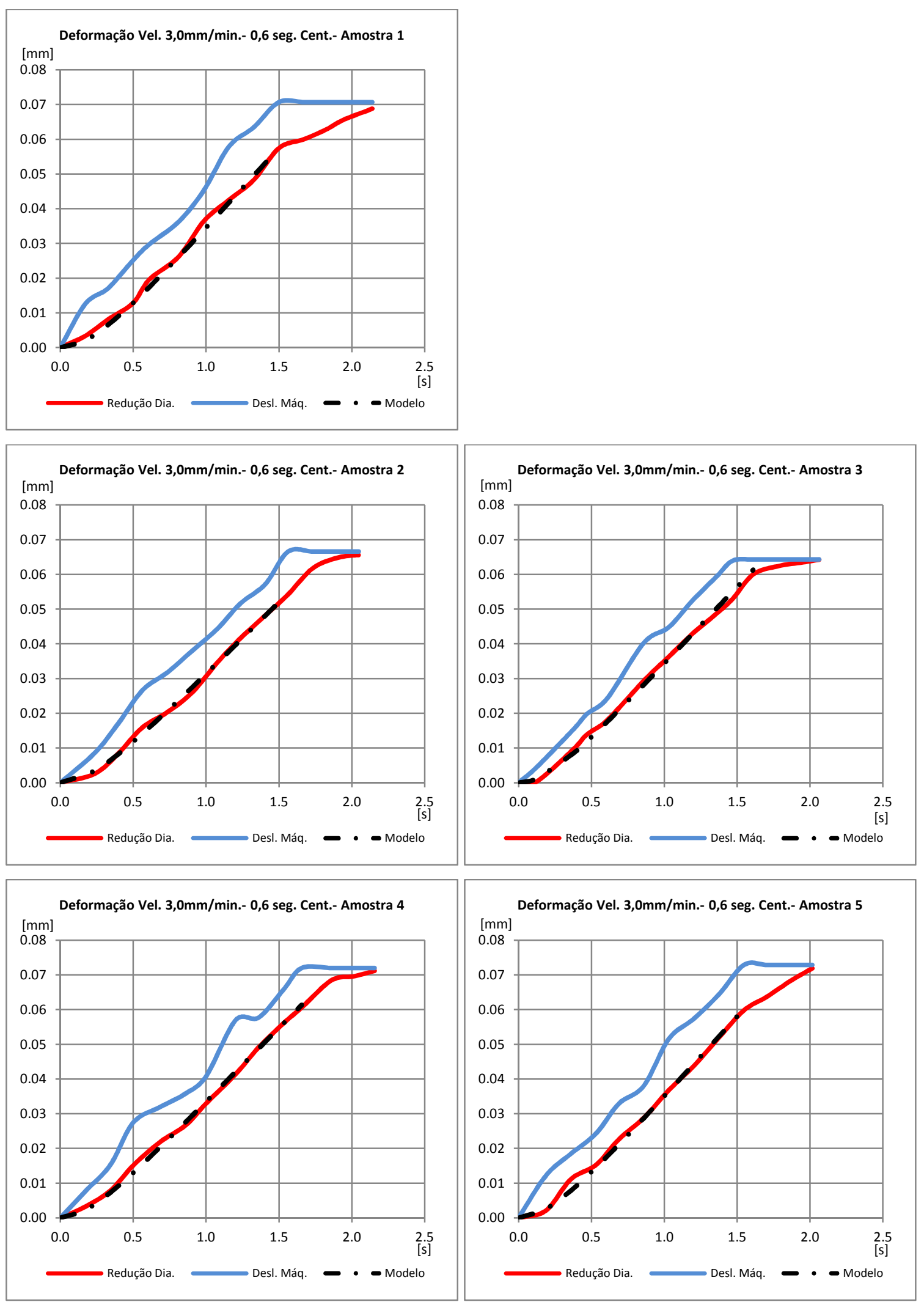

Gráfico 63 - Curvas Experimentais Excel ${ }^{\circledR}$ - Vel. 3,0mm/min. - 0,6 seg. Centelhamento 
Ajuste curvas MatLab ${ }^{\circledR}$ veloc. 3,0 mm/min.- Tempo de centelhamento 0,6 seg. amostras 1 a 5:
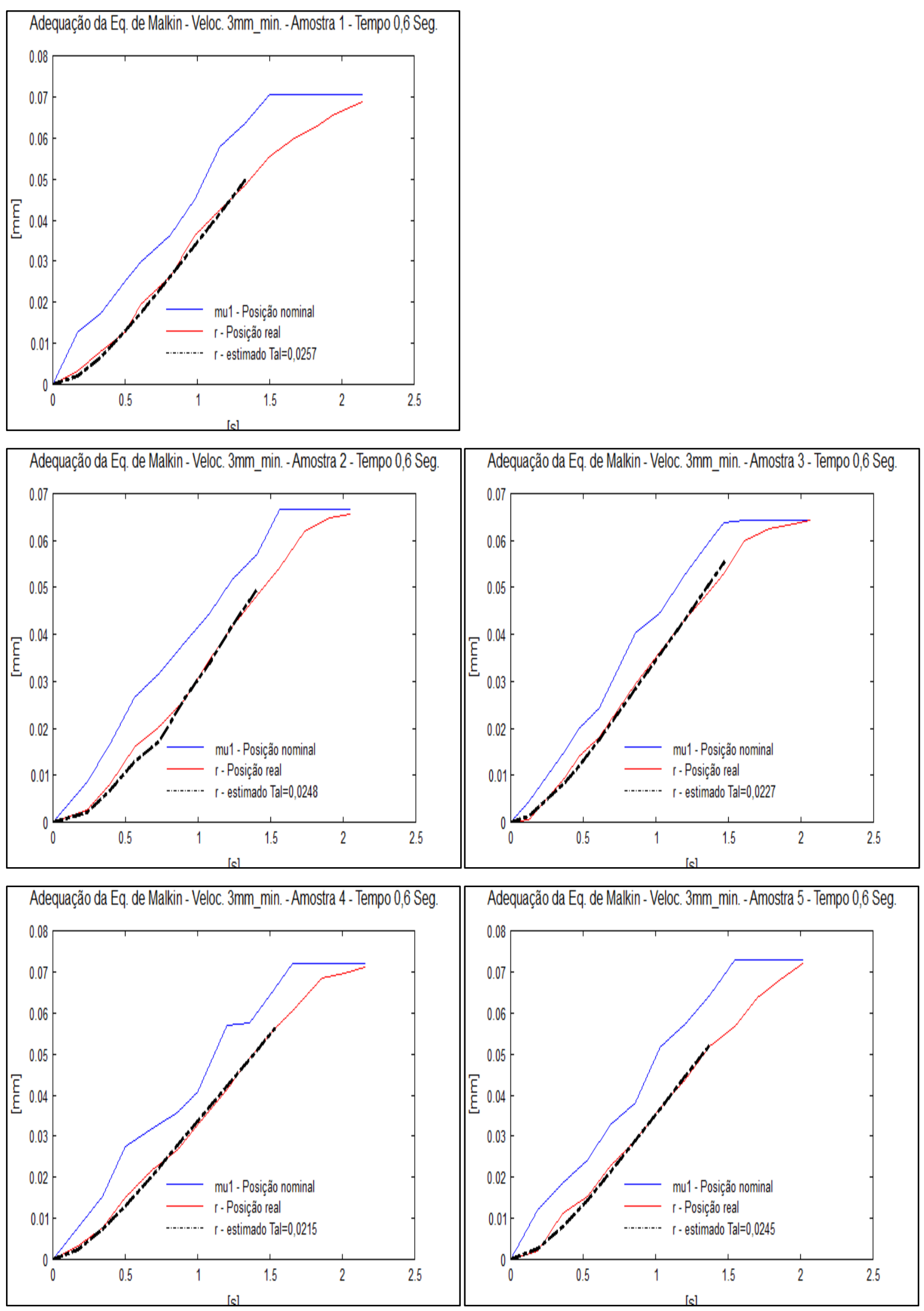

Gráfico 64 - Curvas Experimentais MatLab ${ }^{\circledR}$ - Vel. 3,0mm/min. - Tempo 0,6 Seg. Centelhamento. 
Curvas experimentais veloc. 3,0 mm/min. - Tempo de centelhamento $1 \mathrm{seg}$. - amostras $1 \mathrm{a} 5$ :
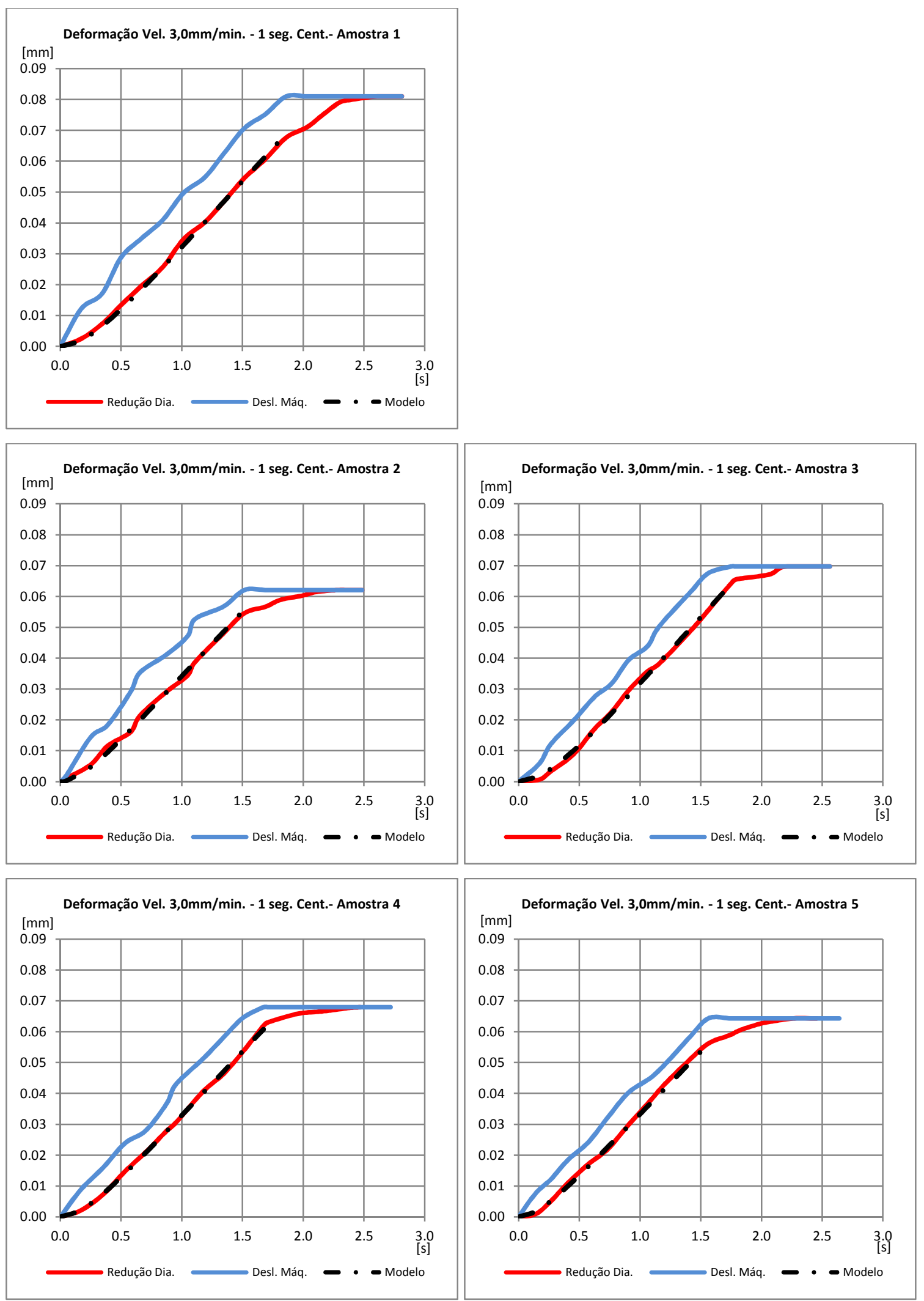

Gráfico 65 - Curvas Experimentais Excel ${ }^{\circledR}$ - Vel. 3,0mm/min. - 1 seg. Centelhamento 
Ajuste curvas MatLab ${ }^{\circledR}$ veloc. 3,0 mm/min.- Tempo de centelhamento $1 \mathrm{seg}$. - amostras 1 a 5:
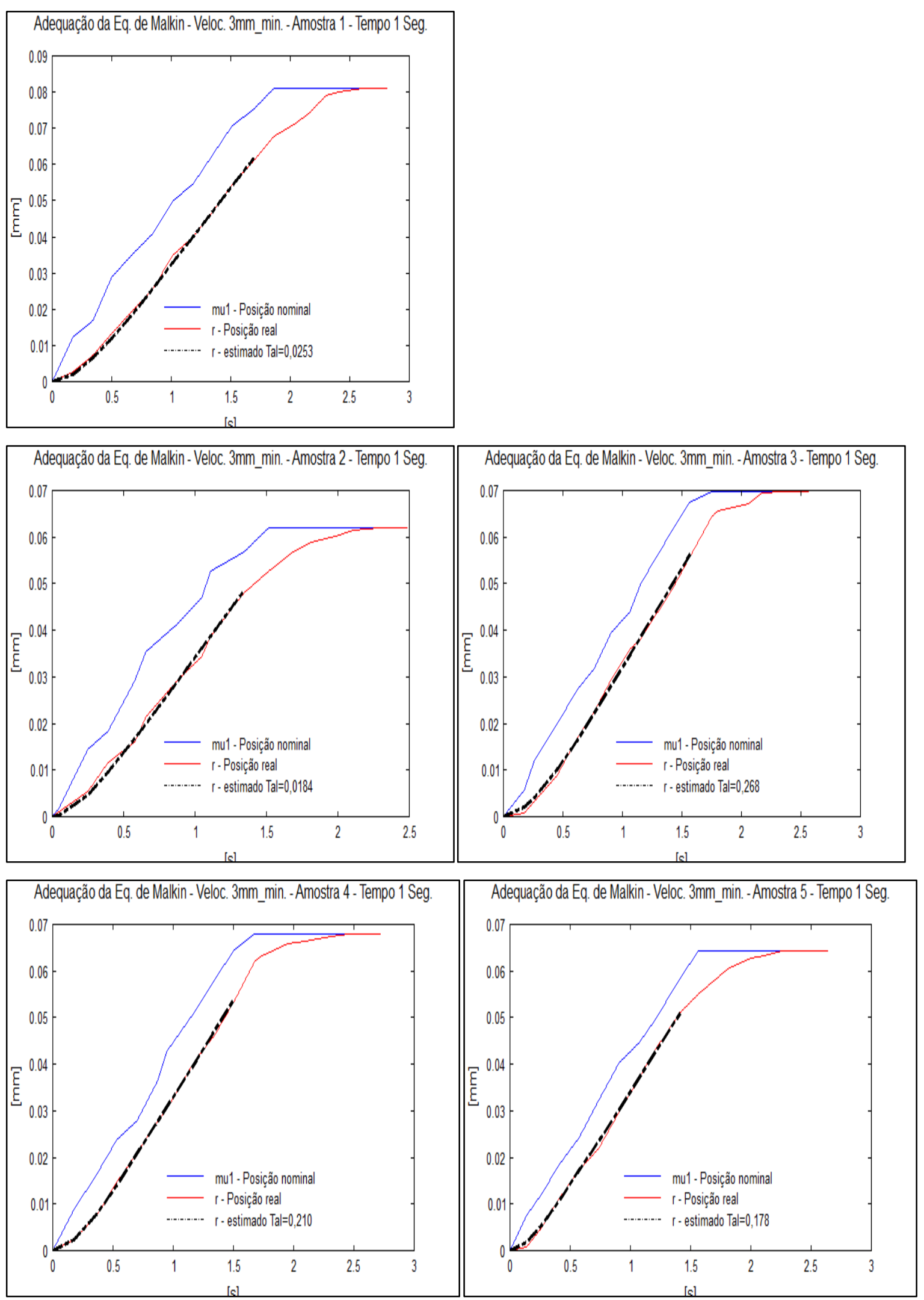

Gráfico 66 - Curvas Experimentais MatLab ${ }^{\circledR}$ - Vel. 3,0mm/min. - Tempo 1 Seg. Centelhamento. 
Curvas experimentais veloc. 3,0 mm/min. - Tempo de centelhamento 2 seg. - amostras 1 a 5 :
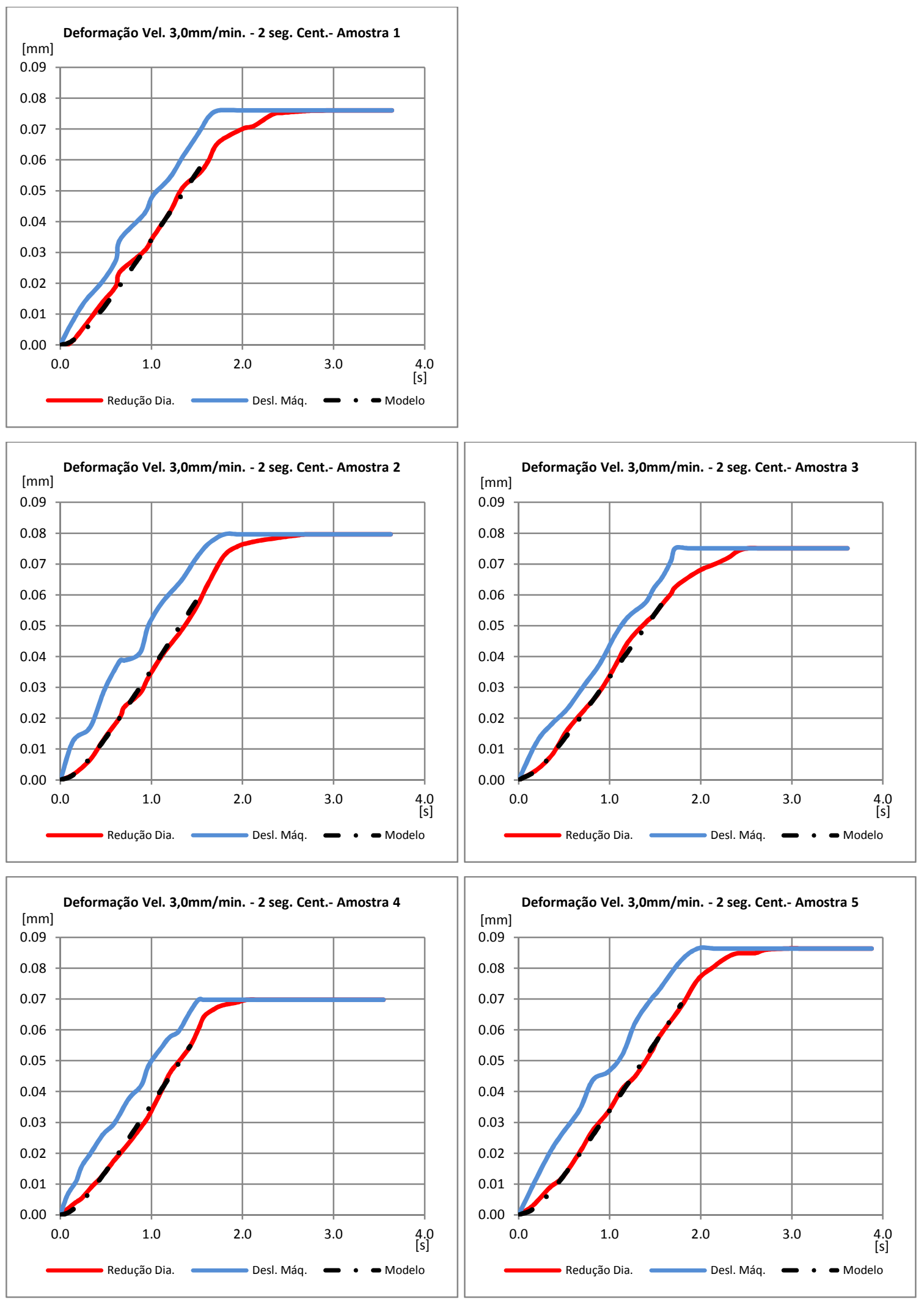

Gráfico 67 - Curvas Experimentais Excel ${ }^{\circledR}$ - Vel. 3,0mm/min. - 2 seg. Centelhamento 
Ajuste curvas MatLab ${ }^{\circledR}$ veloc. 3,0 mm/min.- Tempo de centelhamento 2 seg. - amostras 1 a 5:
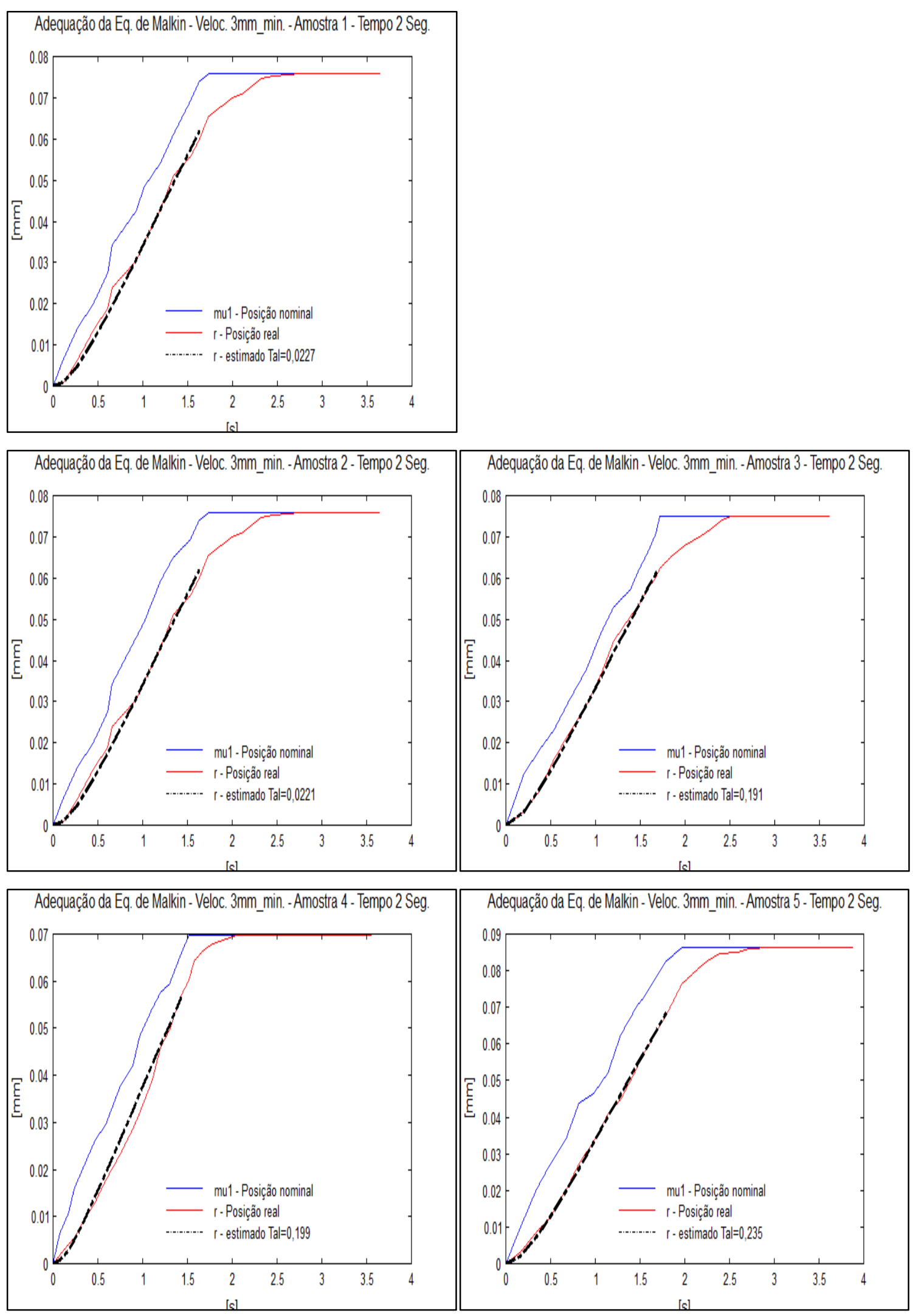

Gráfico 68 - Curvas Experimentais MatLab ${ }^{\circledR}$ - Vel. 3,0mm/min. - Tempo 2 Seg. Centelhamento. 
Curvas experimentais veloc. 3,0 mm/min. - Tempo de centelhamento $3 \mathrm{seg}$. - amostras 1 a 5:
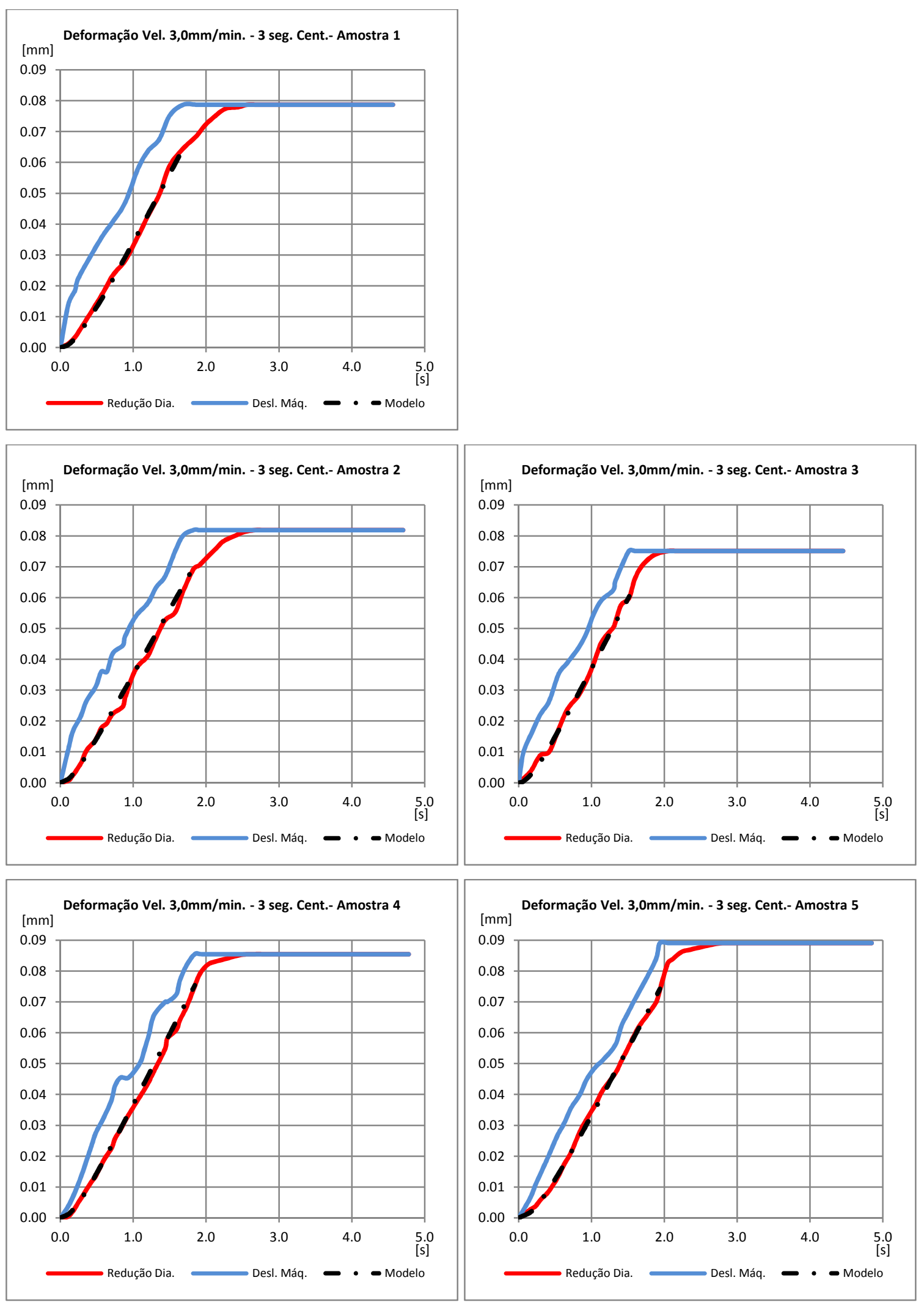

Gráfico 69 - Curvas Experimentais Excel ${ }^{\circledR}$ - Vel. 3,0mm/min. - 3 seg. Centelhamento 
Ajuste curvas MatLab ${ }^{\circledR}$ veloc. 3,0 mm/min.- Tempo de centelhamento 3 seg. - amostras 1 a 5:
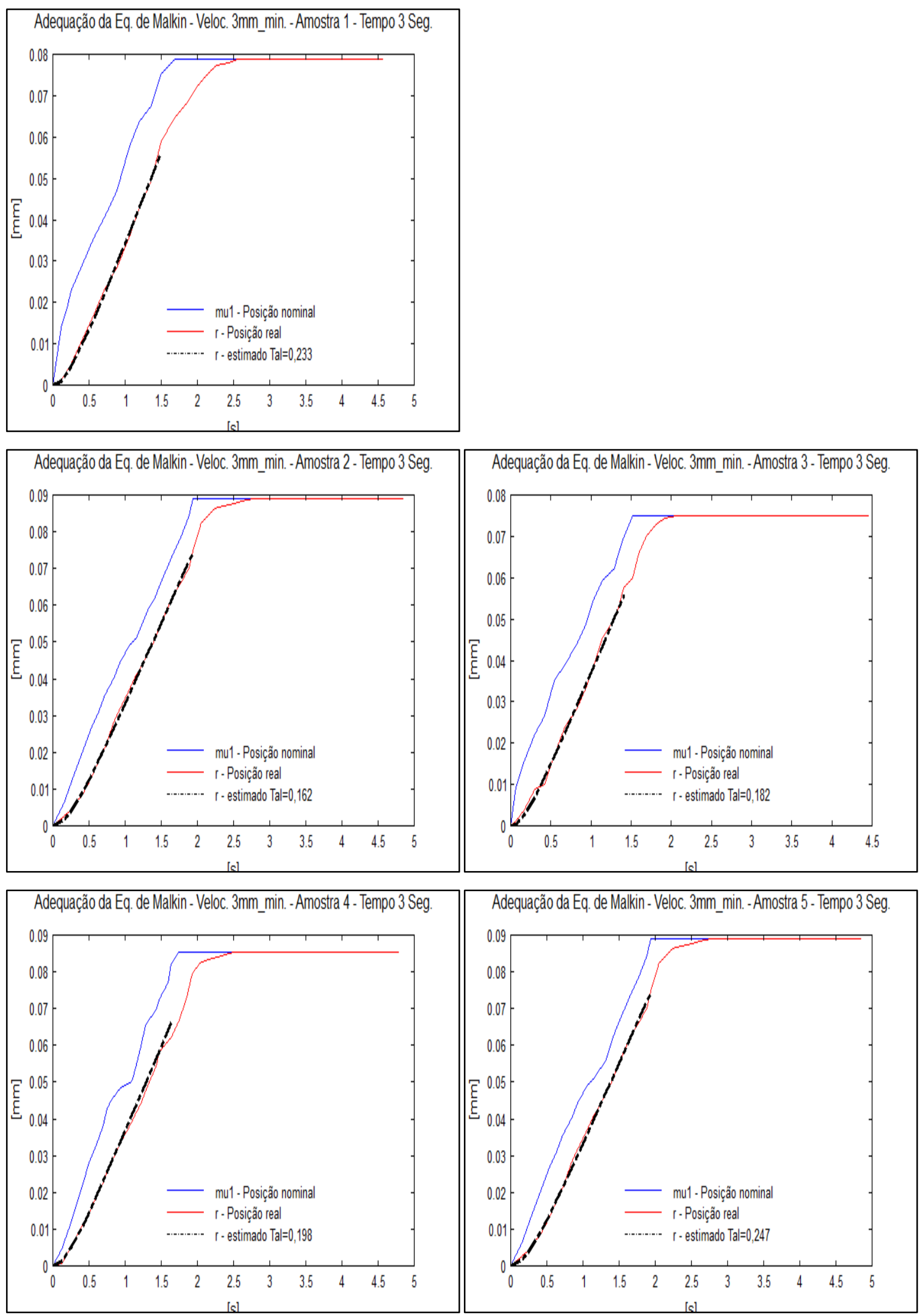

Gráfico 70 - Curvas Experimentais MatLab ${ }^{\circledR}$ - Vel. 3,0mm/min. - Tempo 3 Seg. Centelhamento. 
Curvas experimentais veloc. $2,5 \mathrm{~mm} / \mathrm{min}$. - Tempo de centelhamento 0 seg. - amostras 1 a 5 :
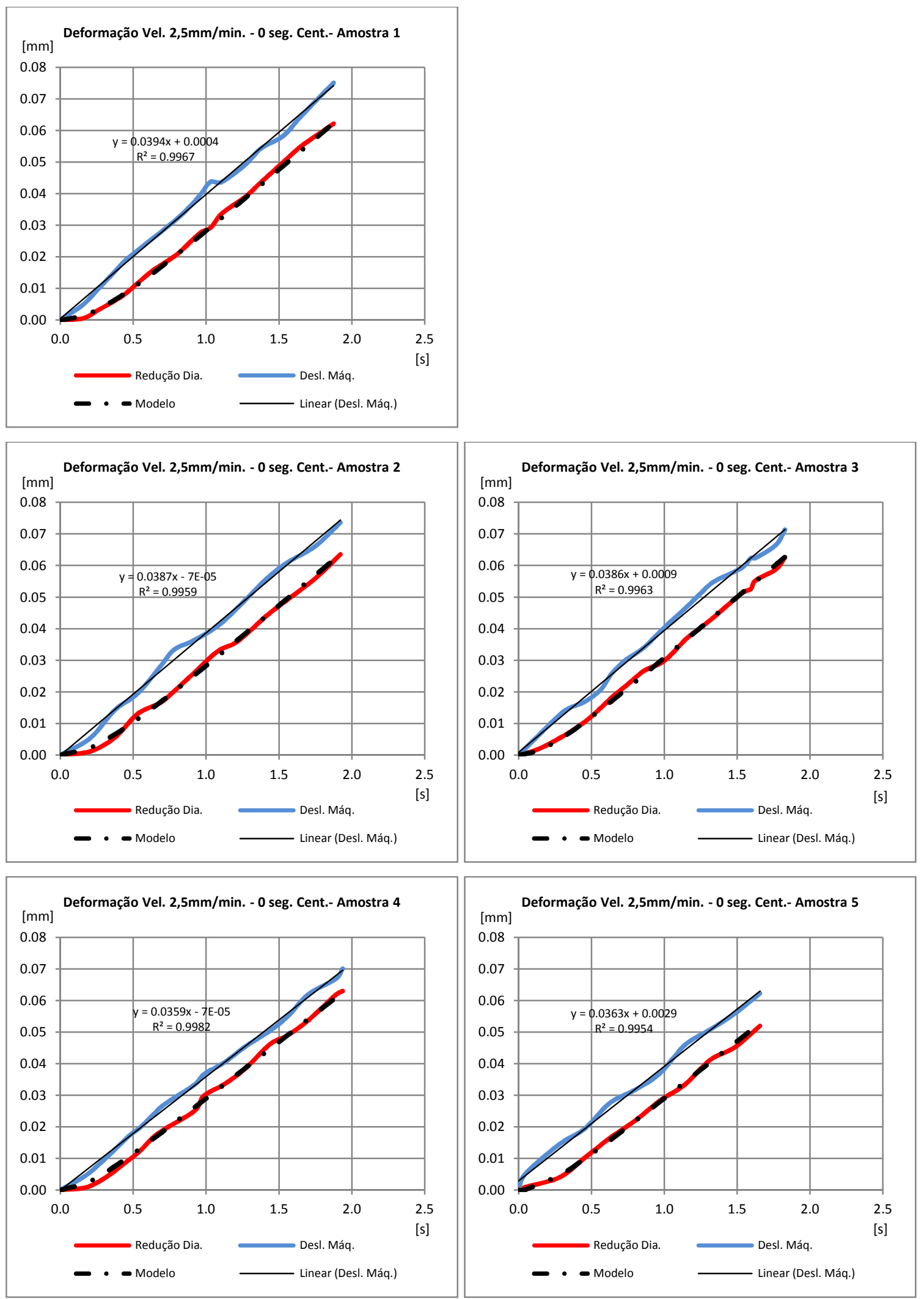

Gráfico 71 - Curvas Experimentais Excel ${ }^{\circledR}$ - Vel. 2,5mm/min. - 0 seg. Centelhamento 
Ajuste curvas MatLab ${ }^{\circledR}$ veloc. 2,5 mm/min.- Tempo de centelhamento 0 seg. - amostras 1 a 5:
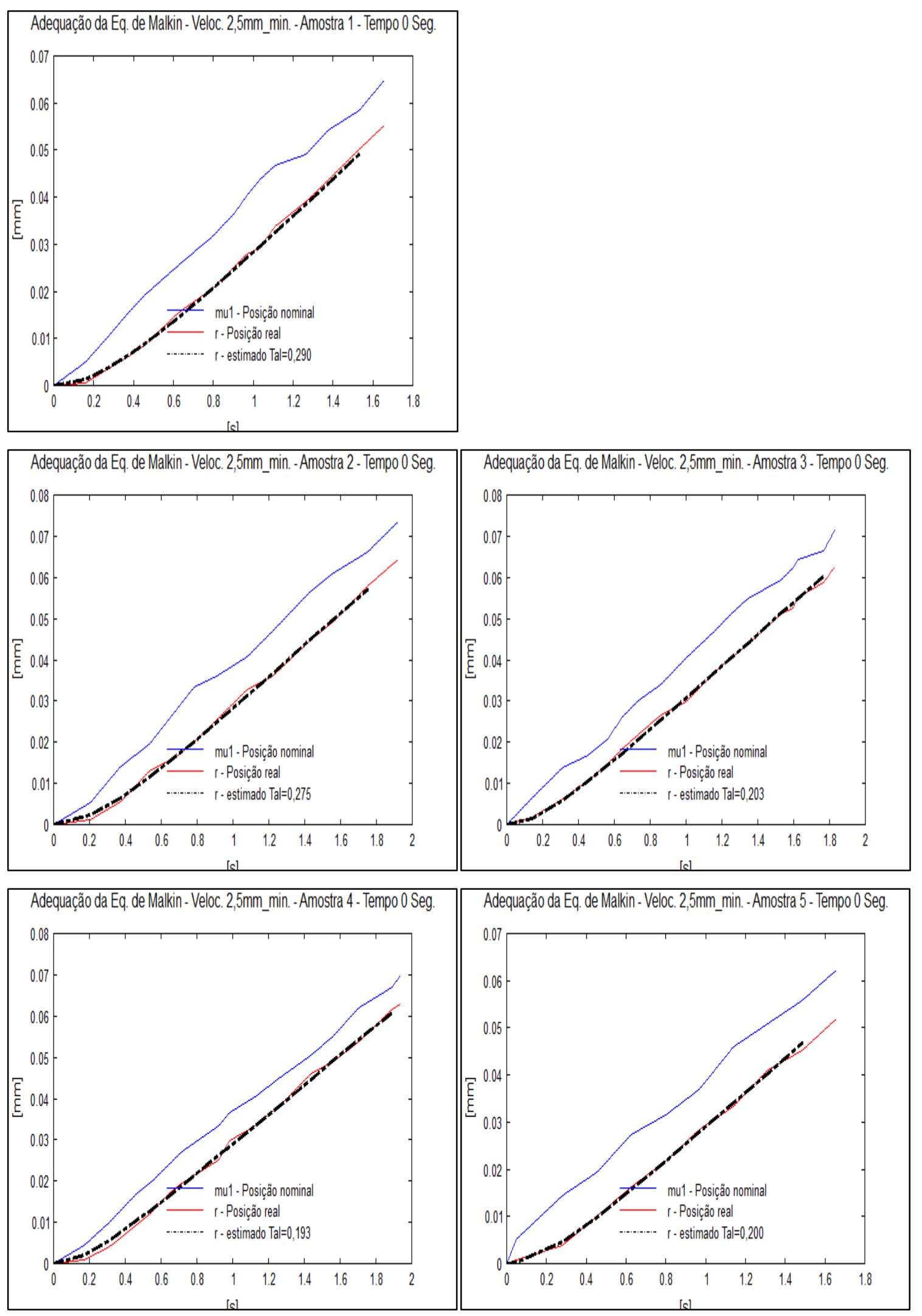

Gráfico 72 - Curvas Experimentais MatLab ${ }^{\circledR}$ - Vel. 2,5mm/min. - Tempo 0 Seg. Centelhamento. 
Curvas experimentais veloc. $2,5 \mathrm{~mm} / \mathrm{min}$.- Tempo de centelhamento 0,6 seg. - amostras 1 a 5 :
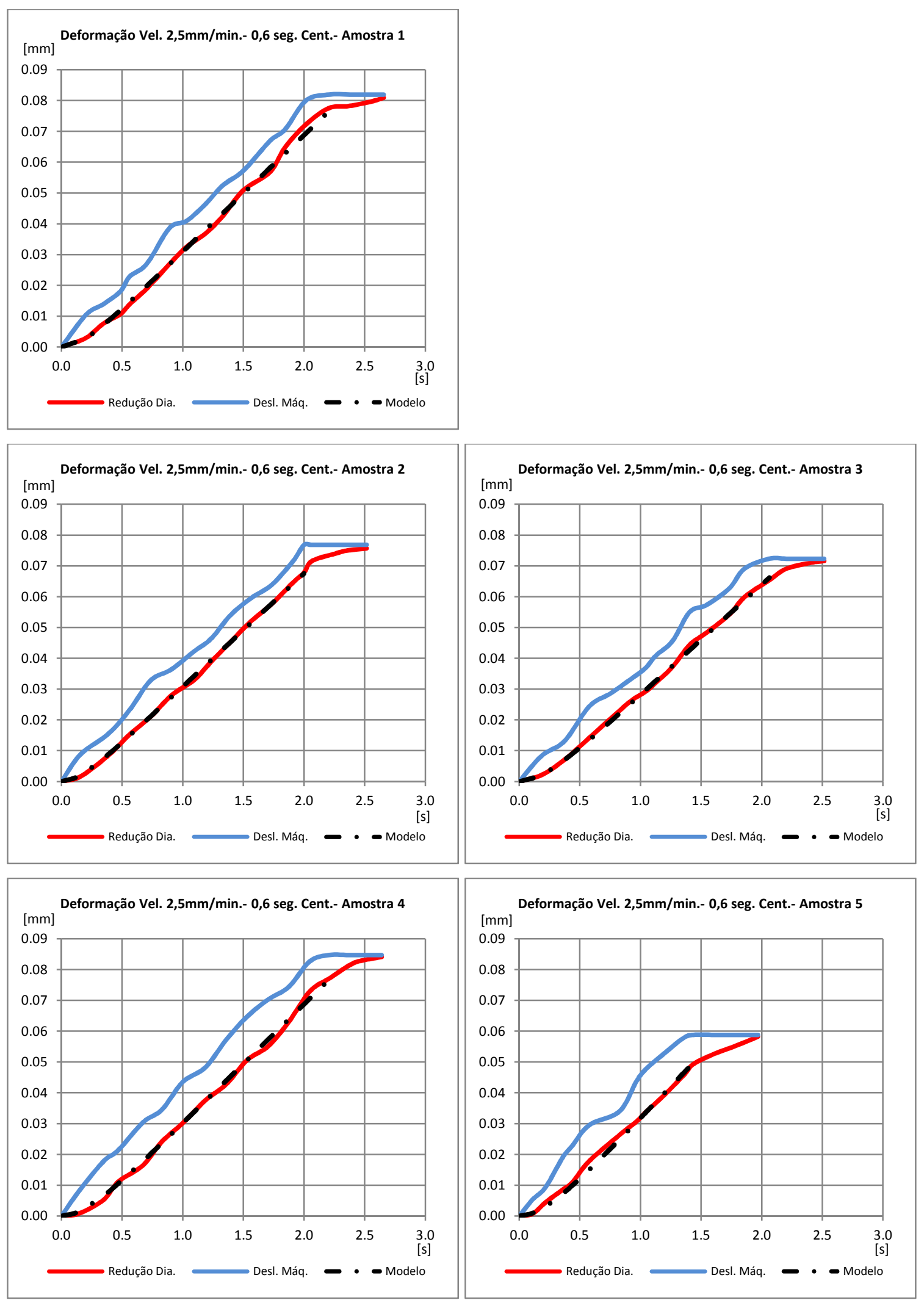

Gráfico 73 - Curvas Experimentais Excel ${ }^{\circledR}$ - Vel. 2,5mm/min. - 0,6 seg. Centelhamento 
Ajuste curvas MatLab ${ }^{\circledR}$ veloc. 2,5 mm/min.- Tempo de centelhamento 0,6 seg. amostras 1 a 5:
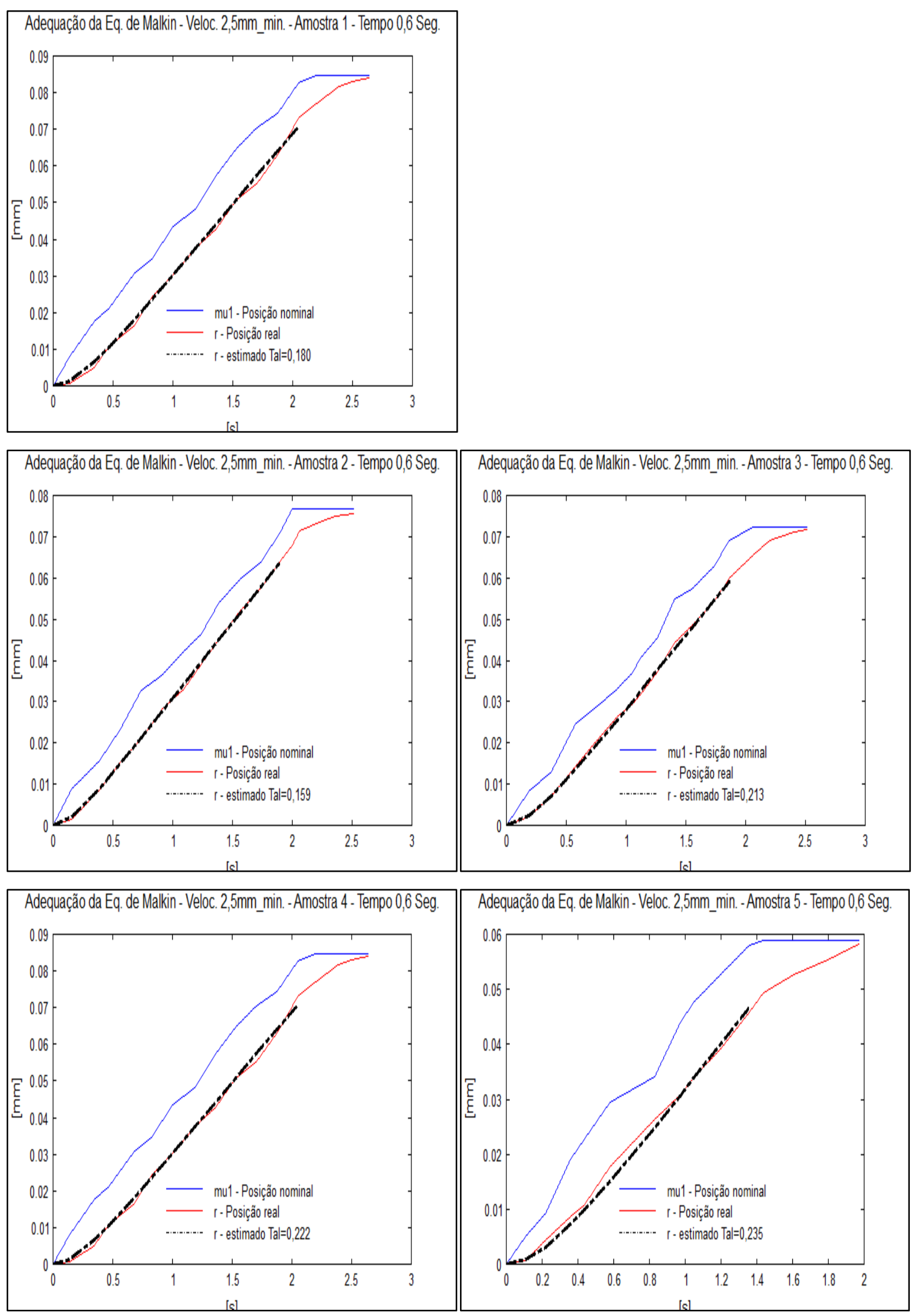

Gráfico 74 - Curvas Experimentais MatLab ${ }^{\circledR}$ - Vel. 2,5mm/min. - Tempo 0,6 Seg. Centelhamento. 
Curvas experimentais veloc. $2,5 \mathrm{~mm} / \mathrm{min}$. - Tempo de centelhamento $1 \mathrm{seg}$. - amostras 1 a 5 :
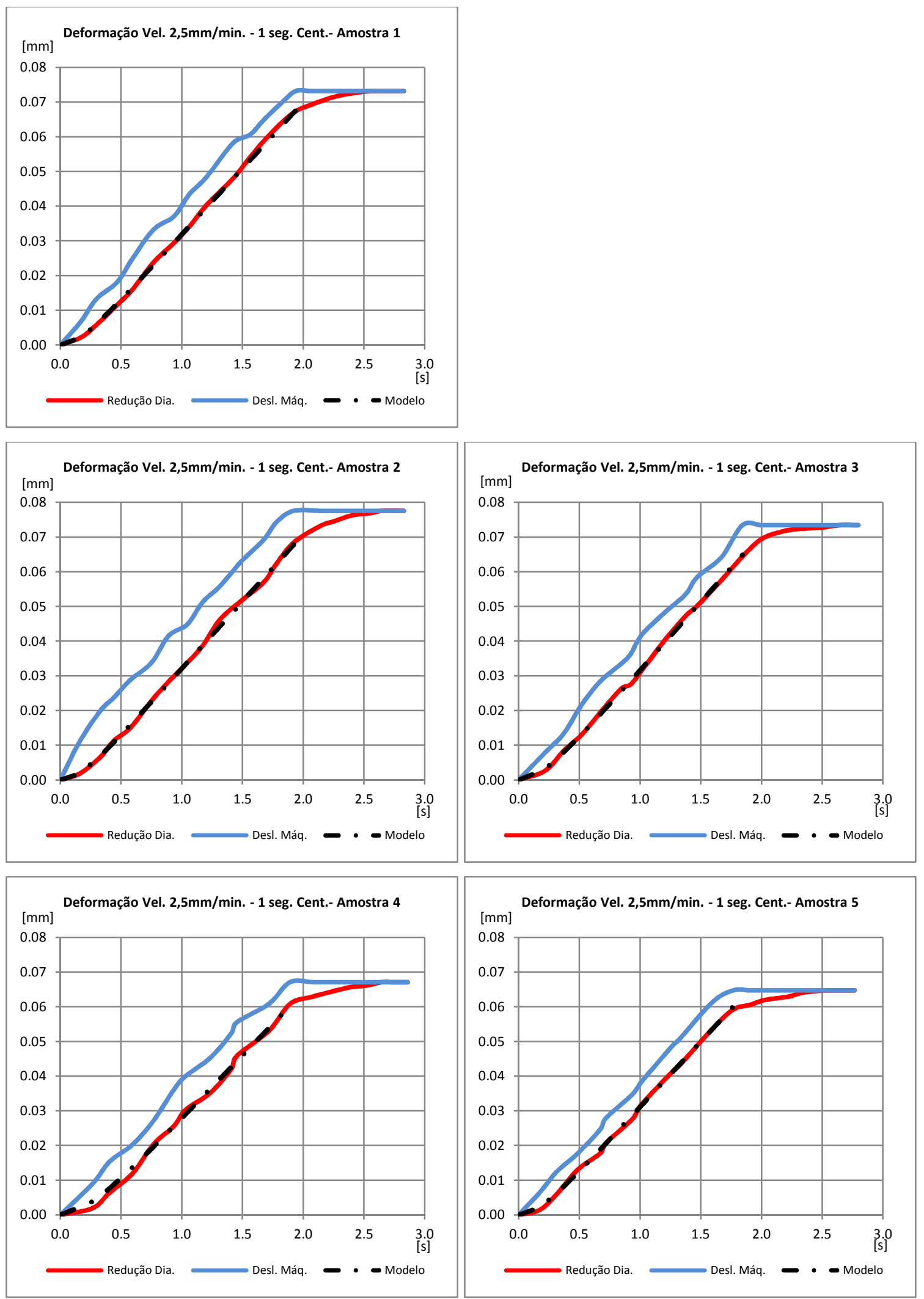

Gráfico 75 - Curvas Experimentais Excel ${ }^{\circledR}$ - Vel. 2,5mm/min. - 1 seg. Centelhamento 
Ajuste curvas MatLab ${ }^{\circledR}$ veloc. 2,5 mm/min.- Tempo de centelhamento $1 \mathrm{seg}$. - amostras 1 a 5:
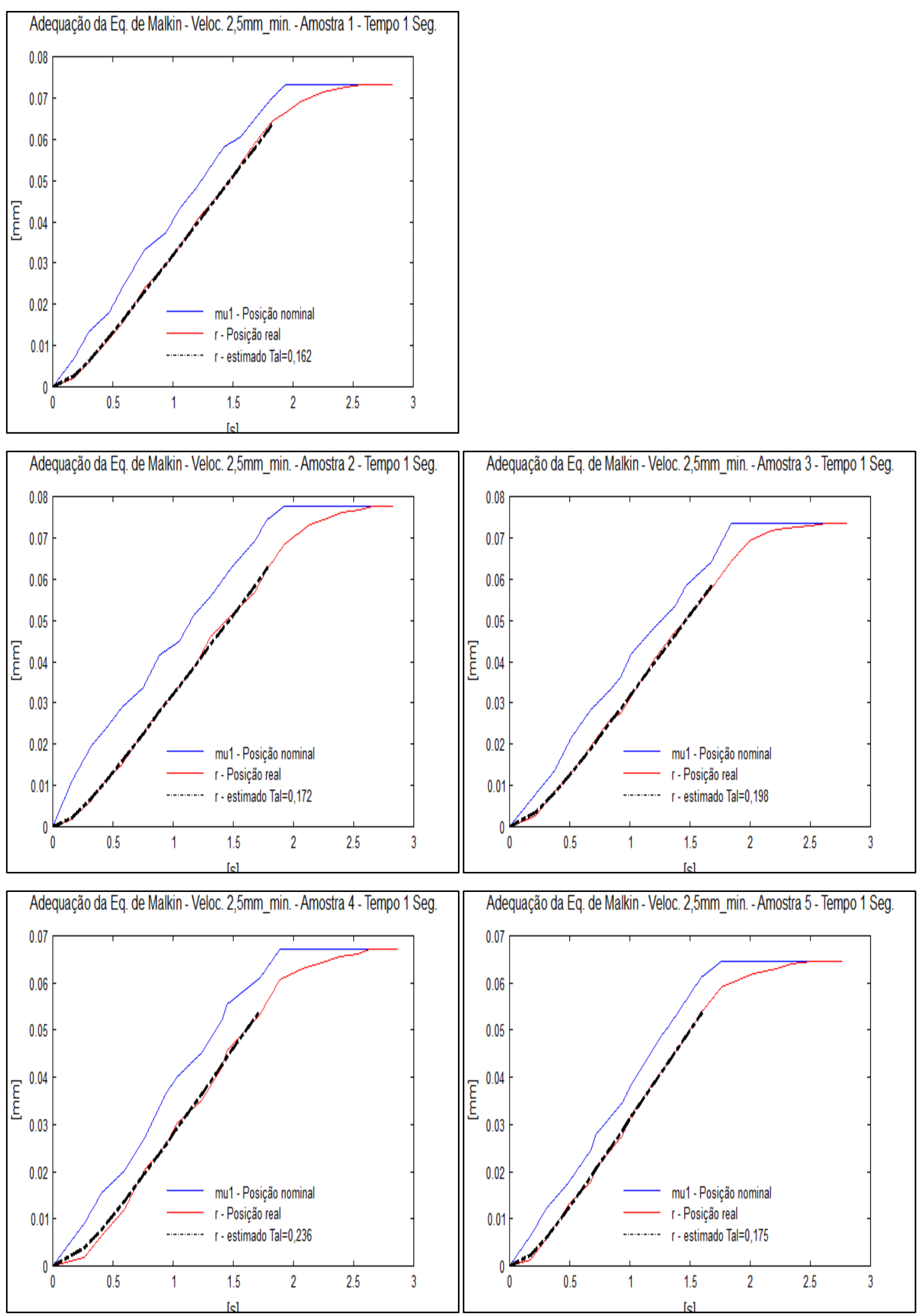

Gráfico 76 - Curvas Experimentais MatLab ${ }^{\circledR}$ - Vel. 2,5mm/min. - Tempo 1 Seg. Centelhamento. 
Curvas experimentais veloc. $2,5 \mathrm{~mm} / \mathrm{min}$. - Tempo de centelhamento $2 \mathrm{seg}$. - amostras 1 a 5 :
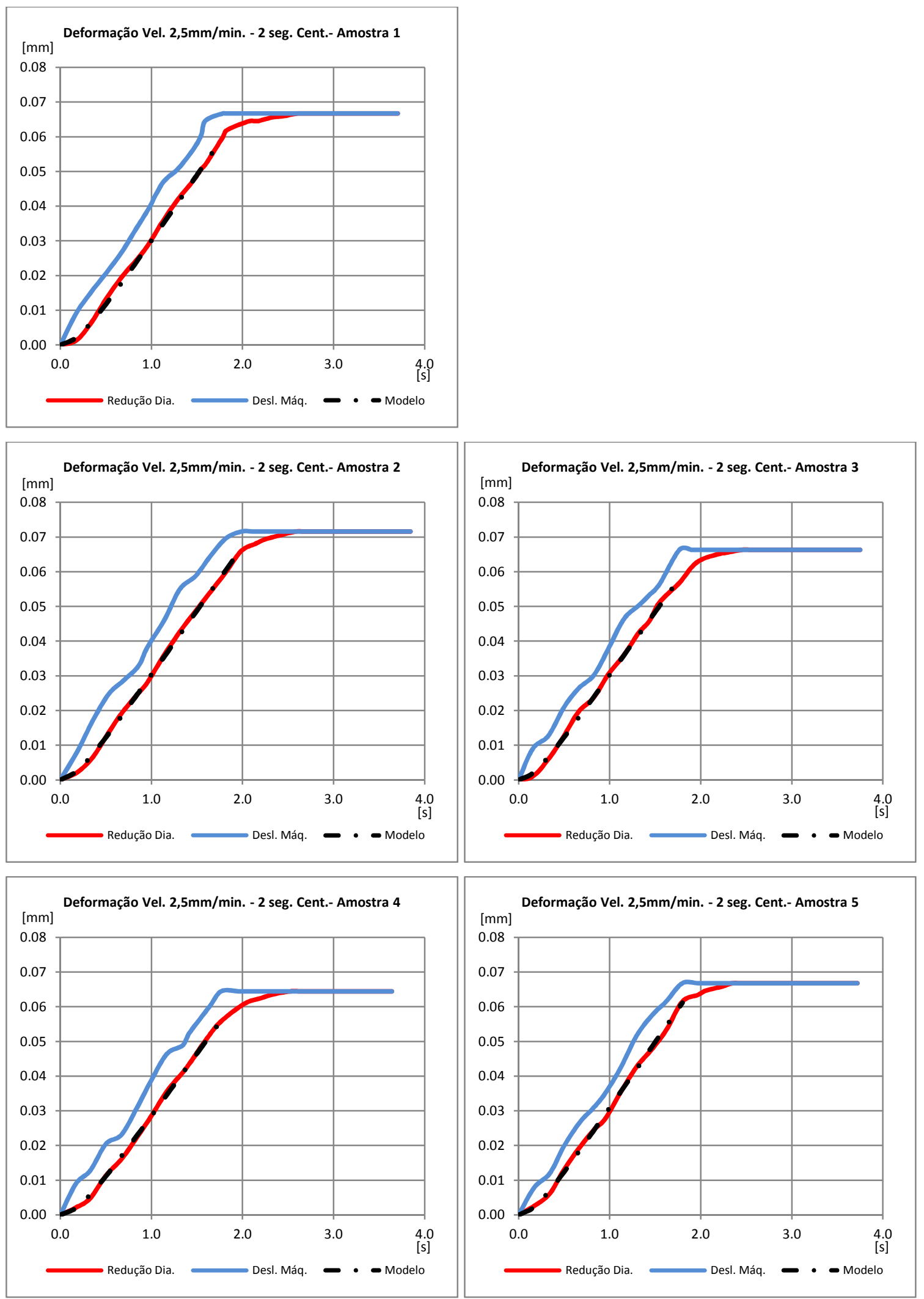

Gráfico 77 - Curvas Experimentais Excel ${ }^{\circledR}$ - Vel. 2,5mm/min. - 2 seg. Centelhamento 
Ajuste curvas MatLab ${ }^{\circledR}$ veloc. 2,5 mm/min.- Tempo de centelhamento 2 seg. - amostras 1 a 5:
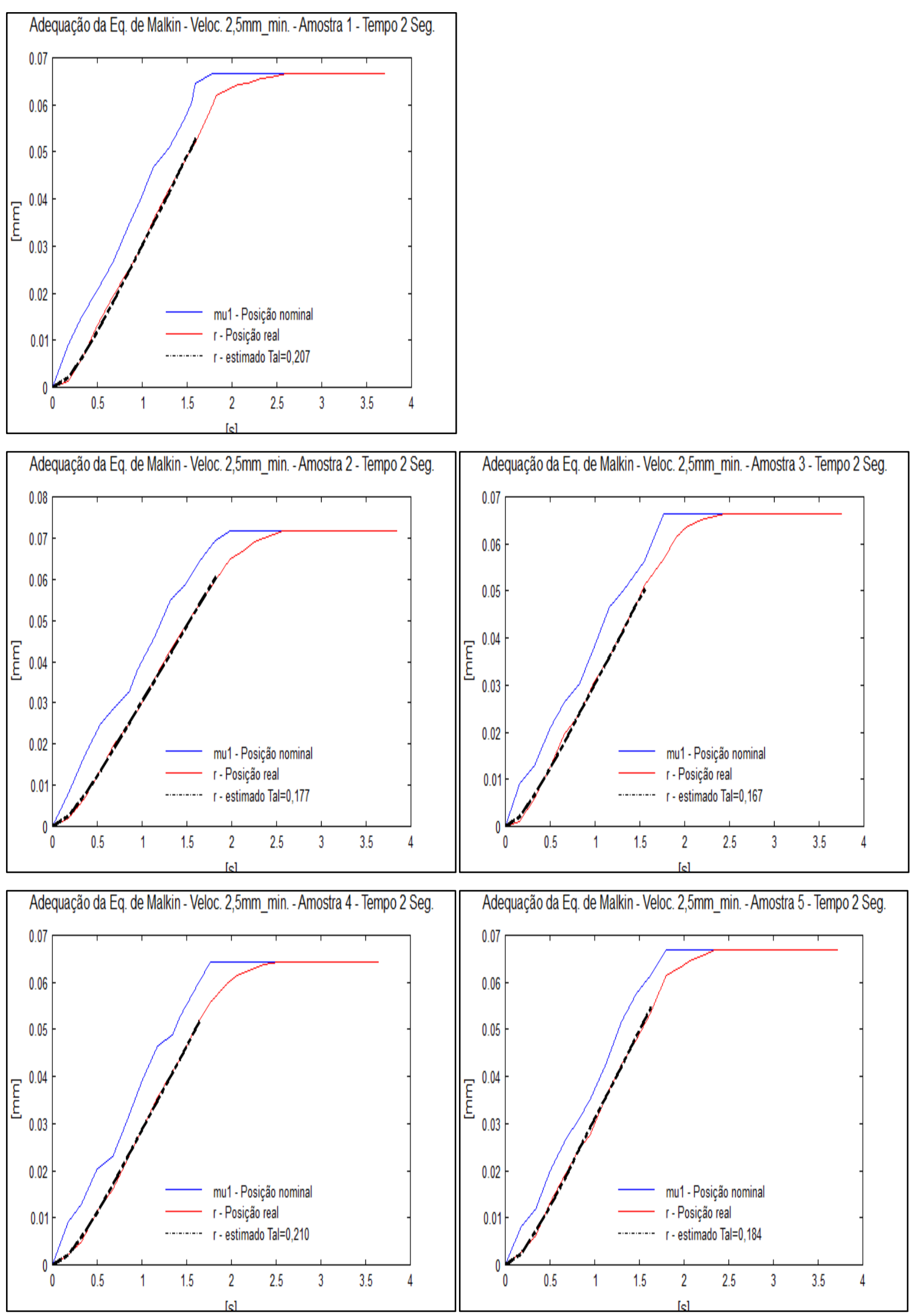

Gráfico 78 - Curvas Experimentais MatLab ${ }^{\circledR}$ - Vel. 2,5mm/min. - Tempo 2 Seg. Centelhamento. 
Curvas experimentais veloc. $2,5 \mathrm{~mm} / \mathrm{min}$. - Tempo de centelhamento $3 \mathrm{seg}$. - amostras 1 a 5 :
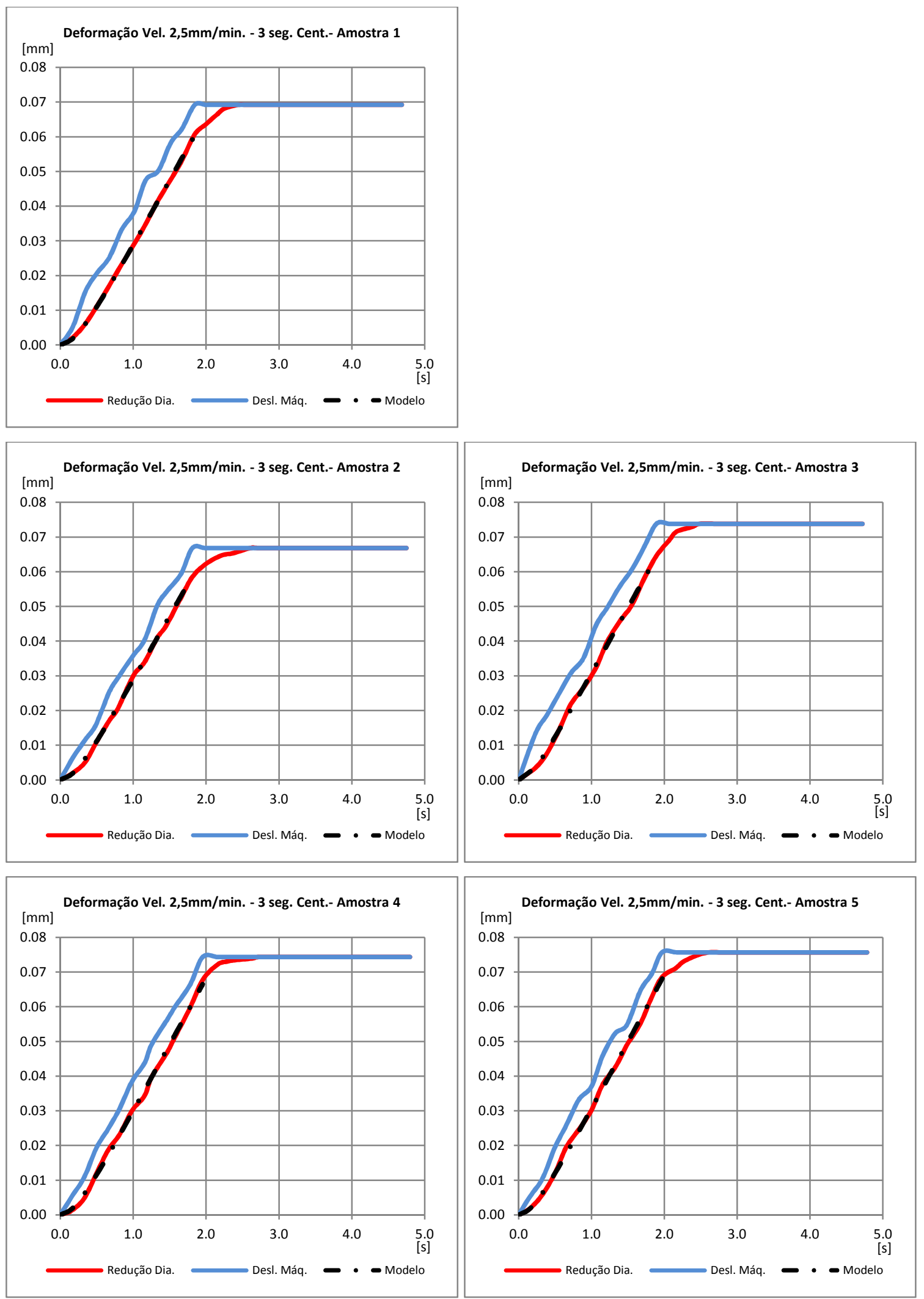

Gráfico 79 - Curvas Experimentais Excel ${ }^{\circledR}$ - Vel. 2,5mm/min. - 3 seg. Centelhamento 
Ajuste curvas MatLab ${ }^{\circledR}$ veloc. 2,5 mm/min.- Tempo de centelhamento 3 seg. - amostras 1 a 5:
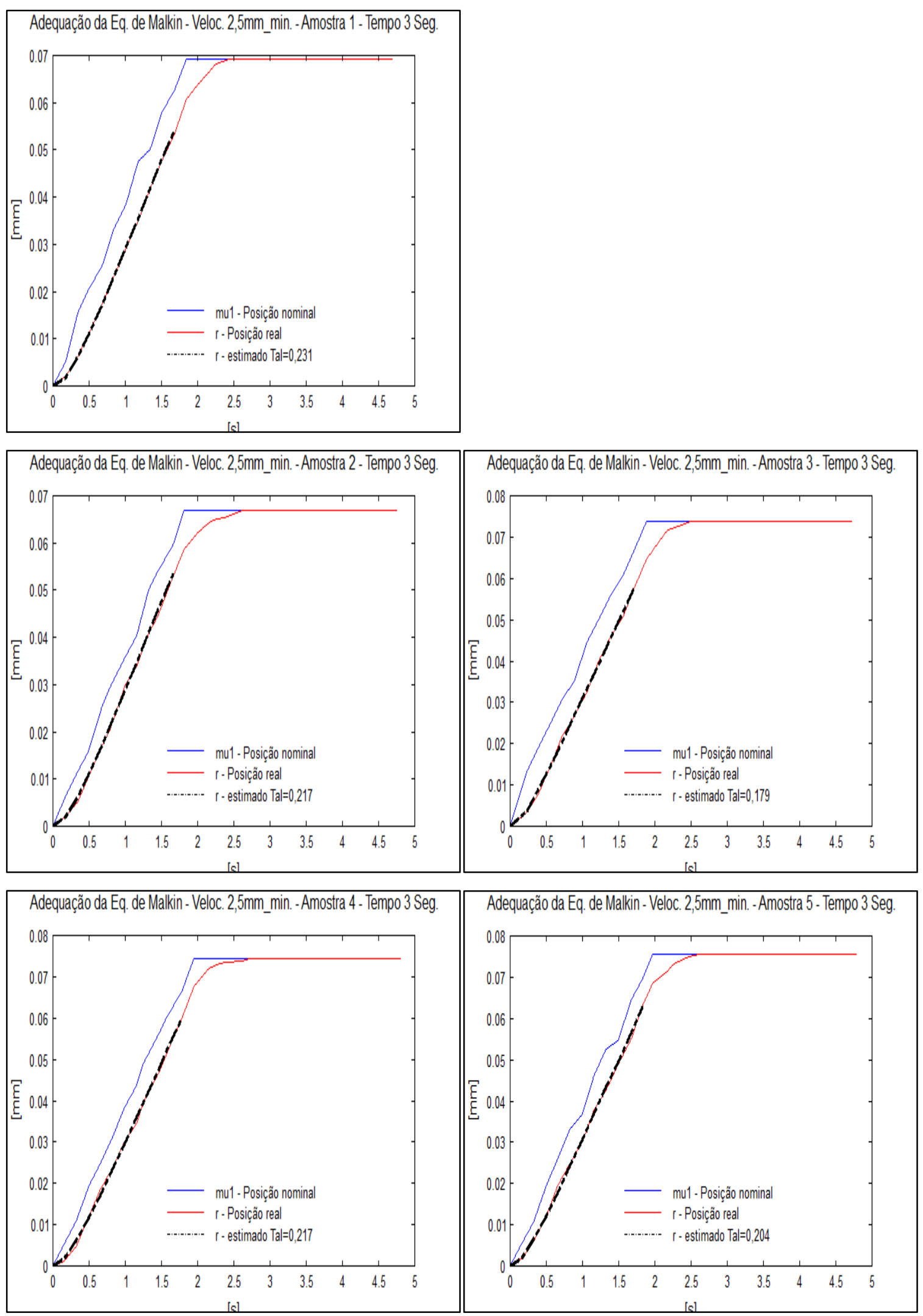

Gráfico 80 - Curvas Experimentais MatLab ${ }^{\circledR}$ - Vel. 2,5mm/min. - Tempo 3 Seg. Centelhamento. 
Curvas experimentais veloc. $1,6 \mathrm{~mm} / \mathrm{min}$. - Tempo de centelhamento $0 \mathrm{seg}$. - amostras 1 a 5:
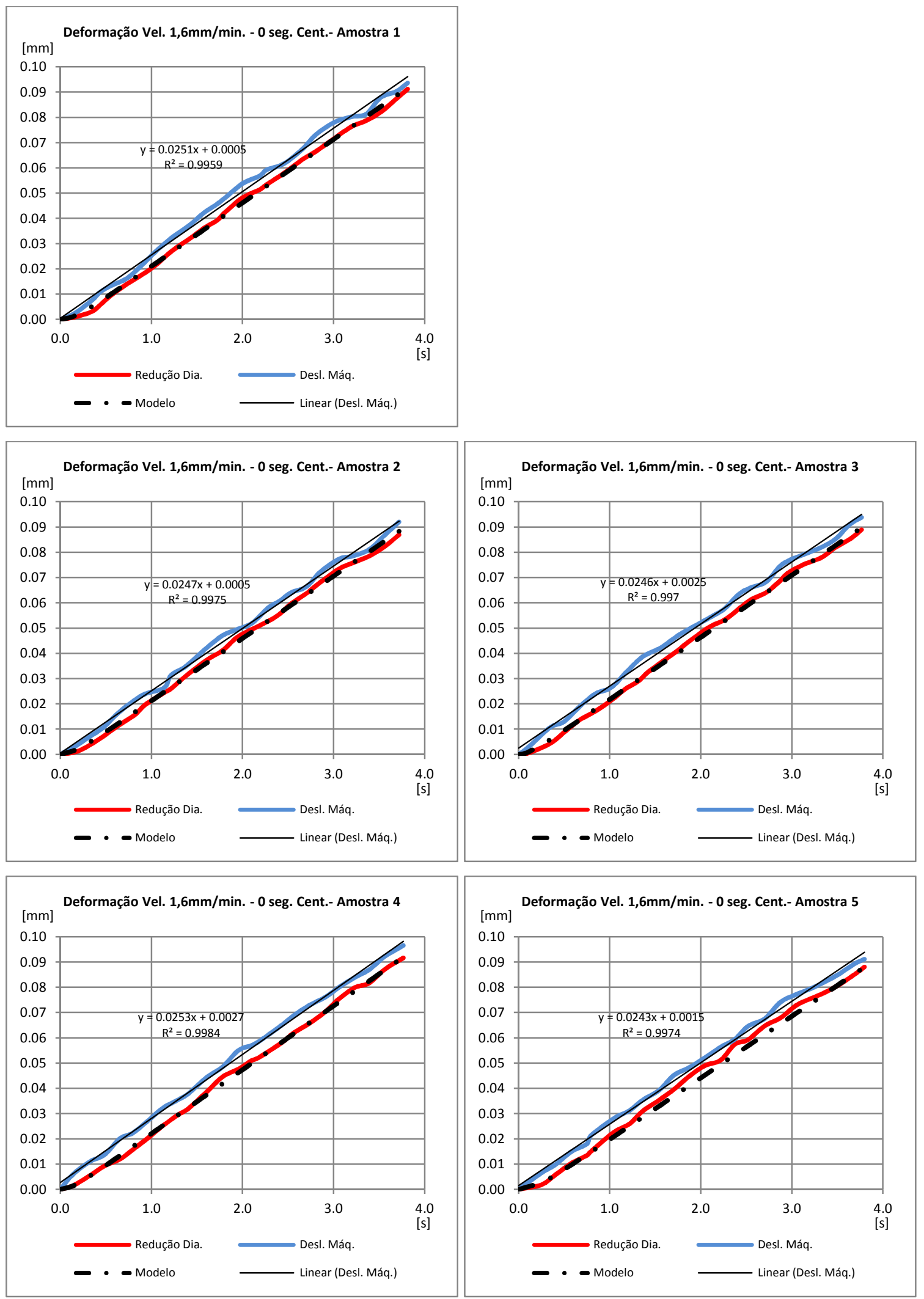

Gráfico 81 - Curvas Experimentais Excel ${ }^{\circledR}$ - Vel. 1,6mm/min. - 0 seg. Centelhamento 
Ajuste curvas MatLab ${ }^{\circledR}$ veloc. 1,6 mm/min.- Tempo de centelhamento 0 seg. - amostras 1 a 5:
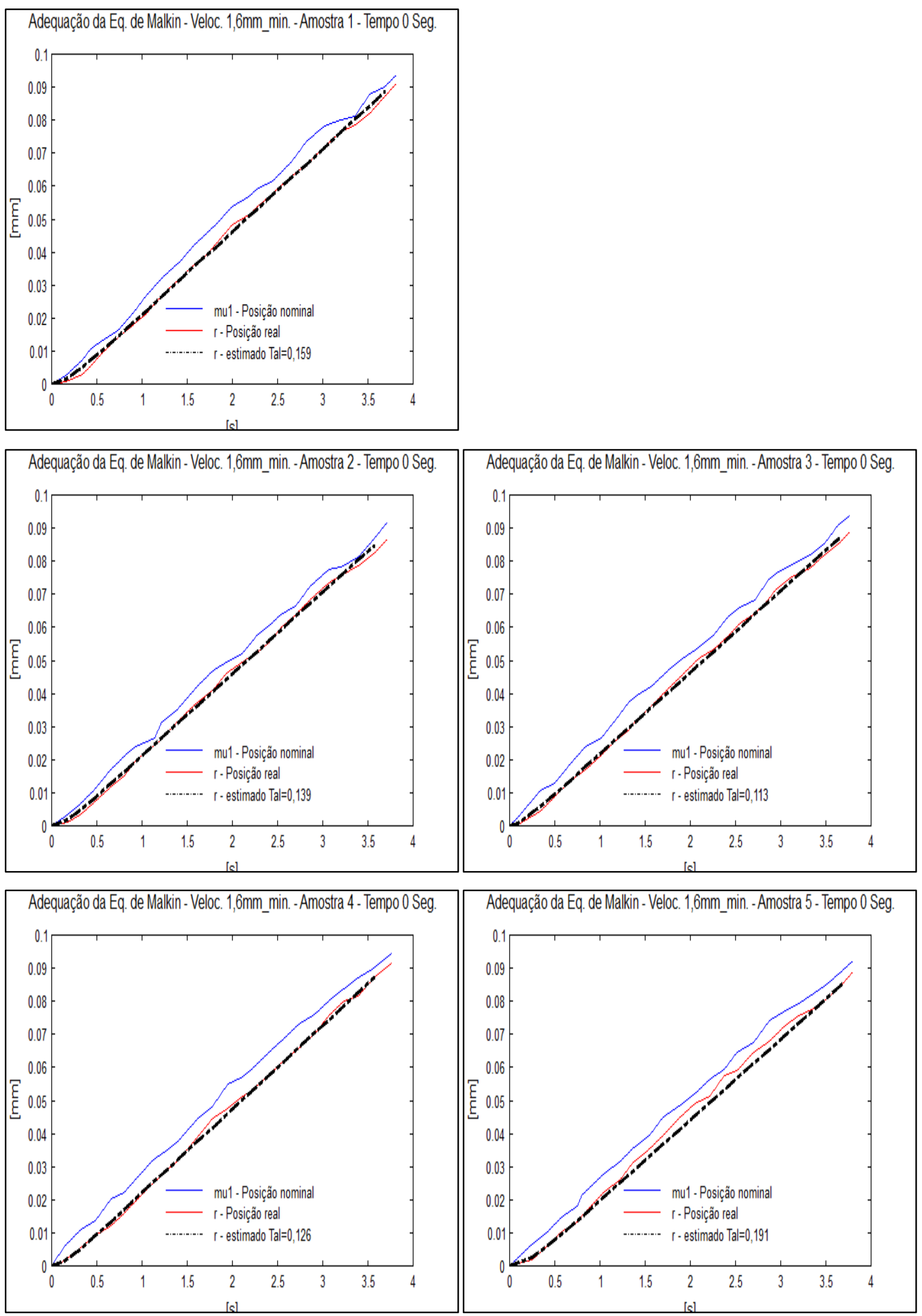

Gráfico 82 - Curvas Experimentais MatLab ${ }^{\circledR}$ - Vel. 1,6mm/min. - Tempo 0 Seg. Centelhamento. 
Curvas experimentais veloc. 1,6 mm/min.- Tempo de centelhamento 0,6 seg. - amostras 1 a 5:
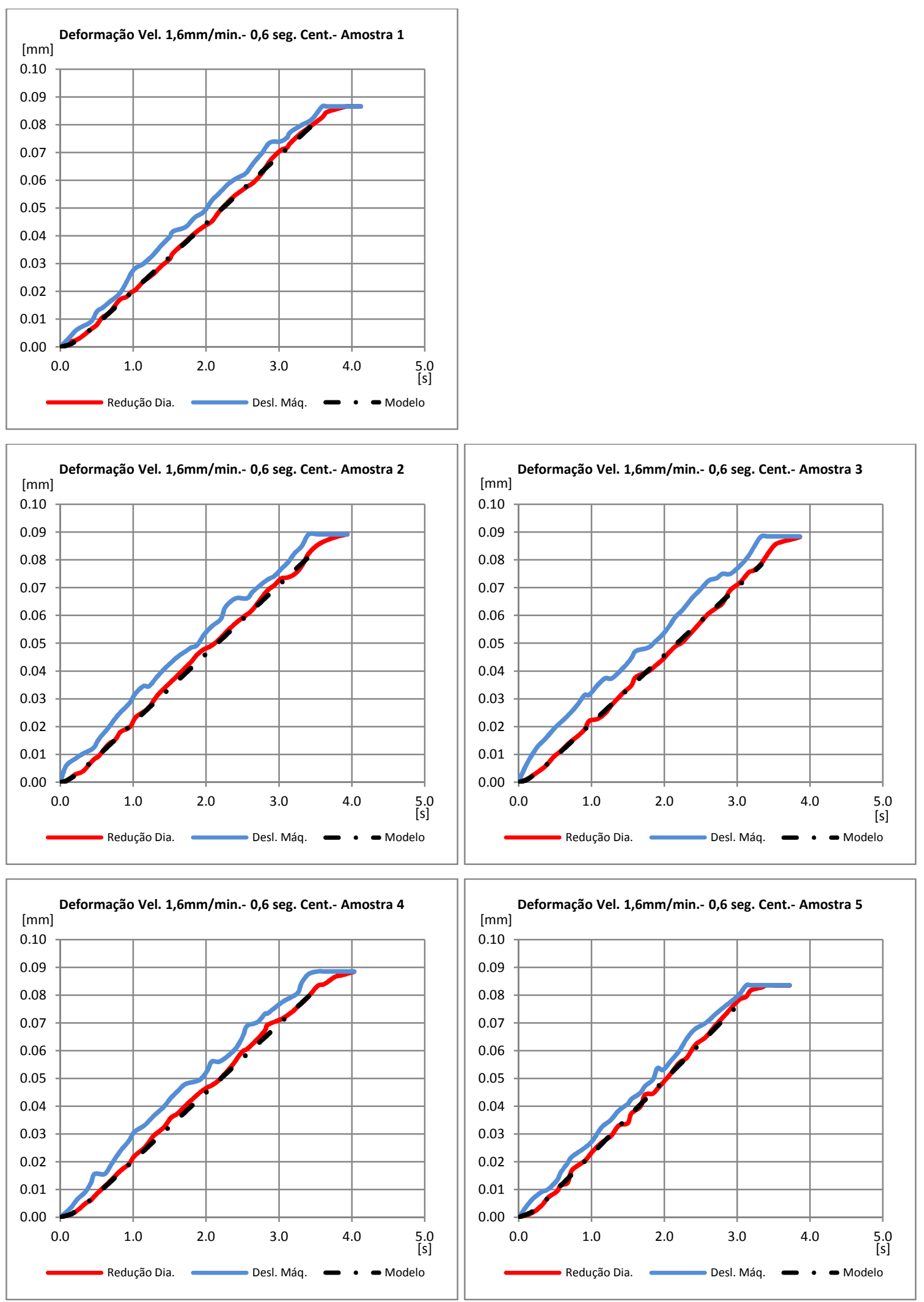

Gráfico 83 - Curvas Experimentais Excel ${ }^{\circledR}$ - Vel. 1,6mm/min. - 0,6 seg. Centelhamento 
Ajuste curvas MatLab ${ }^{\circledR}$ veloc. 1,6mm/min.- Tempo de centelhamento 0,6 seg. amostras 1 a 5:
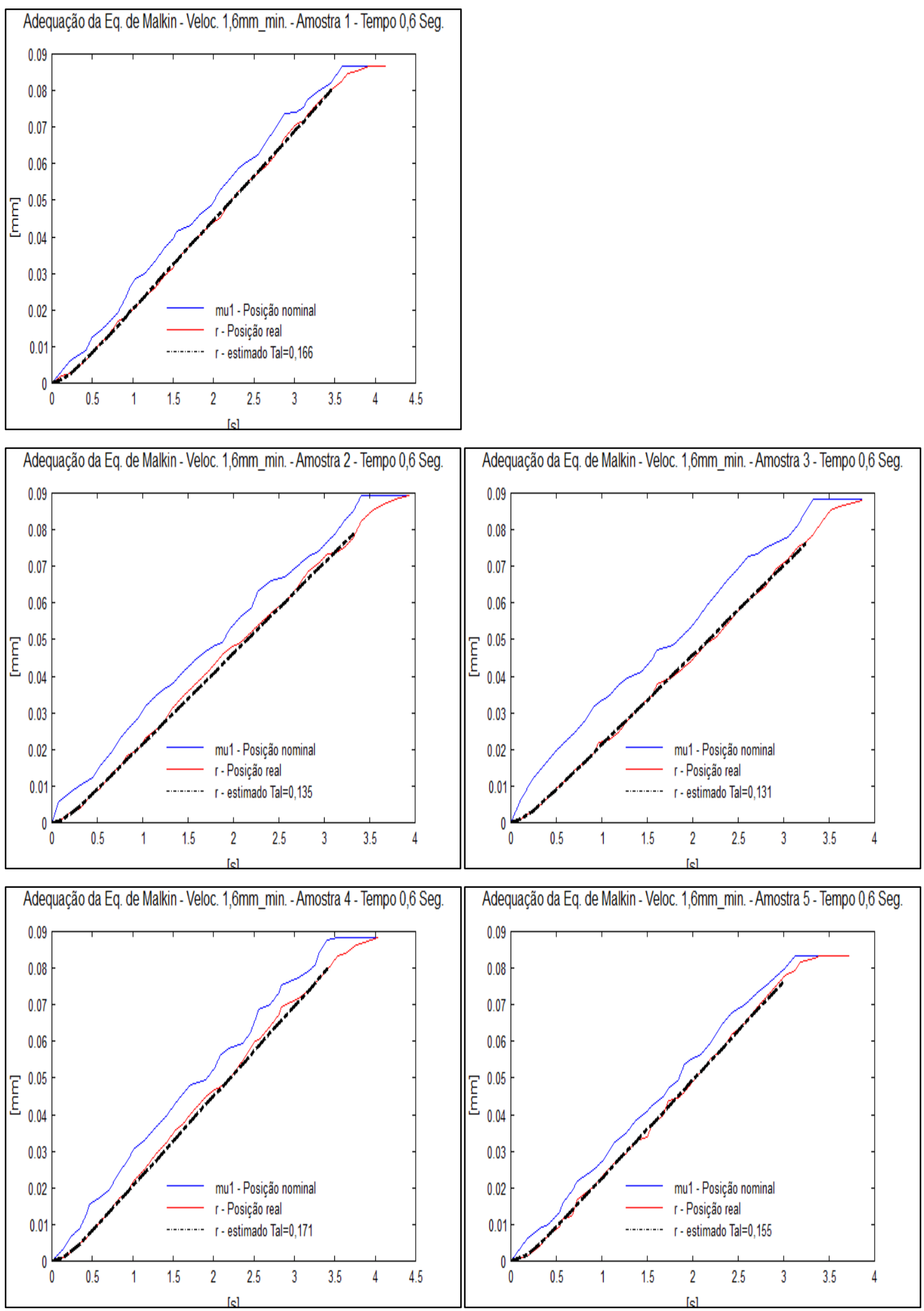

Gráfico 84 - Curvas Experimentais MatLab ${ }^{\circledR}$ - Vel. 1,6mm/min. - Tempo 0,6 Seg. Centelhamento. 
Curvas experimentais veloc. $1,6 \mathrm{~mm} / \mathrm{min}$. - Tempo de centelhamento $1 \mathrm{seg}$. - amostras 1 a 5 :
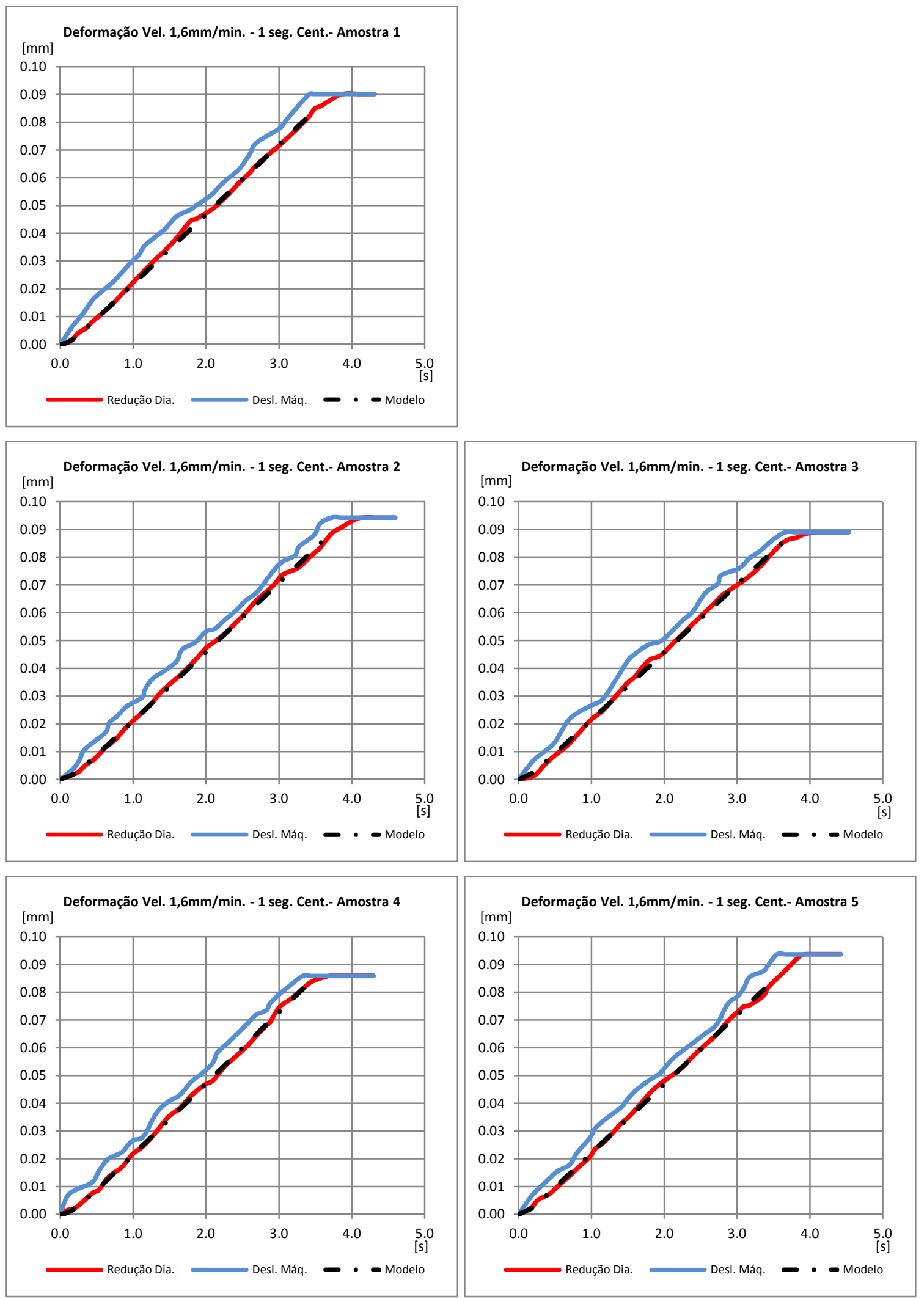

Gráfico 85 - Curvas Experimentais Excel ${ }^{\circledR}$ - Vel. 1,6mm/min. - 1 seg. Centelhamento 
Ajuste curvas MatLab ${ }^{\circledR}$ veloc. 1,6 mm/min.- Tempo de centelhamento $1 \mathrm{seg}$. - amostras 1 a 5:
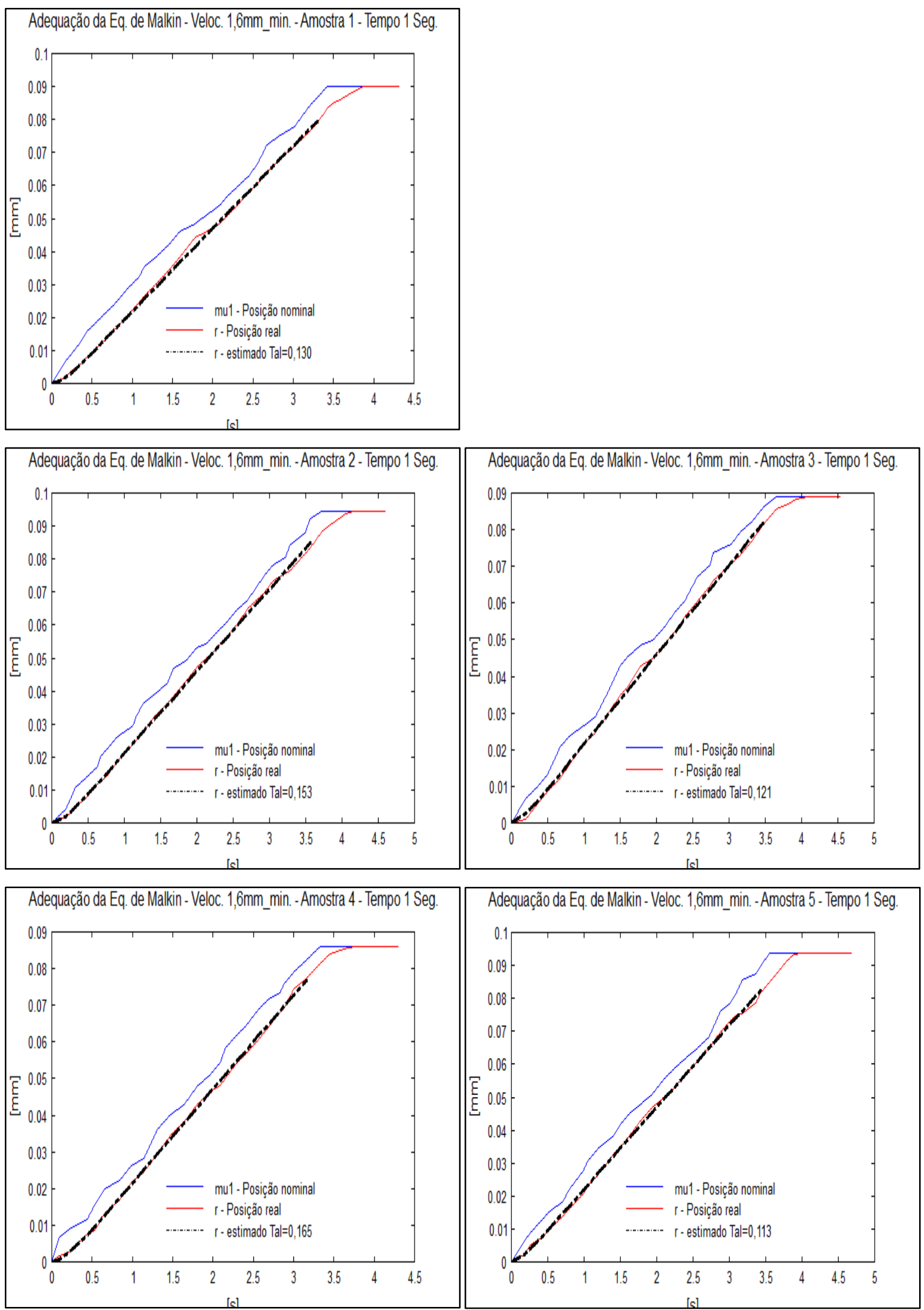

Gráfico 86 - Curvas Experimentais MatLab ${ }^{\circledR}$ - Vel. 1,6mm/min. - Tempo 1 Seg. Centelhamento. 
Curvas experimentais veloc. $1,6 \mathrm{~mm} / \mathrm{min}$. - Tempo de centelhamento $1 \mathrm{seg}$. - amostras $1 \mathrm{a} 5$ :
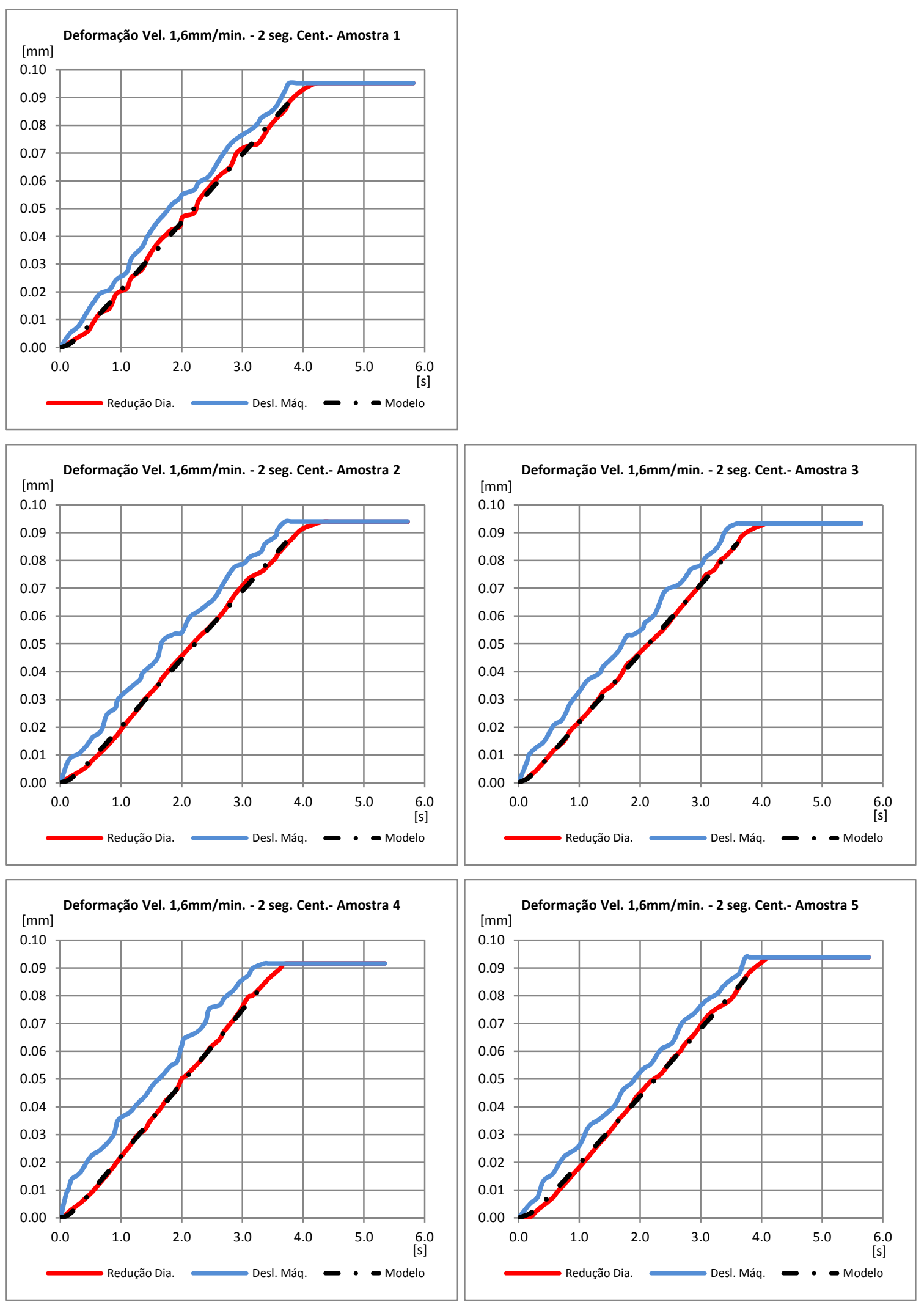

Gráfico 87 - Curvas Experimentais Excel ${ }^{\circledR}$ - Vel. 1,6mm/min. - 2 seg. Centelhamento 
Ajuste curvas MatLab ${ }^{\circledR}$ veloc. 1,6 mm/min.- Tempo de centelhamento 2 seg. - amostras 1 a 5:
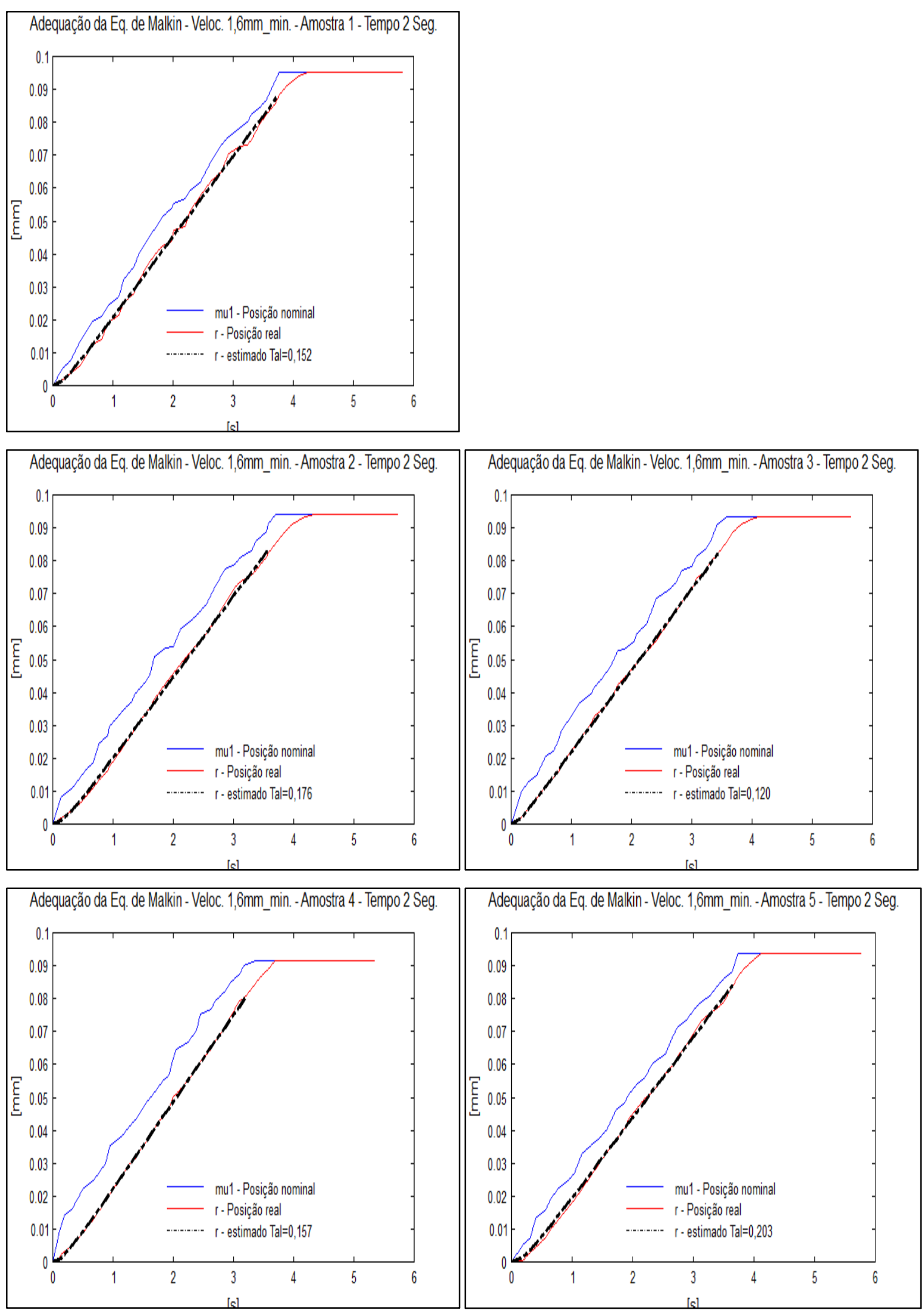

Gráfico 88 - Curvas Experimentais MatLab ${ }^{\circledR}$ - Vel. 1,6mm/min. - Tempo 2 Seg. Centelhamento. 
Curvas experimentais veloc. $1,6 \mathrm{~mm} / \mathrm{min}$. - Tempo de centelhamento $3 \mathrm{seg}$. - amostras 1 a 5:
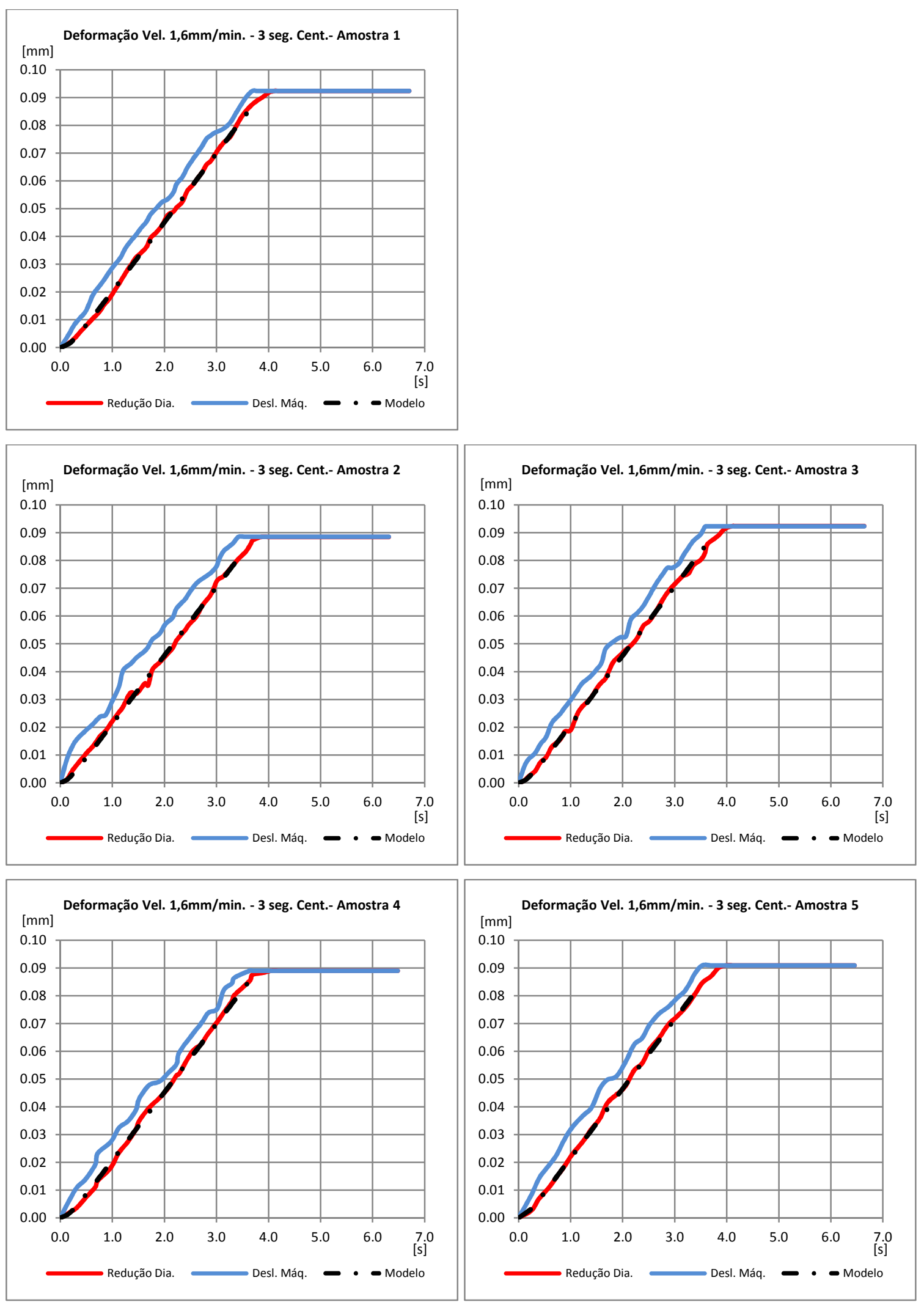

Gráfico 89 - Curvas Experimentais Excel ${ }^{\circledR}$ - Vel. 1,6mm/min. - 3 seg. Centelhamento 
Ajuste curvas MatLab ${ }^{\circledR}$ veloc. 1,6 mm/min.- Tempo de centelhamento 3 seg. - amostras 1 a 5:
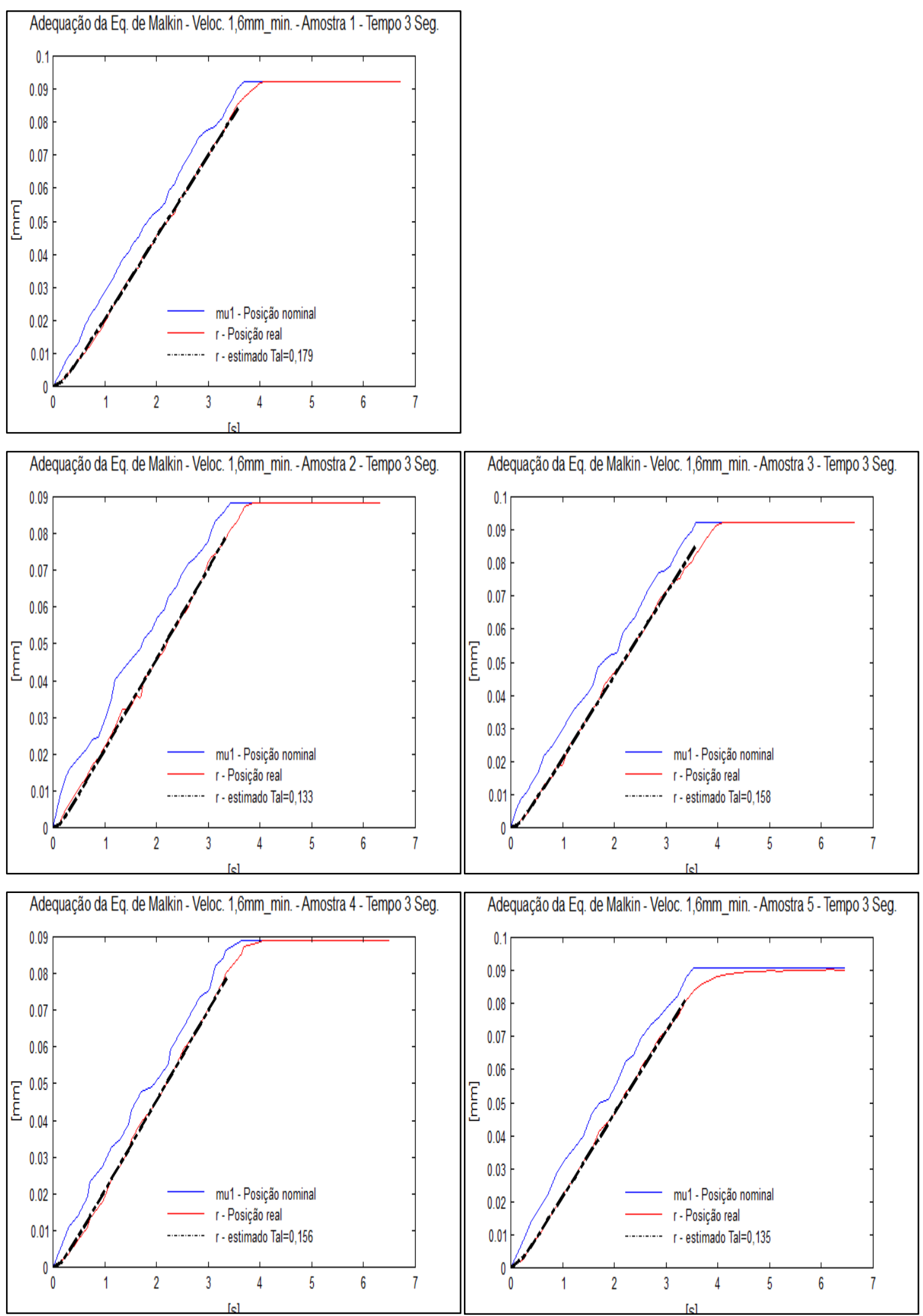

Gráfico 90 - Curvas Experimentais MatLab ${ }^{\circledR}$ - Vel. 1,6mm/min. - Tempo 3 Seg. Centelhamento. 
Curvas experimentais veloc. $0,8 \mathrm{~mm} / \mathrm{min}$. - Tempo de centelhamento $0 \mathrm{seg}$. - amostras $1 \mathrm{a} \mathrm{5:}$
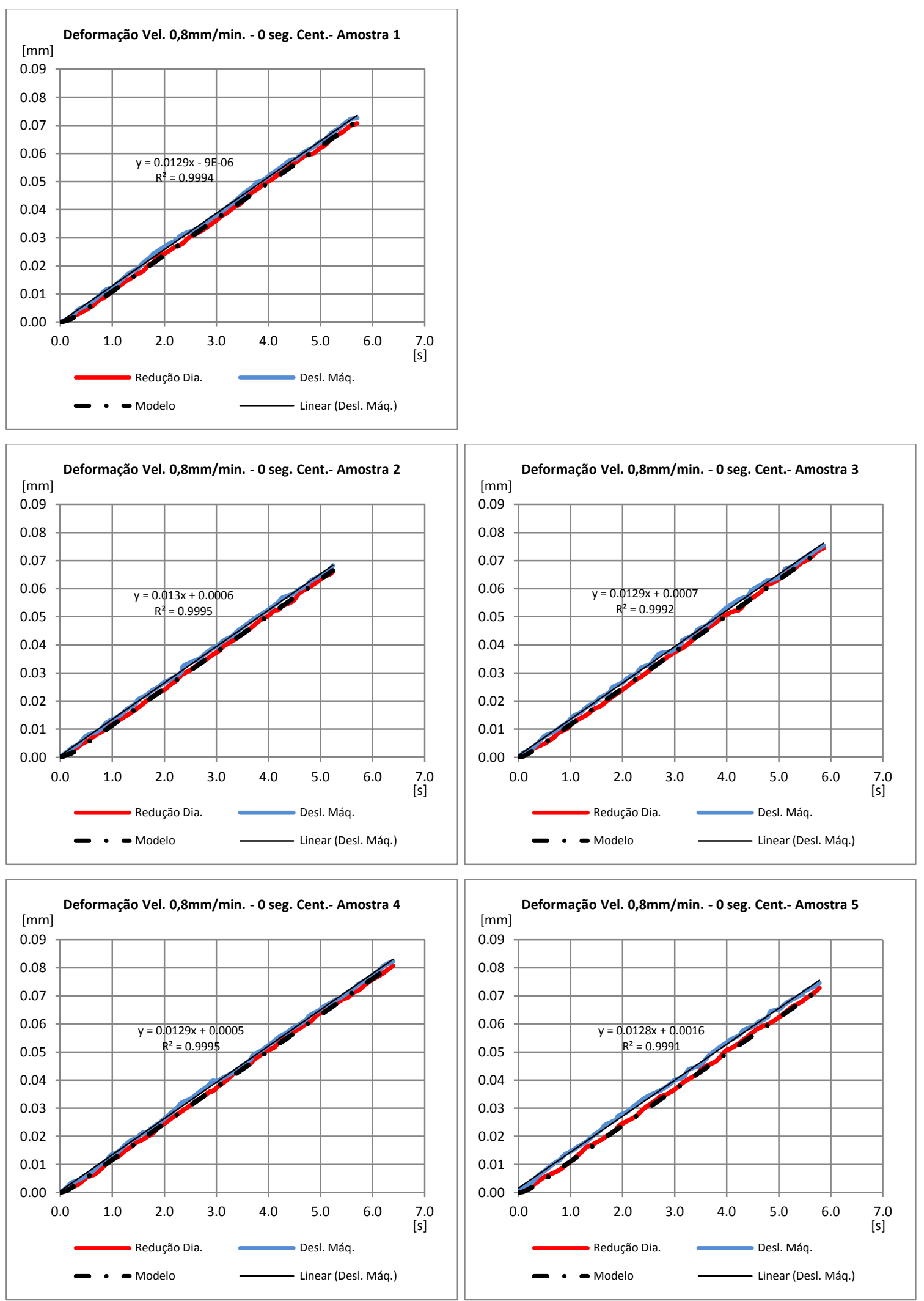

Gráfico 91 - Curvas Experimentais Excel ${ }^{\circledR}$ - Vel. 0,8mm/min. - 0 seg. Centelhamento 
Ajuste curvas MatLab ${ }^{\circledR}$ veloc. $0,8 \mathrm{~mm} / \mathrm{min}$.- Tempo de centelhamento 0 seg. - amostras 1 a 5:
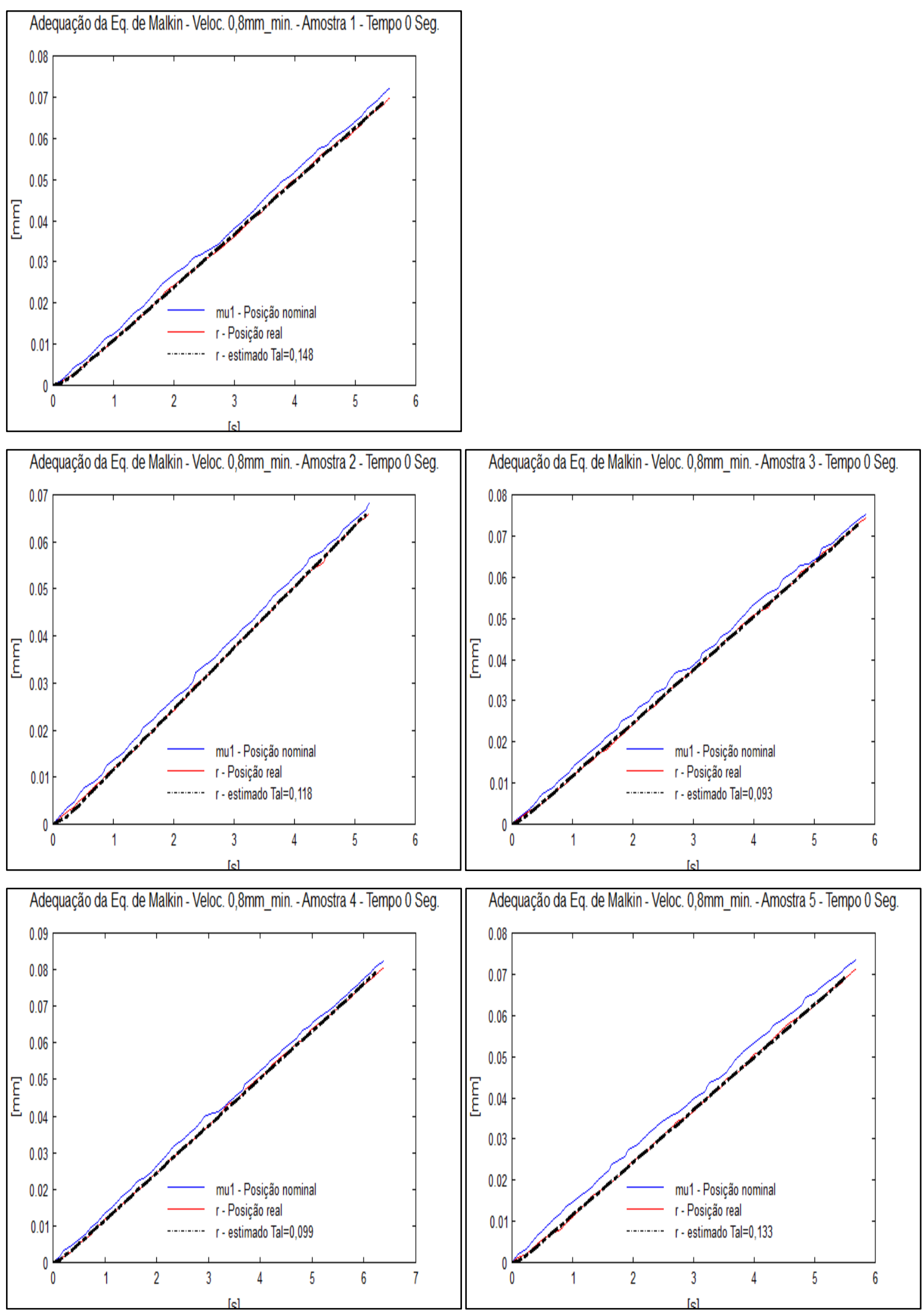

Gráfico 92 - Curvas Experimentais MatLab ${ }^{\circledR}$ - Vel. 0,8mm/min. - Tempo 0 Seg. Centelhamento. 
Curvas experimentais veloc. $0,8 \mathrm{~mm} / \mathrm{min}$.- Tempo de centelhamento 0,6 seg. - amostras 1 a 5 :
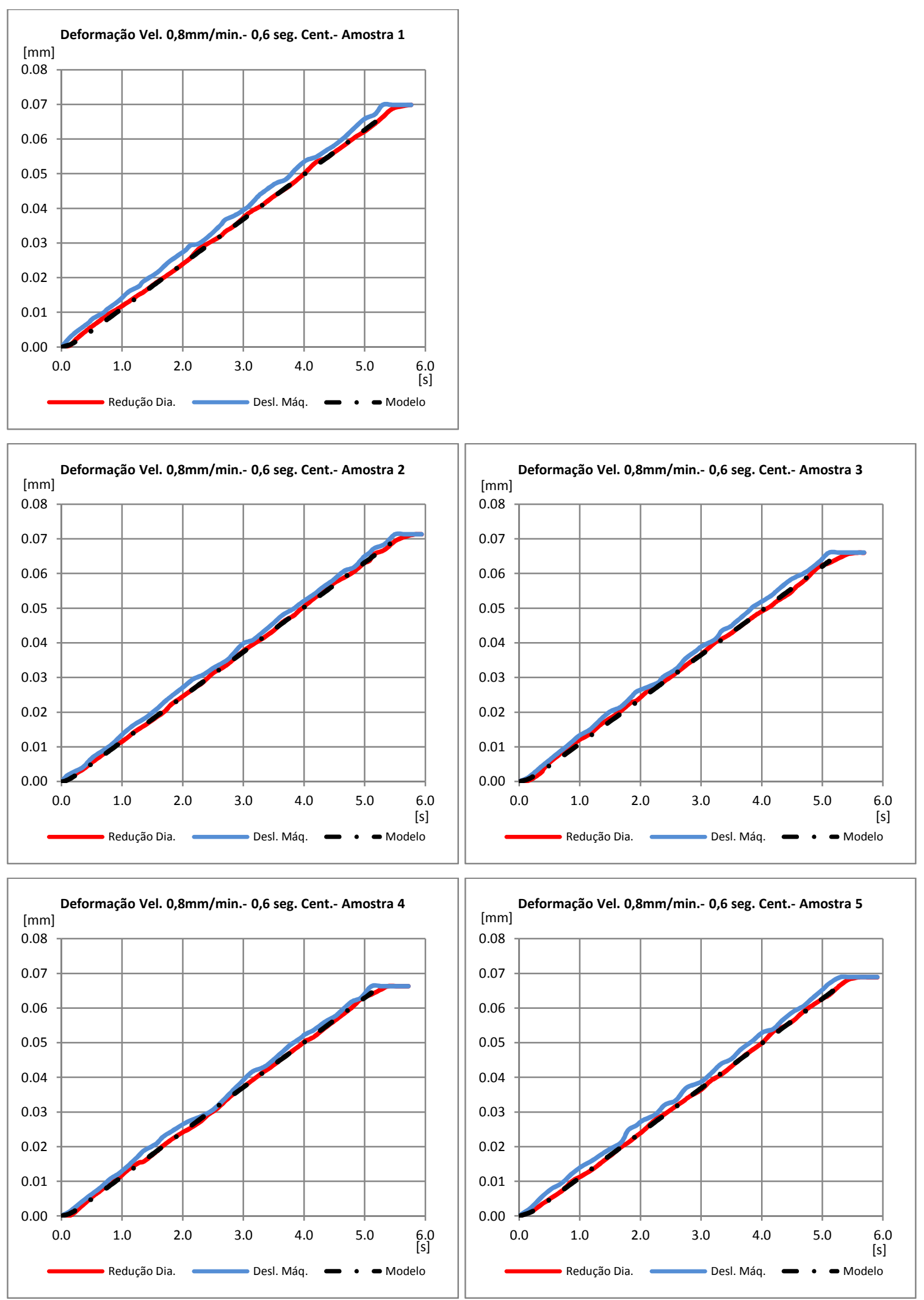

Gráfico 93 - Curvas Experimentais Excel ${ }^{\circledR}$ - Vel. 0,8mm/min. - 0,6 seg. Centelhamento 
Ajuste curvas MatLab ${ }^{\circledR}$ veloc. $0,8 \mathrm{~mm} / \mathrm{min}$.- Tempo de centelhamento 0,6 seg. amostras 1 a 5 :
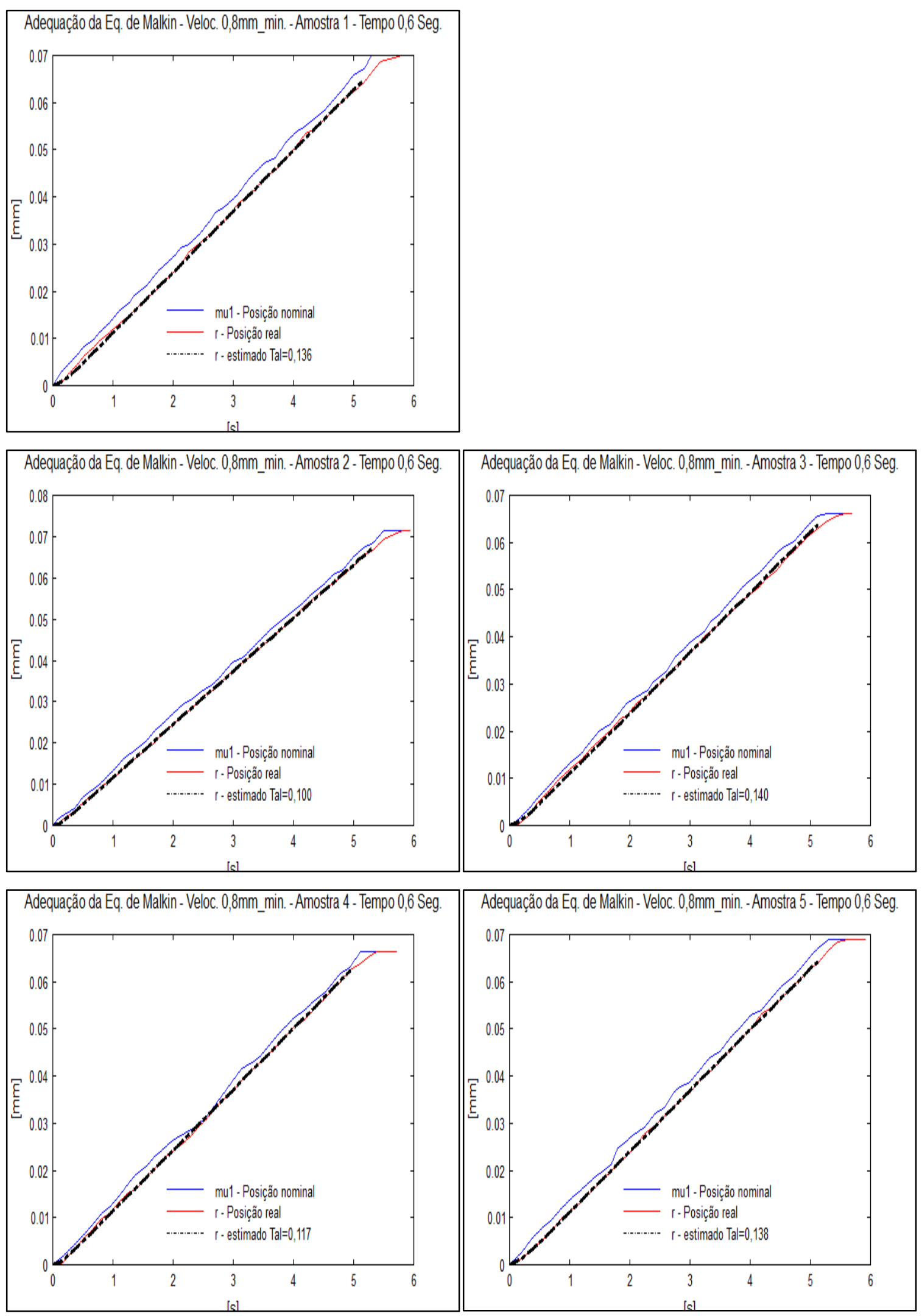

Gráfico 94 - Curvas Experimentais MatLab ${ }^{\circledR}$ - Vel. 0,8mm/min. - Tempo 0,6 Seg. Centelhamento. 
Curvas experimentais veloc. $0,8 \mathrm{~mm} / \mathrm{min}$. - Tempo de centelhamento $1 \mathrm{seg}$. - amostras 1 a 5 :
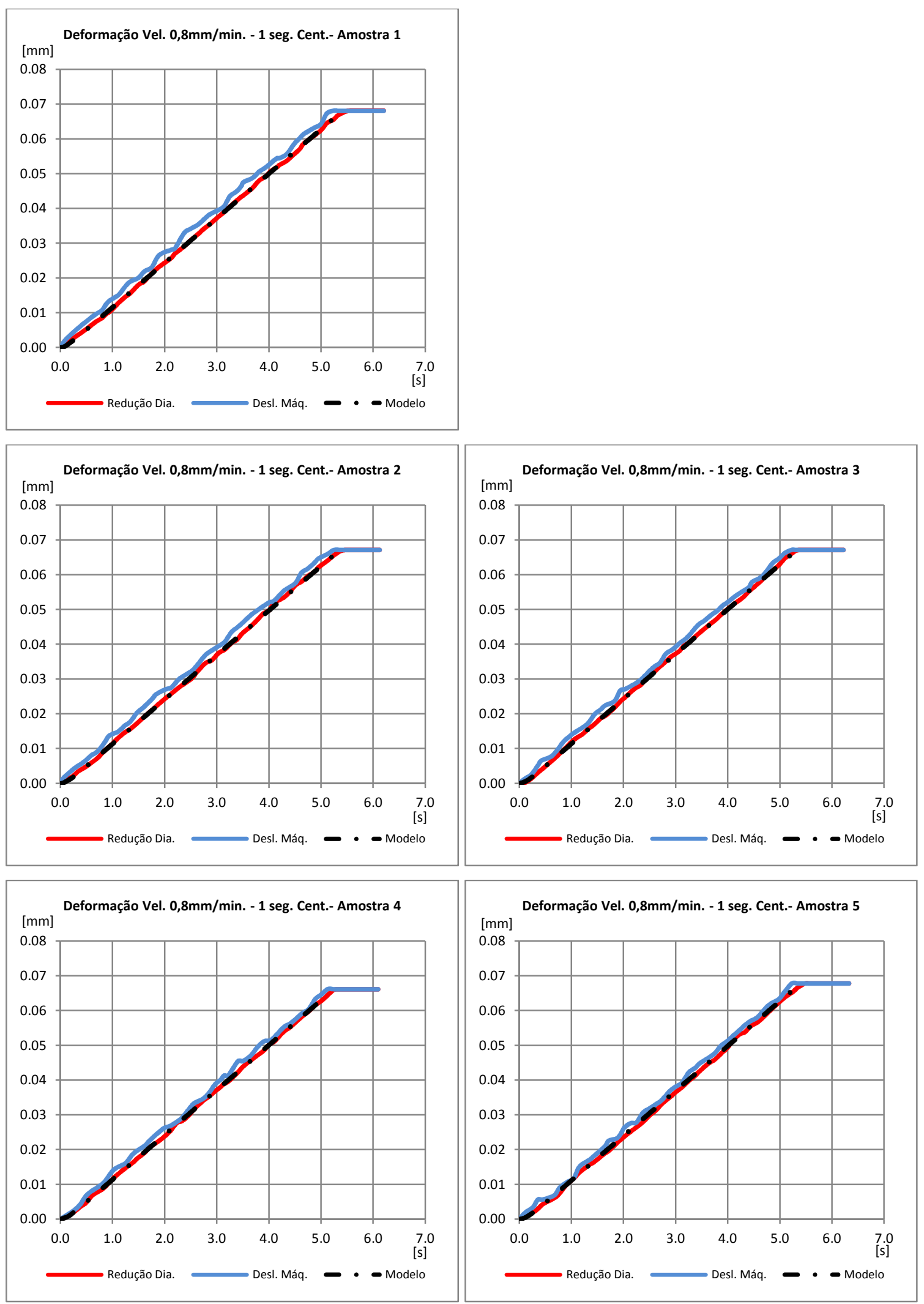

Gráfico 95 - Curvas Experimentais Excel ${ }^{\circledR}$ - Vel. 0,8mm/min. - 1 seg. Centelhamento 
Ajuste curvas MatLab ${ }^{\circledR}$ veloc. $0,8 \mathrm{~mm} / \mathrm{min}$.- Tempo de centelhamento $1 \mathrm{seg}$. amostras 1 a 5:
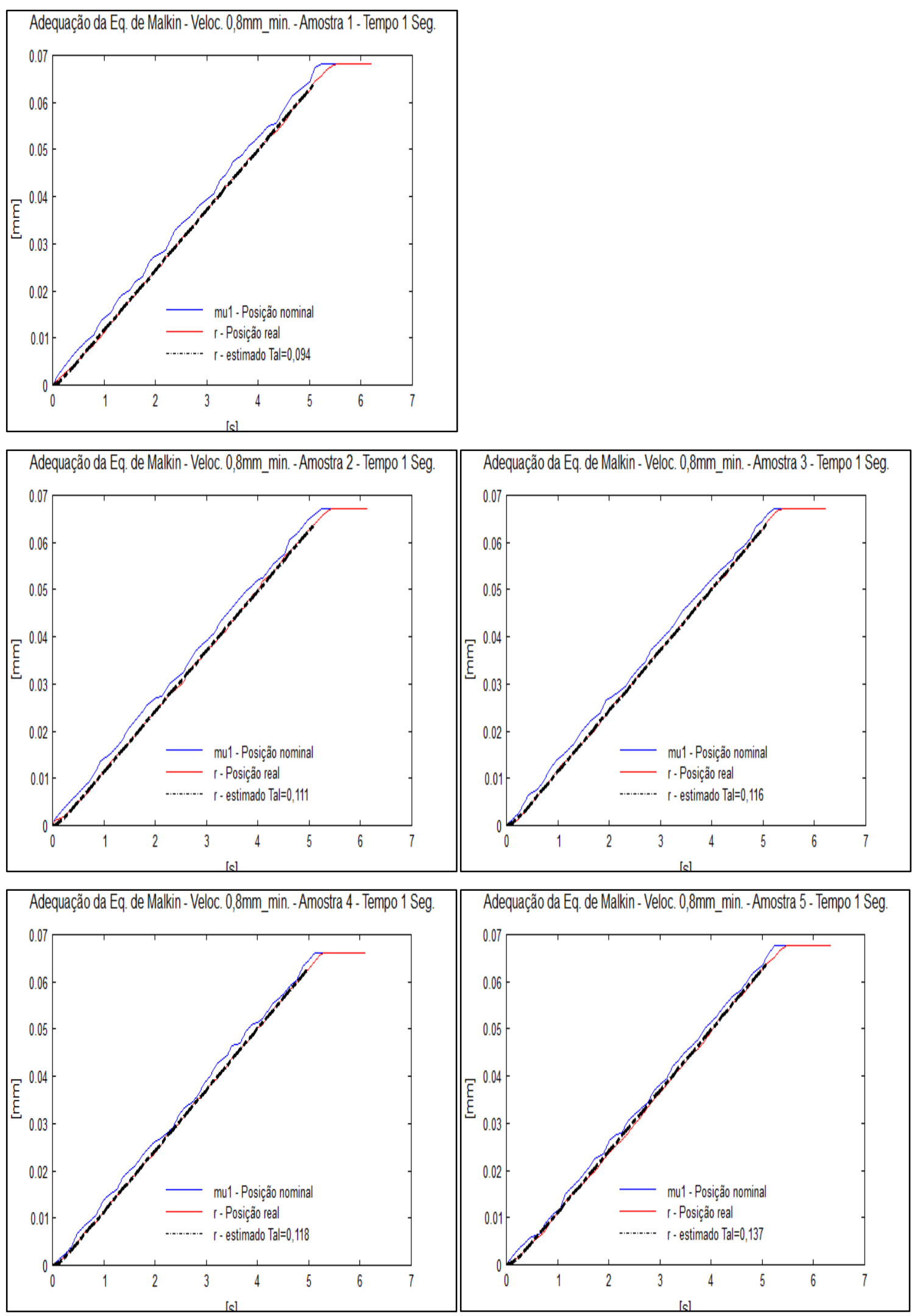

Gráfico 96 - Curvas Experimentais MatLab ${ }^{\circledR}$ - Vel. 0,8mm/min. - Tempo 1 Seg. Centelhamento. 
Curvas experimentais veloc. $0,8 \mathrm{~mm} / \mathrm{min}$. - Tempo de centelhamento $2 \mathrm{seg}$. - amostras 1 a 5 :
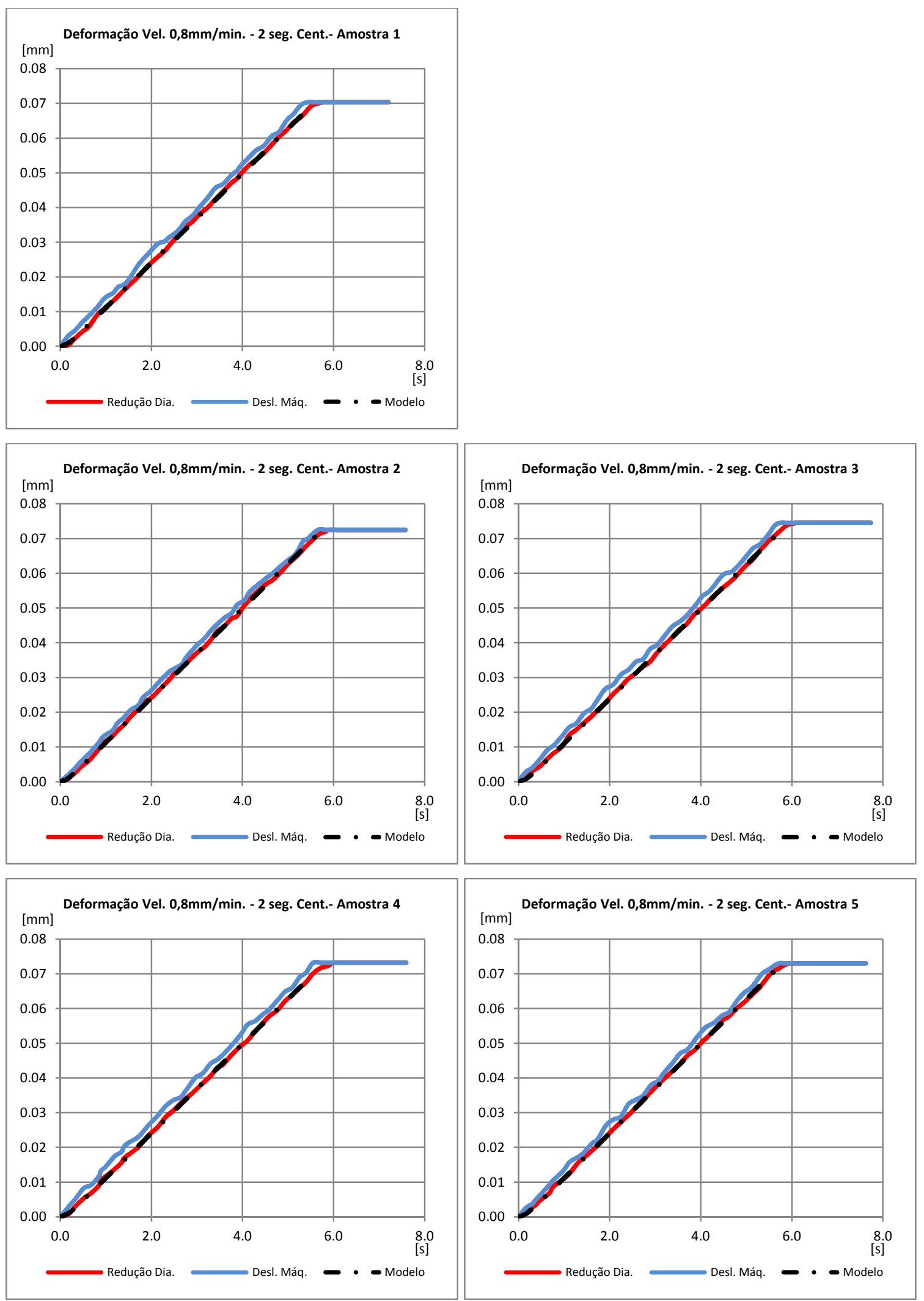

Gráfico 97 - Curvas Experimentais Excel ${ }^{\circledR}$ - Vel. 0,8mm/min. - 2 seg. Centelhamento 
Ajuste curvas MatLab ${ }^{\circledR}$ veloc. $0,8 \mathrm{~mm} / \mathrm{min}$.- Tempo de centelhamento $2 \mathrm{seg}$. amostras 1 a 5 :
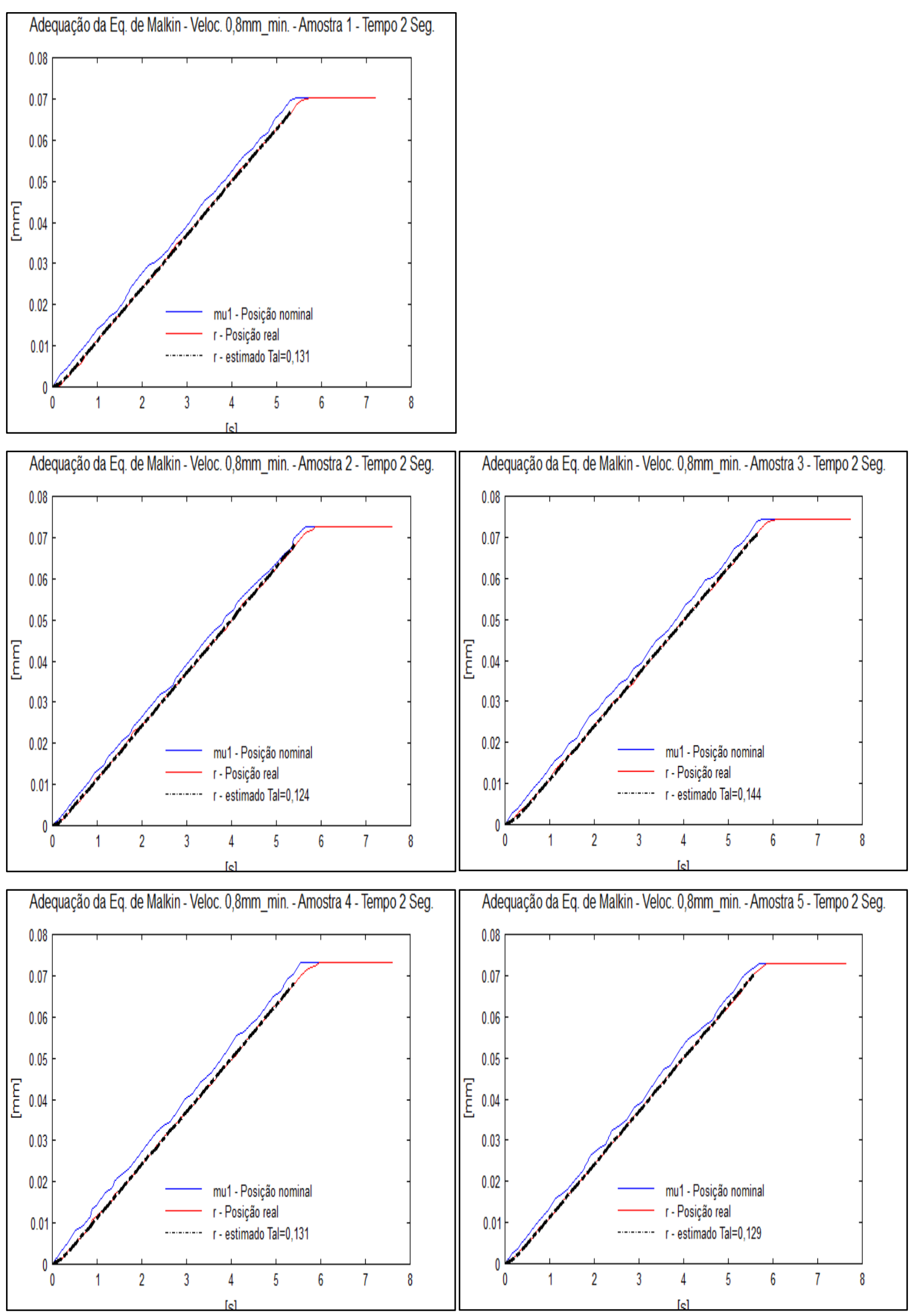

Gráfico 98 - Curvas Experimentais MatLab ${ }^{\circledR}$ - Vel. 0,8mm/min. - Tempo 2 Seg. Centelhamento. 
Curvas experimentais veloc. $0,8 \mathrm{~mm} / \mathrm{min}$. - Tempo de centelhamento $3 \mathrm{seg}$. - amostras $1 \mathrm{a} 5$ :
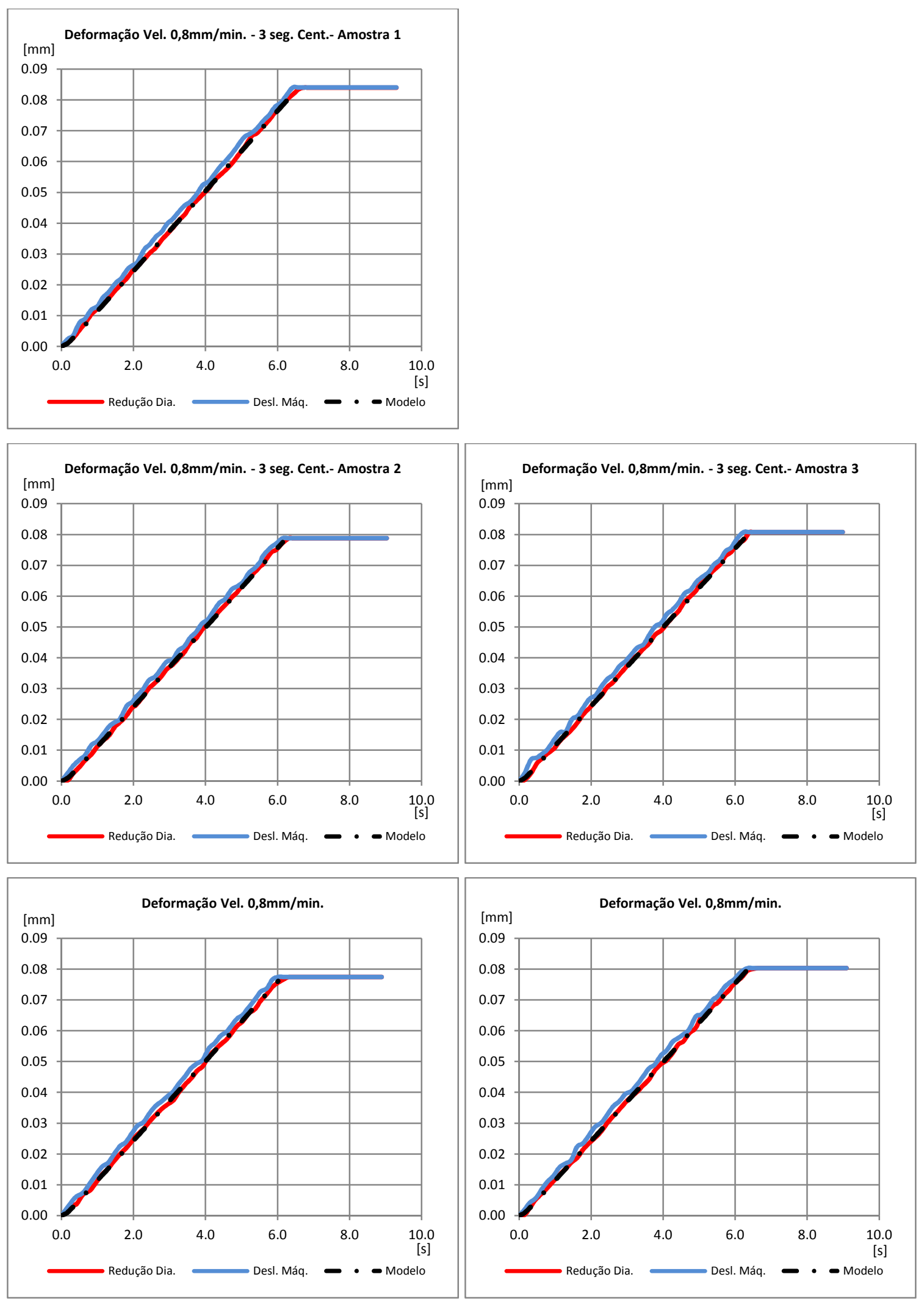

Gráfico 99 - Curvas Experimentais Excel ${ }^{\circledR}$ - Vel. 0,8mm/min. - 3 seg. Centelhamento 
Ajuste curvas MatLab ${ }^{\circledR}$ veloc. $0,8 \mathrm{~mm} / \mathrm{min}$.- Tempo de centelhamento $3 \mathrm{seg}$. amostras 1 a 5:
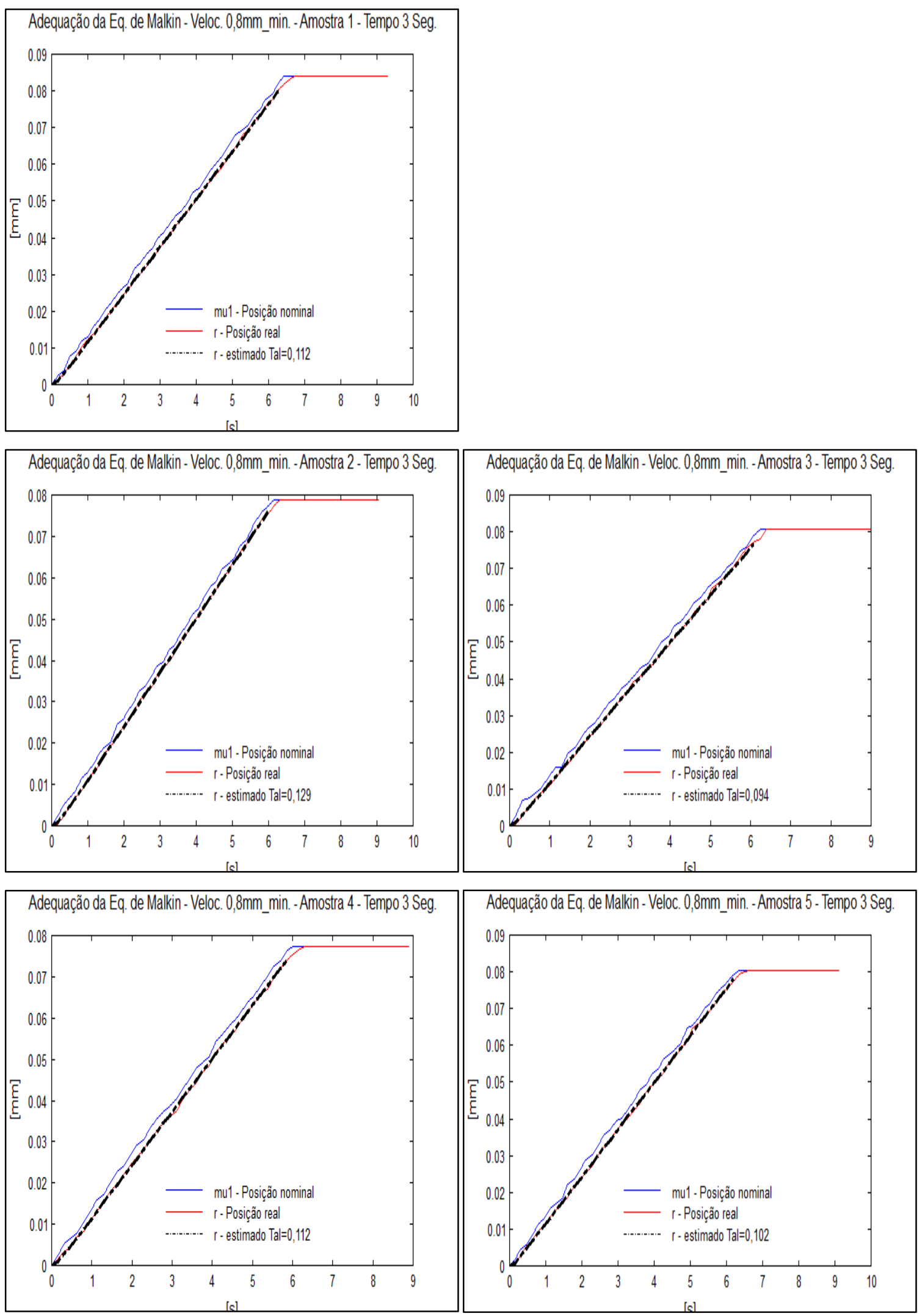

Gráfico 100 - Curvas Experimentais MatLab ${ }^{\circledR}$ - Vel. 0,8mm/min. - Tempo 3 Seg. Centelhamento. 
A tabela 9 indica a média entre 5 amostras com velocidade de $3,0 \mathrm{~mm} / \mathrm{min}$. e tempos de centelhamento de $0 ; 0,3 ; 0,6 ; 1 ; 2$ e 3 segundos.

Tabela 9 - Dados obtidos de deformação com velocidade de 3,0mm / min.

\begin{tabular}{cccccc}
\hline Tempo Cent. & Dia. Inicial & Dia. Final & Sobremetal & Dia. Calibrado & Deformação \\
\hline 0 & 14.1739 & 14.0318 & 0.1421 & 14.0106 & 0.0212 \\
0.3 & 14.1658 & 14.0322 & 0.1336 & 14.0200 & 0.0123 \\
0.6 & 14.1696 & 14.0332 & 0.1363 & 14.0284 & 0.0048 \\
1 & 14.1694 & 14.0258 & 0.1436 & 14.0258 & 0.0000 \\
2 & 14.1693 & 14.0152 & 0.1541 & 14.0152 & 0.0000 \\
3 & 14.1701 & 14.0069 & 0.1632 & 14.0069 & 0.0000 \\
\hline
\end{tabular}

A tabela 10 indica a média entre 5 amostras com velocidade de $2,5 \mathrm{~mm} / \mathrm{min}$. e tempos de centelhamento de $0 ; 0,3 ; 0,6 ; 1 ; 2$ e 3 segundos.

Tabela 10 - Dados obtidos de deformação com velocidade de 2,5mm / min..

\begin{tabular}{crrrcc}
\hline Tempo Cent. & Dia. Inicial & Dia. Final & Sobremetal & Dia. Calibrado & Deformação \\
\hline 0 & 14.1684 & 14.0368 & 0.1317 & 14.0182 & 0.0186 \\
0.3 & 14.1728 & 14.0285 & 0.1443 & 14.0186 & 0.0070 \\
0.6 & 14.1714 & 14.0209 & 0.1505 & 14.0181 & 0.0020 \\
1 & 14.1685 & 14.0198 & 0.1487 & 14.0198 & 0.0000 \\
2 & 14.1737 & 14.0180 & 0.1557 & 14.0180 & 0.0000 \\
3 & 14.1732 & 14.0193 & 0.1540 & 14.0193 & 0.0000 \\
\hline
\end{tabular}

A tabela 11 indica a média entre 5 amostras com velocidade de $1,6 \mathrm{~mm} / \mathrm{min}$. e tempos de centelhamento de $0 ; 0,3 ; 0,6 ; 1 ; 2$ e 3 segundos.

Tabela 11 - Dados obtidos de deformação com velocidade de 1,6mm / min..

\begin{tabular}{cccccc}
\hline Tempo Cent. & Dia. Inicial & Dia. Final & Sobremetal & Dia. Calibrado & Deformação \\
\hline 0 & 14.1780 & 13.9891 & 0.1888 & 13.9783 & 0.0100 \\
0.3 & 14.1760 & 13.9906 & 0.1854 & 13.9861 & 0.0040 \\
0.6 & 14.1773 & 13.9872 & 0.1901 & 13.9871 & 0.0001 \\
1 & 14.1785 & 13.9861 & 0.1923 & 13.9861 & 0.0000 \\
2 & 14.1774 & 13.9851 & 0.1923 & 13.9851 & 0.0000 \\
3 & 14.1731 & 13.9841 & 0.1891 & 13.9841 & 0.0000 \\
\hline
\end{tabular}

A tabela 11 indica a média entre 5 amostras com velocidade de $0,8 \mathrm{~mm} / \mathrm{min}$. e tempos de centelhamento de $0 ; 0,3 ; 0,6 ; 1 ; 2$ e 3 segundos. 
Tabela 12 - Dados obtidos de deformação com velocidade de $0,8 \mathrm{~mm} / \mathrm{min}$..

\begin{tabular}{cccccc}
\hline Tempo Cent. & Dia. Inicial & Dia. Final & Sobremetal & Dia. Calibrado & Deformação \\
\hline 0 & 14.1652 & 14.0160 & 0.1493 & 14.0094 & 0.0060 \\
0.3 & 14.1692 & 14.0186 & 0.1505 & 14.0169 & 0.0010 \\
0.6 & 14.1691 & 14.0265 & 0.1426 & 14.0265 & 0.0000 \\
1 & 14.1655 & 14.0242 & 0.1414 & 14.0242 & 0.0000 \\
2 & 14.1617 & 14.0139 & 0.1479 & 14.0139 & 0.0000 \\
3 & 14.1684 & 14.0038 & 0.1646 & 14.0038 & 0.0000 \\
\hline
\end{tabular}

A tabela 13 indica a média entre 5 amostras com velocidade de $0,08 \mathrm{~mm} / \mathrm{min}$. e tempos de centelhamento de $0 ; 0,3 ; 0,6 ; 1 ; 2$ e 3 segundos.

Tabela 13 - Dados obtidos de deformação com velocidade de $0,08 \mathrm{~mm} / \mathrm{min}$.

\begin{tabular}{cccccc}
\hline Tempo Cent. & Dia. Inicial & Dia. Final & Sobremetal & Dia. Calibrado & Deformação \\
\hline 0 & 14.1735 & 14.0162 & 0.1573 & 14.0143 & 0.0010 \\
0.3 & 14.1740 & 14.0116 & 0.1624 & 14.0116 & 0.0000 \\
0.6 & 14.1720 & 14.0091 & 0.1628 & 14.0091 & 0.0000 \\
1 & 14.1721 & 14.0058 & 0.1663 & 14.0058 & 0.0000 \\
2 & 14.1670 & 14.0030 & 0.1640 & 14.0030 & 0.0000 \\
3 & 14.1659 & 14.0000 & 0.1660 & 14.0000 & 0.0000 \\
\hline
\end{tabular}




\section{APÊNDICE IV - SOFTWARES E ESTRUTURA DO PROGRAMA}

A Figura 32 mostra um esquema geral do software de aquisição de dados utilizado nos experimentos do processo de retificação.

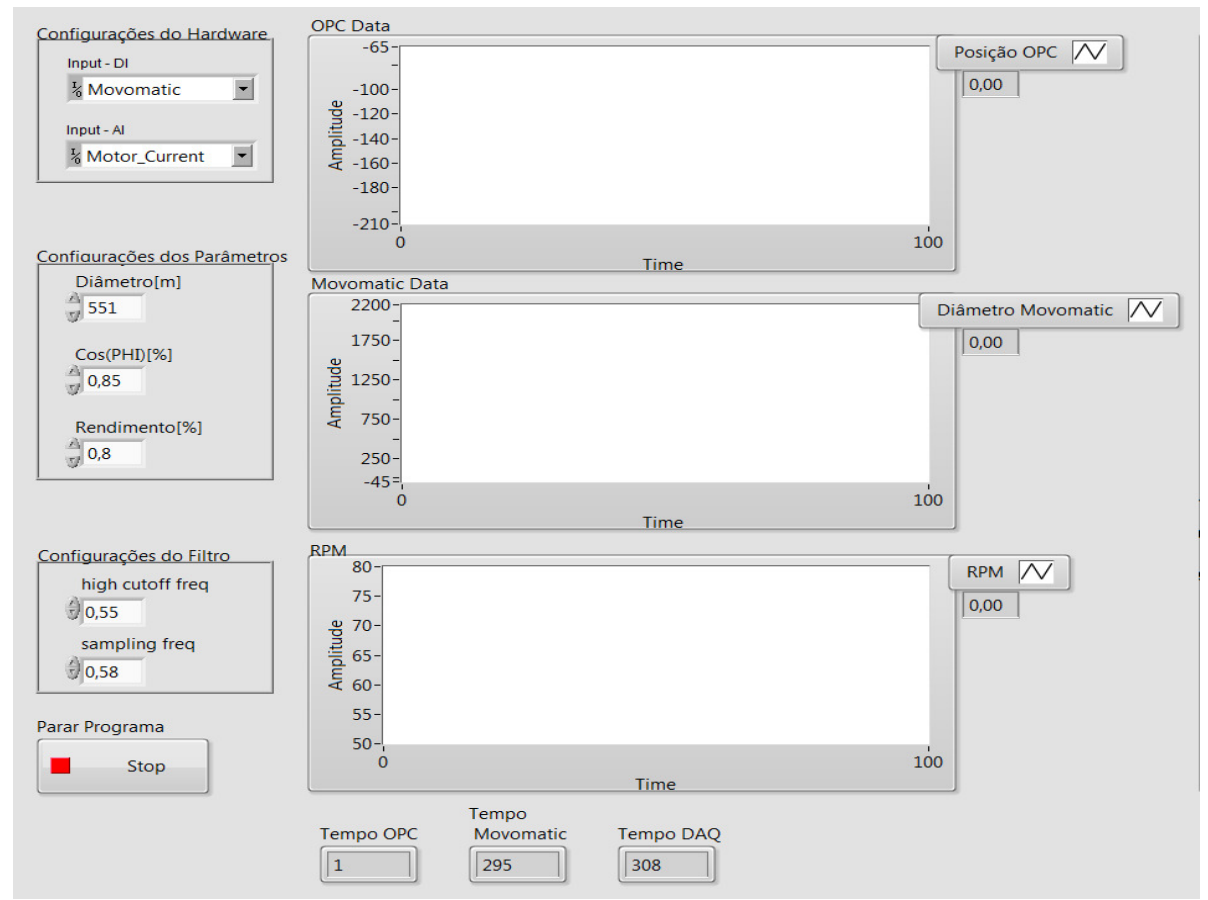

Figura 32- Esquema geral do sistema de aquisição utilizado no experimento 


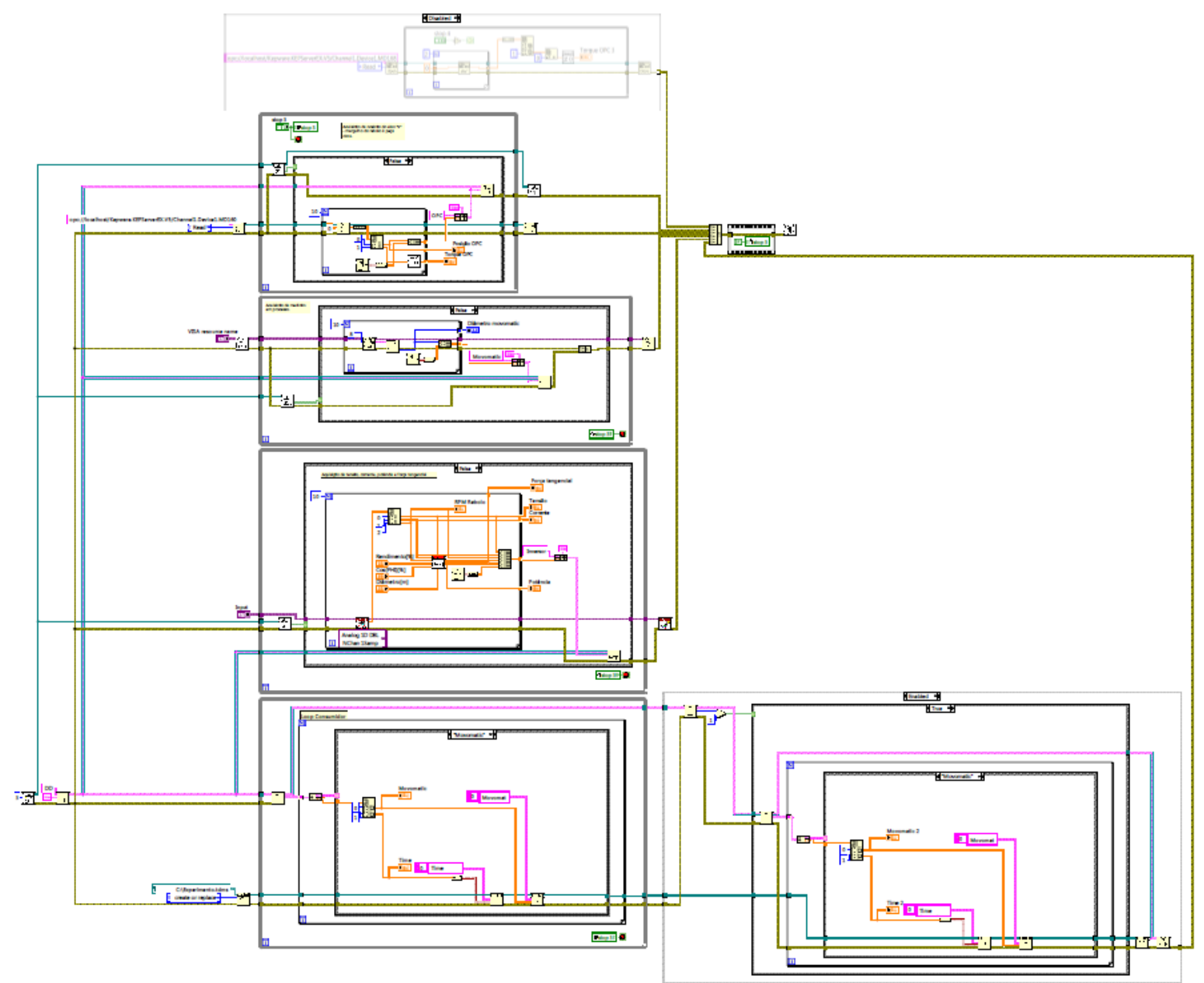

Figura 33 - Programa em LabView do sistema de monitoramento, estruturas gerais.
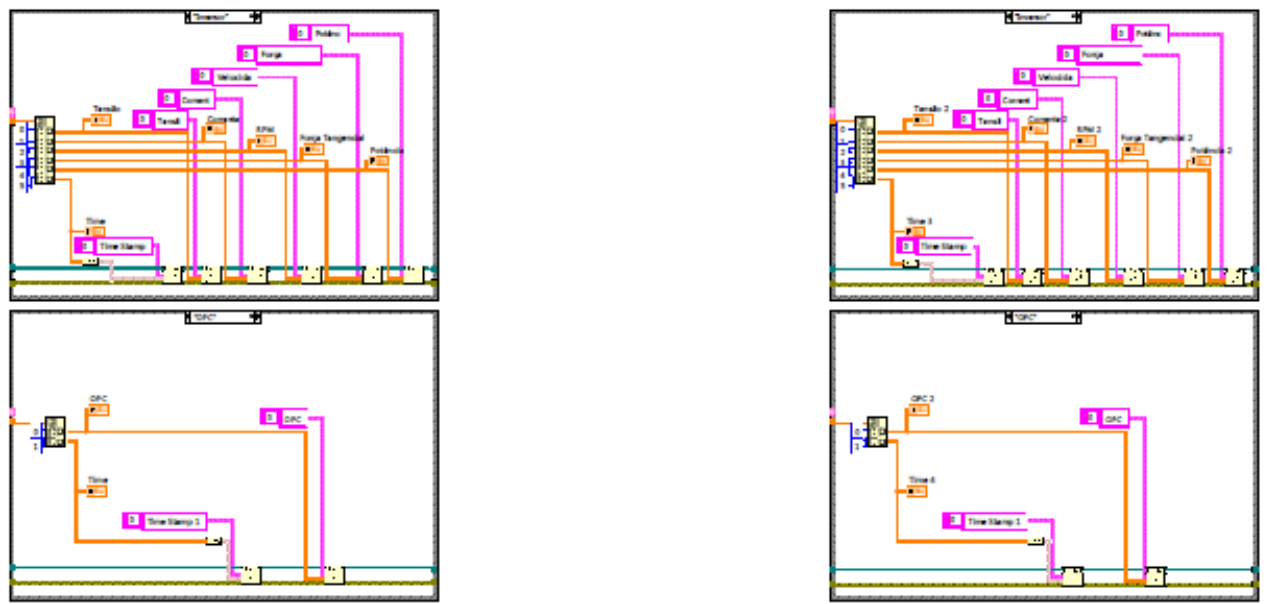

Figura 34 - Programa em LabView do sistema de monitoramento, estruturas em $2^{\circ}$ nível. 


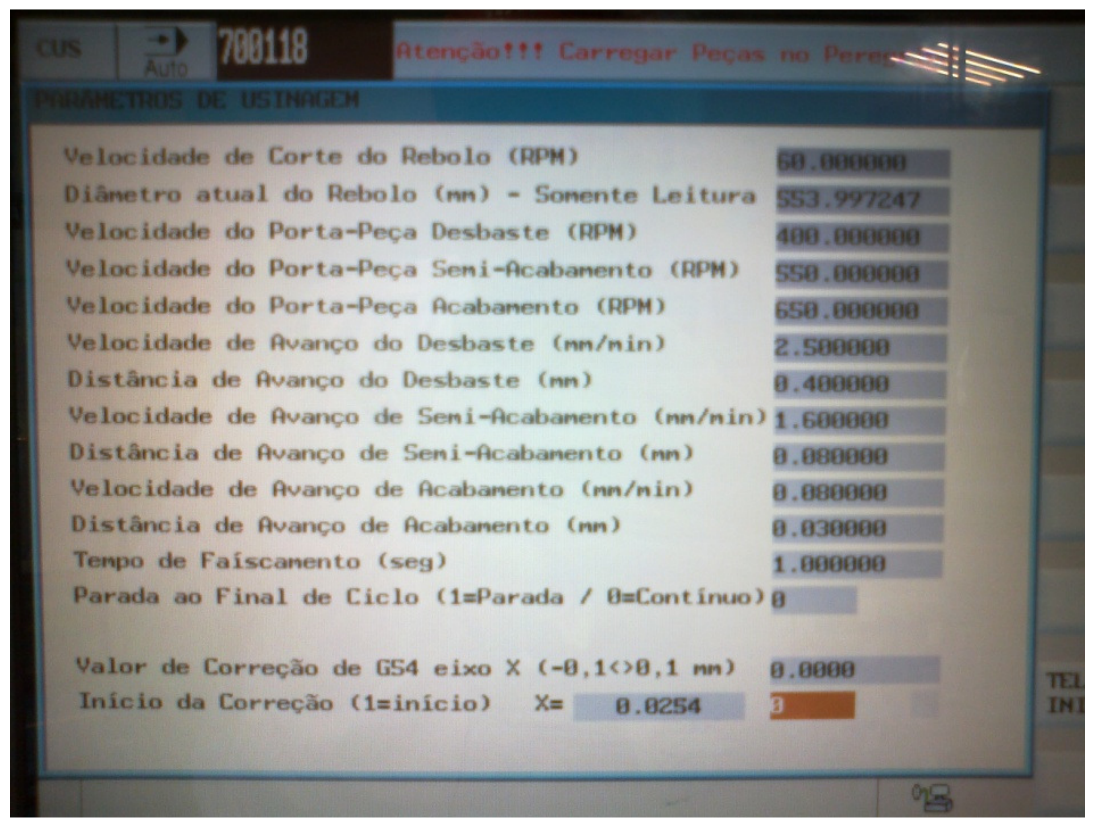

Figura 35 - Tela customizada com os parâmetros de processo para retificação. 


\section{APÊNDICE V - ESQUEMA DO SISTEMA DE FILTRAGEM}

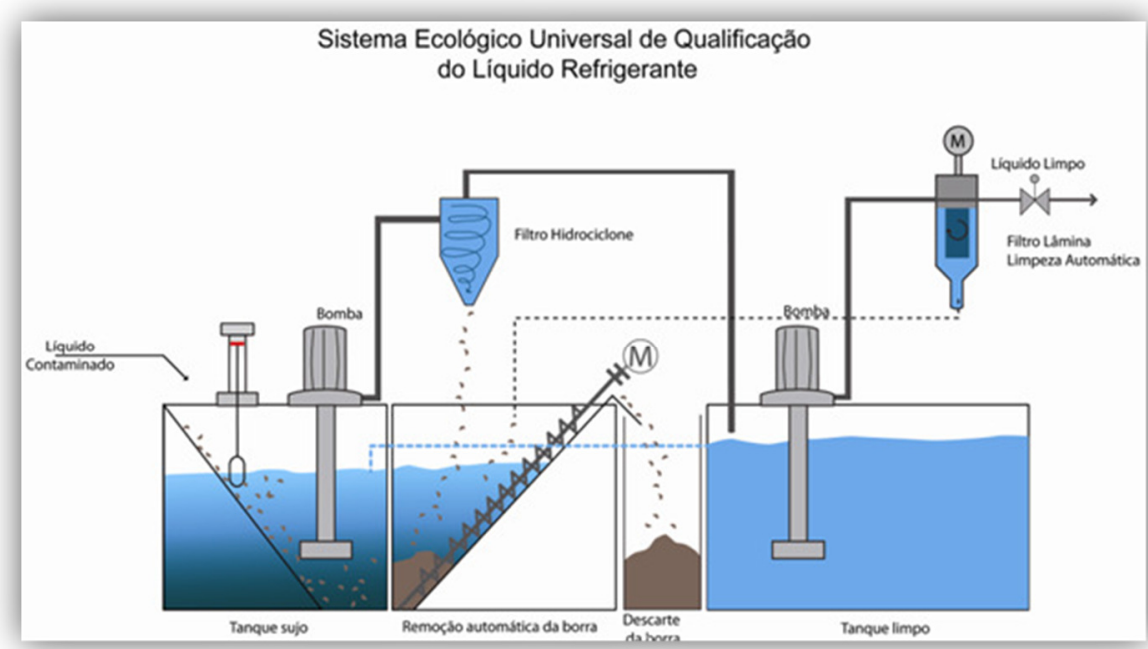

Figura 36 - Sistema filltragem utilizado no experimento de retifícação 


\section{APÊNDICE VI - EQUIPAMENTO DE CARACTERIZAÇÃO DO MATERIAL}

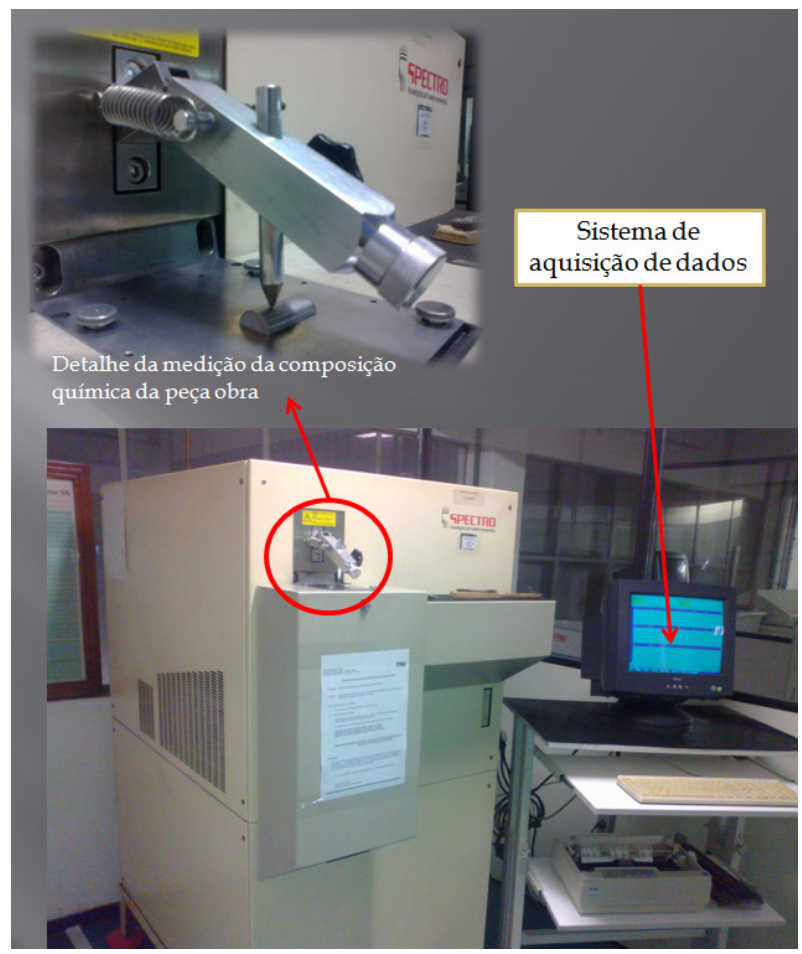

Figura 37 - Equipamento “Spectro" para caracterização de materia-prima da peça 